\title{
WestVirginiaUniversity
}

THE RESEARCH REPOSITORY @ WVU

Graduate Theses, Dissertations, and Problem Reports

2006

\section{Development of predictive NOx model for on -road heavy -duty diesel engines}

Mohan Krishnamurthy

West Virginia University

Follow this and additional works at: https://researchrepository.wvu.edu/etd

\section{Recommended Citation}

Krishnamurthy, Mohan, "Development of predictive NOx model for on -road heavy -duty diesel engines" (2006). Graduate Theses, Dissertations, and Problem Reports. 2717.

https://researchrepository.wvu.edu/etd/2717

This Dissertation is protected by copyright and/or related rights. It has been brought to you by the The Research Repository @ WVU with permission from the rights-holder(s). You are free to use this Dissertation in any way that is permitted by the copyright and related rights legislation that applies to your use. For other uses you must obtain permission from the rights-holder(s) directly, unless additional rights are indicated by a Creative Commons license in the record and/ or on the work itself. This Dissertation has been accepted for inclusion in WVU Graduate Theses, Dissertations, and Problem Reports collection by an authorized administrator of The Research Repository @ WVU.

For more information, please contact researchrepository@mail.wvu.edu. 
Development of Predictive NOx Model for On-Road Heavy-Duty Diesel Engines

Mohan Krishnamurthy

Dissertation submitted to

The College of Engineering and Mineral Resources at West Virginia University in partial fulfillment of the requirements for the degree of

\title{
Doctor of Philosophy
}

in

Mechanical Engineering

\author{
Submitted to: \\ Mridul Gautam, Ph.D., Chair \\ Giampiero Campa, PhD. \\ Nigel N. Clark, Ph.D. \\ Gregory J. Thompson, Ph.D. \\ Scott W. Wayne, Ph.D. \\ John W. Zondlo, Ph.D. \\ Department of Mechanical and Aerospace Engineering \\ Morgantown, West Virginia \\ 2006
}

Keywords: In-use Emissions, Diesel Engines, Emissions Model, NOx 


\section{ABSTRACT \\ Development of Predictive NOx Model For Heavy-Duty Diesel Engines Mohan Krishnamurthy}

Emissions models currently employed by EPA and CARB do not account for the variations in engine operation and their effect on emissions. Alternatively, this study, demonstrates the feasibility of using Engine Control Module (ECM) broadcast parameters such as Engine Speed, Engine Torque, Injection Timing, Fueling Rate, Manifold Air Temperature, Manifold Air Pressure, Coolant Temperature and Oil Temperature as inputs to in order to predict engine-out exhaust $\mathrm{NO}_{\mathrm{x}}$ emissions. These parameters were obtained when the engine operates in the Not-to-Exceed (NTE) zone, (which is defined by 40 CFR $\$ 86.1370-2007$ ) for a continuous time period of at least $30 \mathrm{~s}$ in length.

This study taps into the in-use emissions measurement capabilities and the vast databases that reside at the National Research Center for Alternative Fuels Engine and Emissions (CAFEE), and combines them with an advanced statistical modeling technique called Multivariate Adaptive Regression Splines (MARS) to predict NOx emissions. The MARS technique is an adaptive piece-wise regression approach that can be configured to fit models with terms that represent nonlinear effects and interactions among input variables.

In this study, an on-board portable emissions measurement system called the Mobile Emissions Measurement System (MEMS), developed at West Virginia University (WVU) was used to record in-use, continuous $\mathrm{NO}_{\mathrm{x}}$ emissions along with ECM broadcast parameters from 60 heavy-duty diesel-powered vehicles from model years 2001, 2002 and 2003. The vehicles were classified according to their engine model and model year and four vehicles were tested for each category. The vehicles were tested over different routes which included a mix of urban and highway driving conditions.

Data collected from the on-road tests of a vehicle(s) were combined to form the calibration and validation datasets. 'Calibration' dataset was used to create a predictive model using MARS. Validation datasets which were independent of the 'calibration' datasets were used to check the accuracy of the model predictions. Results indicate that the predictive models developed proved highly successful with the range of uncertainty in predictions within $\pm 20 \%$ of the actual value. 


\section{ACKNOWLEDGEMENTS}

It is a myth that a dissertation is the soul-wrenching creation solely of its author's time, toil and tenacity. Many people inspired me during this journey and I thank these people for doing so.

I am thankful to Prof. Mridul Gautam, my advisor and friend, for giving me guidance and counsel, and for having faith and confidence in me. His patience in reading draft after draft of every paper, proposal and idea I wrote up continues to amaze me. No one should be subjected to the torture of reading my early attempts at technical writing, and thanks to Mridul, no one will. I appreciate Paul's fine balance between giving me the freedom to pursue what fired me and reining in my imagination when it got the better of me. I thank him for always being willing to meet me whenever I barged into his office.

I am grateful to my committee members Drs. Nigel Clark, Greg Thompson, Giampiero Campa, John Zondlo and Scott Wayne, for their comments and suggestions. I have benefitted greatly from their advice. I thank Dr. Natalia Schmid and Xiaohan Chen for lending me guidance with the modeling efforts and putting up with my delays. It has been a pleasure working with my colleagues, in particular, Dan Carder, Wes Riddle, Ron Jarrett and Ben Shade without whom none of the data would have been generated for this dissertation. Many of the ideas in my work originated in discussions with them. I am deeply grateful to them for investing time and energy discussing ideas with me and tolerating my many opinionated digressions. I thank the engine manufacturers for making it possible for me to do my research.

I would be doing injustice if I fail to thank Sairam and Shalini for they were the only two people with unflagging belief in me and motivated me when things were not going my way. I also thank Raffaello, Claudia, Sam, Paola, Micelangelo, and Jess for all the fun and parties, which recharged me every time I needed it. I thank. Special thanks to Dinesh, for it his patience and caring that helped me recover after my surgery and get back to work. All of you made me feel like I had my family right next to me.

I thank my parents, brother, aunt and uncle for their love, support and prayers. I am indebted to my parents for inculcating in me the dedication and discipline to do whatever I undertake well. 


\section{Table of Contents}

1 INTRODUCTION AND OBJECTIVES....................................................................... 1

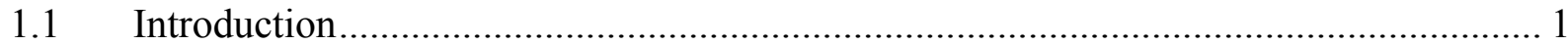

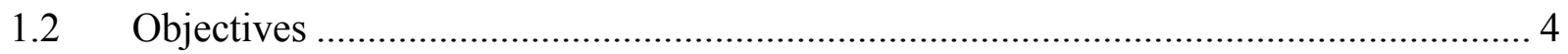

1.3 Technical Approach to Accomplish Objectives ..................................................... 4

2 LITERATURE REVIEW .............................................................................................. 6

2.1 Overview of Conventional Emissions Measurement and Estimation Approaches ........ 6

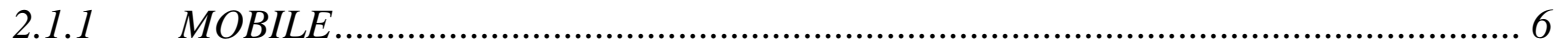

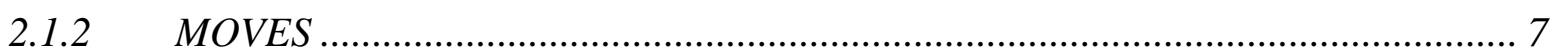

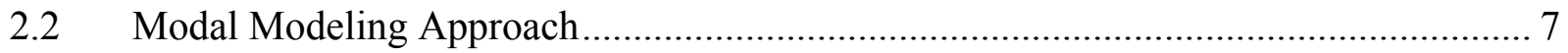

2.2.1 Speed Acceleration Look-up Tables.............................................................. 8

2.2.2 Aggregate Modal Emission Models .................................................................... 9

2.2.3 Neural-Network based Vehicle Emissions Models ............................................. 10

2.2.4 Physical Instantaneous Emissions Models ....................................................... 11

2.3 Need for Engine/Vehicle Operation Parametric Modeling....................................... 12

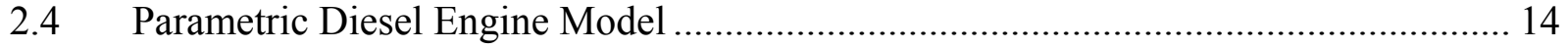

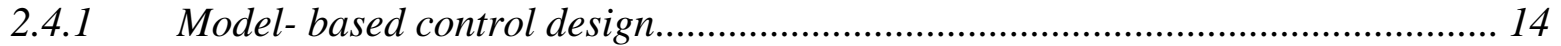

2.4.2 Software-in-the-loop Simulation..................................................................... 14

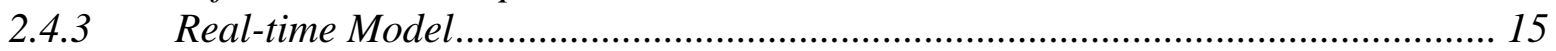

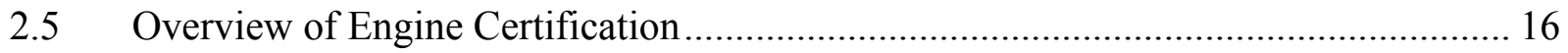

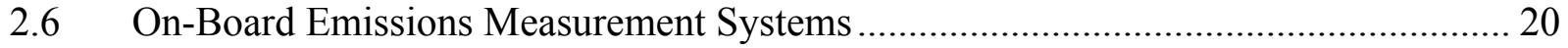

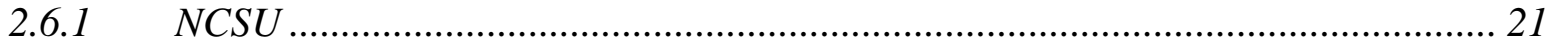

2.6.2 Texas Southern University ............................................................................. 21

2.6.3 University of Alberta .................................................................................... 21

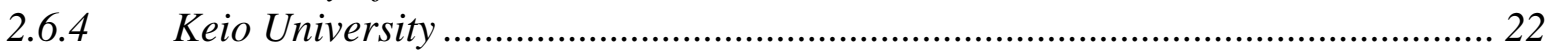

2.6.5 University of California, Riverside ............................................................... 22

2.6.6 University of California, Davis....................................................................... 22

2.6.7 West Virginia University......................................................................... 22

3 VEHICLE TESTING AND DATA COLLECTION ............................................... 24

3.1 Overview of Mobile Emissions Measurement System ........................................... 24

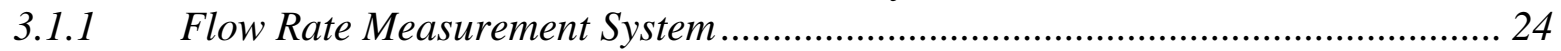

3.1.2 Engine Speed, Torque, and Vehicle Speed Measurement.................................. 28

3.1.3 Data Acquisition, Reduction, and Archival System ........................................... 28

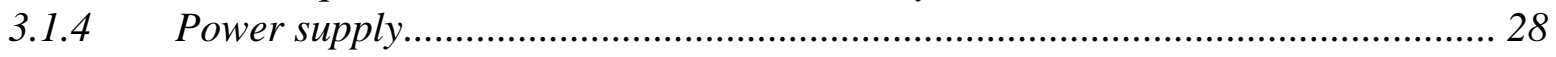

Exhaust Gas Analyzers ........................................................................... 28

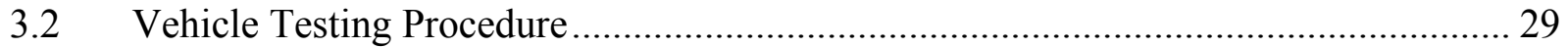

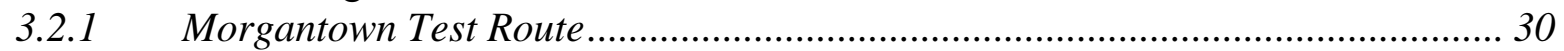

3.2.2 Pittsburgh Test Route ................................................................................... 31

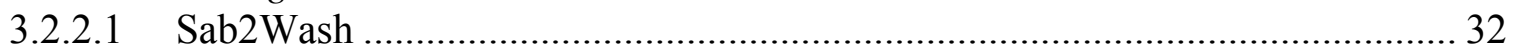

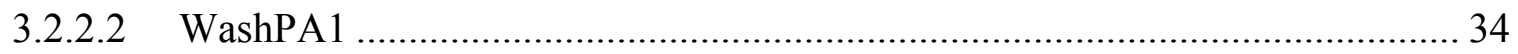

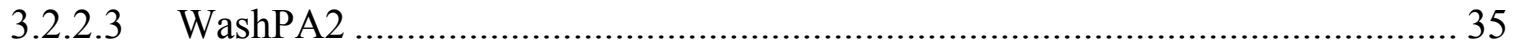

3.2.2.4 WashPA3 / WashPA32sab........................................................................... 37

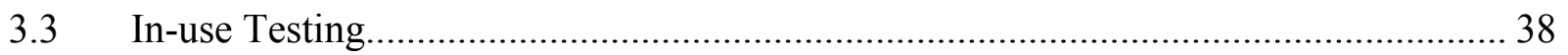

3.4 Quality Assurance of Exhaust Emissions Test Data................................................ 38

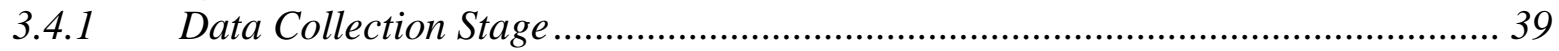


3.4.1.1 Setting Temperature of Heated Elements ……….............................................. 39

3.4.1.2 Calibration of MEXA $\mathrm{NO}_{\mathrm{x}}$ and $\mathrm{EC} \mathrm{NO}_{\mathrm{x}}$ Analyzer......................................... 40

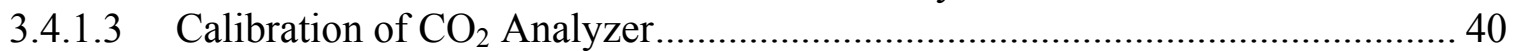

3.4.1.4 Calibration of Differential and Absolute Pressure Sensor ............................... 40

3.4.1.5 Calibration of Annubar T1 And T2 Sensor........................................................ 40

3.4.1.6 Data Acquisition, Synchronization, and Preprocessing Stage .......................... 41

3.4.1.7 Parsing Bad Data.......................................................................................... 41

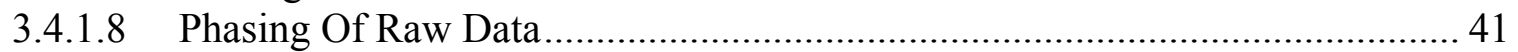

3.4.1.9 Complementing Missing Data .................................................................... 41

3.4.2 Qualitative Observations .............................................................................. 42

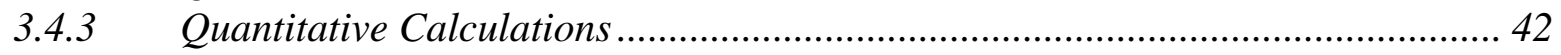

3.4.3.1 Comparison of Concentrations Of Mexa And EC NOx .................................. 42

3.4.3.2 Comparison of ECU Broadcast and GPS Vehicle Speed .................................. 42

3.4.3.3 Comparison of ECU Broadcast and Percent Load Inferred Torque ................. 43

3.4.3.4 Comparison of ECU Broadcast and Emissions Derived Fueling Rate ............. 43

3.4.3.5 Checking Temperatures of Heated Elements................................................... 43

3.4.3.6 Comparison of Exhaust Flow Rates............................................................... 43

3.4.3.7 Determination of Valid NTE Event ............................................................... 44

4 HDD NO $\mathrm{X}_{\mathrm{X}}$ EMISSION MODEL DEVELOPMENT........................................................ 49

4.1 Overview of General Technical and Modeling Approach ............................................. 51

4.2 Problem Statement and Proposed Solution................................................................ 52

4.2.1 Function Estimation....................................................................................... 54

4.3 Multivariate Adaptive Regression Splines................................................................ 54

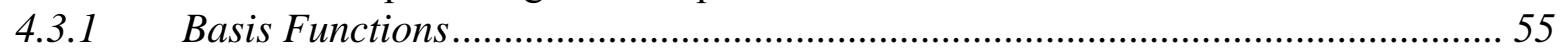

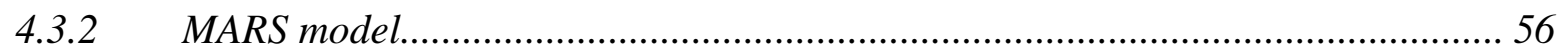

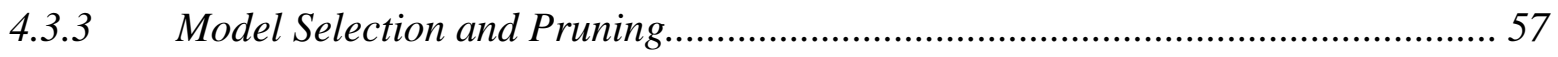

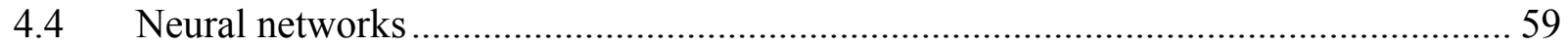

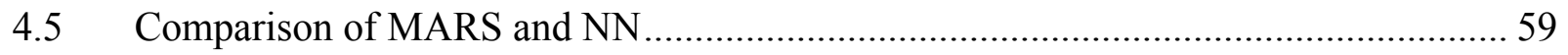

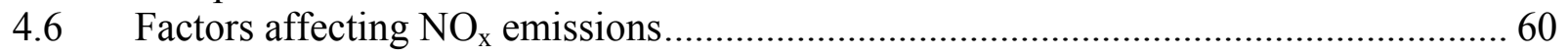

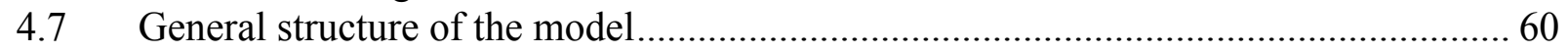

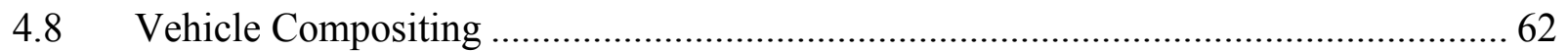

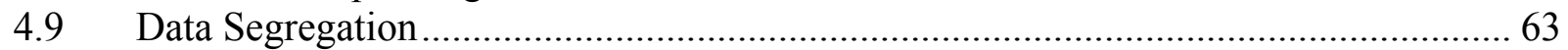

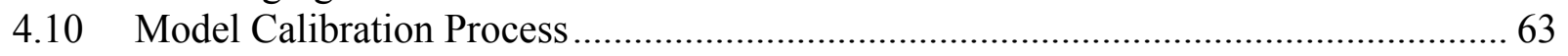

4.10.1 Comparison of observed data with predictions ..................................................... 67

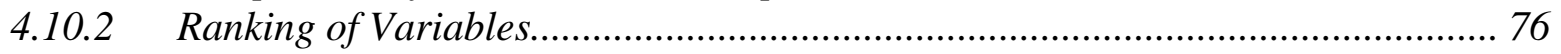

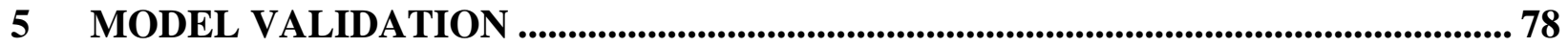

5.1 Model Output Variability and Uncertainty ……………............................................ 79

5.1.1 Emissions Measurement Variability ……………................................................. 79

5.1.2 Vehicle Driving/Operational Variability ............................................................. 79

5.2 Comparison of Validation Data with Predictions ............................................................. 79

5.2.1 Variability in model output due to different engine ratings.................................... 88

5.2.2 Variability in model output due to test weight .................................................. 89

5.3 Summary of Model Validation ............................................................................. 91

6 CONCLUSIONS AND RECOMMENDATIONS................................................................ 92

6.1 Applications ………………………………………............................................ 93 


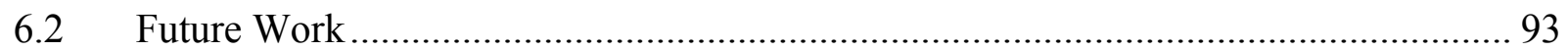

6.2.1 Incorporation of New Vehicle/Technology Categories..................................... 93

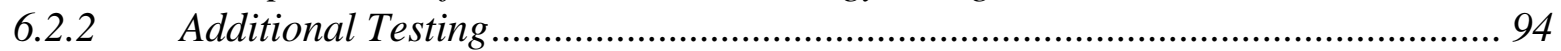

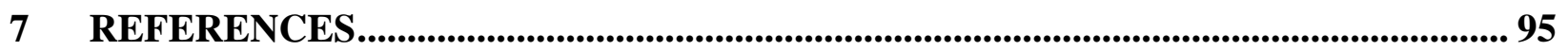

APPENDIX A BASIS FUNCTIONS AND MODELS........................................................... 105 


\section{List of Figures}

Figure 2-1 Graphical definition of NTE zone for gaseous emissions [53] ............................. 19

Figure 3-1 Data acquisition, sample conditioning and analysis systems of MEMS.................. 26

Figure 3-2 Schematic of MEMS sampling System............................................................. 27

Figure 3-3 Representation of the exhaust flow measurement system fitted to the test vehicle .... 27

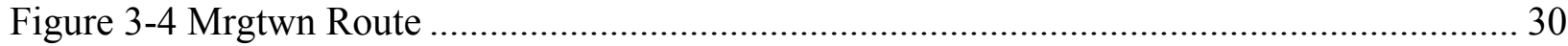

Figure 3-5 Representation of engine speed, engine torque, ........................................ 31

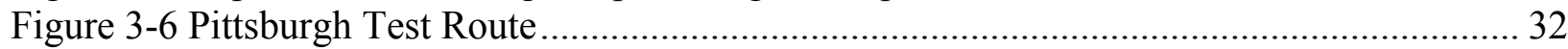

Figure 3-7 Sab2Wash test route ....................................................................................... 33

Figure 3-8 Representation of engine speed, engine torque, ................................................ 33

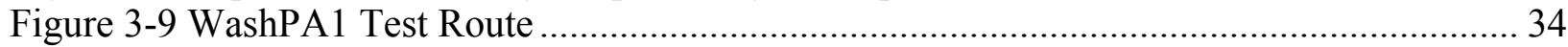

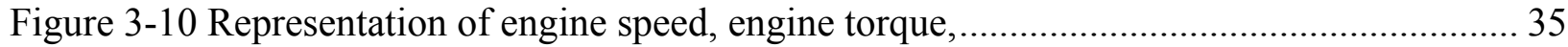

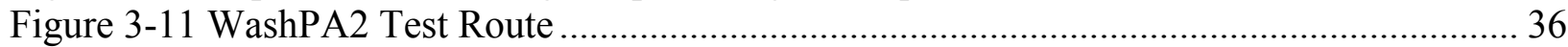

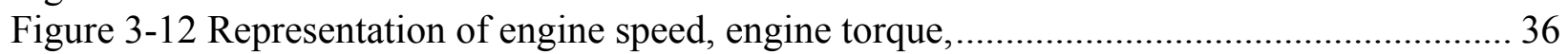

Figure 3-13 WashPA32Sab Test Route .......................................................................... 37

Figure 3-14 Representation of engine speed, engine torque, .............................................. 38

Figure 3-15 Calibration curves for the analyzers and sensors used in MEMS ......................... 44

Figure 3-16 Plot showing the difference between un-phased ................................................ 45

Figure 3-17 Time series of vehicle speed showing spikes at certain points ............................. 45

Figure 3-18 Comparison of concentration of $\mathrm{NO}_{\mathrm{x}}$ measured............................................. 46

Figure 3-19 Comparison of ECU broadcast and GPS vehicle speed..................................... 46

Figure 3-20 Comparison of ECU broadcast torque and inferred torque from percent load values

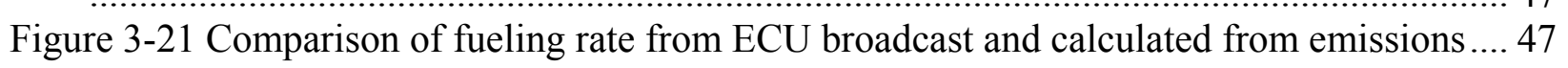

Figure 3-22 Plot of operating temperature of different elements of the exhaust sampling system

Figure 3-23 Representation of exhaust flow rate and the error in measurement of exhaust flow

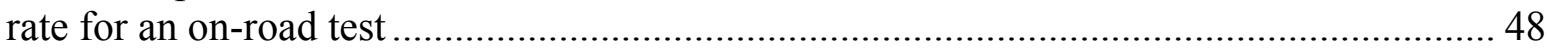

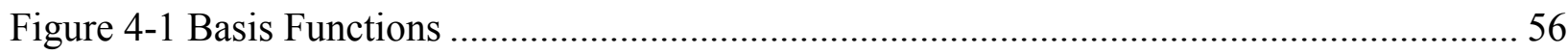

Figure 4-2 The algorithm for determination of best model .............................................. 65

Figure 4-3 MSE and MAD for calibration data from MY 2003 Caterpillar C-15 for $\mathrm{M}_{\max }$ range

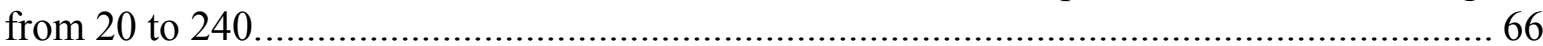

Figure 4-4 MSE and MAD for validation 1 data from MY 2003 Caterpillar C-15 for M $_{\max }$ range

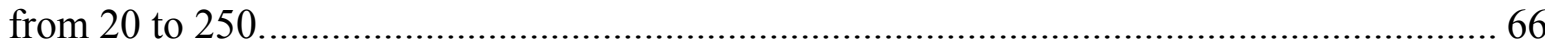

Figure 4-5 The approximated values of NOx and the true output data plotted. ........................ 68

Figure 4-6 Parity plot of measured NOx vs. predicted NOx for category 1 using model 1 ........ 68

Figure 4-7 Parity plot of measured NOx vs. predicted NOx for category 2 using model 2 ......... 69

Figure 4-8 Parity plot of measured NOx vs. predicted NOx for category 3 using model 3 ......... 69

Figure 4-9 Parity plot of measured NOx vs. predicted NOx for category 3 using model 4 ......... 70

Figure 4-10 Parity plot of measured NOx vs. predicted NOx for category 5 using model 5 ........ 70

Figure 4-11 Parity plot of measured NOx vs. predicted NOx for category 6 using model6 ....... 71

Figure 4-12 Parity plot of measured NOx vs. predicted NOx for category 7 using model7 ....... 71

Figure 4-13 Parity plot of measured NOx vs. predicted NOx for category 8 using model 8 ....... 72

Figure 4-14 Parity plot of measured NOx vs. predicted NOx for category 9 using model 9 ....... 72

Figure 4-15 Parity plot of measured NOx vs. predicted NOx for category 10 using model10 ... 73

Figure 4-16 Parity plot of measured NOx vs. predicted NOx for category 11 using model11 .... 73

Figure 4-17 Parity plot of measured NOx vs. predicted NOx for category 12 using model12 .... 74

Figure 4-18 Parity plot of measured NOx vs. predicted NOx for category 13 using model13 ... 74 
Figure 4-19 Parity plot of measured NOx vs. predicted NOx for category 14 using model14 .... 75

Figure 4-20 Parity plot of measured NOx vs. predicted NOx for category 15 using model15 ... 75

Figure 5-1 Observed vs. Predicted NOx Emissions with $95 \%$ Confidence................................ 81

Figure 5-2 Observed vs. Predicted NOx Emissions with $95 \%$ Confidence................................ 82

Figure 5-3 Observed vs. Predicted NOx Emissions with $95 \%$ Confidence.............................. 82

Figure 5-4 Observed vs. Predicted NOx Emissions with 95 \% Confidence.............................. 83

Figure 5-5 Observed vs. Predicted NOx Emissions with $95 \%$ Confidence............................... 83

Figure 5-6 Observed vs. Predicted NOx Emissions with 95 \% Confidence............................... 84

Figure 5-7 Observed vs. Predicted NOx Emissions with 95 \% Confidence............................... 84

Figure 5-8 Observed vs. Predicted NOx Emissions with 95 \% Confidence.............................. 85

Figure 5-9 Observed vs. Predicted NOx Emissions with 95 \% Confidence............................. 85

Figure 5-10 Observed vs. Predicted NOx Emissions with $95 \%$ Confidence............................ 86

Figure 5-11 Observed vs. Predicted NOx Emissions with 95 \% Confidence............................ 86

Figure 5-12 Observed vs. Predicted NOx Emissions with $95 \%$ Confidence............................. 87

Figure 5-13 Observed vs. Predicted NOx Emissions with $95 \%$ Confidence............................. 87

Figure 5-14 Parity plot for Validation type 2 showing bias................................................. 88

Figure 5-15 Observed vs. Predicted NOx Emissions with 95 \% Confidence............................ 89

Figure 5-16 Cat C10 2001 Validation 2 different test weight showing bias ............................. 90

Figure 5-17 Cat C10 Validation 2 different test weight after correction for bias....................... 90 


\section{List of Tables}

Table 2-1 Emissions standards for heavy-duty diesel engines ............................................. 17

Table 2-2 HDDE emissions standard in compliance with the consent decrees ......................... 18

Table 2-3 HDDE emissions standards for post-2001 engines ................................................ 20

Table 3-1 Operating ranges of transducers used................................................................... 25

Table 4-1 List of engine model and model year used in model development .......................... 61

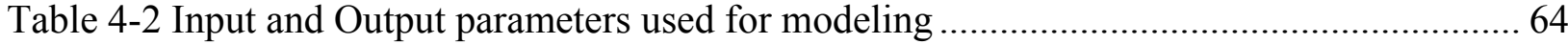

Table 4-3 Order of importance of dynamic input variables................................................... 77

Table 5-1 Summary of type of validation performed on each model ..................................... 80 


\section{INTRODUCTION AND OBJECTIVES}

\subsection{Introduction}

Emissions from mobile sources contribute significantly to overall air pollution [1, 2]. A fundamental requirement in the effort to control pollution in any form is to quantify the emissions being released. As a first step, it is necessary to understand the relationship between emissions and the resulting ambient concentrations. This will further result in developing appropriate policies and methods to ensure that ambient pollutant concentrations remain within acceptable limits. Emissions modeling is one technique employed to quantify and verify emissions levels from the different sources.

The emissions inventory modeling for on-road mobile source emissions is simply a gathering and reporting of information about the activity and emissions of motor vehicles. Traditionally, models have been constructed based upon emissions data obtained from different test programs and research projects conducted that isolate single variables such as speed and temperature to determine their relative effects on emissions. Using these models, estimates of emissions from different vehicles operating under a wide range of ambient and driving conditions can be obtained, and emissions control strategies may be suggested. Some of the popular emissions inventory models include Emission Factor (EMFAC), MOBILE, and MOVES [3]. These models can also be used to determine how temperature and traffic conditions interact during the day, displaying their synergetic effect on emissions from on-road vehicles. Emissions inventory estimates are made for different technology groups and are reported for various vehicle classes. Current emission models do not predict accurately the mobile source emissions primarily due to oversimplified parameterization between vehicle activity and measured emissions output. Most of these emissions inventory models simply relate average emission values to vehicle densities and speeds on a traffic network. This approach is highly error-prone since it does not consider in sufficient detail vehicle operation parameters that are more closely related to emissions output. Estimation of motor vehicle emissions requires the ability to predict or measure the different parameters over the entire operating region. By developing transportation simulations that can accurately portray dynamic vehicle activities (e.g., accelerations, decelerations) and integrating detailed vehicle emissions profiles acquired through in-situ measurements, more accurate emission inventories from mobile sources can be achieved. 
For the development and maintenance of ongoing programs to inventory specific pollutant emissions, specific air pollution requirements are set forth in Title 40, of the Code of Federal Regulations (CFR), Part 51.321 [4], and in the Clean Air Act, as amended. The amendments to the Clean Air Act require the development of "...comprehensive, accurate, and current..."[4] inventories from all sources of each pollutant. Many complex processes govern the formation of pollutants in motor vehicles, and the Environmental Protection Agency (EPA) recognizes that a significant effort is necessary to develop and maintain emission inventories that meet the requirements for both technical analysis and administrative reporting.

The EPA and the California Air Resources Board (CARB) support large data collection programs to quantify the rate at which pollutants are emitted by individual categories of motor vehicles. Both organizations have used this information to develop models that help analysts estimate motor vehicle contributions to the local emissions inventory. These models, commonly known as "emission factor models," are designed to account for the effect of numerous vehicle parameters on the volume of pollutants emitted. The primary components of an emission factor model include the base emission factors, characterization of the vehicle fleet, fuel characteristics, vehicle operating conditions and the effect of local ambient conditions, the effect of alternative inspection and maintenance (I/M) programs and the effect of tampering and misfueling. None of these factors are static: technology is continually evolving, which leads to changing in-use emissions performance. Hence, a substantial effort is required to accurately quantify these factors and to stay current with the influence of all of these factors on vehicular emission levels.

Dynamometer tests in a laboratory test facility which includes engine and chassis dynamometers, remote sensing at specific on-road locations, and tunnel studies have been the most common methods for measuring vehicle emissions. The current generation of emission factor models, including the EMFAC series of models used in California and the MOBILE series of models developed by the EPA, are based upon emissions data for selected driving cycles. A driving cycle is composed of a unique profile of stops, starts, constant speed cruises, accelerations and decelerations, and is typically characterized by an overall time-weighted average speed [3,5]. Different driving cycles are used to represent driving under different conditions. The emission measurements for a driving cycle are typically conducted on a dynamometer in the laboratory. However, it has been well established that in-use emissions exceed the applicable emission limits when engines are operated under real-world conditions [68]. There is presently a lack of realistic test cycles representative of the engine activity regime. 
Substantial portions of a wide variety of real-world driving conditions are not incorporated into specific tests. For example, the U.S. heavy-duty engine Federal Test Procedure (FTP) applies only to a specific temperature range at specified speed and torque points in the order specified by the FTP test cycle. This means that the emissions data obtained may not be representative of emissions in real-world driving [6-8]. According to published research, emission rates are affected by a variety of vehicle characteristics, operating conditions, and transportation system conditions [9]. However, there is a dearth of information that can be used to establish a viable relationship between the behavior of emission rates and interactions of these parameters under real-world conditions. Additionally, the heavy-duty diesel vehicle (HDDV) 'off-cycle' operation is a vehicle component or software-dependent phenomenon that allows emissions expressed in $\mathrm{g} / \mathrm{bhp}$-hr in excess of the FTP certification standards [10], for non-idle conditions. The increased levels of emissions are produced during operating modes which are not explicitly covered by a certification test while still controlling emissions during the certification test [11]. In the case of heavy-duty vehicles, excess NOx emissions that were produced during off-cycle operation occurred most frequently during steady-state operating modes such as cruising down the freeway, and rarely occurred during transient operation. It is therefore imperative that the emissions models developed will consider the variability in emissions measured caused by these parameters.

In this study, the Mobile Emissions Measurement System (MEMS), an on-board portable emissions measurement system developed at West Virginia University (WVU), was used to record in-use, continuous, and brake-specific emissions from heavy-duty diesel-powered vehicles [12-14]. This study taps into the in-use emissions measurement capabilities and the vast databases that reside at the National Research Center for Alternative Fuels Engine and Emissions (CAFEE), and combines them with an advanced statistical modeling technique called Multivariate Adaptive Regression Splines (MARS) to predict emissions. Additionally, beginning in 2007, the certification of heavy-duty diesel engines in the U.S requires engine manufacturers to measure in-use emissions from vehicles under "real-world" operating conditions to complement the current certification procedures. As a first attempt, the model presented has only used those engine operating parameters which were broadcast by the engine's electronic control module (ECM). It should be noted that the model developed would be applicable for a particular engine model, model year, and vehicle type. 
The MARS technique [15] is basically an adaptive piece-wise regression approach. This method has been successfully employed for various prediction and data mining applications in recent years [16-22].

\subsection{Objectives}

The objective of this study was to build a continuous $\mathrm{NO}_{\mathrm{x}}$ prediction model that would be capable of accurately representing real-world emissions from on-road heavy-duty diesel engines in the Not-To-Exceed zone of operation. To achieve this objective it was necessary to perform data collection and analysis of engine activity data about on-highway heavy-duty vehicles for different applications under real-world conditions. WVU's MEMS was used to obtain engine operating conditions, vehicle speed, and in-use emission rates of $\mathrm{CO}_{2}$ and $\mathrm{NO}_{\mathrm{x}}$. The instrumented vehicle was tested on specific routes, which included a mix of highway and city driving patterns. The data obtained from these tests was used to develop the model to predict $\mathrm{NO}_{\mathrm{x}}$ emissions from in-use, heavy-duty diesel engines. It should be noted that the model developed would be applicable to a particular engine model, model year, and vehicle type. To achieve these objectives, it was necessary to:

- Obtain reliable and repeatable measurements of $\mathrm{NO}_{\mathrm{x}}$ using MEMS on-board portable emissions measurement system and engine operating parameters.

- Perform a statistical analysis to determine the major factors influencing $\mathrm{NO}_{\mathrm{x}}$ emissions.

- Employ the MARS technique to formulate a $\mathrm{NO}_{\mathrm{x}}$ prediction model, with inputs being the engine, vehicle, and environmental parameters.

- Validate the above predictions with the in-use data obtained from the on-road tests.

\subsection{Technical Approach to Accomplish Objectives}

The above objectives were accomplished in three phases as described below:

Phase-I: $\quad$ The first phase of this research focused on the measurement of in-use emissions from on-road heavy-duty diesel engines along with engine and vehicle activity. A test vehicle instrumented with WVU's MEMS, was used to obtain engine operating conditions, vehicle speed and in-use emission rates of $\mathrm{CO}_{2}$ and $\mathrm{NO}_{\mathrm{x}}$. On-road testing was conducted in such a manner that the test matrix of the vehicles included a mix of highway and city driving patterns. In order to ensure that the data collected was accurate, quality assurance techniques were employed during different stages of data collection and data processing. 
Phase-II: The second phase involved analyzing the different engine, vehicle, and environmental-operating conditions and their synergistic effect on emissions. The data was collected and analysis was performed for a particular engine model, engine model year, and vehicle type operated over the different routes.

Phase-III: The third phase involved the formulation of a model to predict emissions from heavy-duty diesel engines operating under real-world conditions. It should be noted that the model developed would be applicable for a particular engine model, model year, and vehicle type. It should be noted that this model is general, but any model will have to be tuned to a particular engine family and model. Within this effort, a scheme for $\mathrm{NO}_{\mathrm{x}}$ emissions prediction was developed using advanced regression techniques and tested using engine measurements acquired from on-road testing of an appropriately instrumented vehicle. The scheme uses the recently developed MARS technique to estimate some measured variables as a function of other variables [10]. The above model was then used to predict the $\mathrm{NO}_{\mathrm{x}}$ emission concentrations at different in-use operating conditions.

The in-field data collected were analyzed to obtain the proposed objectives. Specifically, the analysis and modeling focused on effects of parameters, such as engine speed, engine load, injection timing, fueling rate, oil temperature, manifold air temperature, manifold air pressure, coolant temperature and oil temperature on exhaust emissions from the test vehicles. This effort is an attempt towards inventory modeling encompassing the benefits and the limitations of onboard measurement. The benefits include the wide range of operating conditions while the limited by the inaccuracy of measurements outside the NTE zone of operation. 


\section{LITERATURE REVIEW}

There are numerous complexities involved in estimating and predicting mobile-source emissions from the on-road fleet. The fleet is made up of vehicles with a wide variety of emissions characteristics due to differences in condition, type, and age of engines and vehicles, performance of the emissions-control systems, maintenance, and fuel composition. Emissions expressed in $\mathrm{g} / \mathrm{s}$ or $\mathrm{r} / \mathrm{bhp}$-hr are also affected by local factors, such as meteorological conditions and traffic patterns. Developing predictions of future emissions requires projections for all of those characteristics. This requires building a mobile-source emissions model that is appropriate for all applications, a microscale instantaneous emissions modeling component that uses instantaneous operating conditions of individual vehicles and engines to estimate continuous engine/vehicle emissions and that can be used for a variety of applications, including generating conversion factors to predict distance-specific emissions. [23-26]. To be able to develop this kind of model, new measurement techniques are needed. On-board, in-use emissions measurement is one of these techniques and is widely recognized as a desirable approach for quantifying emissions from vehicles, because data are collected under real-world conditions at any location traveled by the vehicle. In this study, the modeling approach will focus on NOx emissions from heavy-duty diesel engines.

The following sections describe some of the past and current mobile-source emissions models that have been developed for emissions inventory purposes.

\subsection{Overview of Conventional Emissions Measurement and Estimation Approaches}

The current generation of emission factor models, are based upon emissions data for selected driving cycles. The description and the drawbacks of these models are described in the following sections.

\subsubsection{MOBILE}

The primary tool used by air-quality planners at national, state, and local levels to estimate on-road mobile-source emissions is the U.S EPA's Mobile Source Emissions Factor (MOBILE) model [27]. The MOBILE model for estimating on-road vehicle emissions factors in grams per mile was first developed by the U.S. EPA in the late 1970s. The latest version, referred to as MOBILE6 was based on recent vehicle-emissions testing data from EPA, the California Air Resources Board (CARB), automobile manufacturers, and petroleum refiners 
[27]. The MOBILE model provides emission factors for on-road vehicles for the three regulated pollutants: VOCs, $\mathrm{CO}$, and $\mathrm{NO}_{x}$. The model provides emission factors separately for the different classes of vehicles, and also for the average on-road fleet using a default national mix of vehicles. The vehicle classes are further subdivided into technology classes in MOBILE to account for emissions differences between, for example, vehicles with carburetors and those with fuel injection. To estimate total on-road mobile emissions in a given area, either the vehicle class emissions factor is multiplied by estimates of Vehicles Miles Traveled (VMT) by vehicle class for the area and summed, or the fleet average emissions factor is multiplied by total VMT for the area. Although the MOBILE6 documentation provides numerical results for changes in specific model components, the model was still based upon emissions data obtained from selected driving cycles.

\subsubsection{MOVES}

Motor Vehicle Emission Simulator (MOVES) [28-30] is another modeling system developed by the EPA's Office of Transportation and Air Quality (OTAQ). This system estimates emissions for on-road and nonroad sources, covers a broad range of pollutants, and allows multiple scale analysis, from fine-scale analysis to national inventory estimation. When fully implemented, MOVES will serve as the replacement for MOBILE6 and NONROAD. However, the drawback of this model is that the emissions data obtained for model building was based on laboratory testing as opposed to real-world conditions.

\subsection{Modal Modeling Approach}

The MOBILE model was developed for calculating regional emissions inventories using aggregated vehicle emissions data and estimates of vehicle activity in the form of VMT and average speed. Because of the inherent emissions and vehicle operation "averaging" that takes place in MOBILE, the model is not sensitive to driving dynamics. The major drawback, in this author's opinion, is that MOBILE uses average speed as the only variable for representing driving dynamics. Vehicle emissions are strongly dependent upon driving dynamics, and average speed does not always properly characterize these dynamics. It is well accepted varying driving patterns can have approximately the same average speed, but completely different driving dynamics, and thus drastically different emissions responses. To better capture emissions effects associated with a wide range of driving dynamics, researchers have investigated at a more fundamental level the modal operation of a vehicle and related emissions to vehicle operating 
modes such as idle, steady-state cruise, and levels of acceleration and deceleration [27]. Models that predict emissions based on these vehicle-operating modes are often referred to as "modal emissions models." The terms modal, instantaneous, and continuous are often used as synonyms when referring to this detailed microscale emissions modeling.

As described in Section 2.2.1, MOBILE is based on emissions testing in which a single average emissions value is determined for a particular driving cycle. In contrast, modal or instantaneous emissions data collection consists of measuring emissions continuously during the chassis dynamometer tests and recording these data at a particular time interval, usually every second. Vehicle operational data are also recorded, such as the instantaneous vehicle speed and acceleration rate. Some of the modal and instantaneous modeling approaches employed for emissions modeling are presented below.

\subsubsection{Speed Acceleration Look-up Tables}

The most basic and most common form of a modal or instantaneous emissions model is a multidimensional look-up table. Given one or more vehicle-operating variables, a table can simply store the corresponding emissions values. The most common emissions table is twodimensional, with rows representing a velocity interval and columns representing acceleration. During an emissions test, all of the emissions measurements are put into different cells in the emissions matrix according to the velocity and acceleration of the measured vehicle at that particular time. Some researchers use a "load" term (e.g., the speed-acceleration product) rather than acceleration for one of the table dimensions [31]. To guarantee the correct emissions value for every possible operating condition, a wide range of real-world driving cycles should be applied. However, this is often impractical; hence, a few driving cycles are applied, filling many cells in the emissions matrix. Values for the remaining cells are then interpolated or extrapolated from the data at hand. The emissions look-up tables can be created for individual vehicles, or consist of a grouping of vehicles, based on common vehicle attributes (e.g., model year and technology type). When this form of an emissions model is used, an applied driving cycle (that is, velocity-time profile) is considered one time step at a time, an emissions value is obtained from the lookup table, and all emissions values are then summed together to obtain an emissions value for the entire cycle.

The instantaneous emissions model based on lookup tables is a straightforward model to implement. However, there are several potential problems with this type of model. First, it is 
crucial that a wide range of vehicle-operating conditions are used when developing the lookup tables, which might require a significant amount of testing time. Second, when using instantaneous lookup tables, there is no explicit accounting for the time dependence in the emissions response to the vehicles operation. If the instantaneous lookup tables were derived from statistical analysis of cycle-based data, the operating history effects could be considered to be inherently accounted for. However, this has yet to be validated. Third, there is no convenient way to introduce other load-producing effects on emissions such as road grade or accessory (e.g., air-conditioning) use other than introducing numerous other look-up tables, or perhaps applying a set of corrections.

\subsubsection{Aggregate Modal Emission Models}

Washington et al. [32] have described the development of an aggregate modal emissions modeling approach. Sophisticated statistical techniques were used for the purpose. The model was developed by first analyzing in detail a large emissions certification database. Hierarchical, tree-based, regression analysis was then applied to the database, using several vehicle technologies and operating characteristics as variables to explain emissions variations. Surrogate variables were also introduced as potential explanatory variables. The tree-based analysis searches for variables that explain the most variance in emissions response. For a set of vehicles tested over a variety of test cycles, the technique attempts to determine what variables have the greatest effect on overall emissions values. A regression tree was formed from the analysis, with the leaves of the tree providing mass emissions rates for the specific, mutually exclusive, vehicle technology groups and operating characteristic combinations that naturally result from the regression-tree analysis [32]. Both individual vehicle technology characteristics and operating mode characteristics appear in the tree. It was found that operating characteristics that had the most explanatory power were surrogate variables of acceleration conditions and power demand. Not unlike other methods, this modeling approach is limited by the representativeness of vehicles and cycles tested. Therefore, the greater the diversity in vehicles and emissions testing cycles, the more reliable the regression-tree model. Although more than 23,000 vehicle tests had been employed in this aggregate modal model development to date, there were too few recent model year vehicles represented in this database. Nevertheless, a strength of this approach was that the algorithms could be re-estimated on an annual basis as new testing data become available on any number of vehicles and cycles. 
This modal model includes hot-stabilized emissions rates and engine-start emissions rates. The model also handles deterioration effects when the test age and odometer of the vehicle are included in the emissions database. This modal model is aggregate in the sense that it predicts a single integrated emissions value given any particular driving cycle. It does not provide instantaneous emissions values for every second of the driving cycle input.

\subsubsection{Neural-Network based Vehicle Emissions Models}

Another approach uses a neural-network-based vehicle emissions model to simulate second-by-second emissions given an arbitrary driving cycle [33]. This neural-network model is trained using dynamometer test results and makes nonlinear and multidimensional associations between vehicle-operating variables (that is, speed and road load) and the emissions values. First, a particular neural-network architecture is designed that allows accurate emissions prediction across the full envelope of vehicle operation. The network is then trained using a limited set of dynamometer-based measured emissions values. The network "learns" the precise relationship between all designated inputs and outputs and can update those relationships over time to allow for engine wear, changes in fuel composition, and/or extreme combinations of operating conditions [33]. Thus far, this technique has been successfully demonstrated on both light-duty passenger vehicles and heavy-duty diesel vehicles. It can also be weighted to reflect the populations of the vehicle fleet when considering composite vehicles. Similar to the aggregate modal emissions technique described above, this modeling approach is limited by the representativeness of vehicles and cycles tested. Promising initial results have been documented. Given the extreme variability in vehicle sensors, control equipment, and deterioration factors, this modeling approach is not likely to provide a long-term practical solution until a very large set of representative on-road data are available for such analyses.

Neural networks offer some advantages of flexibility of functional form in representing data. They require a good training data set. However, the process of selecting appropriate inputs for training of the neural network model is a subjective one. The time it takes to get good results

during training is a function of the a priori assumptions made by the analyst regarding which explanatory variables to include in the model. In addition, since there is some autocorrelation in second-by-second activity and emissions data, it is necessary to consider multiple time steps when training the neural network. A key shortcoming of neural networks is that they do not provide direct measures of sensitivity nor do they provide clear equations that reveal the key 
physical relationships among the inputs and outputs. Techniques exist for trying to interpret the results of a neural network model, but for most users such models are likely to be impenetrable "black boxes" providing no insight other than what a user obtains through sensitivity analysis.

\subsubsection{Physical Instantaneous Emissions Models}

Another approach to instantaneous emissions modeling is to use an analytical, physical modeling approach. In this type of approach, the entire emissions creation process is broken down into different components that correspond to physical phenomena associated with vehicle operation and emissions production [23, 24]. Each component is then modeled as an analytical representation consisting of various parameters that are characteristic of the process. These parameters typically vary according to the vehicle type, engine, and emissions technology. The majority of these parameters are stated as specifications by the vehicle manufacturers, and are readily available (e.g., vehicle mass, engine size, and aerodynamic drag coefficient). Other key parameters relating to vehicle operation and emissions production must be deduced from actual second-by-second emissions data. This type of modeling is considered more deterministic rather than descriptive. Such a deterministic model is based on causal parameters or variables, rather than based on simply observing the effects of emissions and assigning them to statistical bins (that is, a descriptive model). This approach provides understanding, or explanation, for the variations in emissions among vehicles, types of driving, and other conditions.

The Comprehensive Modal Emissions Model (CMEM) developed under sponsorship of the National Cooperative Highway Research Program (NCHRP Project 25-11) uses this approach [24, 25]. Thus far, CMEM is capable of predicting engine-out emissions, tailpipe emissions, and fuel consumption for a comprehensive set of Light Duty Vehicles (LDVs), in various states of condition (for example, properly functioning, deteriorated, and malfunctioning). This model is based on a large, detailed database of second-by-second emissions data. Over 320 vehicles were tested to establish this model in which each vehicle underwent a comprehensive dynamometer testing procedure that consisted of a standard FTP test, the high-speed US06 cycle, and an in-house developed modal emissions cycle. This modal emissions cycle (MEC01) has been designed to include various levels of acceleration and deceleration, a set of constant speed cruises, speed-fluctuation driving, and constant power driving [23-26]. CMEM has been validated against independent emissions measurements and has shown good results. Additional validation efforts using independent vehicles and test conditions are currently in progress. The 
physical modal emissions modeling approach inherently handles all of the factors in the vehicleoperating environment that affect emissions, such as vehicle technology, fuel type, operating modes, maintenance, accessory use, and road grade. Various components model the different processes in the vehicle related to emissions. Also, the model is applicable to all vehicle and technology types. It is not restricted to only steady-state emissions events, as is an emissions map approach, or a speed-acceleration matrix approach. Emissions events that are related to the transient operation of the vehicle can be appropriately modeled. Further, it can easily handle time dependence in the emissions response to the vehicle operation. As stated previously, the operating history (i.e., the last few seconds of vehicle operation) can play a significant role in an instantaneous emissions value. Recent work by Jimenez [34, 35] also uses a physical-based approach for calculating an emissions inventory by investigating the relationship between emissions and vehicle-specific power (VSP). VSP is a vehicle's instantaneous power demand divided by its mass. VSP can be calculated by a number of physical parameters such as rolling resistance, aerodynamic drag, velocity, and acceleration. It is possible to develop a functional relationship between emissions and the single value of VSP, using data both from dynamometer measurements as well as remote-sensing measurements. Further, it is possible to generate an emissions inventory by creating a distribution of VSP using remote-sensing measurements (those that record instantaneous speed and acceleration) then multiplying this distribution by the precalculated VSP-emissions function. Preliminary results of this simplified method show promise.

A problem with both physical approaches described above is that there is tremendous variability in emissions within a vehicle class, which would thwart a 'fundamental' model. Thus, to obtain an accurate estimate of both the mean and distribution of emissions from a particular vehicle type, a very large number of vehicles would have to be characterized. Additionally, the model would require a very large number of inputs that are not typically measured in vehicle activity studies. Therefore, it would be impractical to use such models for estimating fleet average emissions or for many other purposes.

\subsection{Need for Engine/Vehicle Operation Parametric Modeling}

According to published research, emission rates are correlated to a variety of vehicle characteristics, operating conditions, and transportation system conditions. A brief look at the 
factors that influence the formation of emissions is given below with the focus on $\mathrm{NO}_{\mathrm{x}}$ formation.

Central to emissions from engines are complex combustion processes that occur inside the engine cylinders. Various factors affect the combustion process, including the fuel composition and operating parameters such as engine speed, load, fueling, injection timing, manifold air temperature, manifold air pressure, and air-fuel ratio. Hence, there arises a need to have a model that includes engine and vehicle operating characteristics for predicting emissions.

The combustion process in a diesel engine can be divided into four periods, namely the ignition delay, premixed combustion, diffusion combustion and combustion tail [36-38]. Ignition delay is defined as the period between the injection of fuel into the cylinder and the time ignition starts. Of the four stages, ignition delay is of prime importance since it significantly contributes to $\mathrm{NO}_{\mathrm{x}}$ formation inside the cylinder. Engine speed is one of the major factors that affects ignition delay and thus emissions from diesel engines. Higher engine speeds increase the ignition delay, as measured in degrees of crank angle. Also, at higher engine speeds there is improved air and fuel mixing due to enhanced turbulence. This does not affect the chemical delay, but decreases the time available for $\mathrm{NO}_{\mathrm{x}}$ formation. Engine load also plays a crucial role in affecting the emissions from engines. As engine load increases, there is an increase in the amount of fuel injected for the same mass of air at constant speed. As more fuel is burnt, there is an increase in the in-cylinder adiabatic flame temperature. High combustion temperatures provide the needed energy for the chemical reactions that lead to $\mathrm{NO}_{\mathrm{x}}$ formation. Vehicle activity and operating conditions influence emissions, drivability and fuel economy. Recent studies show that emissions and fuel consumption are affected by smoothness and consistency of vehicle speed, which are highly affected by driving behavior and traffic conditions. Sharp acceleration from overtaking or changing lanes or merging onto a freeway from a slip road imposes heavy loads on the engine, which results in high emission levels. During heavy loads, vehicles are designed to operate with a richer fuel-air mixture, thereby producing high levels of emissions. Studies conducted at WVU and NCSU have shown that emission levels had a strong dependence on the mode of operation of the vehicle [7,14]. The analyses of on-road emissions with respect to driving modes, also referred to as modal emissions, have been reported in several published studies $[39,40]$. It was found that the mean emission rates $(\mathrm{g} / \mathrm{bhp}-\mathrm{hr})$ for $\mathrm{NO}_{\mathrm{x}}$ were the highest for cruise mode. The acceleration mode produced slightly lower levels of $\mathrm{NO}_{\mathrm{x}}$ emissions compared to the cruise mode, and the deceleration mode produced the least amount of $\mathrm{NO}_{\mathrm{x}}$ 
emissions. The environmental factors that affect on-road emissions include ambient conditions, road grade, traffic flow conditions and altitude. When a vehicle is operated under an atmospheric condition different from that for which it was optimized, its performance is affected [36-38]. With an increase in the atmospheric pressure, air density increases, thus increasing the intake charge into the engine. This improves the volumetric efficiency of the engine, thereby delivering more power [36-38]. The temperature of the intake air influences the evaporation of fuel injected, flame speed during combustion, hence the power developed. Air humidity at high percentages affects combustion by diminishing flame speed [36-38].

Emissions models developed should account for the impact of these variables on emissions. But, estimating motor vehicle emissions requires the ability to predict or measure the different parameters over the entire operating region. However, current modeling approaches do not have the capability to provide these accurate estimates. This supports the contention that there is a need for an emissions model that can produce precise estimates.

\subsection{Parametric Diesel Engine Model}

The aim of parametric engine modeling is to predict the engine performance and variables that are difficult to measure. Advanced engine control systems require accurate models of the thermodynamic mechanical process, which are substantially non-linear and often timevariant. Currently, these non-linear processes are represented by grid-based look-up tables.

\subsubsection{Model- based control design}

The term "model-based" is used when control law or diagnosis technique need a model of engine system to be computed. Model-based control and diagnosis design should reproduce time evolution of engine output according to inputs variable change. Complexity of these models must comply with control techniques, thus a compact form is often preferred.

\subsubsection{Software-in-the-loop Simulation}

Control system implementation needs a software simulator for off-line testing of control algorithms. An engine simulator allows for investigation of engine behavior and refined tuning of control parameters before experimental validation. 


\subsubsection{Real-time Model}

Real-time engine models are necessary for hardware-in-the-loop (HiL) simulations [41, 42]. The goal of HiL simulation is to test real hardware on simulated components in order to avoid the high-cost of experiments in a test cell. As an example, HiL may consist of coupled simulation of an electronic control unit and engine model implemented on a real-time computer.

Mathematical modeling of internal combustion engines is a far reaching subject. In the development of engine models there are three main steps.

- $\quad$ Thermodynamic models, used for engine design

- Empirical models, used for primary control investigation

- Non-linear models, used for engine simulation and control design

Many diesel engine development programs concentrate almost exclusively on steady state and transient tests performed on dynamometers to benchmark engines performance. As evident from the on-road studies conducted, the engine's sub-systems interact differently under realworld conditions as compared to laboratory evaluation. Hence, the model development technique performed using on-road data obtained under real-world conditions can help resolve the problem of covering the entire matrix of operation of the engine under actual driving conditions.

Few model-based engine control strategies that are currently in use have been published. Even fewer, if any, publications are devoted to control strategy development using on-road data. Some of the work on model development for control design at different organizations is discussed below.

A new training algorithm called Local Linear Radial Basis Fuction Network (LOLIMOT) for online adaptation of look-up tables was introduced at the Darmstadt University of Technology, Germany. This algorithm based on fast neural network, was shown to reduce the convergence time considerably [43].

At the University of Wisconsin Madison, neural network was employed for engine predictions and optimization studies. The neural networks developed were used to predict soot, $\mathrm{NO}_{\mathrm{x}}$, in-cylinder pressure and temperature $[44,45]$.

Research was conducted on the automatic, unmanned, closed-loop optimization of driveability quality on a high-dynamic engine test bed [45]. Tools were developed for the purpose of automation of ECU calibration. The software developed included (1) AVL-DRIVE, 
for objective real-time driveability evaluation tool for applications in the vehicle, on test beds and in simulation, (2) AVL-PUMA, for dynamic engine testing plus simulation of the vehicle; and (3) AVL-CAMEO, for optimization of the ECU parameters according to the specified driveability target.

Control systems for diesel engines developed at Caterpillar, employ mathematical models of control strategies. These models are developed using simulation software called Dynasty. Dynasty integrates simulations of thermodynamic, mechanical, structural, fluid, hydraulic, electrical, and digital systems to predict system behavior. This enables development of better design concepts, optimizes current designs, develops control strategies, and analyzes performance [46].

For advanced engine calibration techniques, new simulation tools and procedures were developed at Delphi Research Labs to rapidly generate optimized calibration maps. GT Power Engine is a simulation software employed and engine models are validated through limited dynamometer tests [48].

A model-based control of fuel injection parameters of a diesel engine equipped with a high pressure, common-rail injection system was researched at Tsinghua University. A new modeling technique which constitutes Neural Network and Adaptive Neuro-Fuzzy Inference System (ANFIS) was developed. The analysis and experimental results demonstrated that effective modeling can be achieved using this method [49].

Research at the University of Oulu, Finland, demonstrated the application of ANFIS, to a non-linear multi-input single-output fuel feeding and combustion system. The ANFIS model developed determined the exact amount of fuel fed to a combustion chamber [50].

At present, model-based control systems are used as a tool to reduce the lengthy design time required by the traditional design process by performing many design iterations early in a vehicle program. These models encompass the uncertainties arising from lack of complete knowledge of behavior of emission rates due to limitations of data availability and nonrepresentativeness of measured data with respect to true on-road vehicle emissions.

\subsection{Overview of Engine Certification}

In the past, the engine certification test entailed exercising the engine through two Federal Test Procedure (FTP) cycles, a 'cold start' and a 'hot start' [10]. The regulated emissions 
limits for an engine operating on FTP cycle for different engine model years are given in Table $2-1[10,51]$.

Table 2-1 Emissions standards for heavy-duty diesel engines

\begin{tabular}{||c||c||c||c||c||}
\hline \hline Year & HC (g/bhp-hr) & CO (g/bhp-hr) & NO $_{\mathbf{x}}$ (g/bhp-hr) & PM (g/bhp-hr) \\
\hline \hline 1990 & 1.3 & 15.5 & 6.0 & 0.60 \\
\hline \hline 1991 & 1.3 & 15.5 & 5.0 & 0.25 \\
\hline \hline 1994 & 1.3 & 15.5 & 5.0 & 0.10 \\
\hline \hline 1998 & 1.3 & 15.5 & 4.0 & 0.10 \\
\hline
\end{tabular}

On October 6, 2000 EPA published Not-To-Exceed (NTE) rules and regulations for heavy-duty diesel engines (65 Fed. Reg. 59895) effective for engines starting with model year 2007 [4]. NTE provisions were also incorporated into the regulations promulgated shortly thereafter requiring further reductions in emissions from heavy-duty engines (66 Fed. Reg. 5001 January 18, 2001). Briefly, the NTE provisions specify brake-specific averaging periods as short as 30 seconds. Under these provisions, testing is restricted to a limited region of engine operation. Namely, when all of the following conditions are simultaneously met for at least 30 seconds, an NTE event is generated. Note, however, that if an aftertreatment system were to regenerate during this time, the minimum time under which all of these conditions must be met would increase to at least twice the regeneration interval [see Figure 2-1]:

1. Engine speed must be greater than $15 \%$ above idle speed.

2. Engine torque must be greater than or equal to $30 \%$ of maximum torque.

3. Engine power must be greater than or equal to $30 \%$ of maximum power.

4. Vehicle altitude must be less than or equal to 5500 feet.

5. Ambient temperature must be less than or equal to 100 degrees $\mathrm{F}$ at sea level to 86 degrees $\mathrm{F}$ at 5500 feet.

6. Brake-specific fuel consumption (BSFC) must be less than or equal to $105 \%$ of the minimum BSFC if an engine is not coupled to a multi-speed manual or automatic transmission.

7. Engine operation must be outside of any manufacturer petitioned exclusion zone. 
8. Engine operation must be outside of any NTE region in which a manufacturer states that less than $5 \%$ of in-use time will be spent.

9. For EGR-equipped engines, the intake manifold temperature must be greater than or equal to $86-100^{\circ} \mathrm{F}$, depending upon intake manifold pressure.

10. For EGR-equipped engines, the engine coolant temperature must be greater than or equal to $125-140^{\circ} \mathrm{F}$, depending on intake manifold pressure.

11. Engine aftertreatment systems' temperature must be greater than or equal to $250^{\circ} \mathrm{C}$.

The ESC speed is calculated as follows [53]:

$$
\eta_{15 \% \text { ESC Speed }}=\eta_{l o}+0.15\left(\eta_{h i}-\eta_{l o}\right)
$$

where $\eta_{1 \mathrm{o}}$ is the lowest engine speed at which $50 \%$ of the maximum power is available and $\eta_{\mathrm{hi}}$ is the highest engine speed where $70 \%$ of the maximum power occurs.

The emissions standards for different model year engines are listed in Table 2-2 and Table 2-3.

Table 2-2 HDDE emissions standard in compliance with the consent decrees

\begin{tabular}{|c|c|c|c|c|c|}
\hline & & $\begin{array}{c}\text { NO }_{\mathrm{x}} \\
\text { (g/bhp-hr) }\end{array}$ & $\begin{array}{c}\text { CO } \\
\text { (g/bhp-hr) }\end{array}$ & $\begin{array}{c}\text { HC } \\
\text { (g/bhp-hr) }\end{array}$ & $\begin{array}{c}\text { PM } \\
\text { (g/bhp-hr) }\end{array}$ \\
\hline $\begin{array}{c}\text { Euro III } \\
\text { Composite } \\
\text { Value Limit }\end{array}$ & $\begin{array}{c}\text { After Dec } \\
31,1998\end{array}$ & $\begin{array}{c}6.0 \text { (or) } \\
1.5^{*} \text { FTP Standard }\end{array}$ & 15.5 & 1.3 & 0.10 \\
\hline NTE Limit & $\begin{array}{l}\text { After Dec } \\
31,1998\end{array}$ & $\begin{array}{c}7.0 \text { (or) } \\
1.75^{*} \text { FTP } \\
\text { Standard }\end{array}$ & 15.5 & 1.3 & 0.10 \\
\hline
\end{tabular}




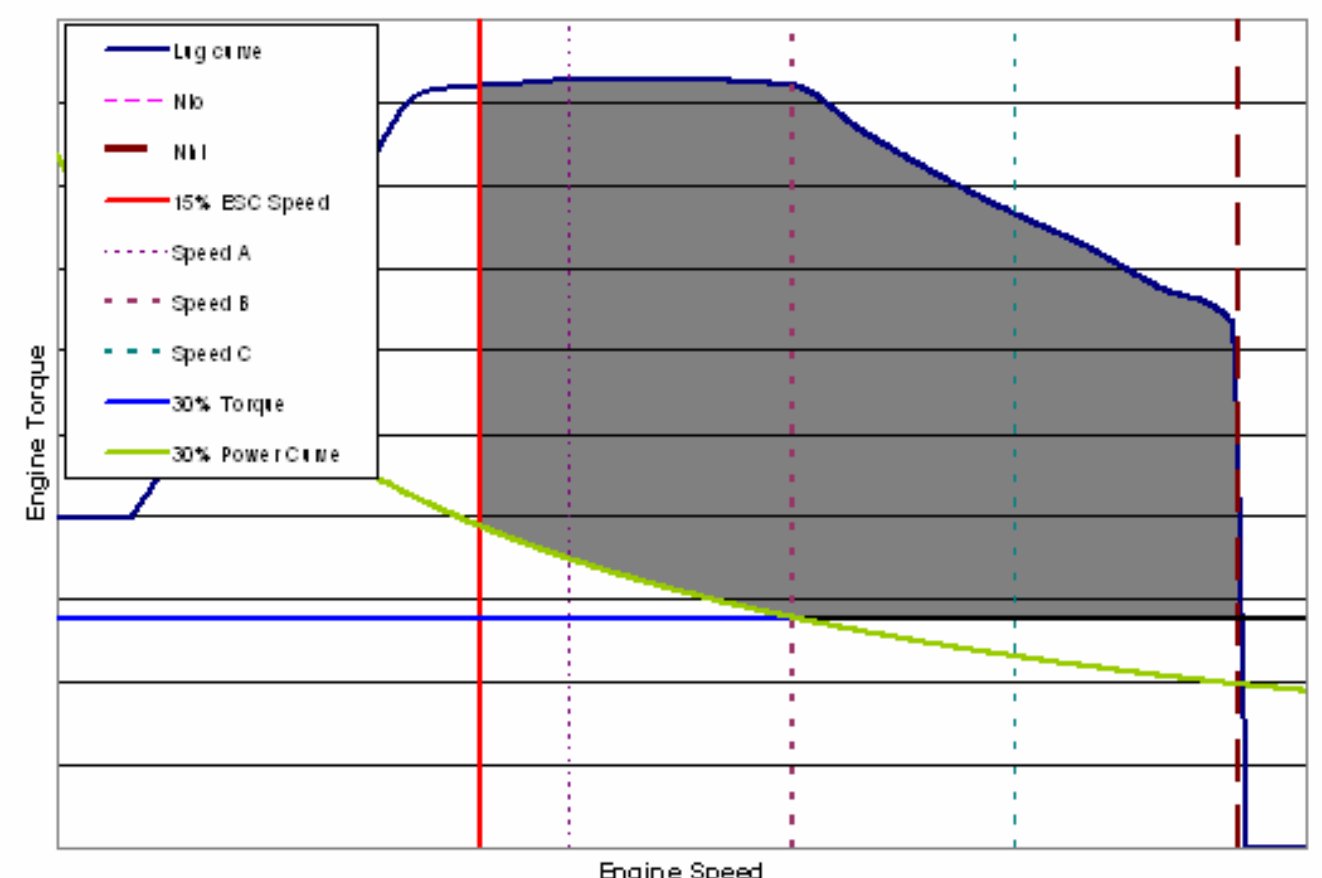

Figure 2-1 Graphical definition of NTE zone for gaseous emissions [53]

Despite significant advances in capabilities of modern engine and chassis dynamometers, and the accuracy and sensitivity of gas analyzers, it has been observed that in-use, on-road emissions testing is imperative. Tunnel studies and on-road data have indicated that emissions differ significantly from those predicted by emissions models [8]. Hence, an in-use testing program was developed by the engine manufacturers as reflected in the Consent Decrees [52]. The details of the in-use testing program are discussed in detail elsewhere [11-14]. 
Table 2-3 HDDE emissions standards for post-2001 engines

\begin{tabular}{|c|c|c|c|c|c|c|}
\hline & & $\begin{array}{r}\mathrm{NO}_{\mathrm{x}} \\
(\mathrm{g} / \mathrm{l}\end{array}$ & $\begin{array}{l}\text { JMHC } \\
\text { o-hr) }\end{array}$ & $\begin{array}{c}\text { CO } \\
\text { (g/bhp-hr) }\end{array}$ & $\begin{array}{c}\text { HC } \\
\text { (g/bhp-hr) }\end{array}$ & $\begin{array}{c}\text { PM } \\
\text { (g/bhp-hr) }\end{array}$ \\
\hline \multirow{2}{*}{ FTP Limit } & $\begin{array}{l}\text { After } \\
\text { Oct 1, } \\
2002\end{array}$ & 2.4 & $\begin{array}{c}2.5 \text { (if } \\
\text { NMHC }< \\
0.5 \\
\text { g/bhp-hr) } \\
\end{array}$ & 15.5 & 1.3 & 0.10 \\
\hline & $\begin{array}{l}2007 \\
\text { and } \\
\text { later }\end{array}$ & 0.20 & N/A & N/A & $0.14(\mathrm{NMHC})$ & 0.01 \\
\hline $\begin{array}{l}\text { Euro III } \\
\text { Composite } \\
\text { Value Limit }\end{array}$ & $\begin{array}{l}\text { After } \\
\text { Oct 1, } \\
2002\end{array}$ & $\begin{array}{c}2.4 \text { (or) } \\
1.0 * \text { FTP } \\
\text { Standard }\end{array}$ & $\begin{array}{c}2.5 \text { (if } \\
\text { NMHC < } \\
0.5 \\
\text { g/bhp-hr) }\end{array}$ & 15.5 & 1.3 & 0.10 \\
\hline NTE Limit & $\begin{array}{l}\text { After } \\
\text { Oct 1, } \\
2002\end{array}$ & $\begin{array}{c}3.0 \text { (or) } \\
1.25^{*} \text { FTP } \\
\text { Standard }\end{array}$ & $\begin{array}{c}3.125 \text { (if } \\
\text { NMHC < } \\
0.625 \\
\text { g/bhp-hr) }\end{array}$ & 15.5 & 1.3 & $\begin{array}{l}0.125 \text { (or) } \\
1.25^{*} \text { FTP } \\
\text { Standard }\end{array}$ \\
\hline
\end{tabular}

\subsection{On-Board Emissions Measurement Systems}

On-board measurements of vehicle and/or engine performance and exhaust emissions can help in studying the effectiveness and proper functioning of heavy-duty emission control technologies and devices. As mentioned earlier, the real-world emissions may be significantly higher than the emissions standards. By providing second-by-second emissions data, the onboard measurements can identify operating modes that produce high emissions. Hence, there is a need for development and implementation of accurate and precise on-board emission measurement systems for measuring these parameters.

Various research organizations and institutes have been involved in the development and usage of an on-board emissions measurement system. Some of them include Caterpillar Inc., Southwest Research Institute, General Motors, US Coast Guard, Flemish Institute for Technological Research, Northeast States for Coordinated Air Use Management (NESCAUM), Ford Motor Company, WPI-Microprocessor Systems Inc., University of Pittsburgh, EPA, Honda R\&D, Nicolet Instrument Corp., Sensors Inc., Keio University, University of Alberta, Horiba Ltd., CE-CERT, Analytical Engineering Inc., National Center for Environmental Research, Engine Fuel and Emissions Engineering Inc., Clean Air Technologies International Inc., and North Carolina State University (NCSU). The details of research and development at these organizations have been discussed in detail elsewhere [53-80] 
WVU developed an on-board emissions measurement system called the Mobile Emissions Monitoring System (MEMS). The details of emissions measurement of $\mathrm{NO}_{\mathrm{x}}$ and $\mathrm{CO}_{2}$ using the MEMS is discussed in detail elsewhere $[11,14,53]$. In this study, the MEMS was used for emissions measurement of $\mathrm{NO}_{\mathrm{x}}$ and $\mathrm{CO}_{2}$. The on-road routes used for testing represent typical in-use vehicle applications, and consist of both urban and highway segments. Two of the routes are comprised primarily of urban driving, while the other two routes are principally highway cycles. The in-use testing routes are described in Section 3 [11-14].

The data obtained from on-board emissions measurement systems have been used to evaluate the real-world performance of heavy-duty diesel engines. Some of the studies that were made using the on-board measurement devices are discussed below.

\subsubsection{NCSU}

Different studies were conducted using the on-board emissions measured using OEM$2100 \mathrm{~m}$ such as emissions reduction through better traffic management, obtaining vehicle-specific emissions models, and comparison of emissions from vehicles using B20 and diesel fuel. These studies were aimed at on-board measurements that would aid in understanding the episodic nature of emissions, on-road emissions hotspots, effect of traffic patterns, effect of fuel variability, and inter-vehicle variability in emissions [81-83].

\subsubsection{Texas Southern University}

Research was conducted to collect real-world vehicle emissions and activity data on freeway, arterials, and local streets in Houston, Texas. Researchers used the Portable Emissions

Measurement system (PEMS) to analyze the characteristics of on-road vehicle emissions and evaluate and validate the mobile source emission factor model MOBILE6. It was inferred that the vehicle emissions are highly related to road types and the truck emissions were higher when driving around intersections [83].

\subsubsection{University of Alberta}

An on-board system was developed to measure and record ambient conditions, driving behavior, vehicle operating parameters, fuel consumption and exhaust emissions [84, 85]. The system employs a Vetronix PXA-1100 five-gas analyzer, which uses a combination of infrared absorption and fast response chemical cells to measure $\mathrm{NO}_{\mathrm{x}}, \mathrm{CO}, \mathrm{CO}_{2}$ and $\mathrm{O}_{2}$. Air mass 
consumption rate was measured using a Siemens HFM 62B mass airflow sensor. The data acquisition system recorded the data from the analyzers and the sensors.

\subsubsection{Keio University}

A study was performed using a simple on-board emissions measurement system of actual $\mathrm{NO}_{\mathrm{x}}$ emissions of a medium-duty freight vehicle [84,85]. The $\mathrm{NO}_{\mathrm{x}}$ mass emissions were calculated by using Zirconia $\mathrm{NO}_{\mathrm{x}}$ sensor and Karman vortices sensor. Engine power was estimated from multiplying vehicle speed by a running resistance that can be calculated from rolling resistance, airflow resistance, climbing resistance, and acceleration resistance. The study demonstrated that on-board measurement system could be used to evaluate road infrastructure, driver's operation, vehicle running conditions, and $\mathrm{NO}_{\mathrm{x}}$ and $\mathrm{CO}_{2}$ emissions.

\subsubsection{University of California, Riverside}

Real-world continuous engine-out and tailpipe emissions were collected on 340 lightduty vehicles using an on-board emissions measurement system. A comprehensive modal emissions model was developed and integrated with a variety of transportation models. Variability in emissions of $\mathrm{CO}_{2}, \mathrm{HC}, \mathrm{CO}$, and $\mathrm{NO}_{\mathrm{x}}$ were observed over different driving modes $[23-25,40]$.

\subsubsection{University of California, Davis}

The variables that affect the on-road emissions such as load factors, terrain gradient, truck payload, overnight idling, and compression braking were studied to quantify the significance of these variables on a heavy-duty diesel vehicle. The EPA's on-road emissions testing trailer was used for the purpose, measuring emissions and vehicle operation simultaneously on-road $[87,88]$.

\subsubsection{West Virginia University}

Using the MEMS, on-road in-use emissions were measured for different heavy-duty vehicles. The brake-specific emissions were calculated over the NTE zone of operation. Results showed that the $\mathrm{NO}_{\mathrm{x}}$ emissions were higher than the certification levels when operated in the NTE region [11-14]. 
On-board emissions measurements have emerged as a promising new approach for obtaining representative real-world tailpipe emissions data based upon actual on-road driving. The increasing availability of instrumentation for performing on-road emissions studies, the development of data collection and analysis protocols, and the increasing availability of example on-board studies suggest that on-board data collection is a potentially practical and useful source of data for the $\mathrm{NO}_{\mathrm{x}}$ predictive model. Therefore, this study is aimed at exploring the potential of on-board data to play an important role in the $\mathrm{NO}_{\mathrm{x}}$ predictive model, and to make recommendations for the development of models and measurement of data needed to support the $\mathrm{NO}_{\mathrm{x}}$ predictive model. 


\section{VEHICLE TESTING AND DATA COLLECTION}

Prior to developing a predictive HDD vehicle $\mathrm{NO}_{\mathrm{x}}$ emissions model, it was necessary to collect required data through a vehicle testing program. Based on the background information described in the previous chapter, a vehicle testing methodology was developed that has provided data for developing the emissions model. This vehicle testing methodology consists of several key components:

1) Defining the vehicle/technology categories for the heavy-duty modules

2) Using the vehicle/technology categories for guidance, determining a vehicle recruitment strategy; and

3) Developing an on-road test procedure for the measurement of heavy-duty modal emissions.

The majority of the data collection was performed using WVU's MEMS described first in Section 4.1. Next, the three components outlined above are described in detail. The fifth section describes the emission testing that has been performed. The last section of this chapter describes the data post-processing that took place.

\subsection{Overview of Mobile Emissions Measurement System}

The various components of WVU's MEMS are briefly described in the following section. The measurement of mass requires the measurement of both concentration of species and total exhaust mass flow rate. Also, the measurement of engine speed and torque is needed for brakespecific emissions calculations. The measurements of brake-specific emissions are discussed elsewhere [11-14].

\subsubsection{Flow Rate Measurement System}

Yaw angles are important when measuring flow rates. However, most pitot-tube-based devices accommodate considerable yaw angles without significantly affecting the measurement errors. Hence for MEMS, exhaust mass flow rates were measured with a Dietrich Standard Annubar $^{\mathrm{TM}}$ [89]. The Annubar is a multi-point averaging pitot tube that works on the principle of Bernoulli's theorem. Of the different configurations of the Annubar ${ }^{\mathrm{TM}}$, the regular threaded PakLok assembly (Model DCR+15S or Model DCR+25S) was used for the measurement process. 
Flow rate calculations required accurate measurements of differential and absolute pressures, and the exhaust gas temperature. Various transducers that were used and their operating ranges are given in Table 3-1. Stranded wire thermocouples leads are much better suited to the rigors of inuse testing and were used for temperature measurement. In order to prevent condensation in the differential pressure lines, heated blanket insulation was used. Moreover, active temperature control of pressure transducer and lines enabled the reduction of the amount of drift associated with the pressure transducer zero and eliminated the condensation problem.

Table 3-1 Operating ranges of transducers used

\begin{tabular}{|l|c|}
\hline Transducer (Model) & Operating Range \\
\hline Absolute Pressure (Omega PX-213) & $0-100 \mathrm{kPa}, 0-200 \mathrm{kPa}$ \\
\hline Differential Pressure (Validyne P55D) & $0-0.2 \mathrm{~m}, 0-0.25 \mathrm{~m}, 0-56 \mathrm{~m} \mathrm{H}_{2} \mathrm{O}$ \\
\hline Relative Humidity (Omega HX92-A) & 3 to $95 \%$ \\
\hline Temperature (J and K) & $0-550^{\circ} \mathrm{C}$ \\
\hline
\end{tabular}

The sampling probe that was placed in the exhaust stream complied with the regulations set by the 40 CFR, Part 89.412 .96 . The stainless steel probe, which has six ports along its periphery, was placed span-wise across the flow so that a representative sample was drawn from the exhaust stream. The other components of the exhaust sampling system included heated Teflon line, heated filter and the pump. The heated Teflon sample line measuring $0.64 \mathrm{~cm}$ $(0.25$ ") on the outer diameter, was used to transfer the sample from the sample probe to the heated filter. Heating the sample prior to any drying device prevents condensation. The MEXA 120 Zirconium Oxide $\mathrm{NO}_{\mathrm{x}}$ sensor was placed downstream of the heated filter and upstream of the Air Dimensions Inc. Micro Dia-Vac sample pump. $\mathrm{A} \mathrm{NO}_{2}$ to $\mathrm{NO}$ converter was incorporated with the $\mathrm{NO}_{\mathrm{x}}$ sensor manifold to minimize space requirements. Downstream of the pump, a custom-designed compact Peltier effect gas chiller removed moisture from the sample stream, and provided an outlet dew point of approximately $5^{\circ} \mathrm{C}$. In order to reduce the effect of inertial effects, a differential pressure regulator, in conjunction with needle valves, controlled flow rate to the $\mathrm{CO}_{2}$ analyzer and the electrochemical NO sensor to 3.0 LPM and 0.5 LPM, respectively. Figure 3-1 shows the data acquisition, flow conditioning, and analysis systems of MEMS. A 
schematic of the sampling system is shown in Figure 3-2. The flowrate measurement system as fitted on a test vehicle is shown in Figure 3-3.

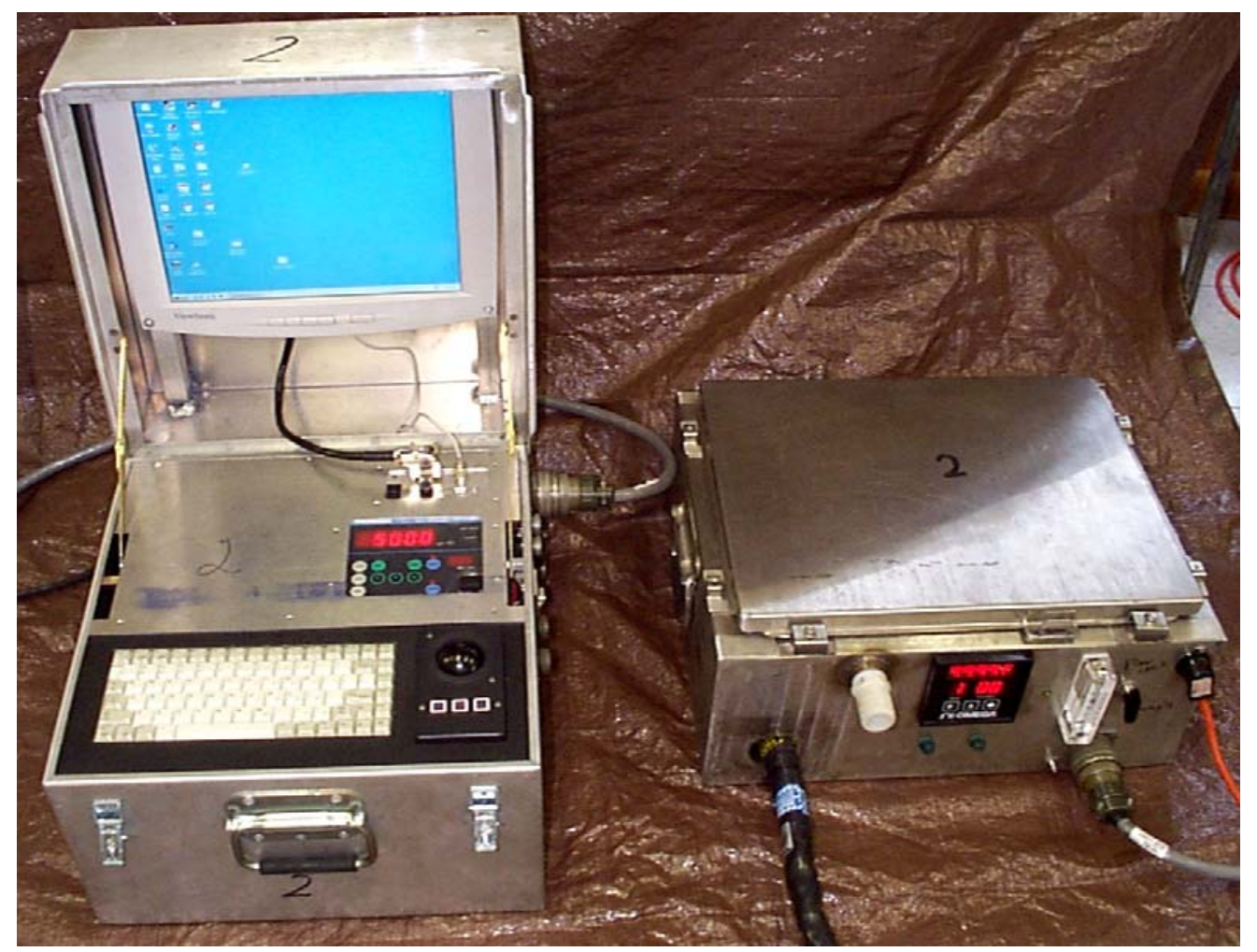

Figure 3-1 Data acquisition, sample conditioning and analysis systems of MEMS 


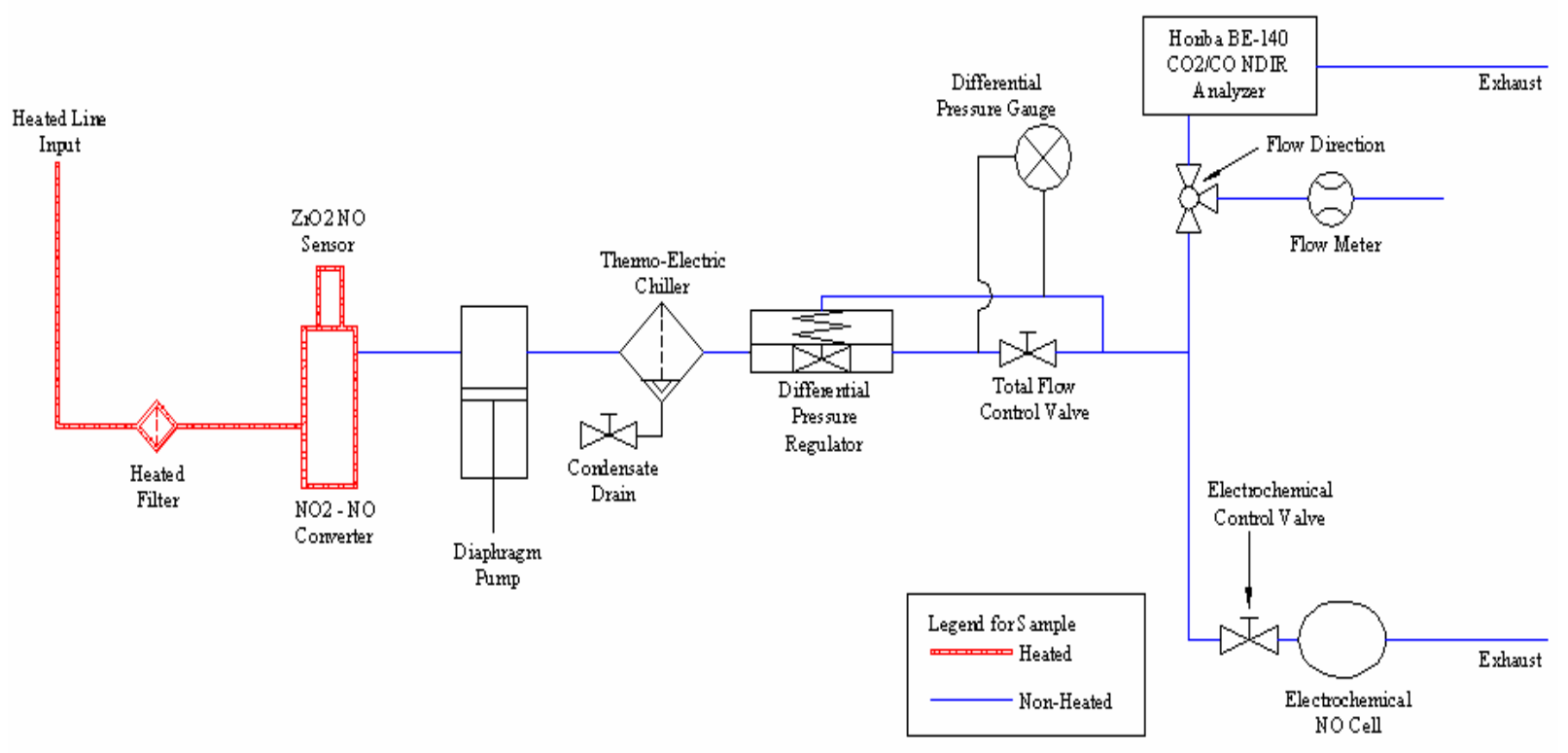

Figure 3-2 Schematic of MEMS sampling System

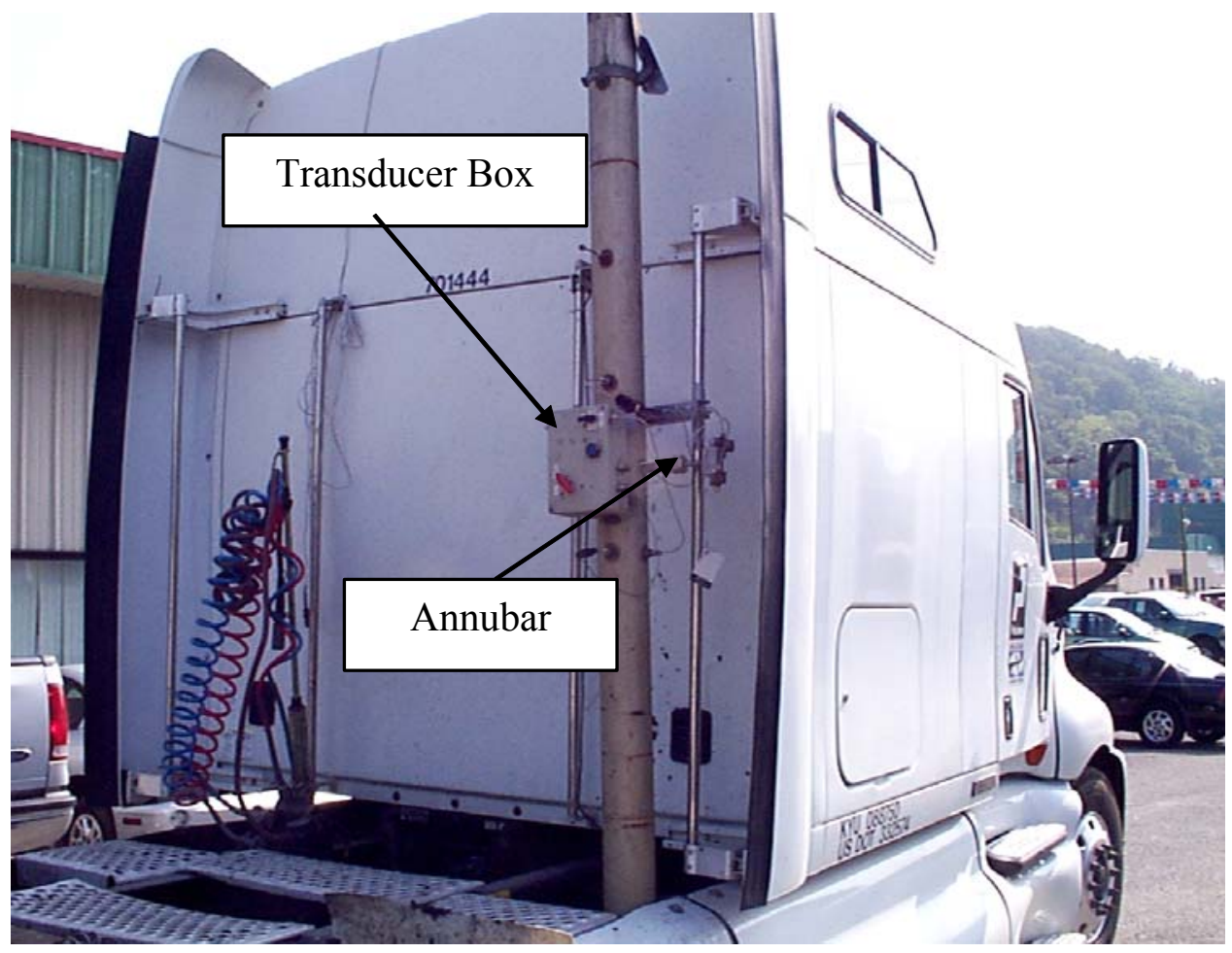

Figure 3-3 Representation of the exhaust flow measurement system fitted to the test vehicle 


\subsubsection{Engine Speed, Torque, and Vehicle Speed Measurement}

The ECU broadcast was used to record various engine and vehicle parameters including engine speed and vehicle speed. The vehicle speed broadcast by the ECU could be used to infer the distance traveled, which was compared with the GPS obtained vehicle speed. The ECU also broadcasts engine load on a percent basis in pre-2001 vehicles that employ the SAE J1587 protocols, and engine torque from engines using the SAE J1939 protocols [90-92, 53].

\subsubsection{Data Acquisition System}

The data acquisition system (DAS) used by the MEMS was designed to withstand vibrations encountered during on-road testing. As with any standard, SAE J1587 allows manufacturers to customize the manner in which data is broadcast. Message Identification (MIDs) addresses may vary from one manufacturer to the next, and components sharing the same MID may cause potential problems when attempting to read data. The DAS was so configured that it can adapt to a wide array of test vehicles and variety of signals. The DAS was a computer platform constructed of National Instruments components which comprises the computer platform, data acquisition card, signal conditioning unit and temperature and voltage cards [53].

\subsubsection{Power supply}

The generator set mounted on the vehicle or on the trailer, dependant upon the test vehicle platform fulfilled the power requirements of the current MEMS design. Surge protectors were used for the DAS. Power conditioning was done using either single source or multiple sources through individual power supplies and were critical for DC operation.

\subsubsection{Exhaust Gas Analyzers}

The MEXA 120 NOx analyzer which includes the zirconium oxide sensor, measured concentrations of the oxides of nitrogen. The $\mathrm{CO}_{2}$ concentrations were measured using a solidstate non-dispersive infrared (NDIR) analyzer.

The choice of zirconium oxide sensor for $\mathrm{NO}_{\mathrm{x}}$ measurement is a prime example that instrumentation must be largely tailor-designed to accommodate the rigors of in-use testing. These sensors seem to be susceptible to failure when directly mounted in a raw exhaust stack if ceramic temperatures are not maintained during engine operation. Moreover, the operating temperatures may not be adequate to prevent PM build-up in the sensor, which can ultimately 
lead to catastrophic failure. Hence, the MEXA 120 Zirconium Oxide $\mathrm{NO}_{\mathrm{x}}$ sensor was placed downstream of the heated filter, thus reducing PM build-up.

Interference of moisture in the exhaust gas stream could affect measurements using a NDIR gas analyzer. Thus, in order to minimize this interference effect, the NDIR $\mathrm{CO}_{2}$ analyzer was placed downstream of the thermoelectric gas chiller which removes moisture from the sample stream.

\subsection{Vehicle Testing Procedure}

The in-use testing conducted in this study was performed by WVU in partial fulfillment of the requirements of Phase III of the Consent Decrees. The EPA approved four routes that were defined by WVU in consultation with the settling manufacturers. These routes were meant to represent typical in-use vehicle applications, and consisted of both urban and highway segments. Two of the routes were comprised of primarily urban driving, while two routes were principally highway cycles. The following paragraph is a subsection of the Consent Decrees describing the route criteria $[52,13]$, and the in-use testing routes are described in the following sections.

"In Phase II of the In-Use Testing Program, the manufacturer shall develop in-use testing procedures to be used in connection with Phases III and IV of the In-Use Testing Program. The development of in-use testing procedures shall be based on testing of HDDE's engages in a variety of typical on-road emissions, and in a variety of seasonal conditions, and shall utilize engines extending over various stages of their Useful Life. The testing procedures shall include the identification of candidate driving routes representing typical urban, suburban and highway driving. The candidate routes shall be of sufficient length to take 45 minutes of data when driven at posted speeds. At least one (1) candidate driving route shall include a portion where at least 15 minutes of operation at $65 \mathrm{mph}$ or greater is permitted and generally attained by trucks. The test routes must be long enough in duration to $\log$ a suitable amount of data for proper analysis, but not so long that the proper calibration of instrumentation is voided and sensor drift occurs." 
WVU has developed several test routes that have been used throughout the test phases of the Consent Decrees in-use testing program. The data that are presented in this study were collected over the test routes that are discussed in the following sections.

\subsubsection{Morgantown Test Route}

The Morgantown route (Mrgtwn), which consists of both urban and highway operation, begins and ends on Earl Core Rd at the I-68 interchange in Morgantown, WV. The route continues west to Hartman Run Rd and south onto the Mileground Rd. The next section of the route then continues on Rt. 705 North to Chestnut Ridge Rd to Van Voorhis Rd. The route follows onto Patteson Dr and then north onto Monongahela Blvd to Star City. The route then continues onto Osage Rd to I-79 South to I-68 East. At exit 4 on I-68 East, the Morgantown route makes its way back to Earl Core Rd to complete the loop. The total distance for this route is 20.5 miles. The test route is shown in Figure 3-4. A plot representing typical engine speed, engine torque, and vehicle speed during the route is given in Figure 3-5.

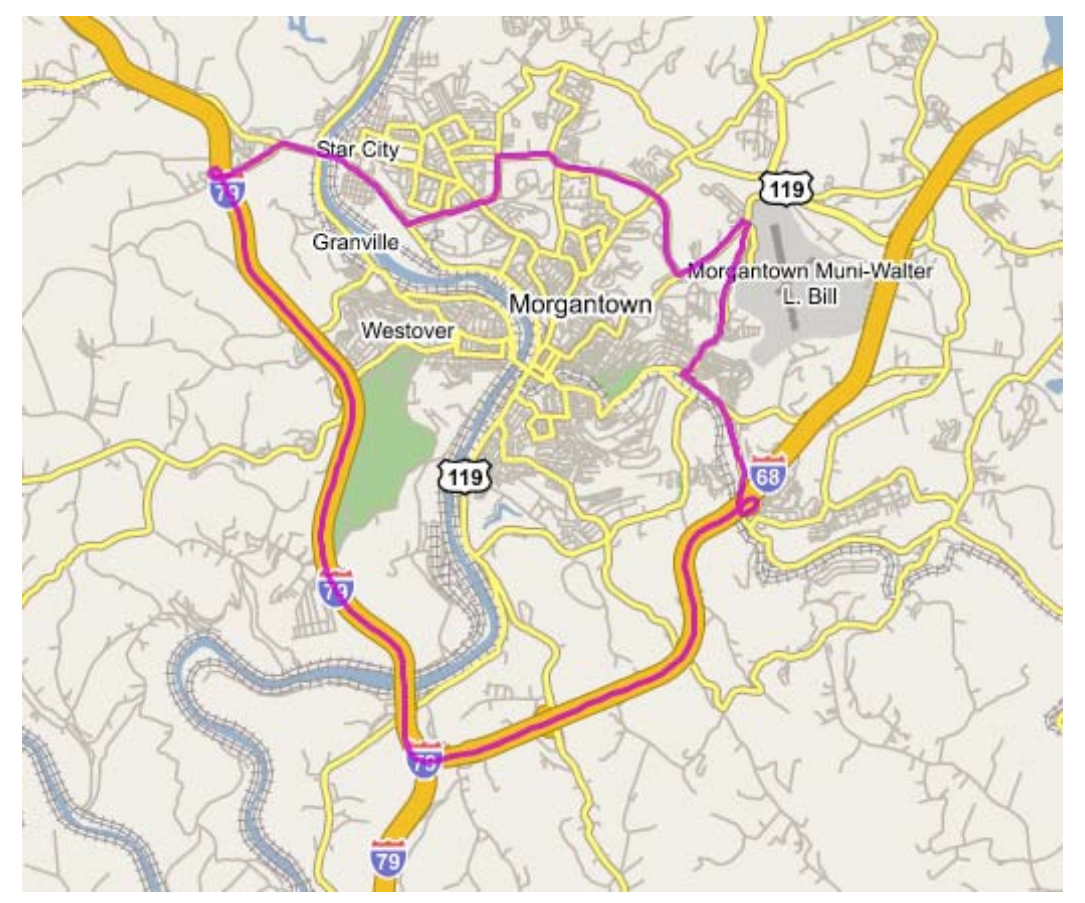

Figure 3-4 Mrgtwn Route 


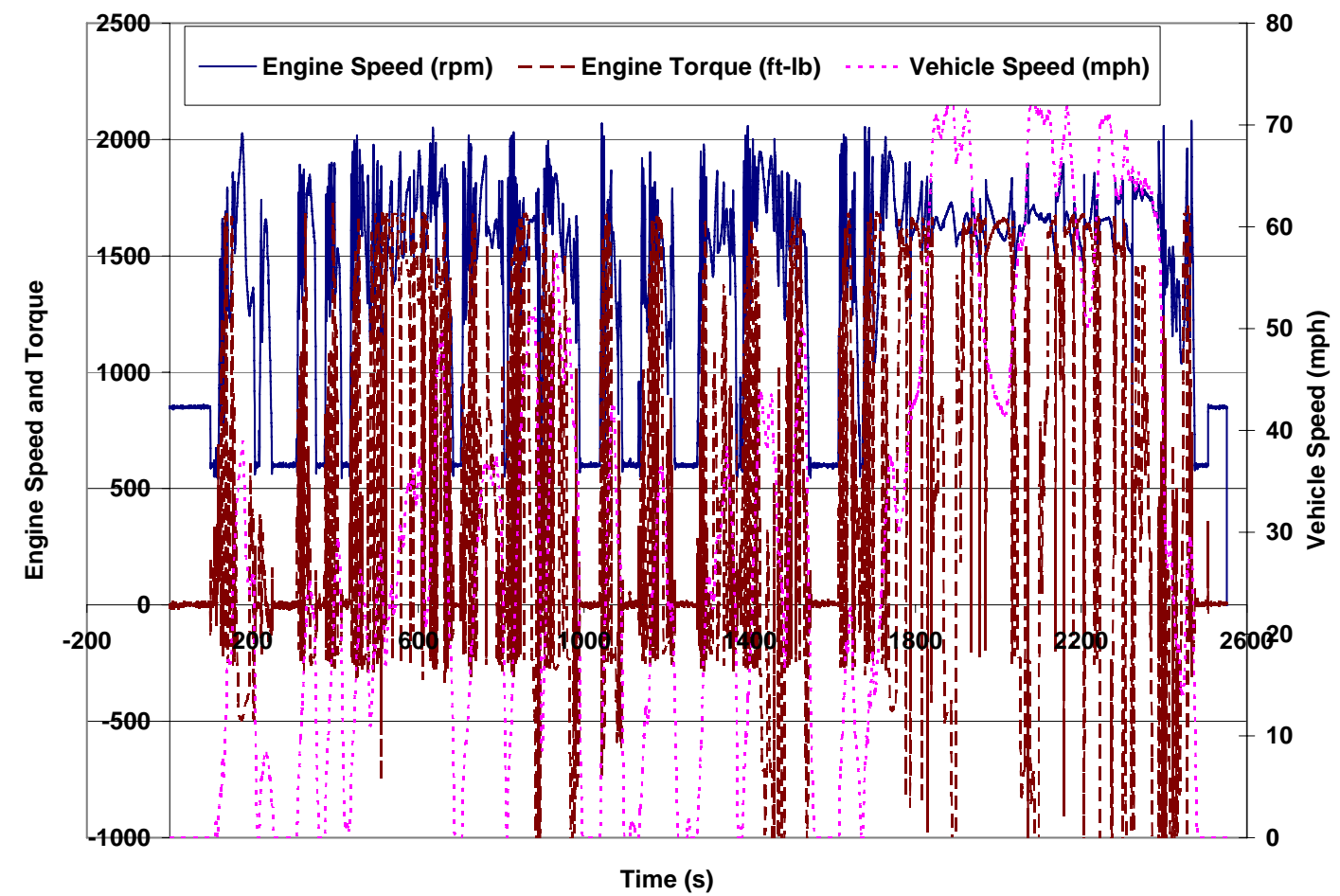

Figure 3-5 Representation of engine speed, engine torque, and vehicle speed during Mrgtwn test route

\subsubsection{Pittsburgh Test Route}

The Pittsburgh test route is comprised of four test runs: Sab2Wash, WashPA1, WashPA2, and WashPA3 or WashPA32Sab. The route begins and ends in the greater Morgantown, WV, area and continues in between through West Virginia and Pennsylvania. The total length of the Pittsburgh test route is 154.3 miles. The entire route is mapped in Figure 3-6. Each run is described in the following sections. 


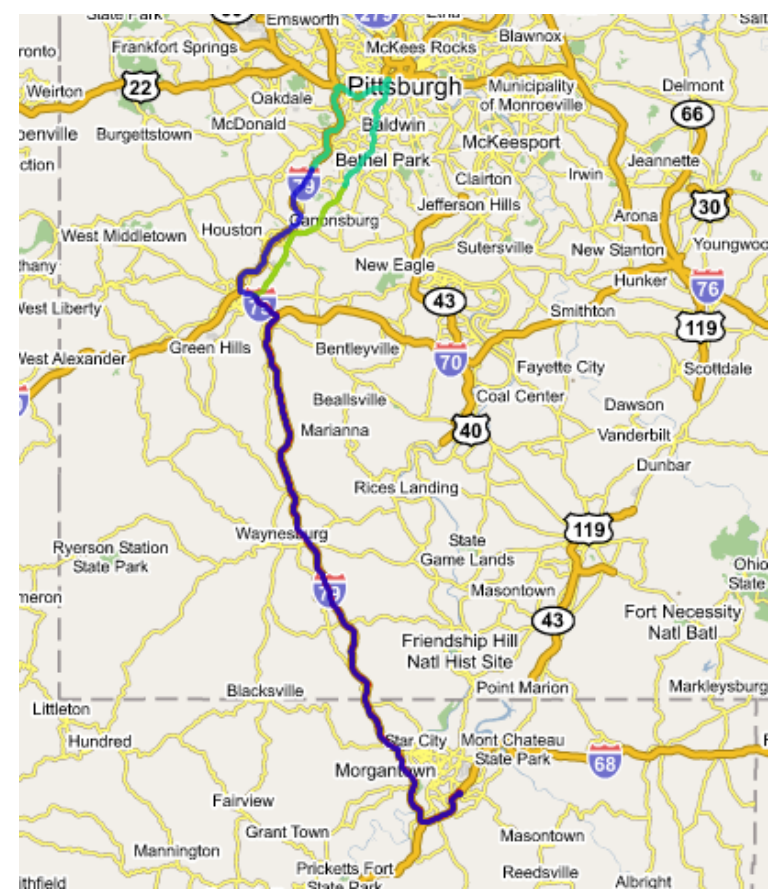

Figure 3-6 Pittsburgh Test Route

\subsubsection{Sab2Wash}

The Sabraton to Washington, PA, route (Sab2Wash), which consists of highway operation, begins at the interchange of Earl Core Road and I-68 in Morgantown, WV. It continues on I-68 West to I-79 North. The route continues on I-79 North into Pennsylvania, and ends alongside the exit ramp at Exit 19B on I-79 North in Washington, PA [Shown in Figure 3-7]. The total distance for this route is 52.7 miles. A plot representing typical engine speed, engine torque, and vehicle speed during the route is given in Figure 3-8. 


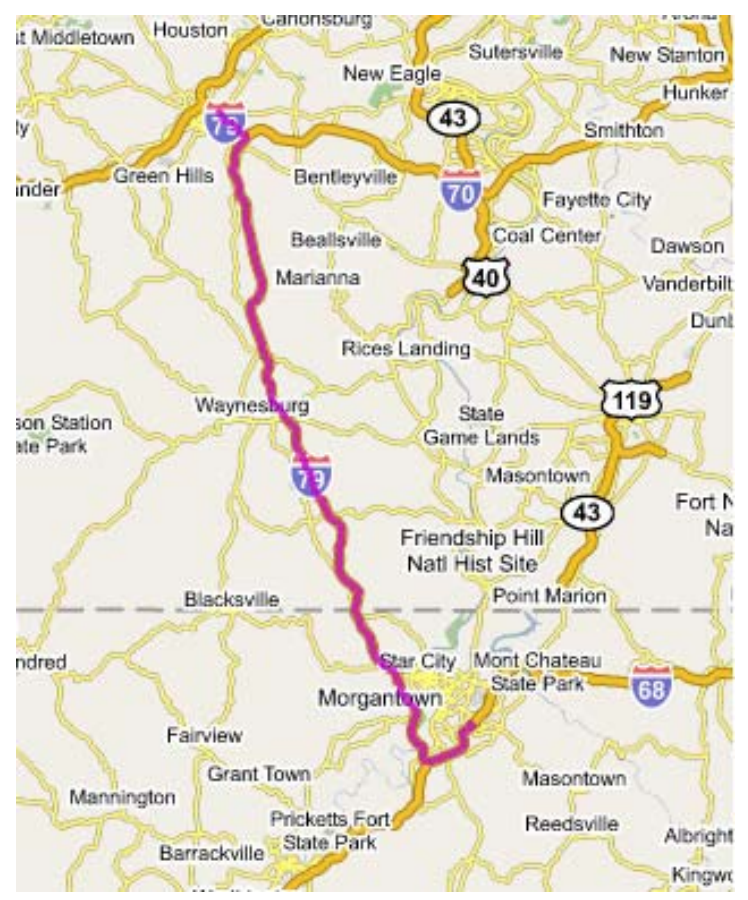

Figure 3-7 Sab2Wash test route

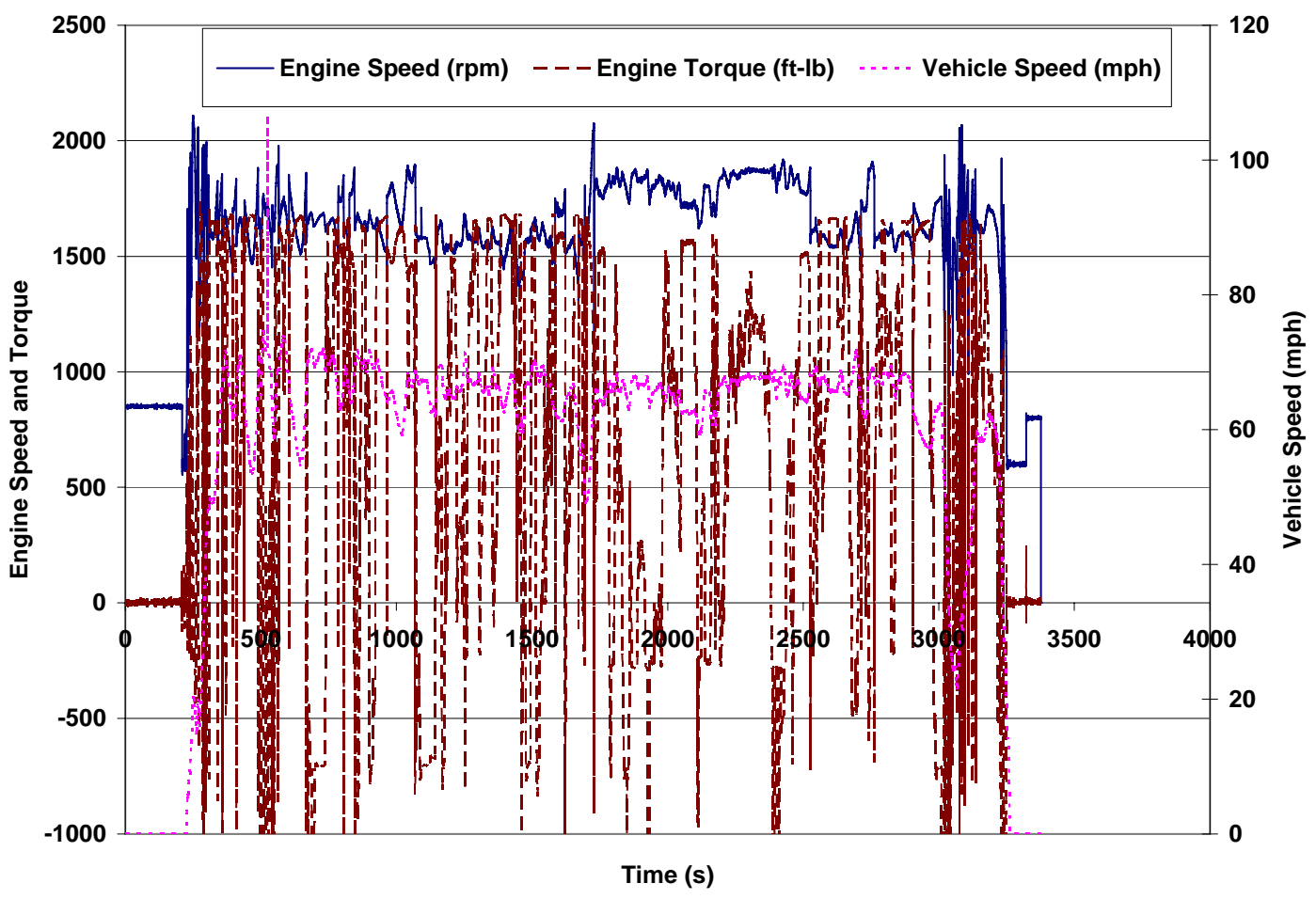

Figure 3-8 Representation of engine speed, engine torque, and vehicle speed during Sab2Wash test route 


\subsubsection{WashPA1}

The first Washington, PA, route (WashPA1) consists of urban traffic operation. The route begins at Exit 19B on I-79 North and continues north on Rt. 19. The route ends at a pullover on the side of Rt. 19 outside of Upper St. Clair, PA [Shown in Figure 3-9]. The total distance for this route is 12.1 miles. A plot representing typical engine speed, engine torque, and vehicle speed during the route is given in Figure 3-10.

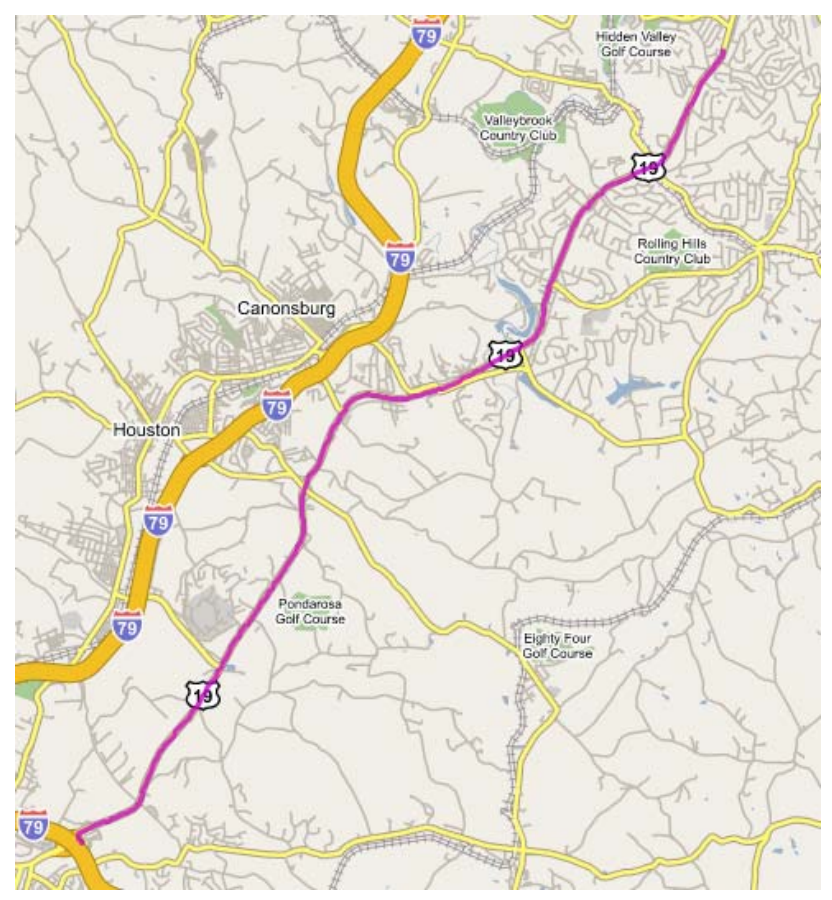

Figure 3-9 WashPA1 Test Route 


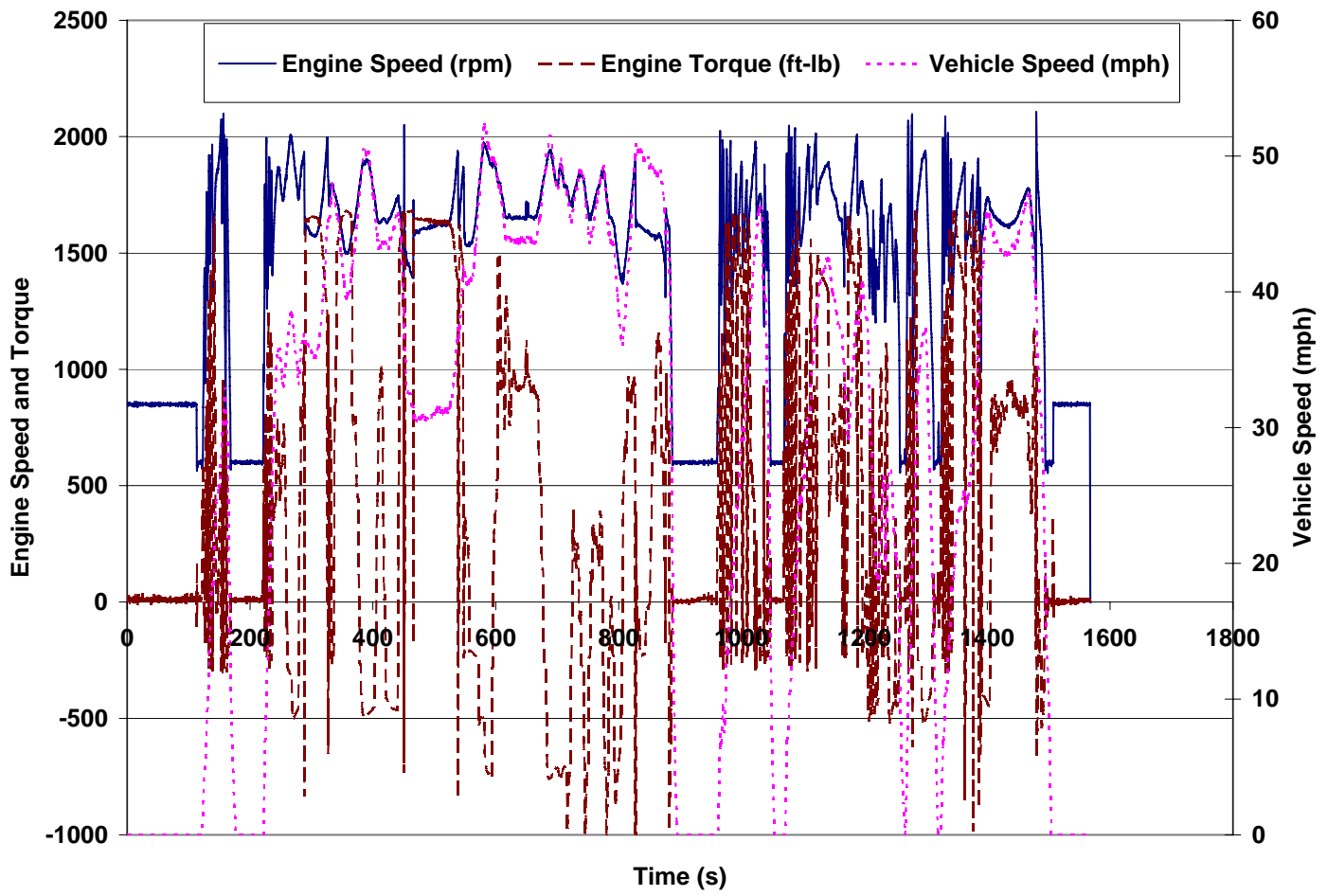

Figure 3-10 Representation of engine speed, engine torque, and vehicle speed during WashPA1 test route

\subsubsection{WashPA2}

The second Washington, PA, route (WashPA2) consists of both urban and highway travel. It begins at the pullover area outside of Upper St. Clair, PA, and follows Rt. 19 through Mt. Lebanon, PA, to I-279, just south of Pittsburgh. The route then follows I-279 South to I-79 South to the rest area at Bridgeville, PA, where the route ends. The total distance for this route is 23.1 miles. The WashPA2 route is mapped below in Figure 3-11. A plot representing typical engine speed, engine torque, and vehicle speed during the route is given in Figure 3-12. 


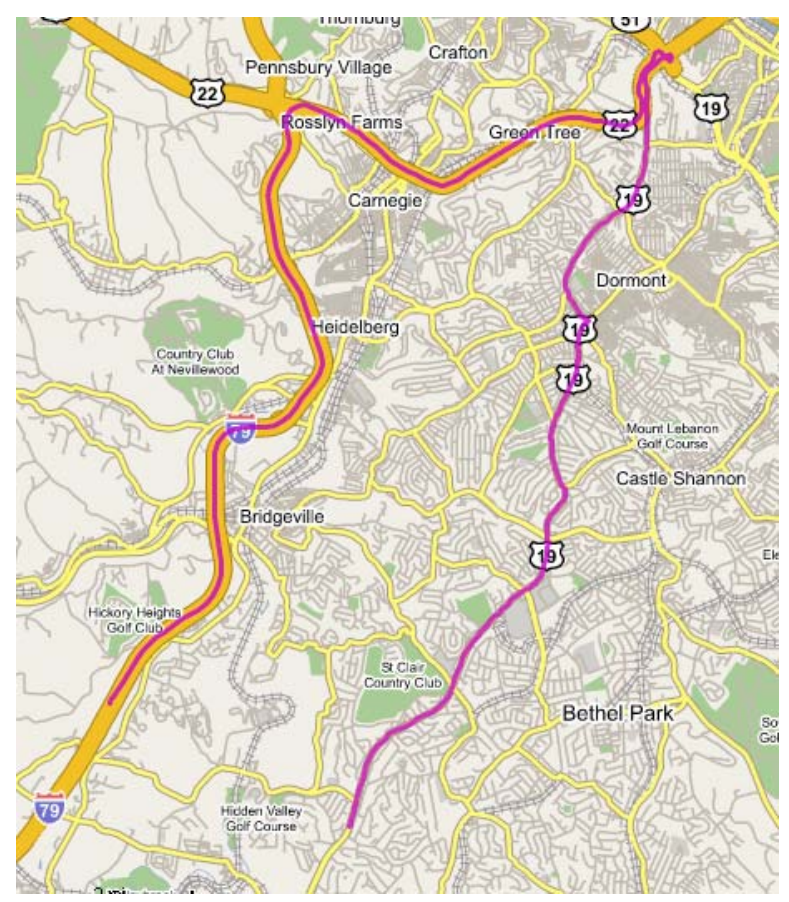

Figure 3-11 WashPA2 Test Route

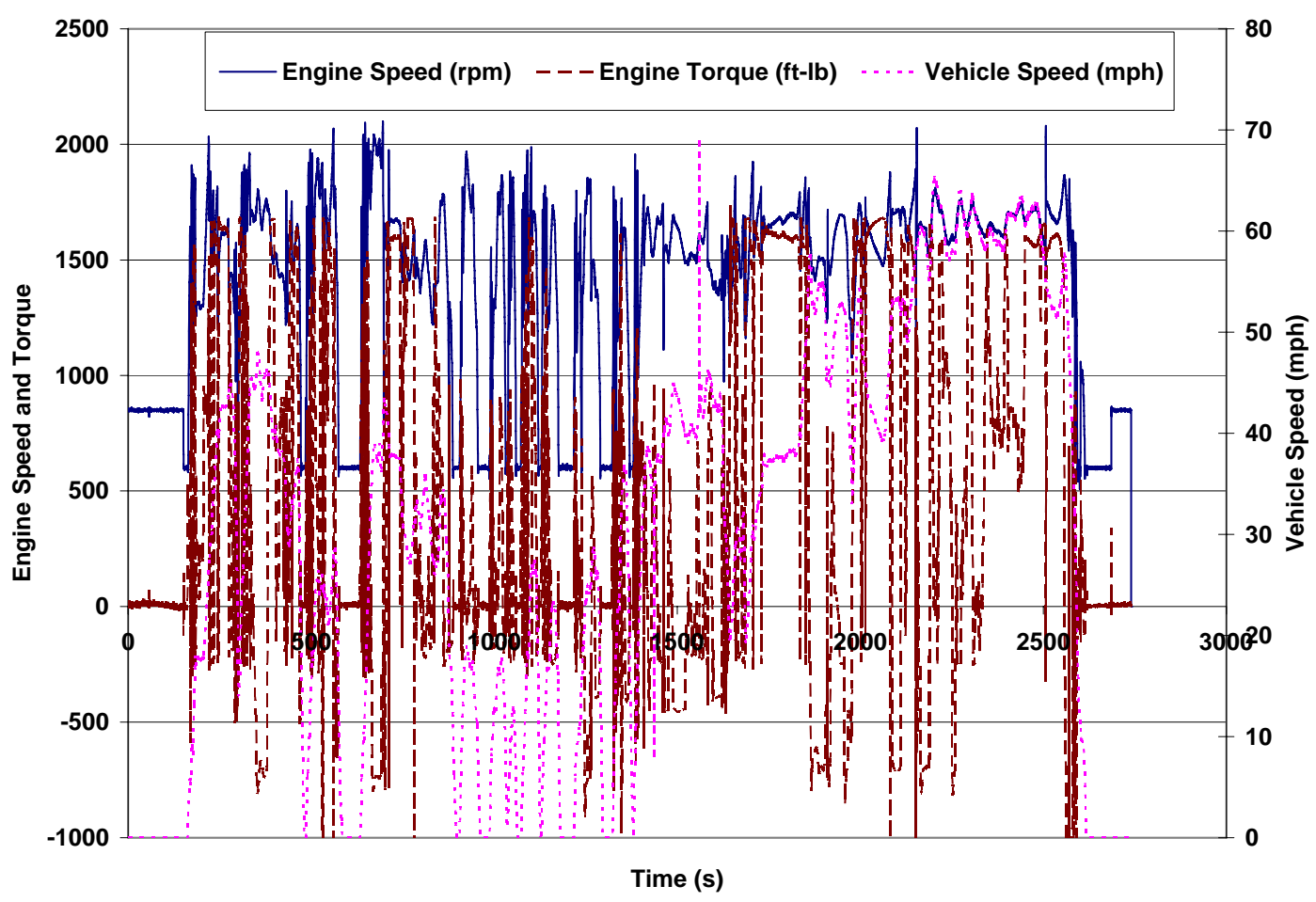

Figure 3-12 Representation of engine speed, engine torque, and vehicle speed during WashPA2 test route 


\subsubsection{WashPA3 / WashPA32sab}

The WashPA3 and WashPA32Sab routes begin at the southbound rest area on I-79 South at Bridgeville, PA. The routes continue on I-79 South into West Virginia. The WashPA3 route stops at the first rest area on I-79 South in West Virginia. The total distance for the WashPA3 route is 51.8 miles. The WashPA32Sab route stops at the end of the ramp at Exit 4 on I-68 East on Earl Core Rd. The total distance for this route is 66.4 miles. The WashPA32Sab route is mapped in Figure 3-13. A plot representing typical engine speed, engine torque, and vehicle speed during the route is given in Figure 3-14.

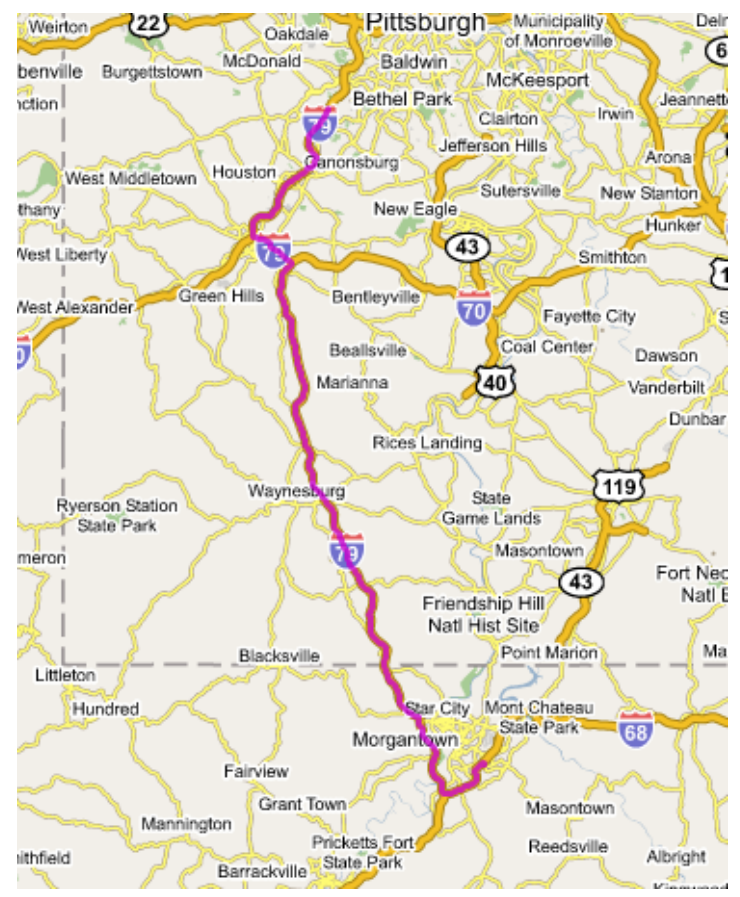

Figure 3-13 WashPA32Sab Test Route 


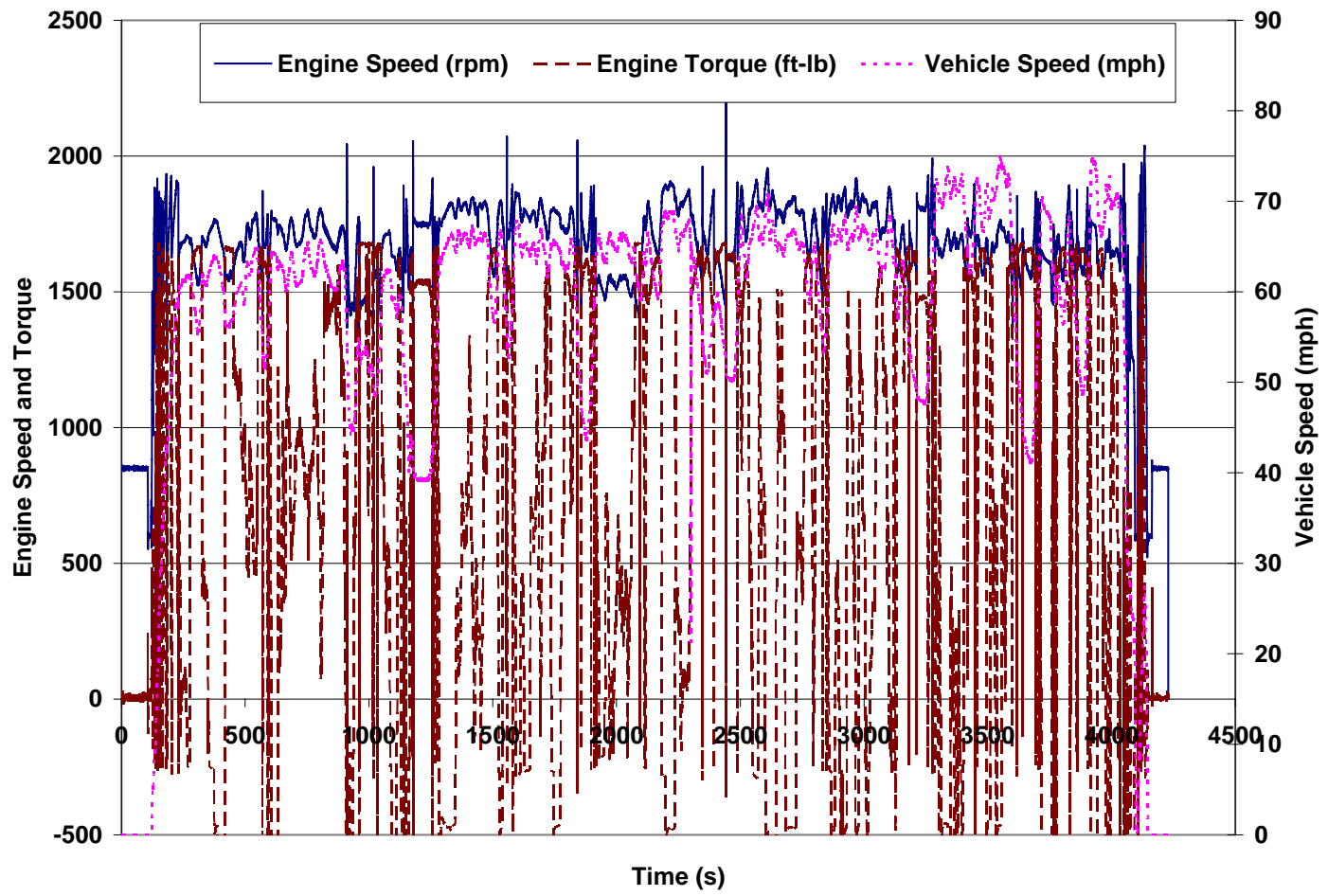

Figure 3-14 Representation of engine speed, engine torque, and vehicle speed during WashPA3 test route

The original Morgantown and Pittsburgh routes began and ended at 1462 Earl Core Rd in Morgantown, WV. However, due to construction, the start/stop point for the test routes was shifted 1.2 miles southeast to the interchange of Earl Core Rd. (Rt. 7) and I-68.

\subsection{In-use Testing}

The routes described above were used to generate the on-road vehicle emissions data for engines from each SHDDE, and they are summarized in [11-14]. Drivers drove the vehicles through the different test routes, while WVU engineers and technicians operated the emissions measurement systems.

\subsection{Quality Assurance of Exhaust Emissions Test Data}

The test data quality assurance procedure must be able to process the acquired test data, point to acquisition problems or experimental errors, accept or reject an experimental data acquisition file, and extract further information concerning the overall operation of the system. 
A preliminary quality assurance procedure [93] comprising of a number of simple steps is formulated in this study and is described in the following sections. These steps include a number of qualitative and quantitative processes.

The exhaust emissions test procedures and equipment usually encounters several types of errors and common problems in experimental results that can be summarized as follows:

- unphased data (different measurements, piping length, and response time of the analyzers, as well as delays in the measurement chain, affect the correct phasing of the emission concentrations);

- inconsistent measurement scales and response between analyzers (rapidly changing emission concentrations from high to low levels and vice versa, oscillations of analyzer measurements);

- condensation of gas phases in the measurement lines;

- reduction in efficiency of operation of heated elements (effect of temperature fluctuations);

- errors due to leakage in sampling lines;

- communication loss with ECU and other devices;

- missing data due to data transfer frequency of the data acquisition devices; and

- method of determination of a valid NTE event.

Exhaust emissions measurement involves a number of transient measurements. Therefore it is important that analyzers with good response times be used. Additionally, due to the multitude of measurement techniques employed in the recording of time series of exhaust gas species, mass flow rates, and temperatures, it becomes important to monitor the quality of the data acquisition. The following section presents a number of qualitative and quantitative measures for improving the data quality and accuracy. The techniques have been successful in exhaust emissions test data processing and reporting.

\subsubsection{Data Collection Stage}

There are a number of steps that can be taken during data collection to reduce experimental errors and improving the accuracy of the data. They are listed below:

\subsubsection{Setting Temperature of Heated Elements}

The heated elements of the MEMS sampling system include the heated line, the heated filter, and the heating element in the $\mathrm{NO}_{\mathrm{x}}$ converter. The heated line was maintained at $275^{\circ} \mathrm{F}$, 
the heated filter at $300^{\circ} \mathrm{F}$, and the converter at $375^{\circ} \mathrm{F}$. Earlier studies have shown that the converter efficiency is the highest when the temperature of the catalyst is maintained at about $375^{\circ} \mathrm{F}$ [9-12]. This additional NOx sensor housed in the exhaust sampling system is employed for quality assurance purposes.

\subsubsection{Calibration of MEXA $\mathrm{NO}_{x}$ and EC NO $\mathrm{N}_{x}$ Analyzer}

The analyzers were calibrated with a Horiba SGD-710C gas divider using gas bottles of known concentrations. The concentrations of gases used were dependent on the maximum concentration in the exhaust of the engine being tested to limit the uncertainty error from the analyzer. Also, the calibration gases used were $\pm 1 \%$ accurate. A three-way valve was placed at the entrance of the heated sample line, which allowed the calibration line to be connected to the analyzer without removing the heated line. The calibration procedure was performed before each test, which included a three-point calibration for the Horiba MEXA 120 and the electrochemical NO cell. Calibration curves for the two analyzers are given in Figure 3-15.

\subsubsection{Calibration of $\mathrm{CO}_{2}$ Analyzer}

The calibration procedure for the Horiba BE140 is performed in a similar manner as the $\mathrm{NO}_{\mathrm{x}}$ analyzer which includes a zero and a span of the concentration of the gas used.

\subsubsection{Calibration of Differential and Absolute Pressure Sensor}

Multi-point calibration curves were developed for the absolute and differential pressure transducers using a Heise ${ }^{\mathrm{TM}}$ PTE-1 pressure calibrator. Barometric pressure readings (taken prior to each test) were used to re-set the calibration curve intercepts of the absolute pressure in order to account for sensor drift. Similarly, pre-test calibration also included zeroing the differential pressure transducer.

\subsubsection{Calibration of Annubar T1 And T2 Sensor}

The different temperature sensors were calibrated using the Fluke temperature calibrator. The calibration curve for one of the temperature sensors is shown in Figure 3-15. The calibration curve for the temperature sensor is given in Figure 3-15.

After the calibration is performed for each analyzer and sensor, the R-Squared value of the curve fitted are checked with a predetermined pass/fail criteria which 0.9 . If the calibration curve does not meet the criteria then the calibration process is redone. 


\subsubsection{Data Acquisition, Synchronization, and Preprocessing Stage}

After the initial calibration of the different sensors and analyzers, the vehicle fitted with the MEMS unit is tested on-road over specific routes. The data from the sensors, analyzers, and ECU broadcast are collected using the DAQ system described earlier. The raw experimental data are time series of gas species concentrations, temperatures, differential and absolute pressures, vehicle speed, engine speed, engine load, and injection timing. Raw data acquired using the DAQ system is preprocessed where it is reduced using a WVU developed software. The following steps are taken to produce data that can be used for further analysis, which include checking for completeness and phasing of raw data.

\subsubsection{Parsing Bad Data}

There are numerous instances where the data generated during an on-road test may be incomplete, a few of which are listed below.

- The power supply could be interrupted with the generator turned off during the testing and no data would be collected.

- The cables from the various sensors could get disconnected during testing and no data would be logged.

- A traffic incident for instance an accident would require termination of the test and the data could be used for further analysis.

- The DAQ system could lose communication with the different analog devices.

\subsubsection{Phasing Of Raw Data}

Carbon dioxide and NOx emissions from internal combustion engines are affected primarily by engine power while also dependant on a number of other factors. According to the above reasoning, a valid time correlation of the signals of interest in the present methodology can be attained by means of the following major steps. The difference in the phased and unphased data series is shown Figure 3-16.

\subsubsection{Complementing Missing Data}

There are a few instances where the data collection frequency can be limited by the operating speed of the communication devices. Limited by this criteria, there would be some missing data for a short interval. If data is missing, interpolation is done for engine speed, torque, 
and timing. The interpolation is limited to only 5 seconds. If interpolation is need for more than 5 seconds, a flag is generated denoting a longer interval of missing data.

ECU vehicle speed broadcast might be lost for a few seconds or there might be a glitch in the value as shown in Figure 3-17. These values are smoothed and the data processing is done.

\subsubsection{Qualitative Observations}

In order to perform the qualitative observations on the operation of the engine over different routes, the results are compared with the respective figures existing in the database. Implications of the type of engine, its displacement, management system, and the exhaust treatment system installed are employed in the cross-checking of the data. For instance, flow from a 12.0 liter engine cannot be 100 liters and the bsNOx values for the engines should be within some reasonable value of the certified limits.

\subsubsection{Quantitative Calculations}

The quantitative observations are performed with the assistance of several calculations and graphs produced by the software. Such graphs include continuous emissions of exhaust gas species, as well as a number of cross-checking calculations.

\subsubsection{Comparison of Concentrations Of Mexa And EC NOx}

The concentration values of MEXA NOx and the EC NOx are compared. The plot showing the comparison of the shifted and humidity-corrected concentration values from both the analyzers are shown in Figure 3-18. It should be noted that the MEXA NOx measures the NOx values on a wet basis while the EC NOx placed downstream of the chiller measures on a dry basis. A humidity correction factor [13] is applied and both the measurements are reported on a wet basis and compared.

\subsubsection{Comparison of ECU Broadcast and GPS Vehicle Speed}

The GPS vehicle speed and ECU broadcast vehicle speed are compared. The plot demonstrating the comparison is shown in Figure 3-19. In order to calculate distance-specific emissions, the distance traveled during each route was calculated from either the ECU broadcast or GPS vehicle speed. As a default, the ECU broadcast vehicle speed is used for distancespecific emissions calculations. The total miles traveled during a test route were inferred from both the ECU broadcast and GPS vehicle speeds are compared. 


\subsubsection{Comparison of ECU Broadcast and Percent Load Inferred Torque}

The ECU's on the engines used in this study broadcast engine load both on a percent basis and total load basis. The manufacturer-supplied lugcurve is used to infer torque values from the broadcasted percent load values. This is explained in earlier sections. The value of engine torque calculated from the broadcast percent load is designated as inferred load in this study. The ECU broadcast torque and the inferred torque using the broadcast percent load and the lugcurve are compared. The comparison is shown in Figure 3-20.

\subsubsection{Comparison of ECU Broadcast and Emissions Derived Fueling Rate}

The instantaneous concentration values of $\mathrm{CO}_{2}$ measured during the test conducted can be used to calculate the mass of fuel consumed during the test. The calculations are done as mentioned in the CFR 40, Part 86. The total fuel consumed during the test can also be inferred from the ECU broadcast fueling rate. The comparison of instantaneous fuel rates is shown in Figure 3-21. This comparison could also suggest possible leaks in the exhaust system. Normally, a percent difference of $10 \%$ is used as an acceptable value.

\subsubsection{Checking Temperatures of Heated Elements}

As mentioned earlier, the temperature of the heated elements is critical in their operation. The sampling lines are heated to about $250^{\circ} \mathrm{F}$ so that the moisture in the exhaust does not condense. The NOx converter is maintained at $425^{\circ} \mathrm{F}$ for the catalyst to enable the conversion of $\mathrm{NO}_{2}$ to NO. Another important element in the sampling system is the chiller. The chiller based on Peltier cooling principle brings down the temperature of the exhaust sample below the dew point temperature and thereby removes the moisture in the sample. If the temperature of the cold side of the chiller is not below the dew point temperature, not all the moisture in the exhaust will be removed. The performance of the chiller is dependent on the ambient air temperature. One other problem could be that the chiller temperature drops below freezing, thereby clogging the chiller and restricting flow. Therefore, it becomes important to check the operating temperature of the chiller during the test run. The normal operating temperatures of the different elements of the exhaust sampling system is shown in Figure 3-22.

\subsubsection{Comparison of Exhaust Flow Rates}

The exhaust flow measurement system described in the earlier section is used to calculate the exhaust flow. The flow rate measured is used to calculate the mass basis of emissions. It is 
critical that the flow measurement values are accurate in order to produce accurate results. The exhaust flow rate calculated based on the engine configuration and the operating parameters the exhaust flow is calculated. This calculated value is compared with the measured value. If the percent difference is more than $5 \%$ between these two values, the test is voided. Possible causes for error would be leaks in the exhaust measurement system, and steps are taken to reduce this error.

\subsubsection{Determination of Valid NTE Event}

For this study, the brake-specific emissions in the NTE zone of operation is of interest. In this study, the leading average of the engine operating conditions that define the NTE zone is used to determine if the engine is operating in the NTE zone.
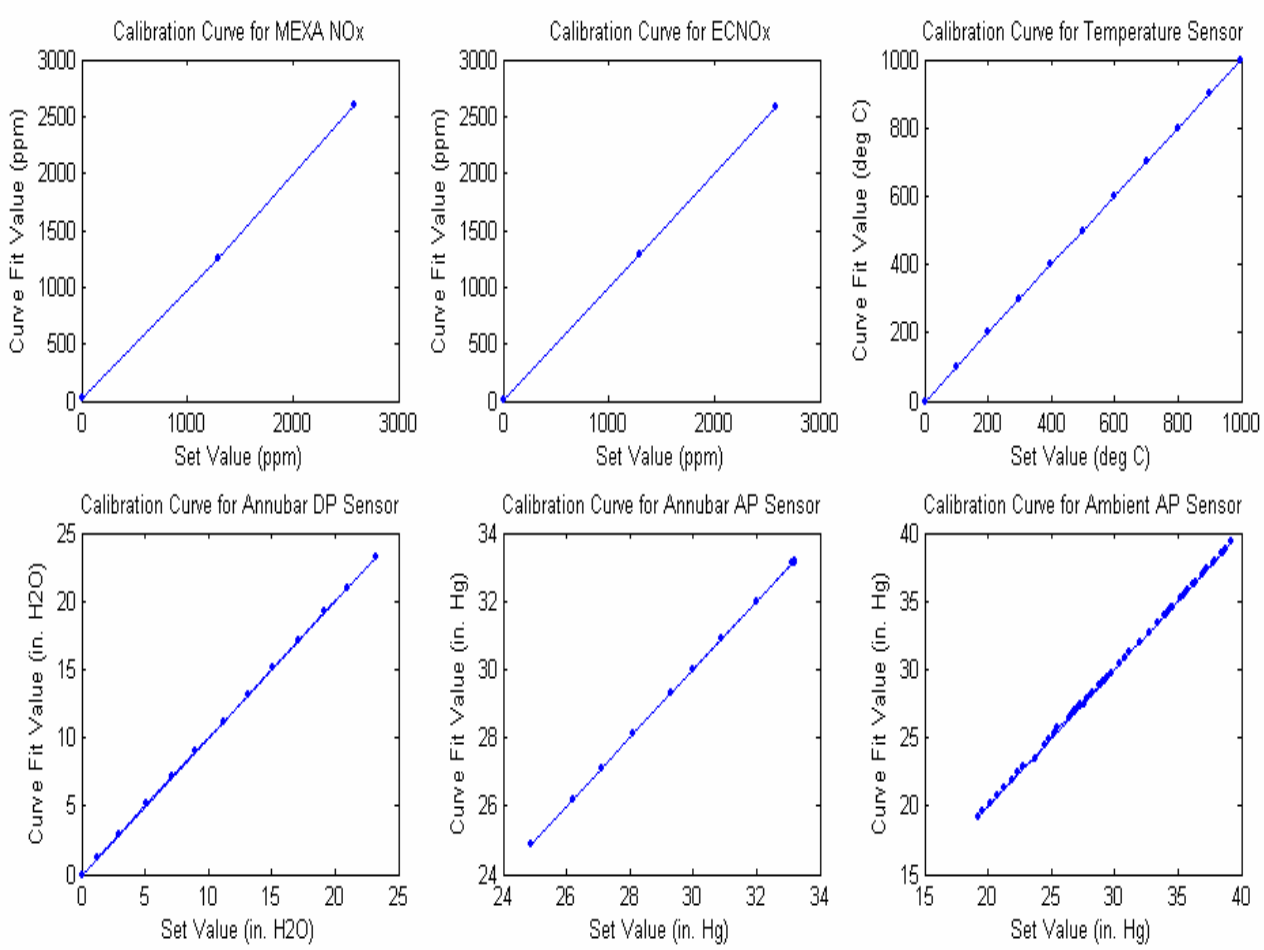

Figure 3-15 Calibration curves for the analyzers and sensors used in MEMS 


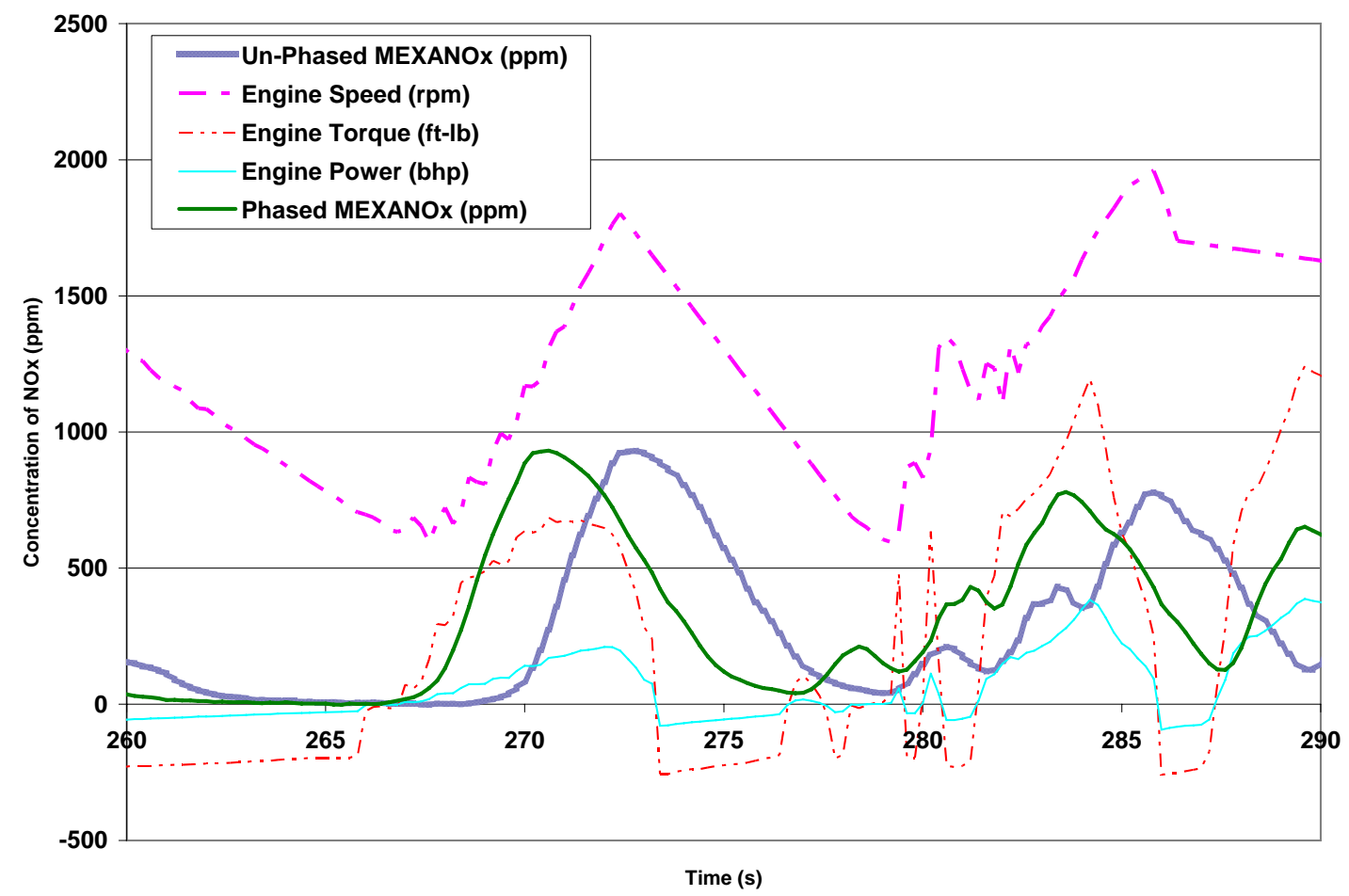

Figure 3-16 Plot showing the difference between un-phased and phased concentration of $\mathrm{NO}_{\mathrm{x}}$

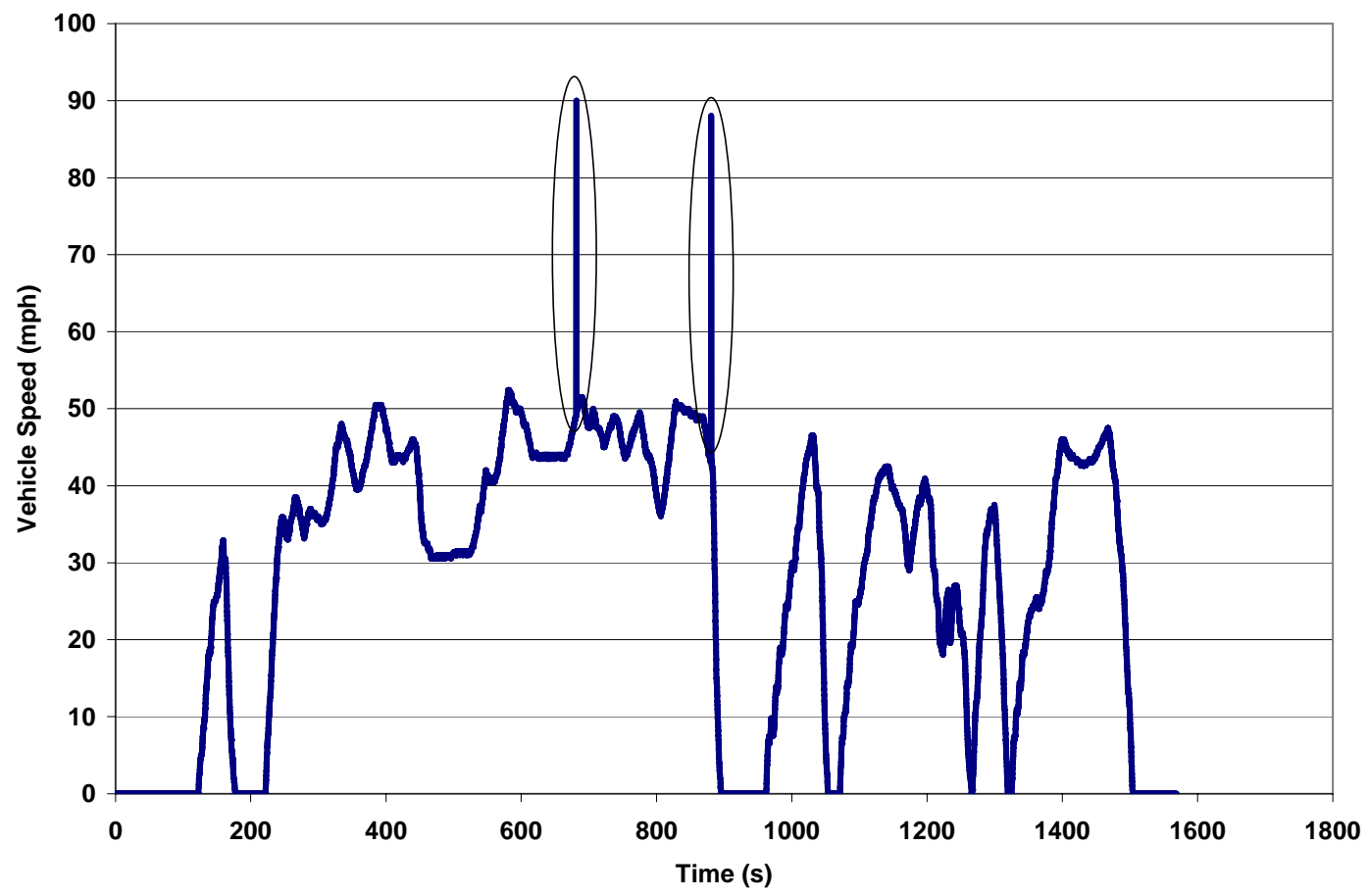

Figure 3-17 Time series of vehicle speed showing spikes at certain points 


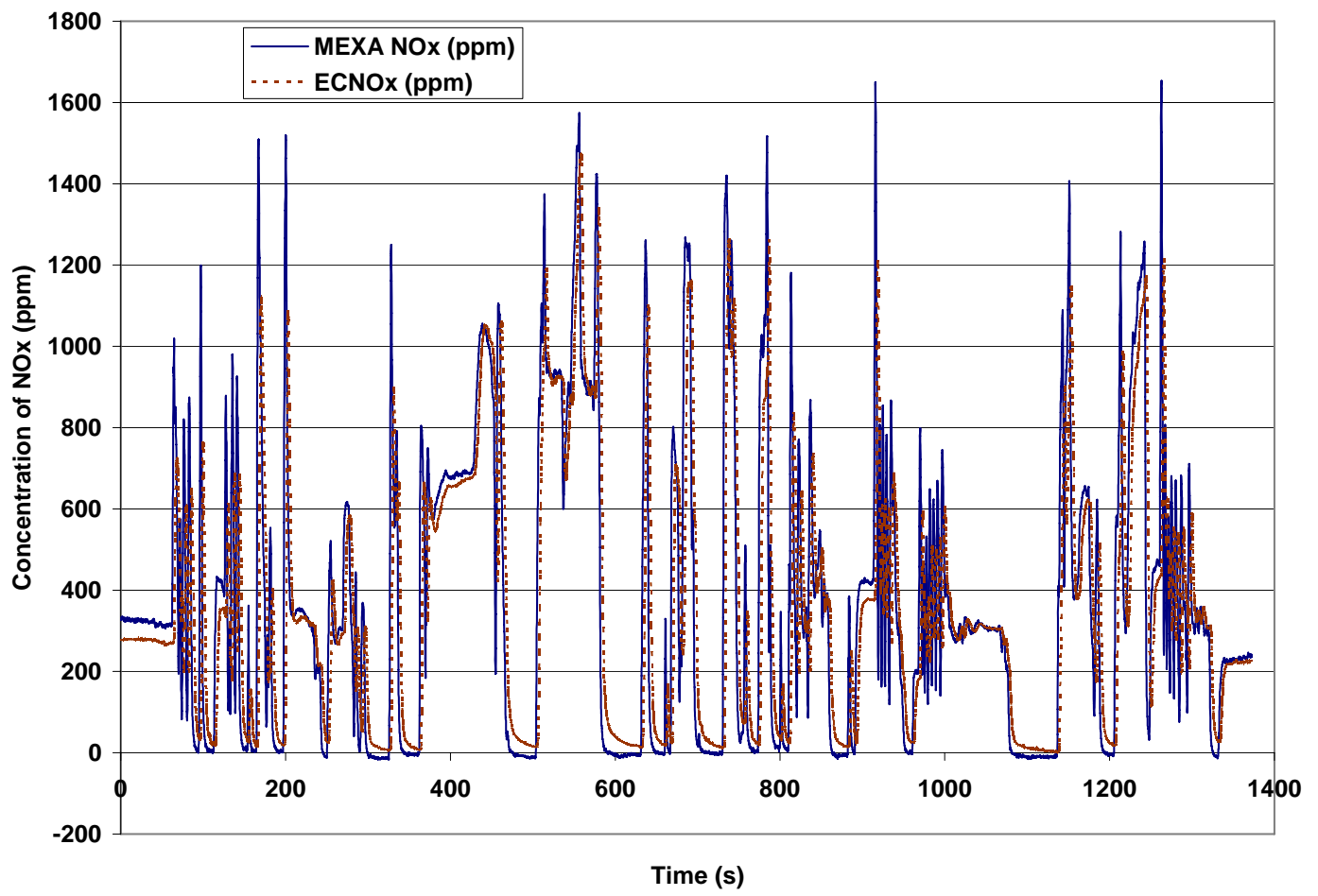

Figure 3-18 Comparison of concentration of $\mathrm{NO}_{\mathrm{x}}$ measured using the MEXA and EC analyzers

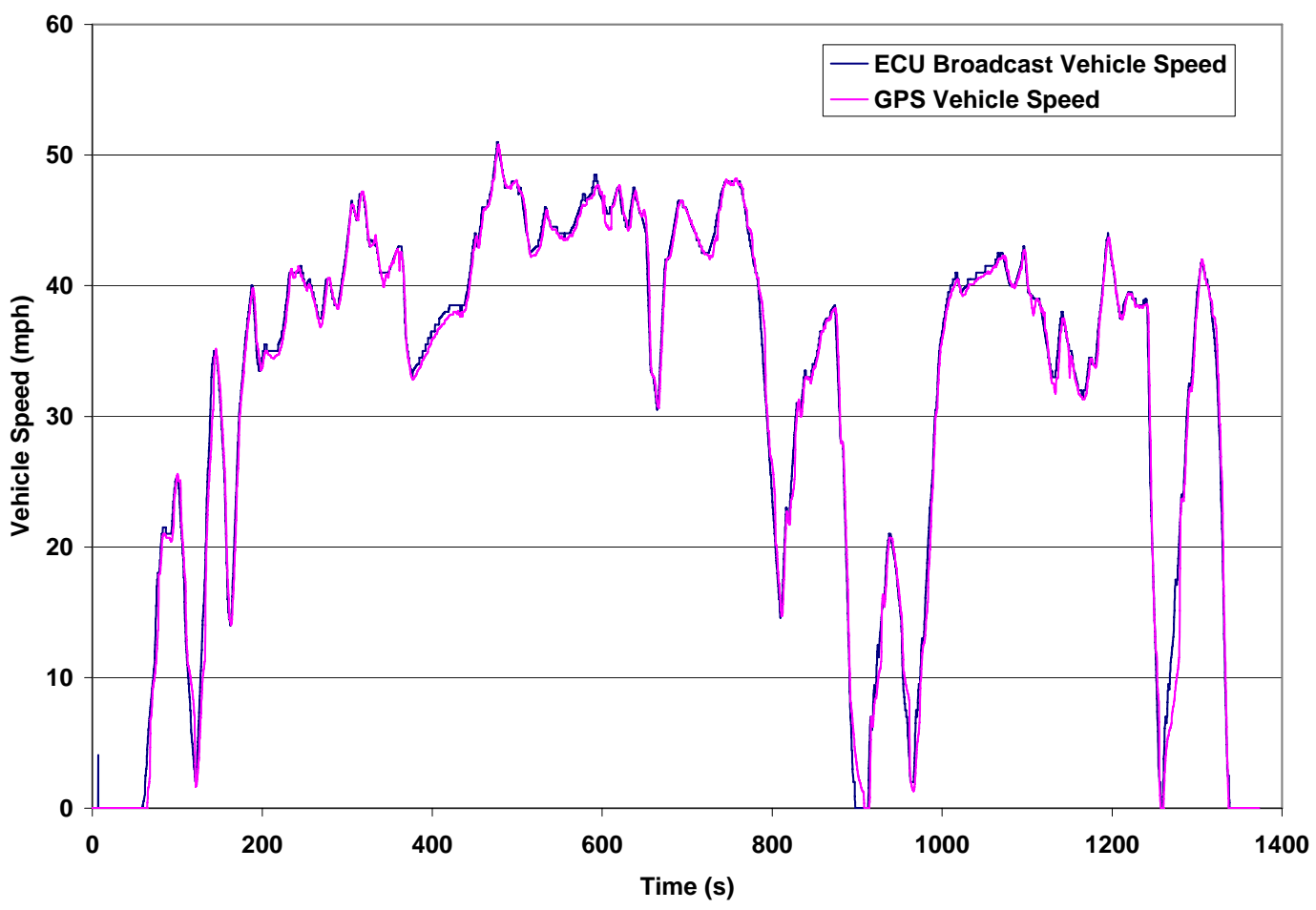

Figure 3-19 Comparison of ECU broadcast and GPS vehicle speed 


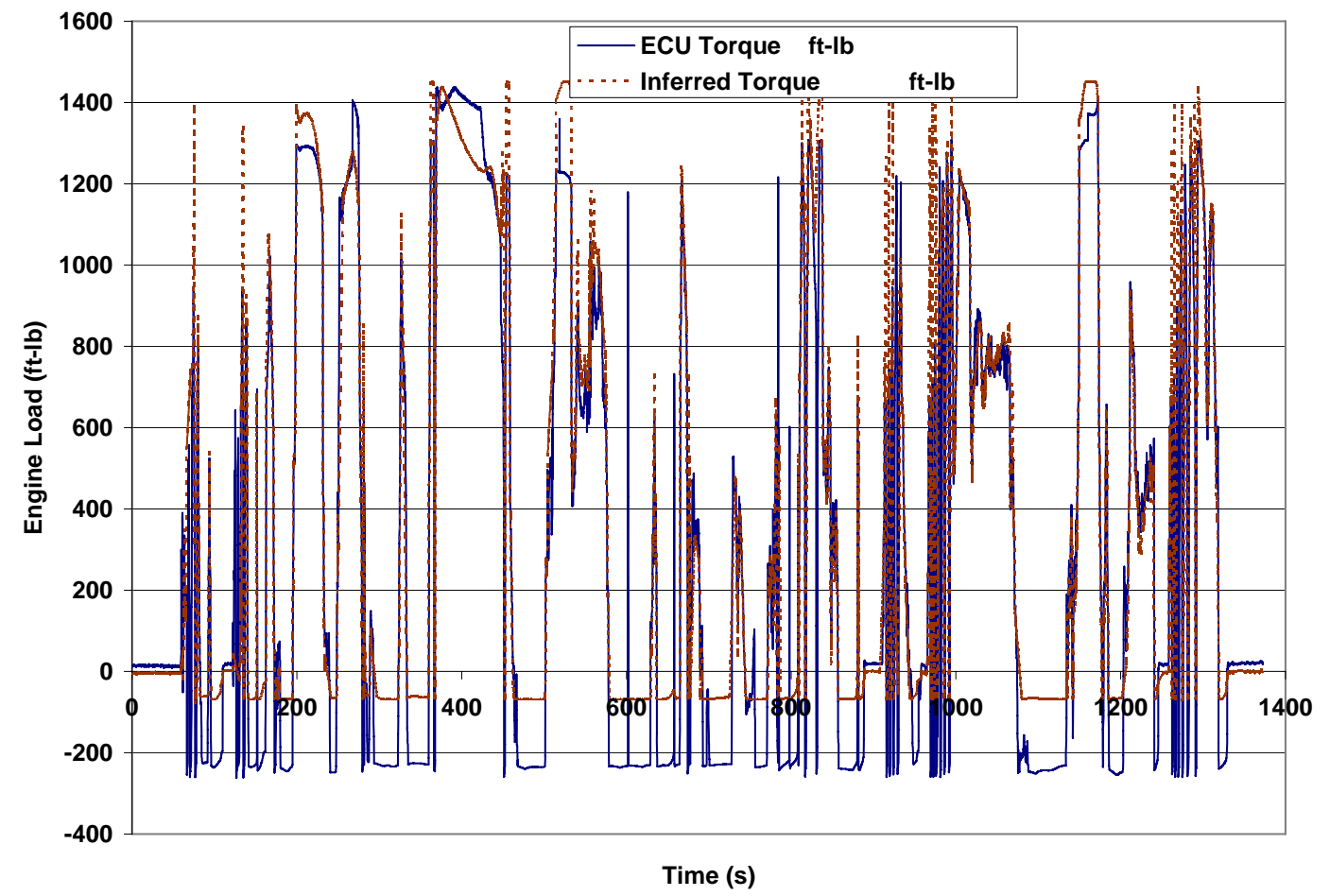

Figure 3-20 Comparison of ECU broadcast torque and inferred torque from percent load values

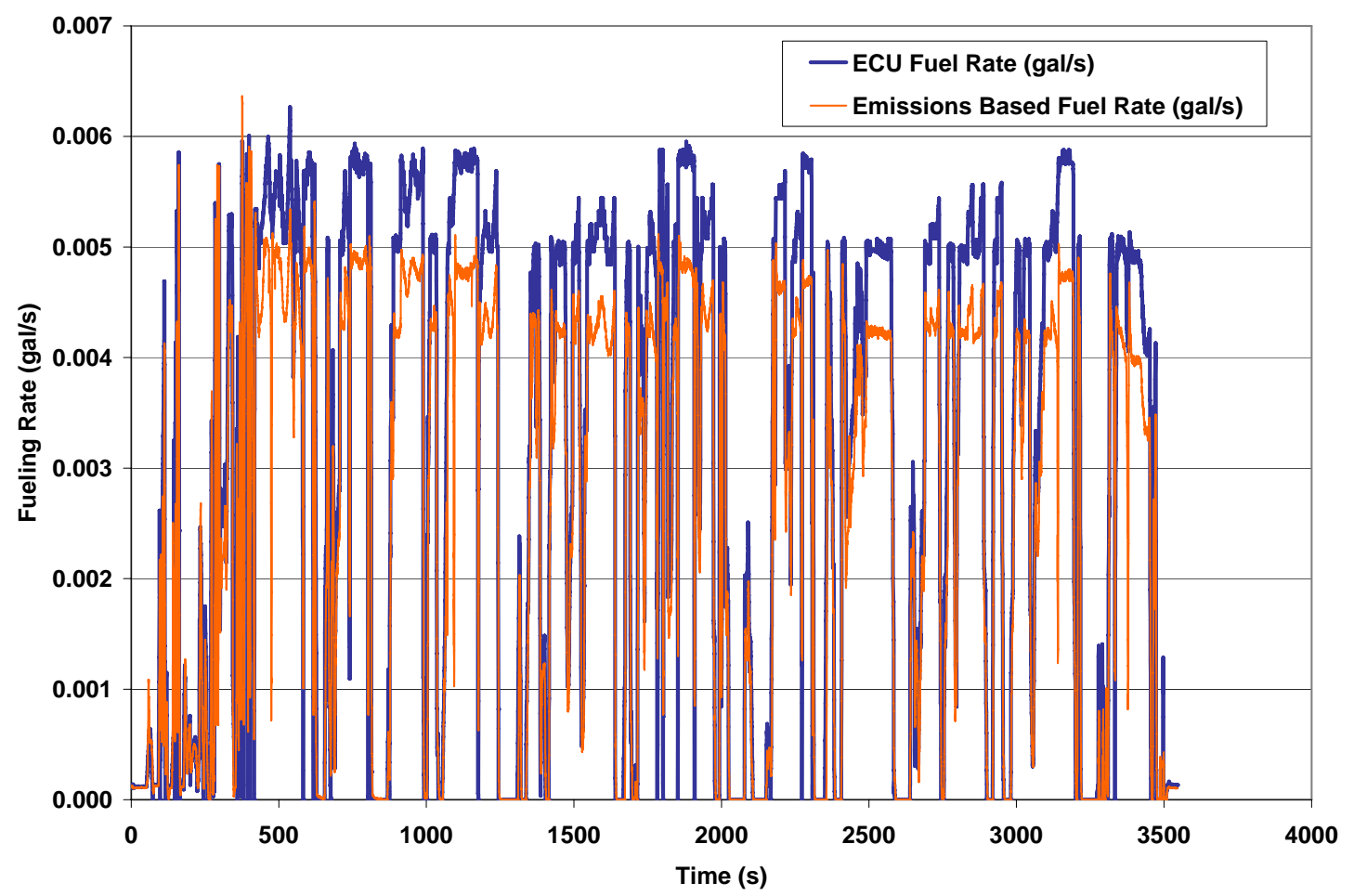

Figure 3-21 Comparison of fueling rate from ECU broadcast and calculated from emissions 


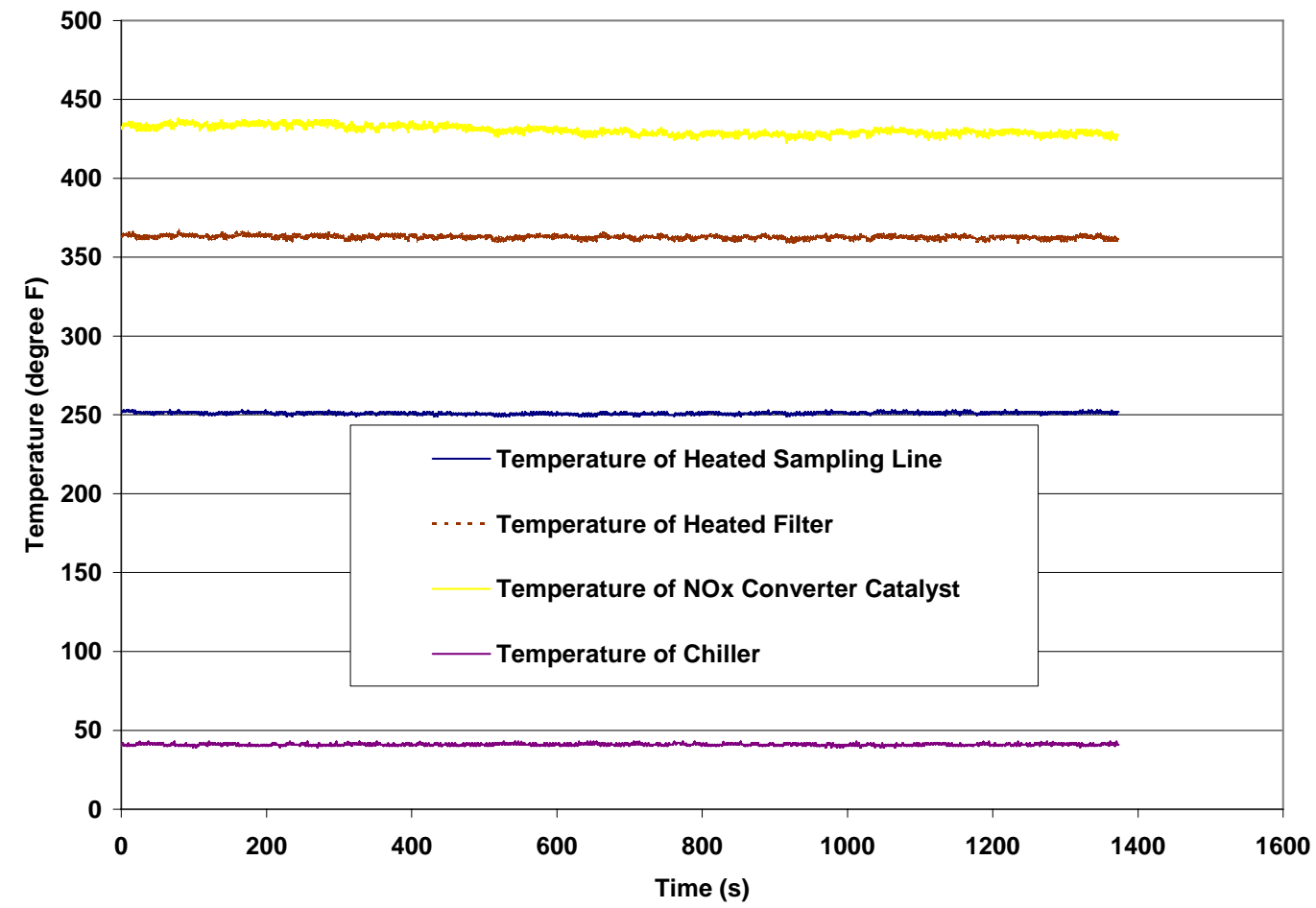

Figure 3-22 Plot of operating temperature of different elements of the exhaust sampling system

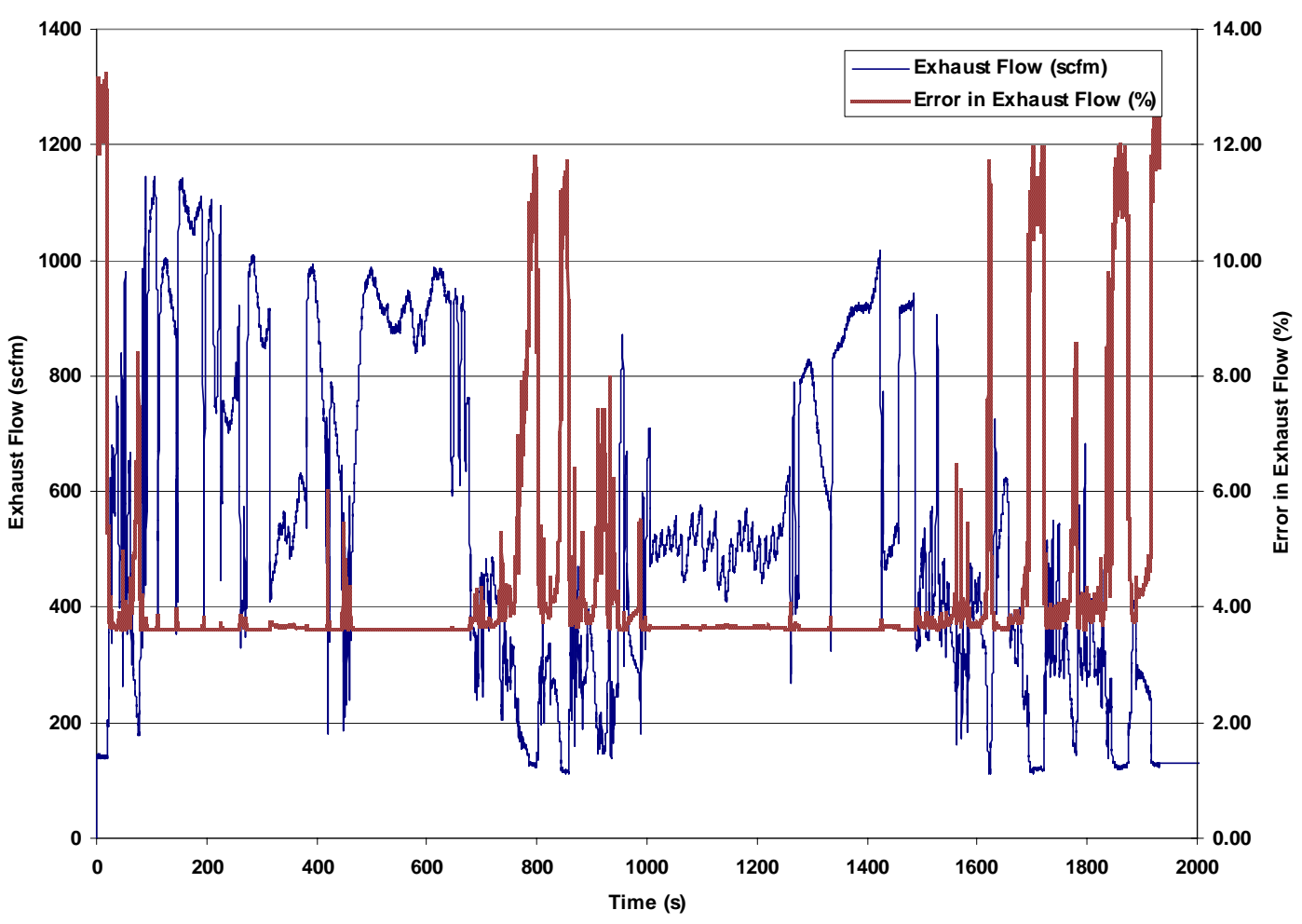

Figure 3-23 Representation of exhaust flow rate and the error in measurement of exhaust flow rate for an on-road test 


\section{HDD NO ${ }_{X}$ EMISSION MODEL DEVELOPMENT}

Many vehicle emission models, such as the speed dependent models which are used widely, are overly simple. Other models are sufficiently complicated as to require excessive inputs and calculations, which can slow down computational time. It has been widely recognized that models based on the average speed from fixed driving cycles, such as the US EPA's MOBILE 6, do not adequately capture the effects of driving and vehicle dynamics on emissions [25]. Therefore, their applicability is limited to the estimation and forecasting of large-scale emissions inventories.

Emission models can be classified into emission maps, statistical models, and load-based models. Although easy to generate and use, emission maps are not satisfactory because they can be highly sensitive to the driving cycle that was used to calibrate them. Purely statistical models typically consist of linear regressions that employ functions of instantaneous vehicle speed and acceleration as explanatory variables. These models can lack a clear physical interpretation and can also overfit the calibration data due to a large number of explanatory variables. Load-based models simulate, through a series of modules, the physical phenomena that generate emissions. However, these models are quite complex and, when applied to the entire flow of vehicles in a network over a period of time, the computational effort can be high.

Engine calibration processes during engine development employ modeling techniques, but these methods are detailed and require extensive laboratory and on-road testing during development. Also, due to the proprietary nature, there is a dearth of published literature on these models.

In the development of an emissions prediction model, it is important that physical insight play a role, and this approach was pursued in this effort. Also, it was critically important that there be a good empirical basis for the model. It was typically the case for many models that the model outputs are most critically sensitive to only a subset of all possible model inputs. Therefore, it was not necessary, useful, or practical to exhaustively include all possible inputs. Cullen and Frey [81-83, 94-96] and others discuss issues of model complexity, aggregation, and exclusion that are relevant here. A model should have a clear data quality objective and clear criteria regarding the desired domain of applicability. The domain over which the model was valid should ideally correspond to the domain for which model predictions are desired. In this effort, the domain is chosen to be the Not-to-Exceed region. 
The complexity of a model is characterized by the number of inputs, and by the function form of the equations. Complexity and size are two different issues, however. A model may be large but simple in that it may be composed of a large number of inputs but have a linear functional form. A model can be small and complex because it might be highly nonlinear with extensive interactions among the components. Complex systems are often hierarchies, which can be described in terms of the "span" of each level in the hierarchy and in terms of the number of levels. A simple model may have repetitive components at only one level. It is generally believed that simple models are more limited in their applicability than complex models. For example, if a simple model is a local linearized version of a more complex model, then the simple model will provide accurate predictions close to some specific point but the accuracy of the predictions will degrade as the model is extrapolated farther away from the calibration point.

For policy purposes, models should be made "as simple as possible, but no simpler" [9799]. This means that models should not contain any extraneous features that have no real bearing on the policy applications of the model. Thus, if a model is to be used for development of modal or macroscale emission inventories involving averages over a fleet of vehicles, for example, then it may be extraneous to include excessive design details regarding individual vehicle make and model among the inputs to the model. However, this does not mean that such considerations should not enter into the process of developing the model. It only means that the final model should be of an appropriate level of complexity consistent with its intended use. For example, a complex, detailed, physical-based model could be developed initially to obtain fundamental insights regarding key relationships that should be preserved in the final model, perhaps using surrogate variables that are more readily measurable. Various methods, such as response surface techniques or other sensitivity analysis methods [81-83, 93, 94] can be used to identify key relationships in the complex model that should be preserved in a more simplified model intended for wider use.

It is valuable to design a model that simultaneously obtains realistic results, is fast to run, and is easy to calibrate in different situations. This chapter provides a general description of the developed HDD truck emissions model, a simple statistical model for instantaneous $\mathrm{NO}_{\mathrm{x}}$ emissions. In order to realistically capture the emissions behavior, the explanatory variables have been obtained from the ECM broadcast which was captured by the on-board measurement system. The model, due to its simple structure, is relatively easy to calibrate and requires less computational time. The in-field data collected will be analyzed to establish the proposed 
objectives. Specifically, the analysis and modeling will focus on effects of parameters, such as engine speed, engine load, injection timing, fueling rate, oil temperature, oil pressure, manifold air temperature, manifold air pressure, and ambient conditions on exhaust emissions from the test vehicles. Heavy-duty diesel vehicles have a variety of vehicle/technology categories, each having different emissions and fuel consumption characteristics representative of the vehicle/technology sub-model. The model developed would be specific to an engine family and model year.

The chapter is organized as follows; Section 4.1 presents the modeling technique employed; Section 4.2 presents the structure of the model; Section 4.3 describes the data used to calibrate the model.

\subsection{Overview of General Technical and Modeling Approach}

The general modeling approach employed in this dissertation involves key considerations which include performing an iterative approach to model development. The model development also considers the empirical relationships observed in actual data. Quantification of variability and uncertainty in model predictions is also performed. It should be noted that the model predictions cannot be more accurate than the measurement accuracy.

When evaluating a data set and developing a model from the data set, it is important to begin with hypotheses regarding relationships based upon physical insights. Such insights might be obtained based upon previous work. For example, parametric experiments in laboratory settings provide some indication of what are the key sensitivities of emissions to various factors, such as engine load, engine speed, injection timing, and so on. Knowledge of these factors is important in identifying "independent" or input variables to use in initial model development.

The emission modeling is developing relationships between emissions and explanatory variables. It should be realized that the development of the functional form of a model should be informed not only by a priori assumptions based upon theoretical expectations, but also upon relationships that are inferred from the data. In this section, a mapping function is estimated that relates input data, a set of parameters that affect the emissions, and output data, $\mathrm{NO}_{\mathrm{x}}$. Since the input data are multidimensional, while the output data reside on a non-negative portion of the real line, a multidimensional regression analysis has to be involved [15]. Evaluation of a multidimensional function using an input-output relationship is a complex problem. To reduce its complexity, a two-step approach is proposed. During the first step, the dimensionality of input 
data is reduced. This is achieved by analysis of the physical relationships among parameters. During the second step, the mapping function relating input and output data is estimated. This process is called the calibration process. The estimated function is further tested using verification data. Note that calibration and verification data do not overlap. The modeling technique employed in this dissertation is the Multivariate Adaptive Regression Splines (MARS) which is described in detail in Section 4.2.

Regression problems are used to determine the relationship between a set of dependent variables (also called output, outcome, or response variables) and one or more independent variables (also known as input, explanatory, or predictor variables). The dependent variable is the one whose values you want to predict based on the values of the independent (predictor) variables. Regression allows the researcher to ask (and hopefully answer) the general question "what is the best predictor of." A simple case of regression is the linear regressions where the response variable is hypothesized to depend linearly on the explanatory variables. Linear regression also falls into the category of so-called parametric regression, which assumes that the nature of the relationships (but not the specific parameters) between the dependent and independent variables is known a priori (e.g., is linear). By contrast, nonparametric regression does not make any such assumption as to how the dependent variables are related to the predictors. Instead it allows the regression function to be "driven" directly from data.

MARS is an implementation of techniques for solving regression-type problems, with the main goal to predict the values of a continuous output variable from a set of independent or predictor variables. MARS is a nonparametric regression procedure which does not assume any underlying functional relationship between the dependent and independent variables. The method is based on the "divide and conquer" strategy, which partitions the input space into regions, each with its own regression equation. This techniques makes MARS becomes suitable for problems with higher input dimensions.

\subsection{Problem Statement and Proposed Solution}

The major objective of this study is to determine the relationship between the emissions NOx and the following set of input parameters: engine speed, load, air-fuel ratio, injection timing, manifold air temperature, manifold air pressure, coolant temperature, and oil temperature. This problem can be stated as a multivariate regression problem. Suppose that $N$ pairs of input-output parameters are available: $\left\{y_{i}, x_{1 i}, \cdots x_{m i}\right\}_{1}^{N}$, where the dependent 
variable $y_{i}, i=1,2 \ldots, N$, is the $i$ th measure of $\mathrm{NOx}$ and the predictor $x_{l i}, i=1,2 \ldots, N$, $l=1,2 \ldots, m$, is the $i$ th measure of the $l$ th parameter. It was assumes that the data $\left\{y_{i}, x_{1 i}, \cdots x_{m i}\right\}_{1}^{N}$ are related through the following equation

$$
y=f\left(x_{1}, \cdots, x_{m}\right), \quad\left(x_{1}, \cdots, x_{m}\right) \in D \subset R^{m}
$$

Equation 4-1

where $f(\cdot)$ is an unknown multivariate deterministic function and $D$ is the domain of inputs. Since the true mapping function in Equation 4-1 is not known, it is desired to have a function $\hat{f}\left(x_{1}, \cdots, x_{m}\right)$ that provides a "good" approximation of the output data, assuming that this will also result in a good approximation of the unknown function $f(\cdot)$. The goodness of fit between $\hat{f}\left(x_{1}, \cdots, x_{m}\right)$ and the output data is measured using the integrated mean square error (MSE)

$$
M S E=\frac{1}{N} \sum_{i=1}^{N}\left[y_{i}-\hat{f}\left(x_{1 i}, \cdots x_{m i}\right)\right]^{2}
$$

Equation 4-2

Approximation of a continuous function using a finite amount of data is an ill-posed problem [17-23], since an infinite number of continuous functions can pass through specified data points. To regularize the problem, that is, make it well-posed, a restriction is imposed for the solution $\hat{f}\left(x_{1}, \cdots, x_{m}\right)$ to functions residing in the linear space.

$$
\mathcal{F}=\left\{f: f(\cdot)=\beta_{0}+\sum_{m \in \mathcal{M}} \beta_{m} h_{m}(\cdot)\right\}
$$

where $\left\{h_{m}(\cdot)\right\}_{m=1}^{\infty}$ is a set of known basis functions and $\left\{\beta_{m}\right\}_{m=0}^{\infty}$ are coefficients of representation. In this work, $h_{m}(\cdot)$ is the spline basis function developed as:

$$
h_{m}(\cdot)=\prod_{k=1}^{K_{m}}\left[s_{k, m} \cdot\left(x_{v(k, m)}-t_{k, m}\right)\right]_{+},
$$

Equation 4-4

where $s_{k m}$ are variables that take values $\pm 1, v(k, m)$ labels the predictor variables and the $t_{k, m}$ represents values on the corresponding variables. The quantity $K_{m}$ is the number of "splits" that gives rise to each basis function $\beta_{m}$. Here the subscript "+" indicates a value of zero for negative values of the argument. The basis functions involved in (Equation 4-1) are known as "hockey stick" basis function. 
Then the problem of a continuous function estimation is reduced to finding a finite set of parameters including the coefficients $\left\{\beta_{m}\right\}_{m=0}^{M}$, predictor variables $x_{v(k, m)}$ and "split point" $t_{k, m}$, that is,

$\beta_{m}^{*}, x_{v^{*}(k, m)}, t_{k, m}^{*}=\underset{\beta_{m}, x_{v(k, m)}, t_{k, m}}{\arg \min } \frac{1}{N} \sum_{i=1}^{N}\left[y_{i}-\beta_{0}-\sum_{m=1}^{M} \beta_{m} \prod_{k=1}^{K_{m}}\left[s_{k, m} \cdot\left(x_{v(k, m)}-t_{k, m}\right)\right]_{+}\right] \quad$ Equation 4-5

To efficiently solve Equation 4-5, MARS approach is invoked. MARS searches over the space of all inputs and predictor values (knots) as well as interactions between variables. During this search, an increasingly larger number of basis functions are added to the model to minimize a lack-of-fit criterion. As a result of these operations, MARS automatically determines the most important independent variables as well as the most significant interactions among them [15].

\subsubsection{Function Estimation}

Now, given the estimated coefficients $\left\{\beta_{m}^{*}\right\}_{0}^{M}$, basis functions $\left\{h_{m}^{*}(\cdot)\right\}_{0}^{M}$ and operation parameters describing a new measurement, the emission of the new measurement can be predicted by taking the following steps:

1. Segregate operation parameters including engine speed, load, air-fuel ratio, injection timing, manifold air temperature, manifold air pressure, coolant temperature, and oil temperature from the raw data.

2. Predict the emission NOx by using the approximate function $\hat{f}(\cdot)$ with $\left\{\beta_{m}^{*}\right\}_{0}^{M}$ and $\left\{h_{m}^{*}(\cdot)\right\}_{0}^{M}$, that is

$$
\hat{f}\left(x_{1 i} \cdots x_{m i}\right)=\beta_{0}^{*}+\sum_{m=1}^{M} \beta_{m}^{*} h_{m}^{*}\left(x_{1 i} \cdots x_{m i}\right), i=1 \cdots N
$$

where $\left\{x_{1 i} \cdots x_{m i}\right\}_{1}^{N}$ are from the new measurements.

\subsection{Multivariate Adaptive Regression Splines}

There are a large number of methods available for this problem, such as linear regression, nonparametric regression, neural network, etc. A simple case of regression is linear regression where the response variable is hypothesized to depend linearly on the predictor variables. Linear regression also falls into the category of so-called parametric regression, which assumes that the 
nature of the relationships (but not the specific parameters) between the dependent and independent variables is known a priori (e.g., is linear). While parametric regression methods are relatively easy to develop, they have a limited flexibility and work well only when the true underlying relationship is close to the pre-determined function in the model.

Neural networks are also powerful tools to deal with data approximation or even model multi-input multi-output systems. A significant disadvantage of neural network is that they are a "black box." The functions fit by neural network are difficult for people to understand.

MARS is a technique for solving non-linear regression-type problems. It makes no assumption about the underlying function relationship between the dependent and predictor variables. Instead, MARS constructs this relation from a set of coefficients and basis functions that are entirely "driven" from the regression data. In addition, the approximate function can be used to understand and explain the model. MARS is based on the "divide and conquer" strategy, which partitions the input space into regions, each described by its own regression equation. This technique makes MARS suitable for problems with higher input dimensions, where the curse of dimensionality would likely create problems for other techniques [16].

\subsubsection{Basis Functions}

The core to build the MARS model is the "hockey stick" basis function. This two-sided truncated functions shown in Fig. 8 map variable $X$ to new variable $X^{*}$ by (Equation 4-6) (solid line) or by (Equation 4-7) (dashed line):

$$
\begin{aligned}
& X^{*}=(X-t)_{+}=\left\{\begin{array}{cc}
X-t & X \geq t \\
0 & X<t
\end{array}\right. \\
& X^{*}=(t-X)_{+}=\left\{\begin{array}{cc}
t-X & X \leq t \\
0 & X>t
\end{array}\right.
\end{aligned}
$$

where $t$ is the knot of the basis function. 


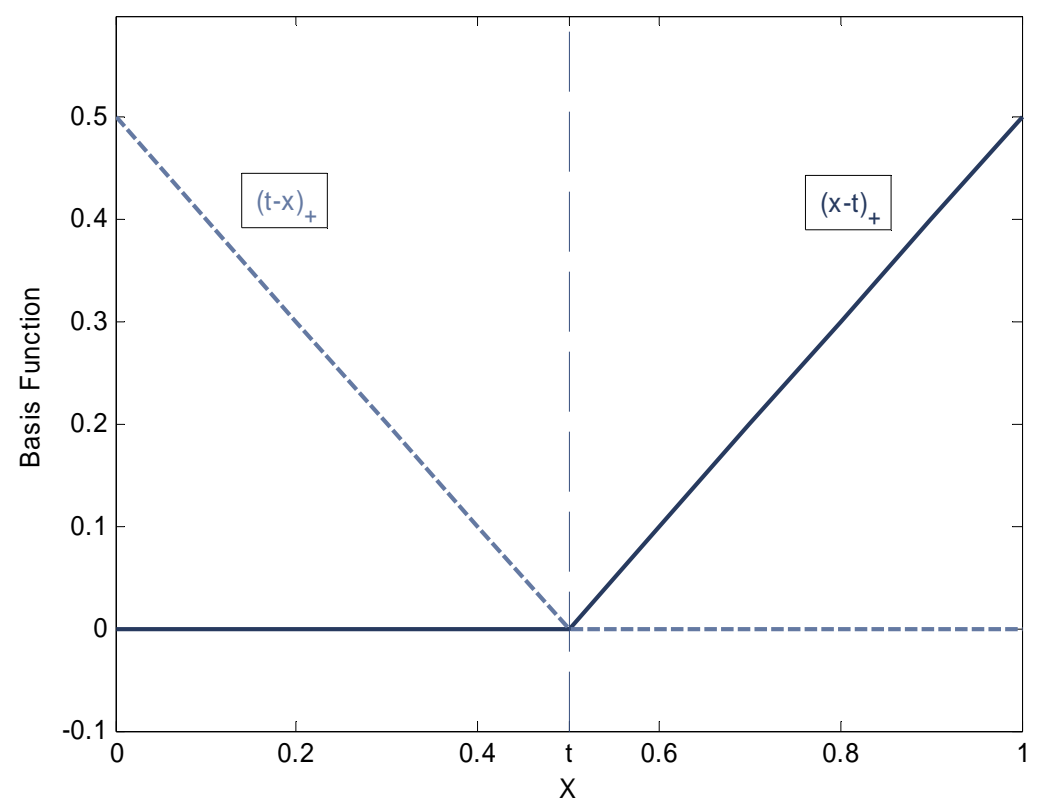

Figure 4-1 Basis Functions

\subsubsection{MARS model}

The basis functions, together with the model parameters, are combined to produce the predictions given the inputs. The general MARS model equation is given as:

$$
\hat{f}(X)=\beta_{0}+\sum_{m=1}^{M} \beta_{m} h_{m}(X)
$$

Equation 4-8

where $\left\{\beta_{m}\right\}_{0}^{M}$ are the coefficients of the model that are estimated to yield the best fit to the data, and $\mathrm{M}$ is the number of sub-regions or the number of basis functions in the model. $h_{m}(X)$ is the spline basis function developed as:

$$
\beta_{m}=\prod_{k=1}^{K_{m}}\left[S_{k, m} \cdot\left(x_{v(k, m)}-t_{k, m}\right)\right]_{+}
$$

Equation 4-9

where $s_{k m}$ takes on values $\pm 1, v(k, m)$ labels the predictor variables, and the $t_{k, m}$ represents values on the corresponding variables. The quantity $K_{m}$ is the number of "splits" that gives rise to each basis function $\beta_{m}$. 
This model searches over the space of all inputs and predictor values (referred to as "knots") as well as interactions between variables. During this search, an increasingly larger number of basis functions are added to the model to minimize a lack-of-fit criterion. As a result of these operations, MARS automatically determines the most important independent variables as well as the most significant interactions among them [17-19].

\subsubsection{Model Selection and Pruning}

In general, nonparametric models are adaptive and can exhibit a high degree of flexibility that may ultimately result in overfitting [15], if no measures are taken to counteract it. Although such models can achieve zero error on training data, they have the tendency to perform poorly when presented with new observations or instances (i.e., they do not generalize well to the prediction of "new" cases). In MARS, an optimal model is developed through a two-step, forward/backward process. In the forward step, a model is grown by adding basis functions until an overly large model is found. In the backward step, the basis functions, which no longer contribute to the accuracy of the fit, will be removed. To make the MARS algorithm computationally affordable, the maximum level of interaction between variables and the maximum number of basis functions in the model are specified by the user.

A modified form of the generalized cross validation criterion (MGCV) is used as the lack-of-fit criterion [20].

$$
\begin{aligned}
& M G C V=\frac{1}{N} \frac{\sum_{i=1}^{N}\left(y_{i}-\hat{f}\left(X_{i}\right)\right)^{2}}{\left[1-\frac{\widetilde{C}(M)}{N}\right]^{2}} \\
& \text { where }\left[1-\frac{\widetilde{C}(M)}{N}\right]^{2} \text { is a complexity function, and } \widetilde{C}(M) \text { is defined as: } \\
& \widetilde{C}(M)=C(M)+d \cdot M,
\end{aligned}
$$

where $C(M)$ is the number of parameters being fit and $d$ represents a cost for each basis function optimization and is a smoothing parameter of the procedure. Parameter $\mathrm{d}$ is set to the default value of 3 as suggested in prior literature $[15,18]$. This setting can be changed to any 
non-negative number by entering a new value. Setting the penalty higher will tend to favor a smaller optimal model.

Ideally, the predictive performance of models fitted would be assessed by making predictions for sites not used in the model fitting, with these predictions then compared with actual probabilities of occurrence at the independent sites. However, in a study such as this it is generally desirable to include all possible sites in fitting the final model. Two alternatives can be used to robustly assess the performance of the final model when making predictions to independent sites. The degree of freedom penalty for the data is computed by using these techniques. The first technique is a k-fold cross-validation $[17,18]$, where the data is divided into $\mathrm{k}$ subsets of (approximately) equal size. The data is trained the net $\mathrm{k}$ times, each time leaving out one of the subsets from training, but using only the omitted subset to compute whatever error criterion is chosen. If $\mathrm{k}$ equals the sample size, this is called "leave-one-out" cross-validation. "Leave-v-out" is a more elaborate and expensive version of cross-validation that involves leaving out all possible subsets of $\mathrm{v}$ cases. Model performance is assessed by successively removing each subset, re-fitting the model to the retained data, and predicting to the omitted data. The average error when predicting to new sites can then be calculated by averaging the predictive performance across each of the subsets. Alternatively, repeated bootstrap samples of the same size as the original data can be selected from it at random, but with replacement $[15,18]$. On average, these will include around $63 \%$ of the sites in the original dataset. When a model is fitted to such a bootstrap sampled dataset, predictions can be made to the omitted sites, and comparison of the actual and predicted occurrences can be used to assess the predictive performance of the model. Repeated implementation of this procedure (e.g. 200-300 times) allows the predictive performance to be averaged across many samples of the original data rather than five or ten subsets, so that boot-strap sampling can be seen as a smoothed or averaged form of k-fold cross-validation. Variations in this bootstrap methodology focus on whether predictive performance is assessed only on omitted sites, or on weighted or unweighted combinations of omitted and modeled sites. Weighted combinations tend to give the most unbiased estimates, so the $0.632+$ procedure of Efron and Tibshirani $[15,18]$ is followed. The area under the ROC curve was then calculated to measure model performance, as described in the cited references to the $0.632+$ bootstrap. 


\subsection{Neural networks}

The most common form of neural networks, sometimes called backpropagation networks are feedforward networks with the sigmoidal activation functions. They can, in the simplest case of a single layer of $\mathrm{N}$ hidden nodes, be written in the form

$$
y_{i}=\sum_{j=1}^{N} \omega_{i j} \sigma_{j}(x)
$$

where,

and the weights $\omega_{\mathrm{ij}}$ and $\omega_{\mathrm{jk}}$ are selected by a nonlinear optimization method to minimize the mean squared error over the training set.

The simplest algorithm to use is gradient descent ('backpropagation'), in which each weight is iteratively changed proportionately to its effect on the error, but more advanced methods such as conjugate gradient methods and sequential quadratic programming are being used increasingly.

Neural networks are attractive as automatic model-building tools because they can be proven, or given enough nodes, to be able to represent any well-behaved function, with arbitrary nonlinear interactions between the inputs. They are also, besides being suitable for implementation on massively parallel computers, relatively robust to outliers and poor data. In $\sigma_{j}(x)=1 /\left(1+\exp -\sum_{k} \omega_{j k} x_{k}\right)$ short, they have been seen as a way of doing nonlinear modelbuilding without the pain of learning statistics. They have one major disadvantage: due to the high degree of interaction and collinearity between the variables and basis function, it is almost impossible to interpret the models.

\subsection{Comparison of MARS and NN}

MARS and neural networks have some obvious similarities and differences. Both are methods of deriving nonlinear models from data. Additionally, both require significant amounts of data to build a reasonable model, and do so by using models with such a large numbers of parameters that the models may be considered to be nonparametric. The methods differ in that MARS is based on subset selection, while neural networks offer a nonlinear projection method [100]. 
MARS and neural networks also share a subtle but important similarity. They can be both viewed as methods which select basis functions adaptively based on the data. When there are multiple independent variables, methods which construct basis functions based on the data can be shown to give more accurate models than methods which use a fixed set of basis functions [100]. Thus neural networks and MARS are more efficient than Fourier series expansions or higher order NARMA models.

When trained with sufficient data, both MARS and neural networks yield a substantially lower predictive error than linear regression. A brute force implementation of the MARS search procedure requires running times proportional to $\left(\mathrm{pN}^{2} \mathrm{M}^{4}\right)$ where $\mathrm{p}$ is equal to the number of variables, $\mathrm{N}$ is equal to the sample size, and $\mathrm{M}$ is equal to the maximum number of allowed basis function [16]. In most cases, MARS was found to be much faster than neural networks and, for sufficiently large data sets, it produced more accurate models. For the above mentioned similarities and advantages over neural networks, MARS was chosen as the technique for modeling purposes in this study.

\subsection{Factors affecting $\mathrm{NO}_{\mathrm{x}}$ emissions}

Various factors affect the combustion process including the operating parameters, such as engine speed, load, fueling, injection timing, manifold air temperature, manifold air pressure and air-fuel ratio. There arises a need to select a set of parameters that most contribute to the emission. In this study operating parameters such as engine speed, load, fueling rate, injection timing, manifold air temperature, manifold air pressure, coolant temperature, oil temperature, and vehicle speed as the inputs of this emission estimation system.

\subsection{General structure of the model}

This section provides a general description of the developed $\mathrm{HDD} \mathrm{NO}_{\mathrm{x}}$ emission model. The HDD $\mathrm{NO}_{\mathrm{x}}$ emission model consists of sub-models that focus on specific engine model and model year, each having different emissions and fuel consumption characteristics. The several categories that are included in the model are described in Table 4.1.

Using a bottom-up approach, the basic building block of the emissions model is the individual truck operating on a fine time scale (i.e., second-by-second). Separate sub-models for trucks tested from each category have been created. All of these sub-models have similar structure; however, the parameters used to calibrate each sub-model are different. Each 
calibrated sub-model corresponds to a truck representing the characteristics of a particular truck sampled randomly from that category.

For the scope of this study, a total of sixty vehicles were tested which includes four vehicles for each category listed in Table 4-1.

Table 4-1 List of engine model and model year used in model development

\begin{tabular}{|c|c|c|c|}
\hline Category No. & Manufacturer & Model & Model Year \\
\hline 1 & Caterpillar & 3126 & 2001 \\
\hline 2 & Caterpillar & C-10 & 2001 \\
\hline 3 & Caterpillar & C-15 & 2001 \\
\hline 4 & Caterpillar & 3126 & 2002 \\
\hline 5 & Caterpillar & C-10 & 2002 \\
\hline 6 & Caterpillar & C-16 & 2002 \\
\hline 7 & Caterpillar & 3126 & 2003 \\
\hline 8 & Caterpillar & C-9 & 2003 \\
\hline 9 & Caterpillar & C-15 & 2003 \\
\hline 10 & Cummins & ISB & 2001 \\
\hline 11 & Cummins & N-14 & 2001 \\
\hline 12 & Cummins & ISB & 2002 \\
\hline 13 & Cummins & ISC & 2002 \\
\hline 14 & Cummins & ISX & 2002 \\
\hline 15 & Cummins & ISB & 2003 \\
\hline & & & \\
\hline & & & 2003 \\
\hline
\end{tabular}

In developing these sub-models, it is important to strike a balance between achieving high modeling accuracy and reducing the number of model input parameters. Because the design, calibration, and in-use conditions of trucks vary, there is always the temptation to add more input parameters for special situations of different trucks to improve modeling accuracy. In order to control the number of independent input parameters, focus has been placed on the most common operating parameters rather than trying to accommodate every available engine parameter.

It is important to remember that the main purpose of the HDD emission sub-models is to predict vehicle tailpipe $\mathrm{NO}_{\mathrm{x}}$ emissions for operation within the NTE region for each category. In 
the developed HDD $\mathrm{NO}_{\mathrm{x}}$ emission model, second-by-second tailpipe emissions are modeled as a function of engine speed, engine load, MAP, MAT, coolant temperature, oil temperature, and vehicle speed. Using MARS, basis functions are developed and the final output is a product of the different basis functions that are dependent on the individual parameters. It is important to note that this generic model with its modules applies to each of the truck categories, and differences between the sub-models show up only in their defining parameters.

In addition to these operating variables, each sub-model uses a total of 8 static parameters in order to characterize the vehicle tailpipe emissions for the appropriate vehicle/technology category. A summary list of the parameters is given in Table 4.2.

In Table 4.3, the model input parameters are first divided into two large categories: 5 Engine Parameters and 3 Vehicle Parameters.

\subsection{Vehicle Compositing}

Data sets had to be created for the purpose of modeling and were required to represent the vehicle/engine technology categories listed in Table 4-1. Thus, a compositing procedure has been developed to construct a composite vehicle to represent each of the categories. The individual routes for each vehicle within a category was blended to form a profile that represents the operation and emissions over different routes. The individual vehicles within each category were blended into a composite vehicle with a composited emissions trace. The composited file would contain the emissions and engine operation data from the different routes the vehicle was tested.

The combined data sets were used to create specific data sets for different analyses throughout the project. These data sets included the following:

- A "Modeling" or "Calibration" data set comprised of on-board data composited from at least two vehicles within a category with identical engine configuration; and

- A "Validation" data set is created using data from the other two vehicles. The validation data can further be divided into two classes:

o If engine configuration for the validation data set was same as the engines used to generate a calibration data set, then the two remaining vehicles were used to generate the validation dataset, named 'Validation 1', 
o If the test weights were different then the validation dataset would be named as 'Validation 2' and

0 If the engine/test configuration of each of the engines were different from the engines used to generate calibration data set, then each of the remaining vehicle will serve to generate validation data sets, named 'Validation 3'.

\subsection{Data Segregation}

In this study, only data from engine operation during continuous NTE operation is used for modeling purposes. A MATLAB code was written to extract the data during continuous NTE operation from the MEMS files and create a separate input file to be used with MARS. An input data file represents the operation within the NTE region combined from the different routes the vehicle was tested for either a single vehicle or from composited vehicles.

\subsection{Model Calibration Process}

After segregation of data, MARS was used to fit the data using the dependent variables. As the model was developed, vehicles from each category were modeled by determining all of the parameters described in Section 4.5. The data set used for the model development is called the 'calibration' data set. The challenge is to approximate a function between the system inputs and outputs given only the measurement values of all variables. The reasons for selecting the explanatory variables were explained in Section 4.4. In fitting regression to the data, a multiple adaptive regression splines technique was employed as explained in Section 4.3. The result from MARS is a statistically significant model with statistically significant parameters. The model selection and pruning are described in the previous section.

During the model calibration stage, different combinations of factors that affect the final model were tested, which include:

- changing the number of maximum basis functions available;

- changing the interactions between explanatory variables;

- $\quad$ limiting the order of fit; and

- varying the sample size for bootstrapping during model selection. 
Different models were developed for a single composited vehicle based on the above mentioned combinations. Table 4-2 presents the 9 input variables and 1 output variable used for modeling, along with their short term representation throughout the dissertation.

Table 4-2 Input and Output parameters used for modeling

\begin{tabular}{|c|c|c|}
\hline Variables & Parameter & Abbreviation \\
\hline \multirow{4}{*}{ Inputs } & Engine Speed (rpm) & RPM \\
\cline { 2 - 3 } & Engine Load/Torque (ft-lb) & TQE \\
\cline { 2 - 3 } & Engine Timing (degree-btdc) & TIM \\
\cline { 2 - 3 } & ECU Fueling Rate (gal/s) & FR \\
\cline { 2 - 3 } & Manifold air Temperature (degree F) & MAT \\
\cline { 2 - 3 } & Coolant Temperature (degree F) & CT \\
\cline { 2 - 3 } & Oil Temperature (degree F) & OT \\
\cline { 2 - 3 } & Vehicle Speed (mph) & VS \\
\cline { 2 - 3 } & Manifold Air Pressure (psig) & MAP \\
\hline Output & Shifted NOx Corr $(\mathrm{g} / \mathrm{s})$ & NO \\
\hline
\end{tabular}

After segregation of data, MARS is used to fit the data using the predictor variables. The problem being approached is to construct a mapping function between the system inputs and outputs, given only the measurement values of all variables. MARS operates as a fully automated algorithm if the parameter $M_{\max }$ is selected properly. The maximum number of basis functions $M_{\max }$ should be set properly to protect against overfitting. Friedman [18] suggested setting $M_{\max }$ as at least two times to four times of the "true" number of basis functions. However, since no prior knowledge about the optimal number of basis functions is available, an exhaustive search is performed to find a proper $M_{\text {max }}$ and estimate the optimal mapping function.

In the iterations performed $M_{\max }$ is increased from 20 to $240 . M_{\max }$ cannot exceed 240, a limitation imposed by memory in MARS. For each given $M_{\max }$, the best function $\hat{f}(\cdot)$ is found by approximating the output data by using MARS algorithm. Applying these functions to training and testing data, the mapping function $\hat{f}(\cdot)$ that provides the best fitting performance is selected as the final model. To ensure consistency of results, two measures of estimation performance was used: MSE defined in Equation 4-2 and the maximum absolute difference (MAD) given by 


$$
M A D=\max _{i=1, \ldots N}\left|y_{i}-\hat{f}\left(x_{1 i}, \cdots x_{m i}\right)\right|
$$

The algorithm that is followed to determine the best model for a given set of conditions is displayed in Figure 4-2.

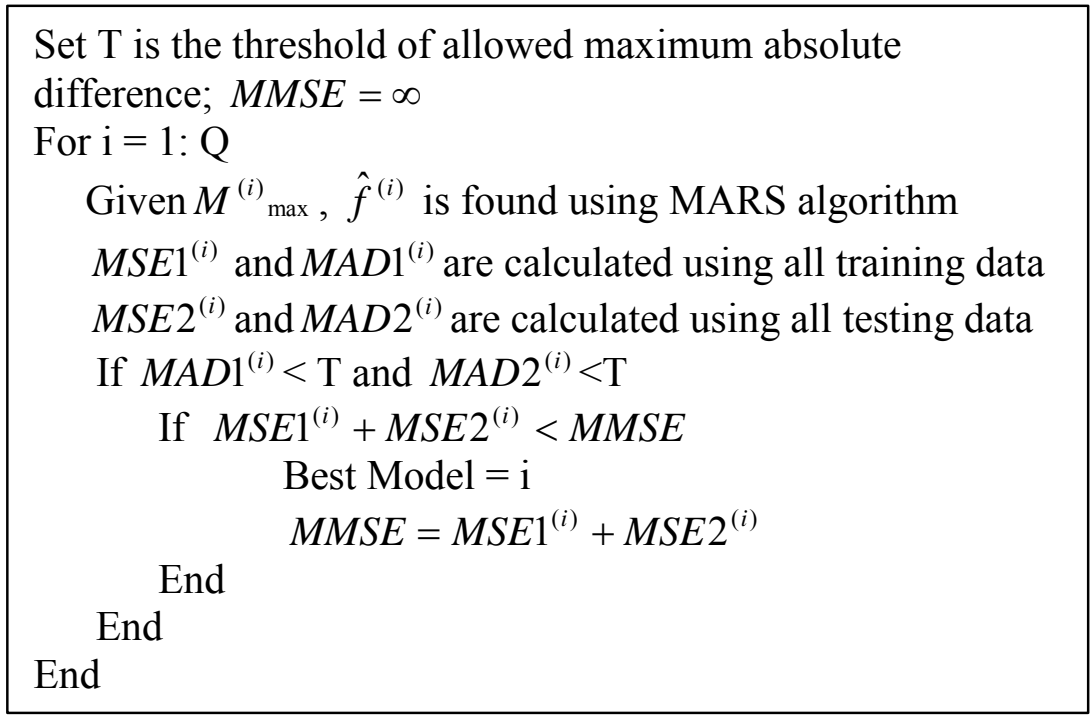

\section{Figure 4-2 The algorithm for determination of best model}

A single mapping function was finally chosen for a composited vehicle/engine category. As explained earlier, the model calibration data comprised of operation within the NTE region as continuous NTE windows.

Figure 4-3 and Figure 4-4 shows the performance of the estimated mapping function using calibration data and valiation1 data from composited vehicles from category 3 . The maximum number of basis functions is selected from the range [20,240]. From these two graphs, it can be seen that MSE (marked as bar plot) and MAD (marked using solid line) have the same trend as $M_{\max }$ increases. $M S E$ and $M A D$ increase dramatically when $M_{\max }$ is greater than 90 for calibration data set. This indicates overfitting of the mapping function associated with large values of $M_{\max }$. From the Figure it can be inferred that the model prediction is the best when $\mathrm{M}_{\max }=80$. 


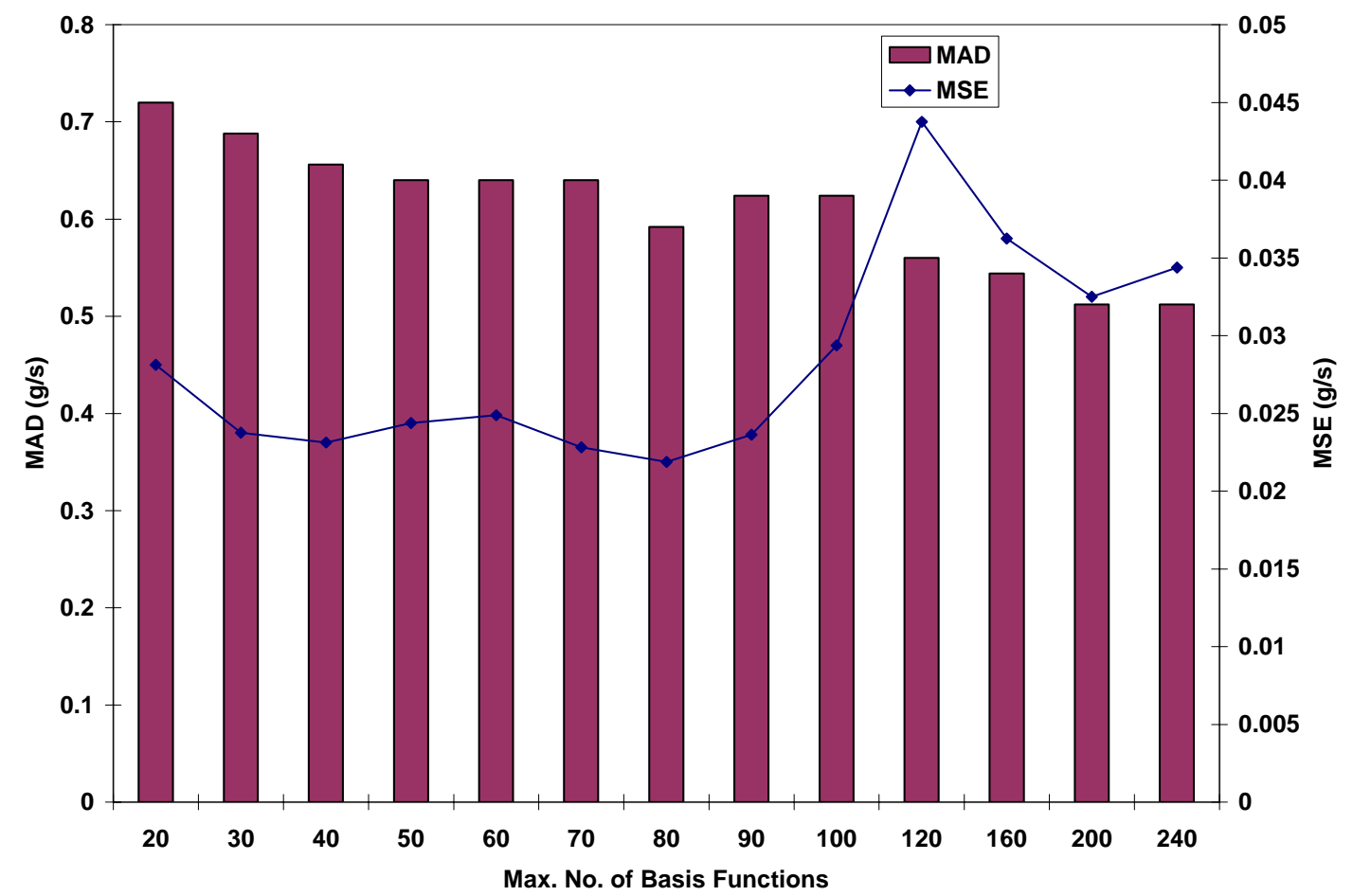

Figure 4-3 MSE and MAD for calibration data from MY 2003 Caterpillar C-15 for $\mathbf{M}_{\max }$ range from 20 to 240

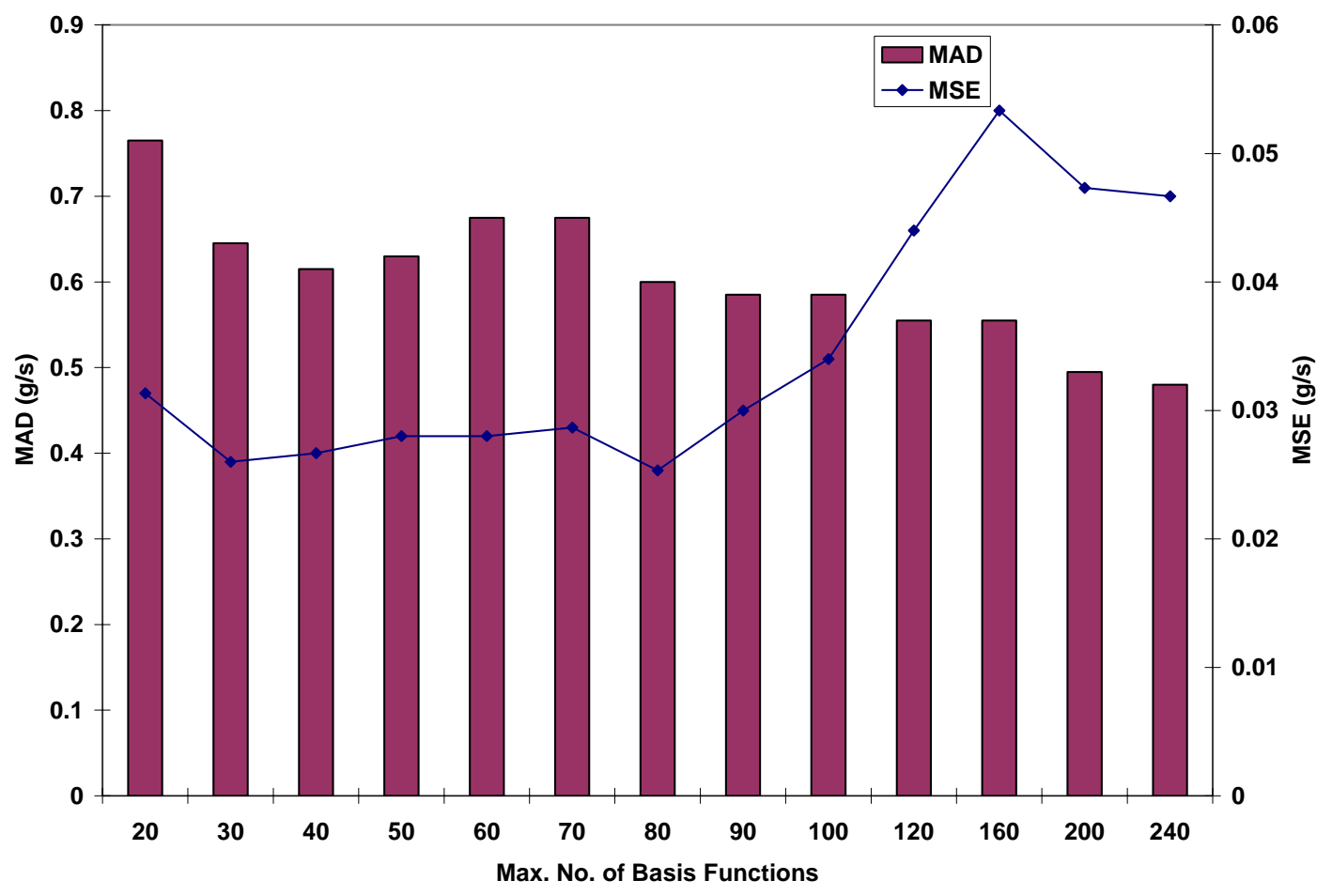

Figure 4-4 MSE and MAD for validation 1 data from MY 2003 Caterpillar C-15 for $\mathbf{M}_{\max }$ range from 20 to 250. 


\subsubsection{Comparison of observed data with predictions}

In order to determine whether the selected model performs well, continuous emissions of $\mathrm{NO}_{\mathrm{x}}$ estimations from the model were compared to observed data. The $\mathrm{NO}_{\mathrm{x}}$ approximated values

and predicted results from calibration data generated using MARS strategy when $M_{\max }$ is 90 are plotted against the corresponding actual values for calibration data set from composited vehicle for Category 1 as shown in Figure 4-5. This figure provides a detailed view of a small portion of the data. Note that the approximated and predicted values generated by the estimated mapping function follow the actual data with sufficiently high precision. In Figure 4-5, large gaps between the true data and the predicted values appear since the number of basis functions is insufficient to support this dramatic variation. Based on experience, having 10 data points per predictor variable provides enough information to guarantee a good approximation. In the computations, it has 9 predictors and about $30 \mathrm{k}$ training data points. This means that 350 basis functions have to be used to guarantee a good approximation. Thus, the maximum number of basis function should be sought in the range from 1 to 700 (at least twice of the true number). Because of the memory restriction in the simulation tool, the maximum value that $\mathrm{M}_{\max }$ can take is 240 . This leads to selection of a locally optimal value for in place of selection of the global optimum. Another likely cause of disagreement between model predictions and observed values is due to a possible incompleteness of the model, since the models are based upon a limited set of independent variables. In this stage, performance of the model was evaluated by comparing model predictions and actual observations based upon the calibration data set. 


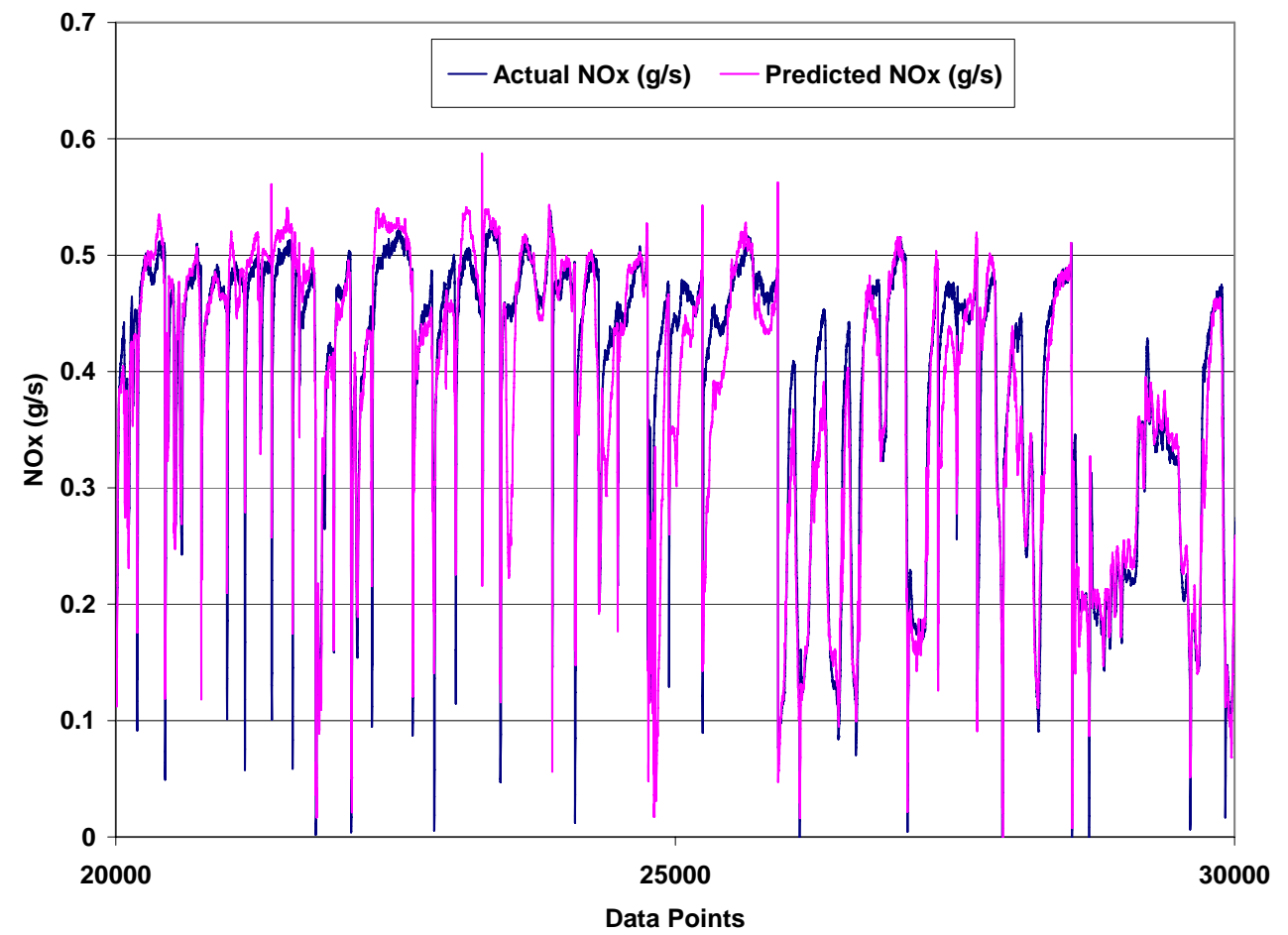

Figure 4-5 The approximated values of NOx and the true output data plotted.

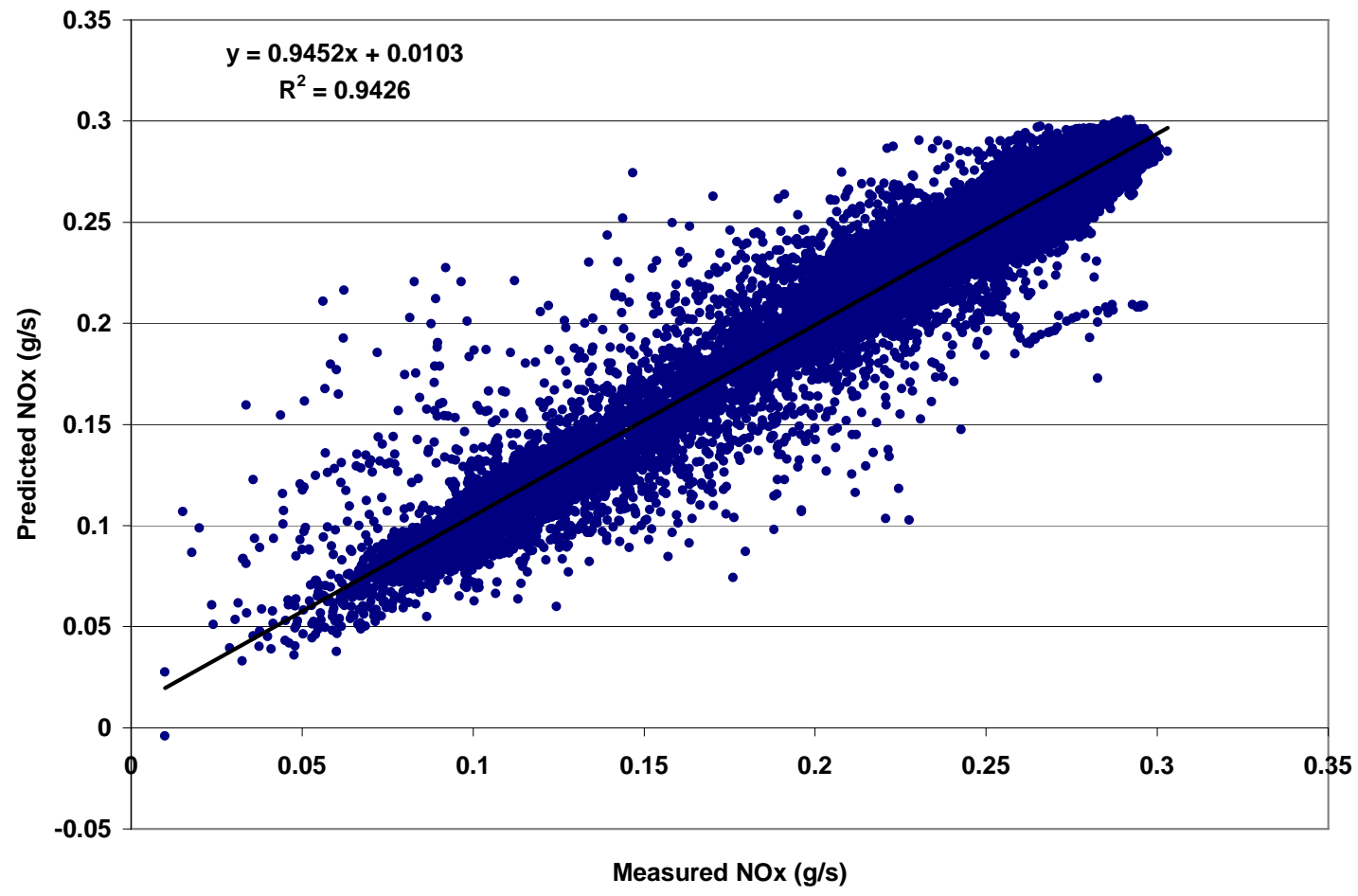

Figure 4-6 Parity plot of measured NOx vs. predicted NOx for category 1 using model1 


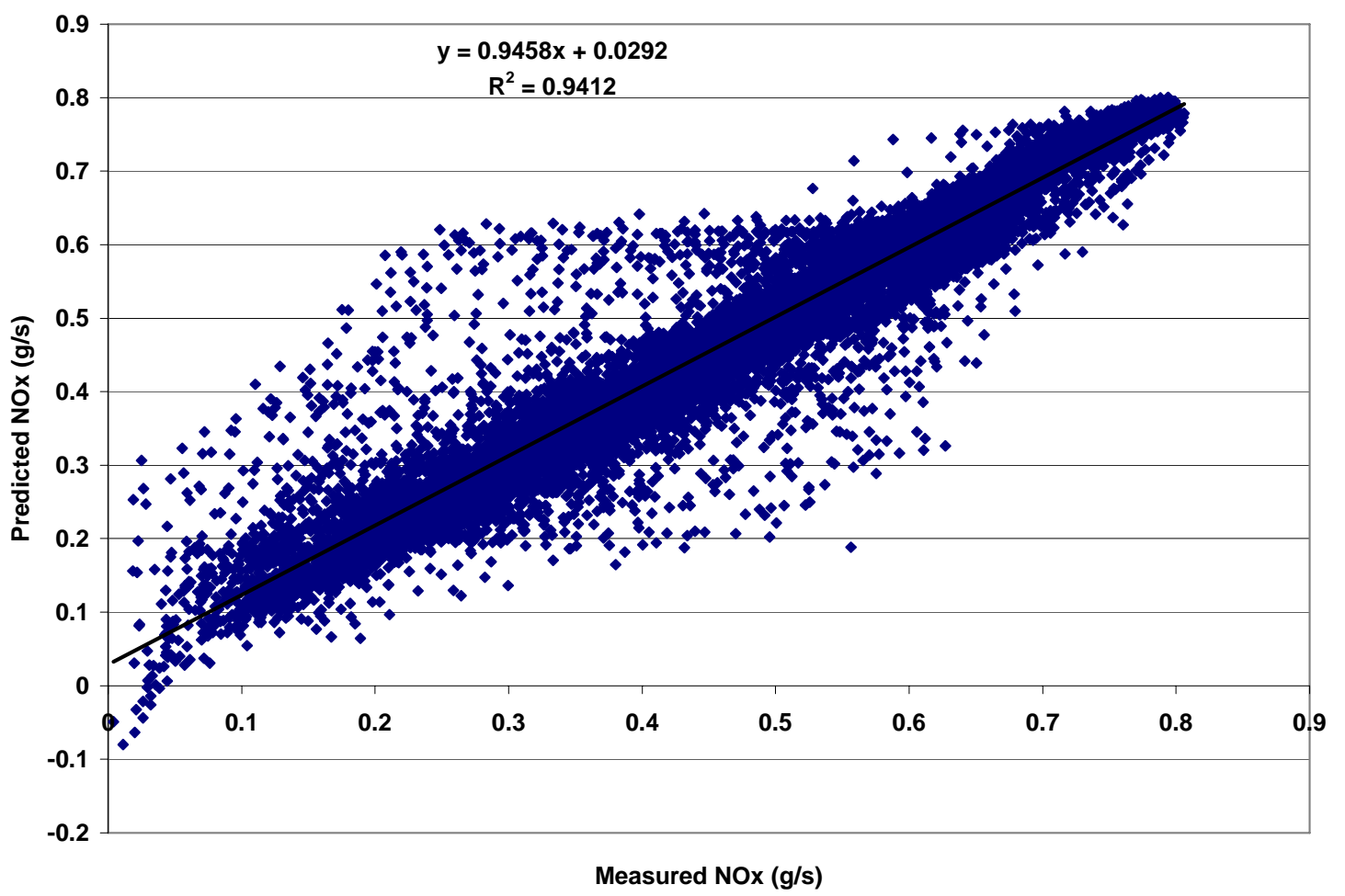

Figure 4-7 Parity plot of measured NOx vs. predicted NOx for category 2 using model2

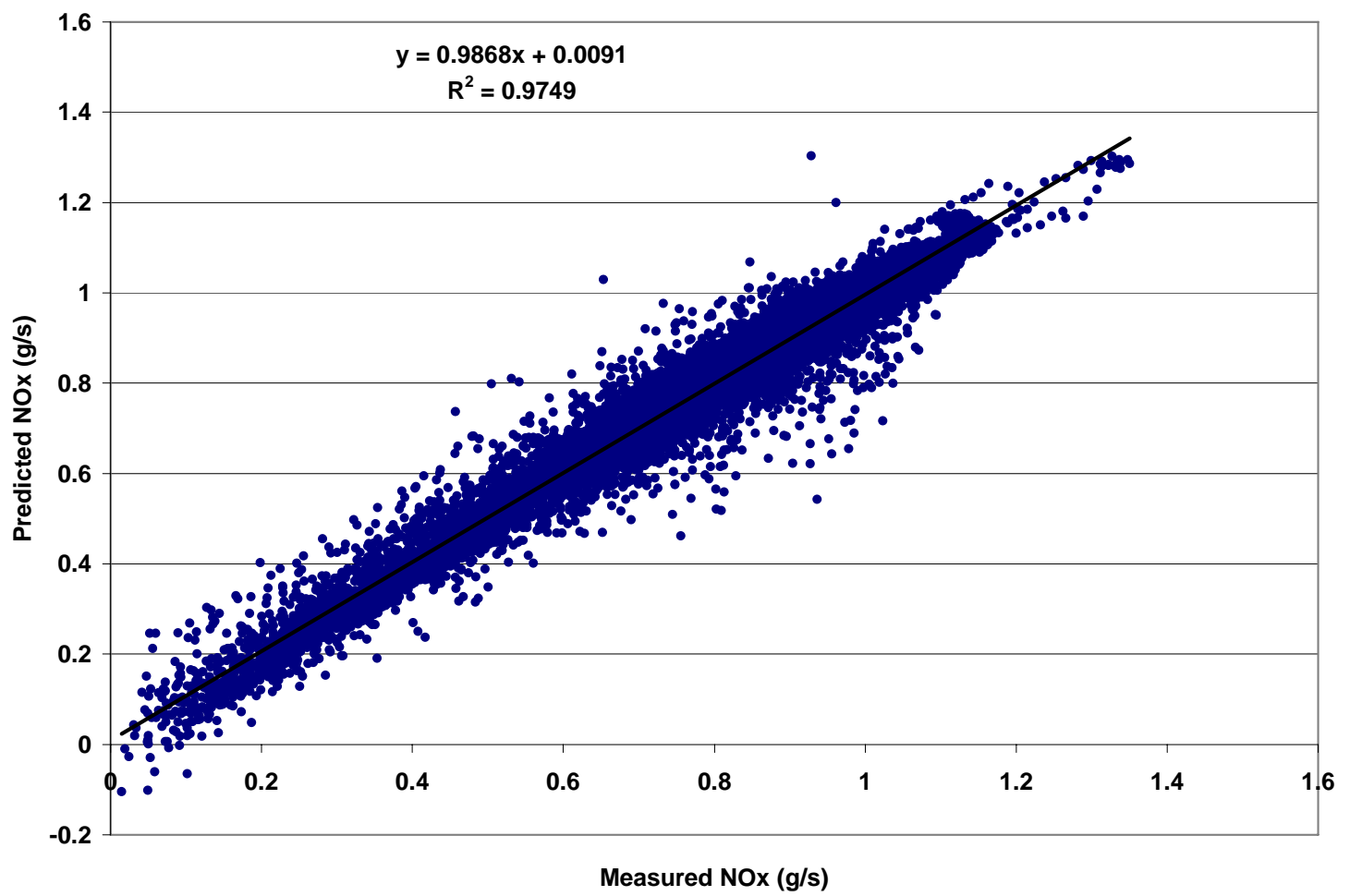

Figure 4-8 Parity plot of measured NOx vs. predicted NOx for category 3 using model3 


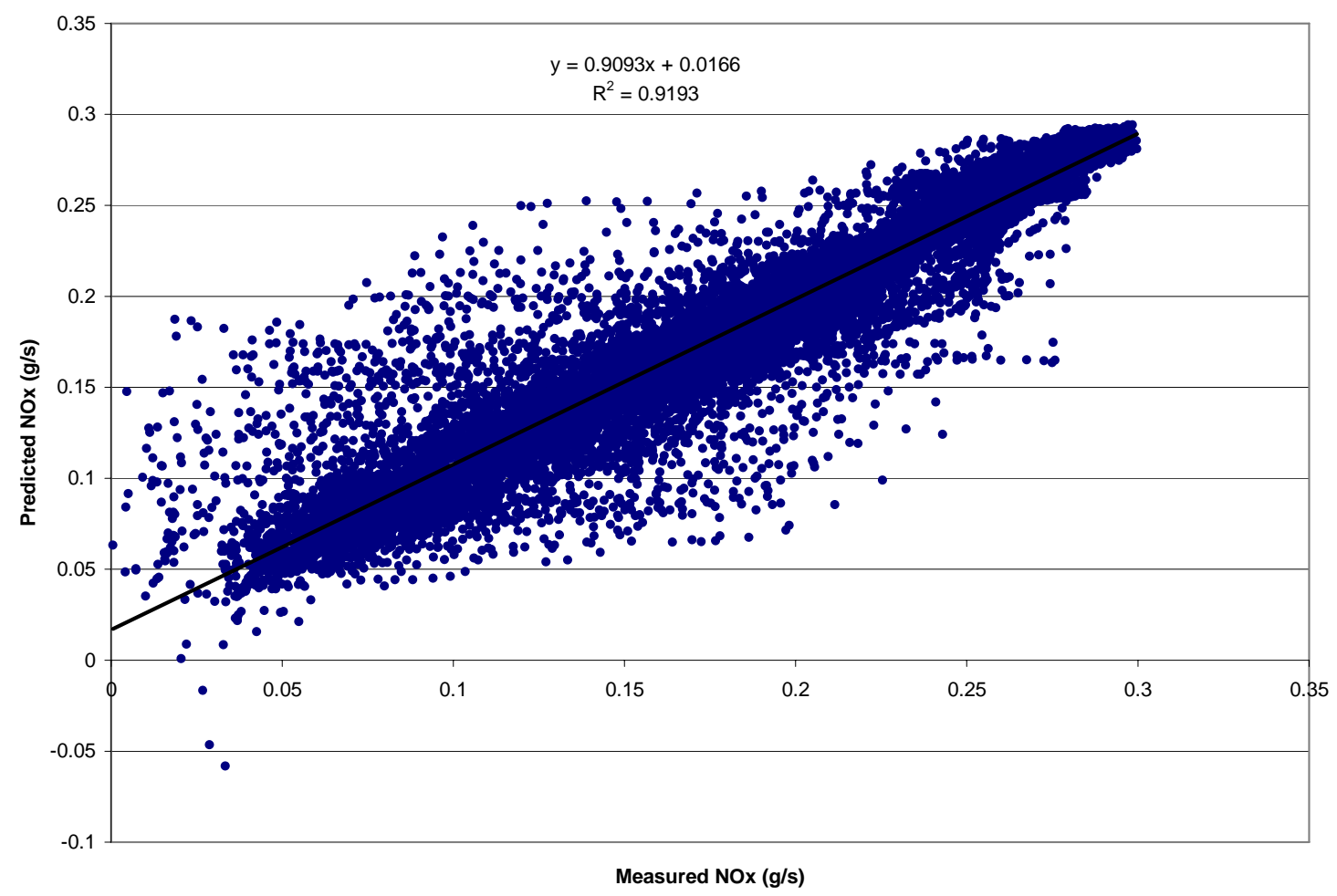

Figure 4-9 Parity plot of measured NOx vs. predicted NOr for category 3 using model 4

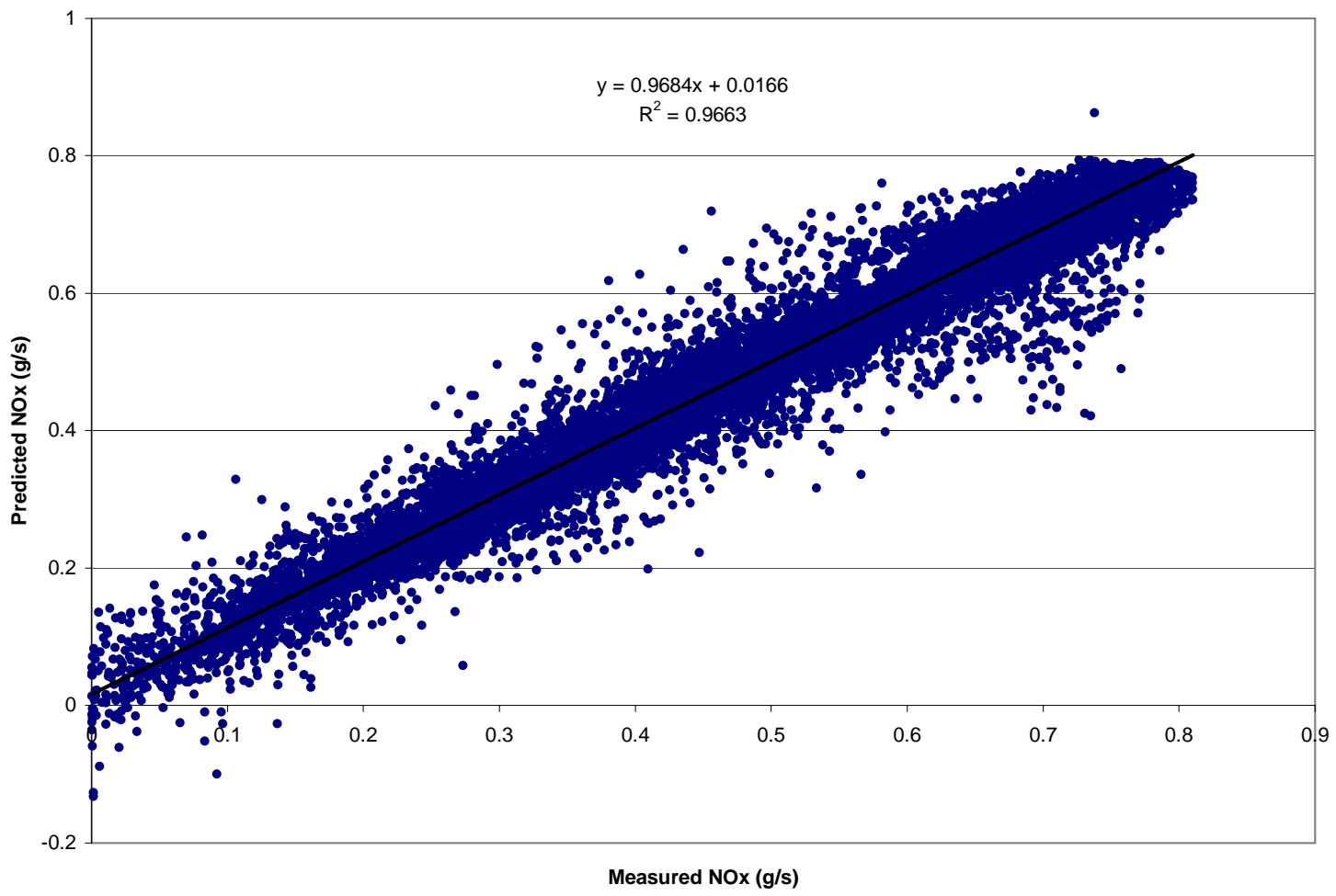

Figure 4-10 Parity plot of measured NOr vs. predicted NOr for category 5 using models

70 


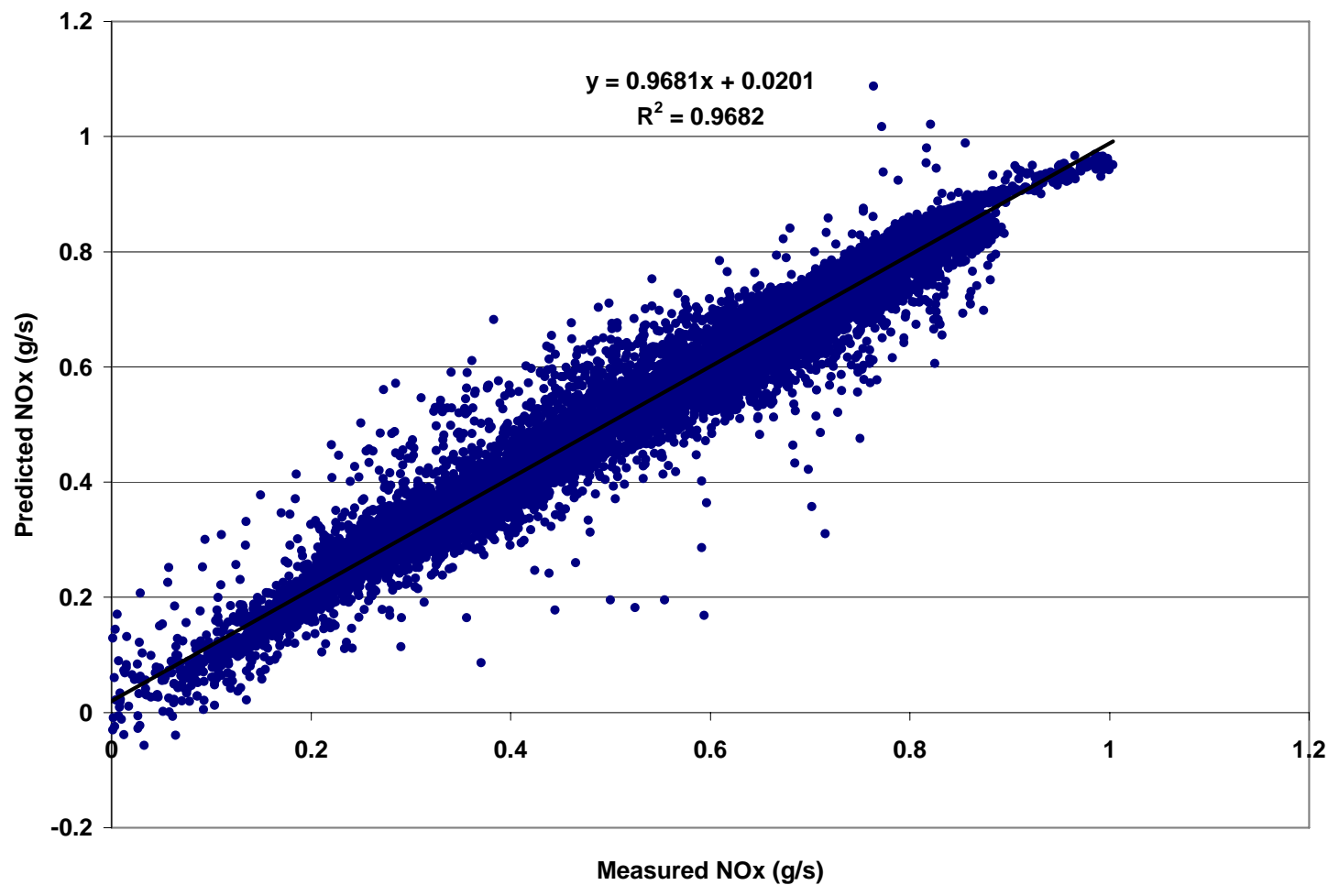

Figure 4-11 Parity plot of measured NOx vs. predicted NOx for category 6 using model6

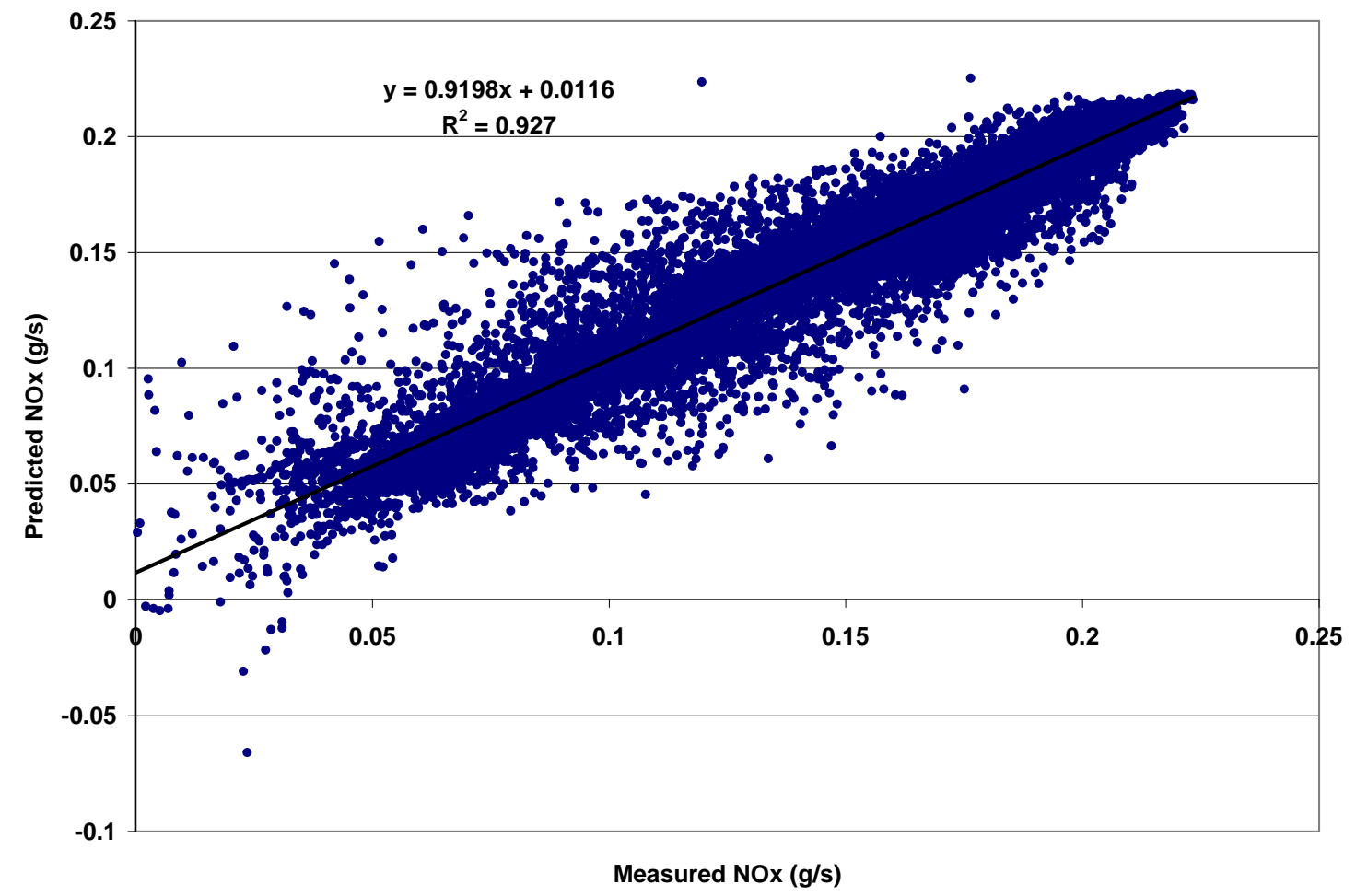

Figure 4-12 Parity plot of measured NOx vs. predicted NOx for category 7 using model7 


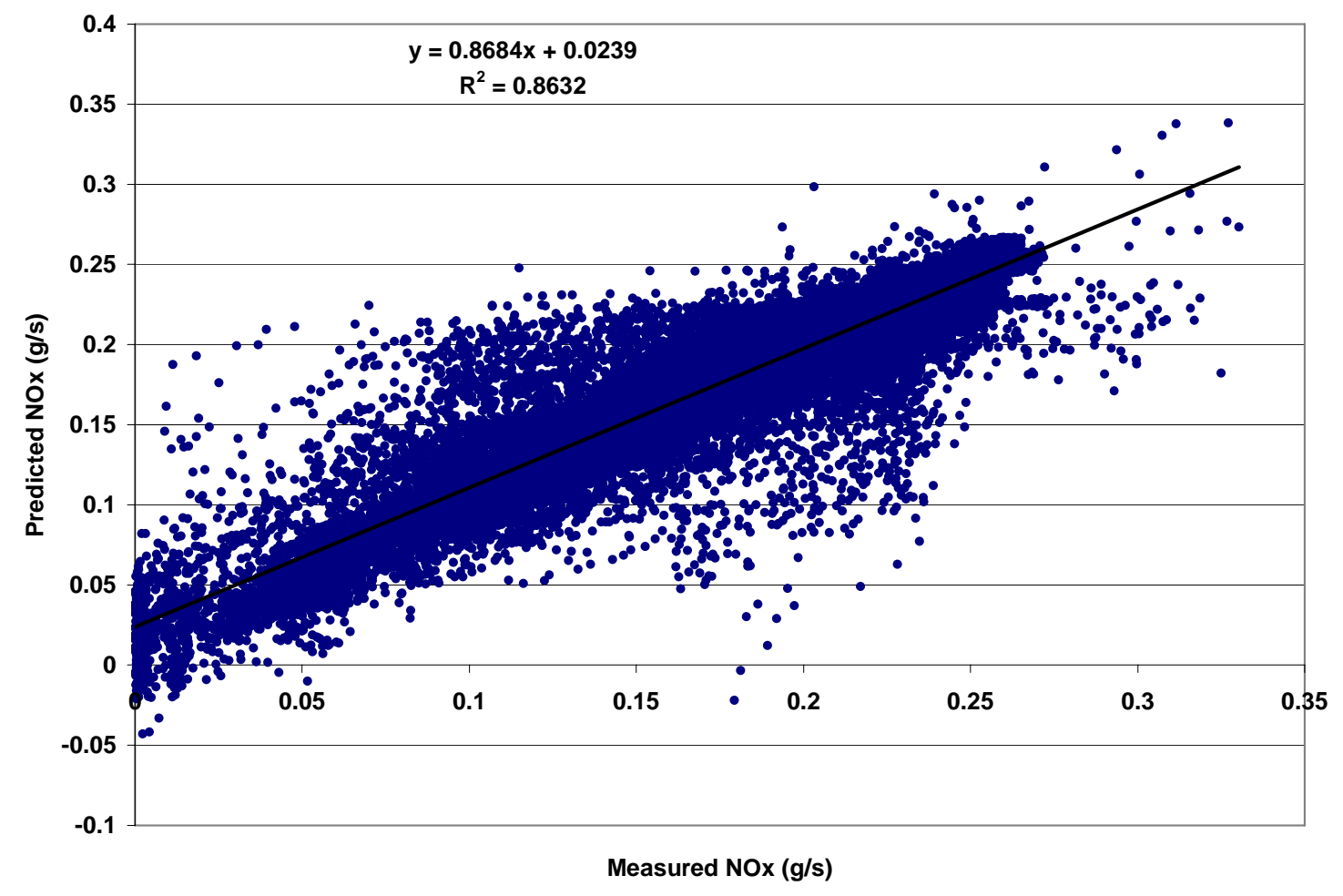

Figure 4-13 Parity plot of measured NOx vs. predicted NOx for category 8 using model8

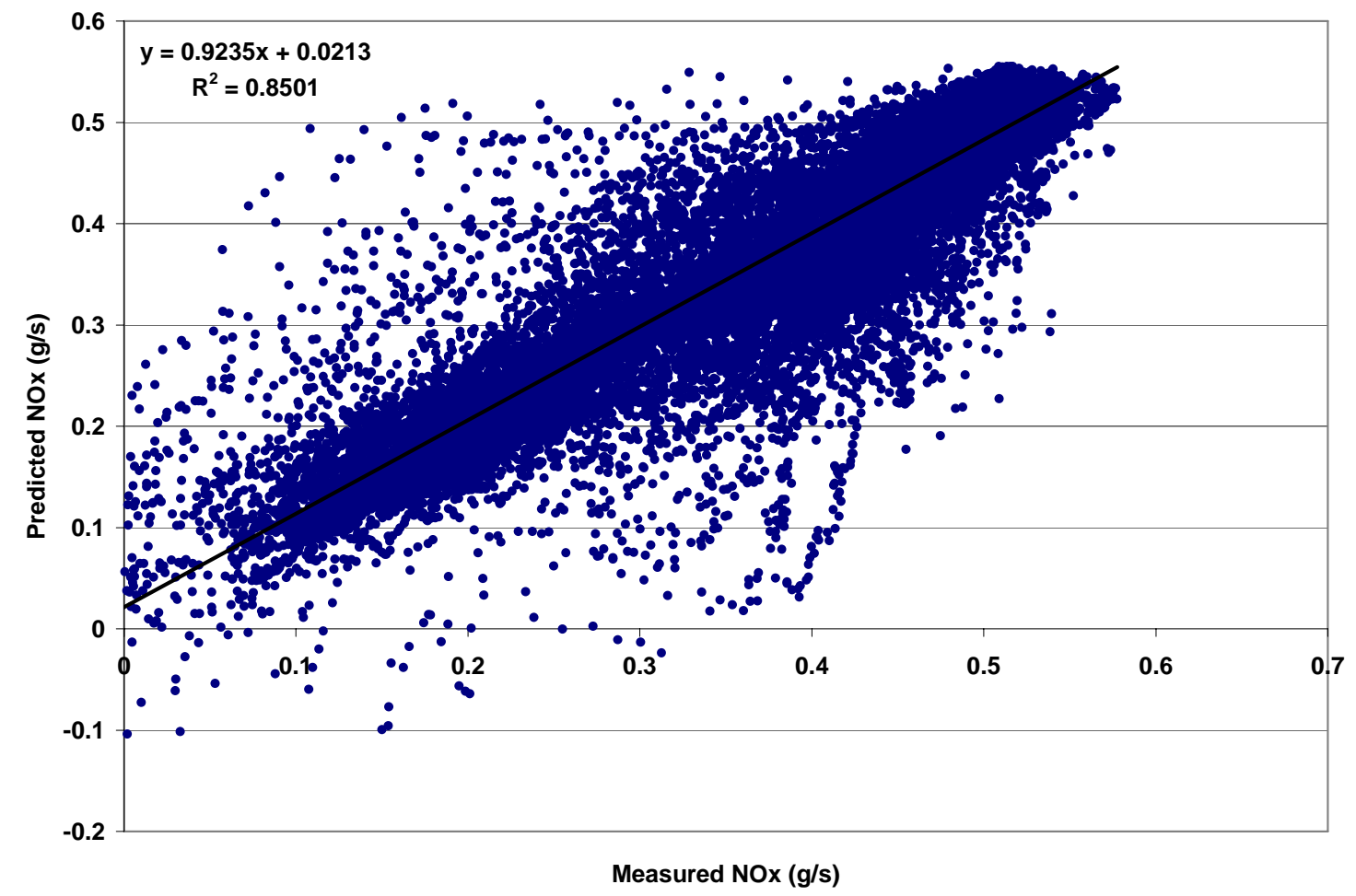

Figure 4-14 Parity plot of measured NOx vs. predicted NOx for category 9 using model9 


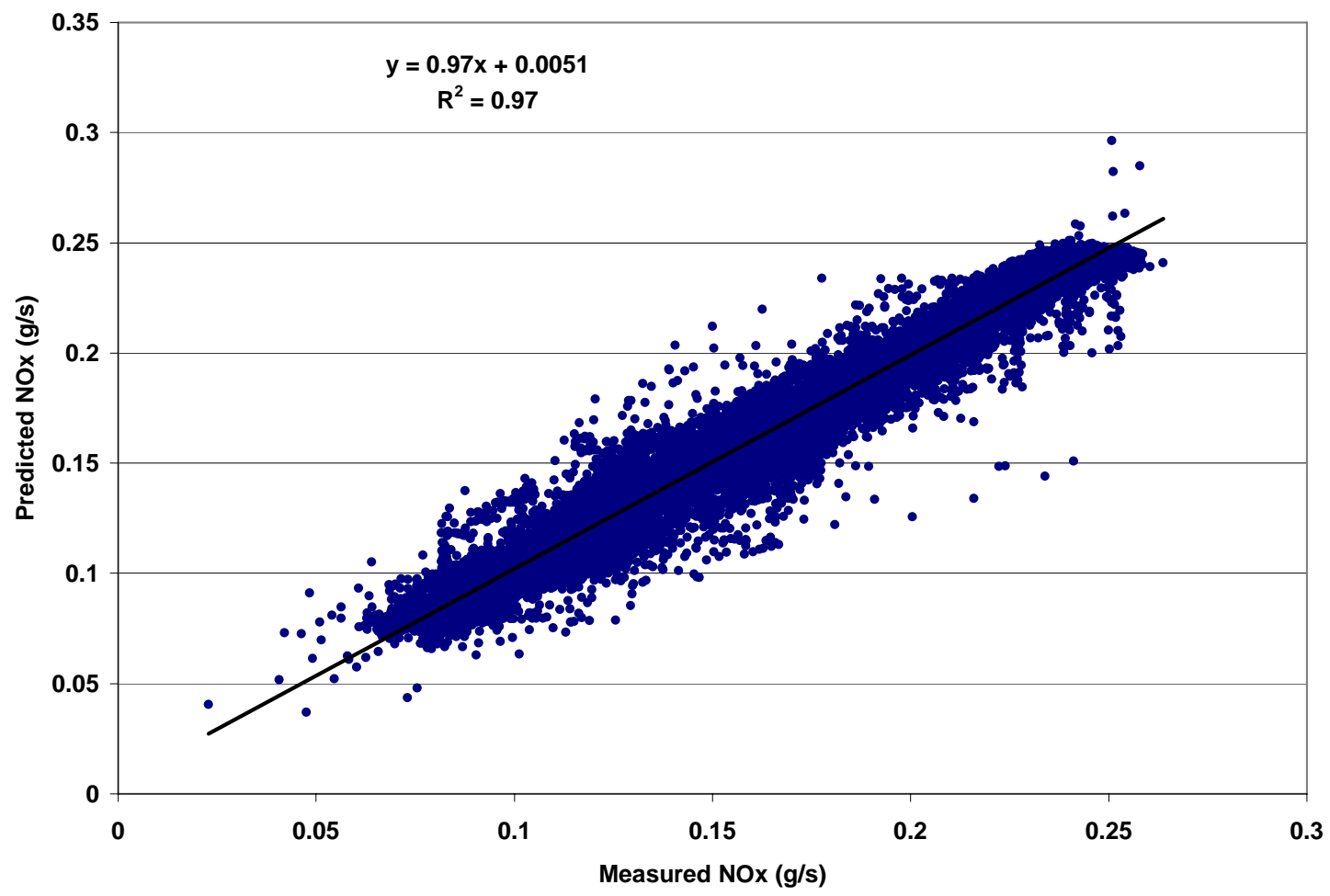

Figure 4-15 Parity plot of measured NOx vs. predicted NOx for category 10 using model10

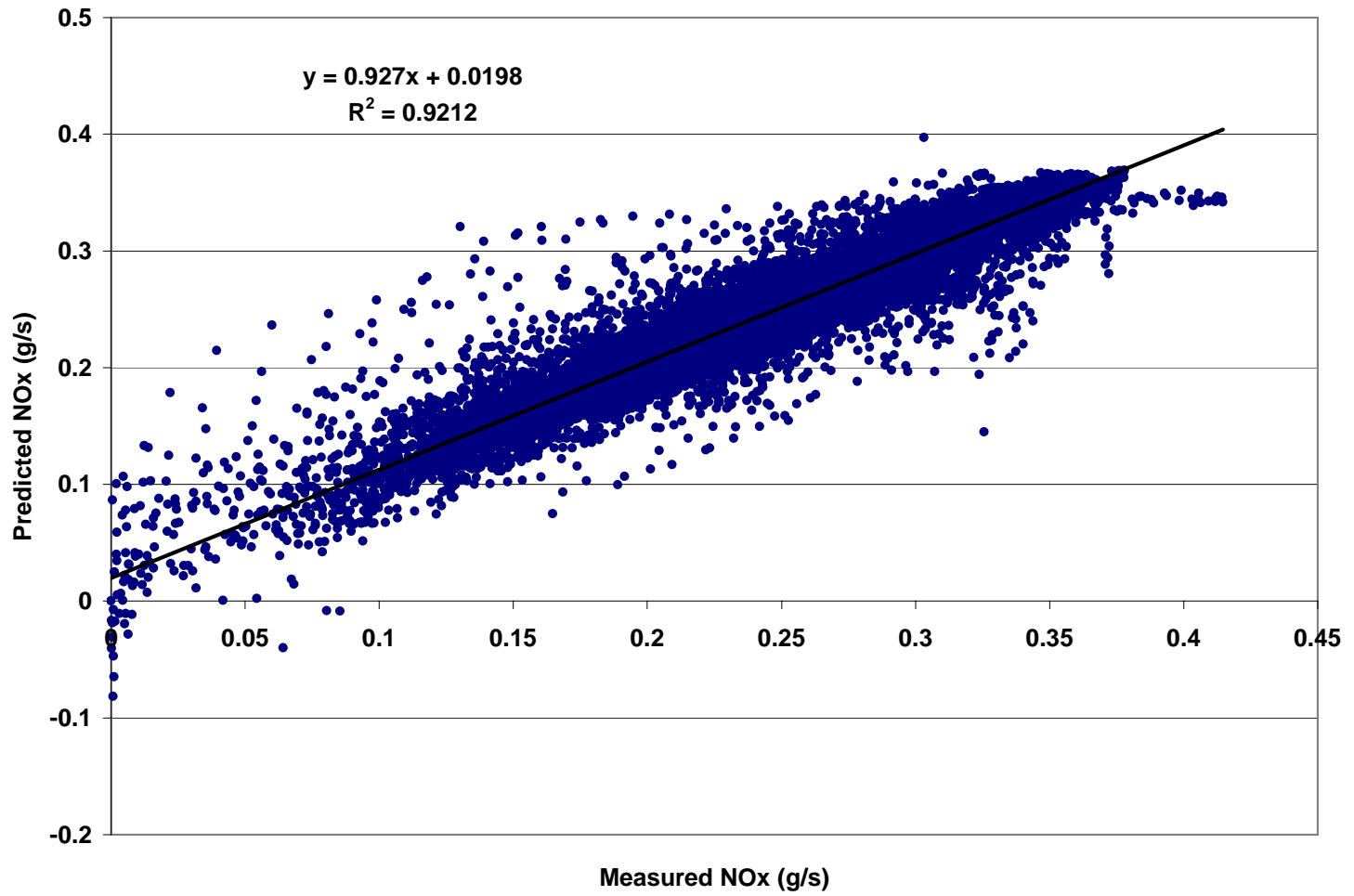

Figure 4-16 Parity plot of measured NOx vs. predicted NOx for category 11 using model11 


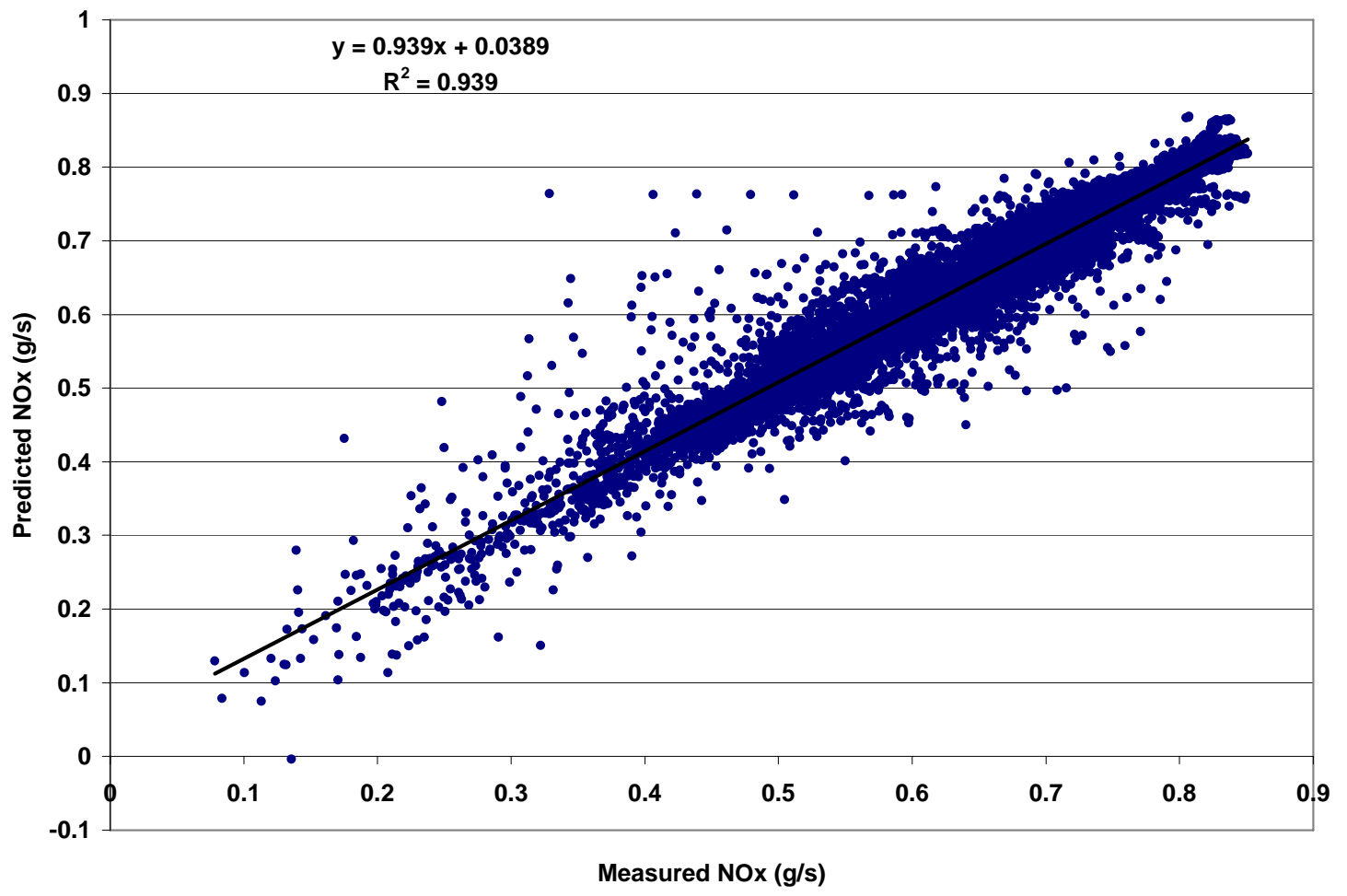

Figure 4-17 Parity plot of measured NOx vs. predicted NOx for category 12 using model12

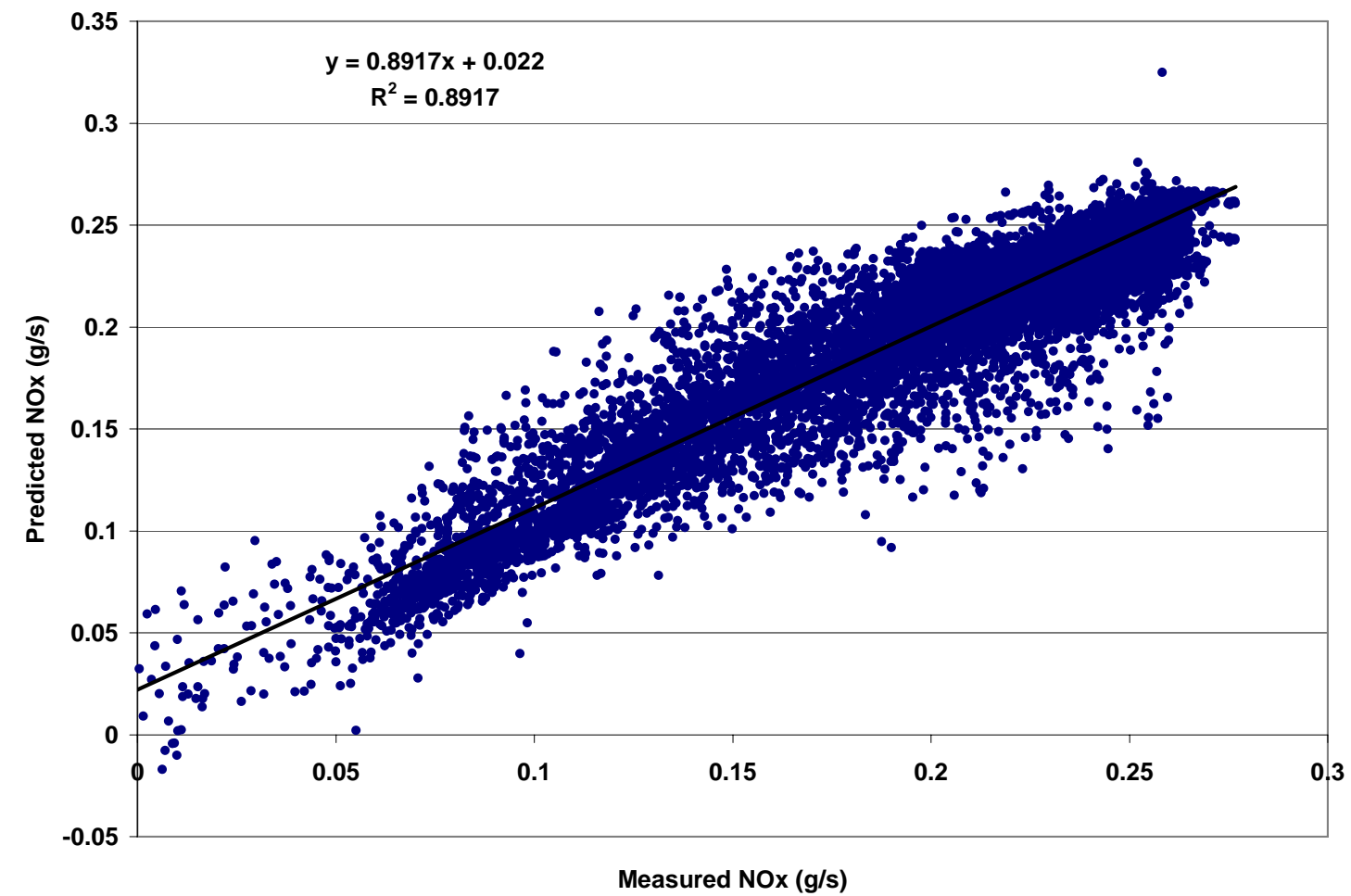

Figure 4-18 Parity plot of measured NOx vs. predicted NOx for category 13 using model13 


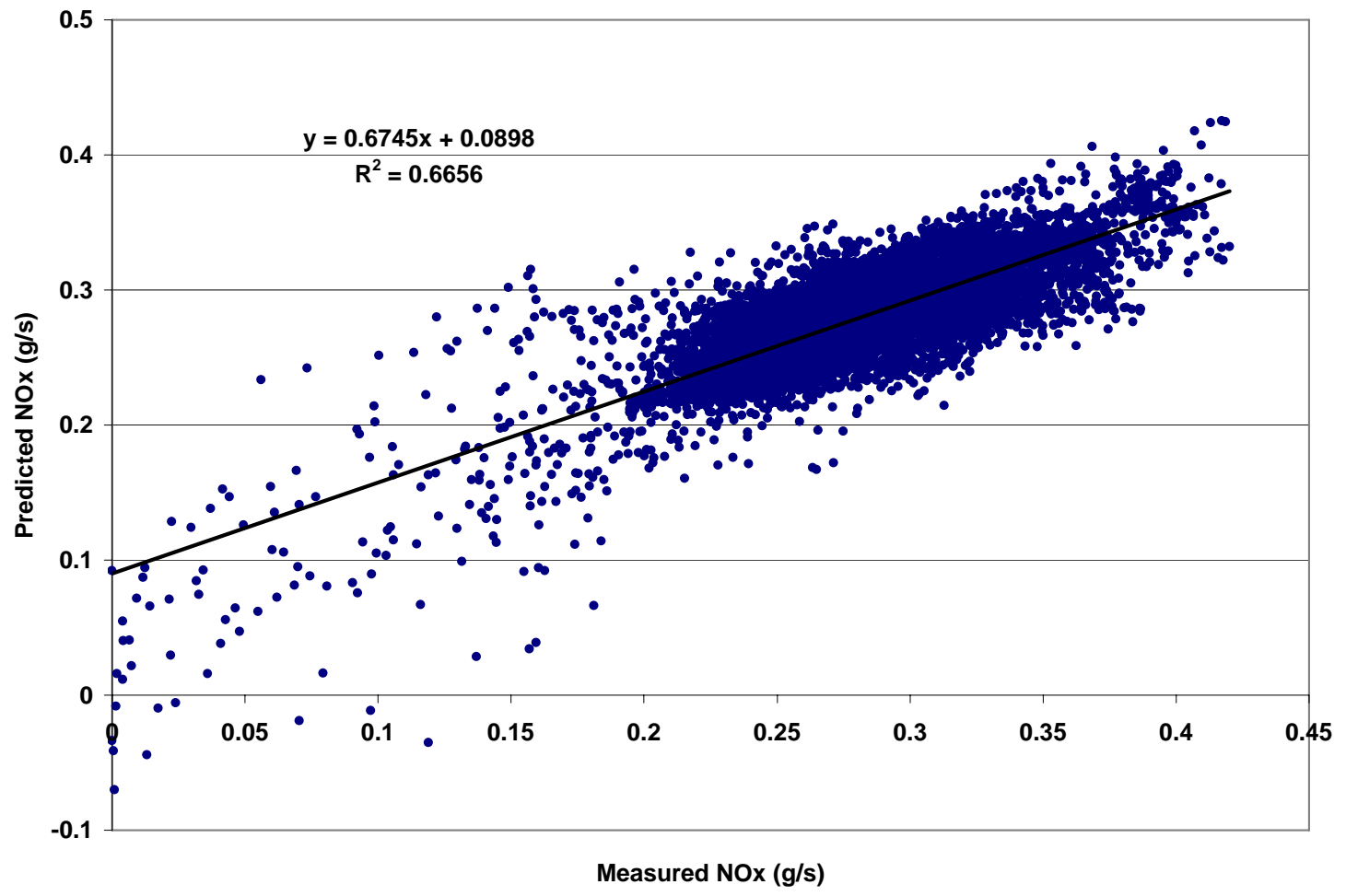

Figure 4-19 Parity plot of measured NOx vs. predicted NOx for category 14 using model14

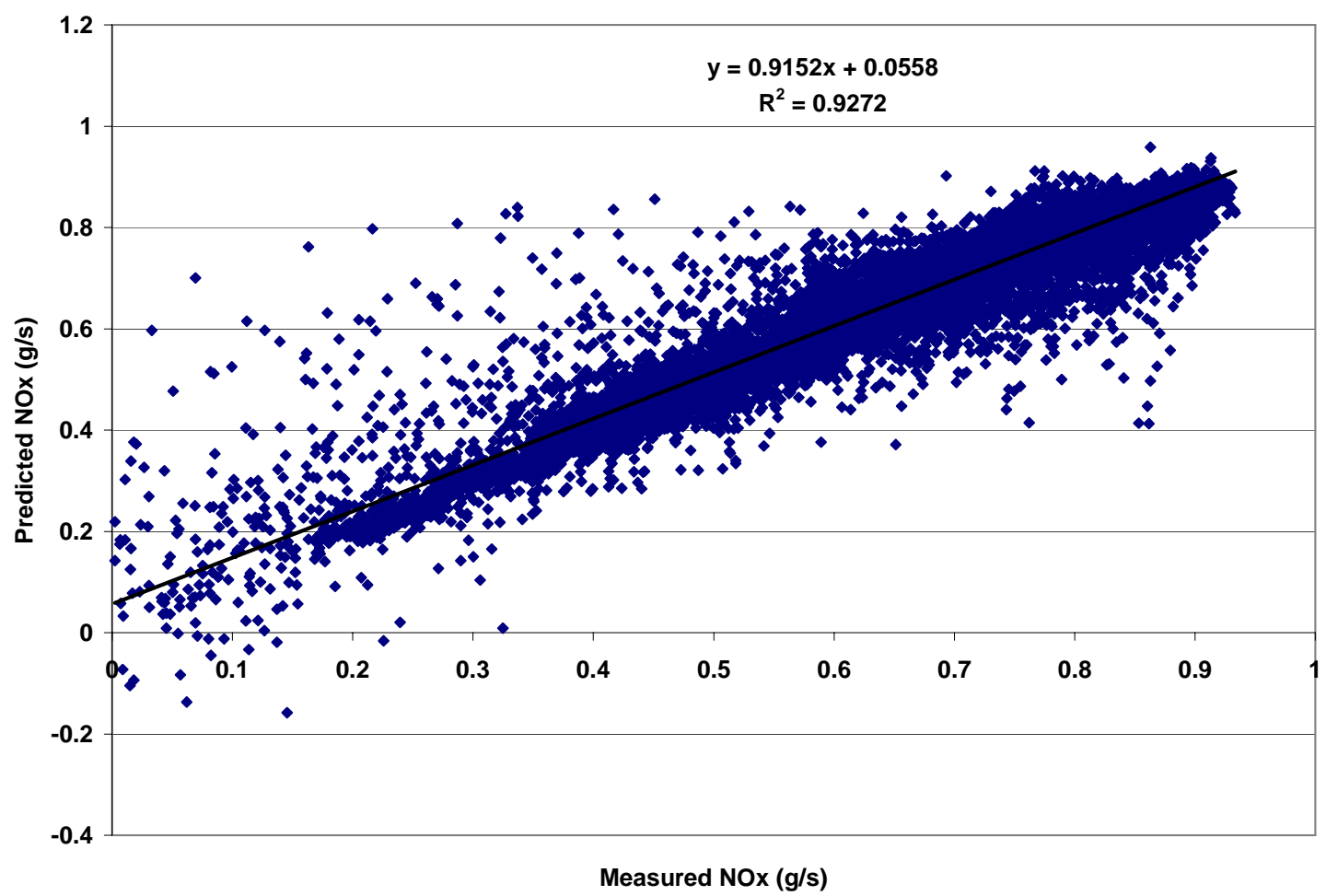

Figure 4-20 Parity plot of measured NOx vs. predicted NOx for category 15 using model15 
The performance of the model can be evaluated in terms of precision and accuracy. The $\mathrm{R}$-squared value is an indication of precision. Higher R-squared values imply a higher degree of precision and less unexplained variability in model predictions than lower $\mathrm{R}$-squared values. The slope of the trend line for the observed vs. predicted values is an indication of accuracy. A slope of one indicates an accurate prediction in that the average prediction of the model corresponds to an average observation. For example, as seen in Figure 4-6, the trendline between the observed and predicted values of NOx has an R-squared value of 0.9426 . The R-squared value of 0.94 indicates that the model can explain 94 percent of the variability in NOx emissions with 95 percent confidence level. The slope of the trend line for NOx is 0.9239. The lowest and the highest NOx g/s within a 95 percent confidence interval were 0.145 and 0.521 , respectively. Thus the range of variation in observed emissions is of the order of 3.6. The model predicts, on average, a variation from $0.146 \mathrm{~g} / \mathrm{s}$ to $0.522 \mathrm{~g} / \mathrm{s}$, which is approximately a factor of 3.6. Therefore, from perspectives of the R-squared, slope of the trend line, and variability captured by the model, it appears that this model is performing reasonably well.

This approach was used for each of the models developed for each category listed in Table 4.1, and the results of this analysis are presented in Figure 4-6-Figure 4-20. As seen from Figure 4-6-Figure 4-20, the slope of the fitted line in the parity plots is lesser than 1, indicating that the predicted values are biased to be lower than the actual $\mathrm{NO}_{\mathrm{x}}$ values. But, no correction was employed, as this bias did not affect the accuracy of predictions of the model by more than $\pm 2 \%$. It should be noted that larger the basis functions used for the modeling purpose, more knots could be used and hence better prediction accuracy. The reason for this bias is attributed to the memory limitation of the software employed for the modeling purpose. However, with an increase in software memory, the same modeling procedures can be employed for better results. The models developed for each category is presented in Appendix A. In Chapter 5, the selected model was applied to make predictions for a validation data set that was different from the calibration data set is explained in detail. The results indicate that the models developed are performing reasonably well with respect to calibration dataset.

\subsubsection{Ranking of Variables}

Apart from finding the optimal mapping function relating input and output parameters and analyzing its performance, the contribution of each input parameter to the final model was also evaluated. The input variables were ranked in the order of their influence on the prediction 
model performance. The study is motivated by the assumption that, by removing some noncritical variables, the multivariate regression model may be further simplified. To rank variables, the Variable Important Table provided in MARS package is used [16], which refits the model after dropping all terms involving the variables in question and calculates the reduction in goodness-of-fit. The most important variable is the one that, when omitted, degrades the model fit the most. The least important variable is the one that results in the smallest impact on the model quality. The measure of the goodness of fit is given by the global cross validation (-GCV). The higher the value of (-GCV) when one of the variables is omitted, the more important the variable is. An example of variables of importance, and their ranking is shown in Table 4-3.

Table 4-3 Order of importance of dynamic input variables

\begin{tabular}{|c|c|c|}
\hline Variable & Importance & -GCV \\
\hline MAT & 100.000 & 0.003 \\
\hline TQE & 91.694 & 0.003 \\
\hline MAP & 76.853 & 0.002 \\
\hline RPM & 76.106 & 0.002 \\
\hline FR & 52.132 & 0.002 \\
\hline OT & 41.791 & 0.002 \\
\hline TIM & 33.606 & 0.002 \\
\hline VS & 29.523 & 0.002 \\
\hline CT & 13.389 & 0.002 \\
\hline
\end{tabular}




\section{MODEL VALIDATION}

An essential step in the modeling process is performing model validation, which entails examining the model uncertainty, and analyzing model sensitivity. This section addresses these three topics. In addition, a large amount of analysis has been performed on emissions data to support many of the model categories and the development of specific model components. With the HDD vehicle sub-models, the validation is complicated by the on-road nature of the data collected for modeling. Uncontrollable external factors such as wind, grade, humidity, and air temperature all complicate the modeling as well as the validation. Basing the model on in-use emissions measurements provides a better reflection of actual emissions and emissions variability.

One of the key reasons to address uncertainty in model predictions is to enable comparisons. For example, in this study, "modeling" or "training" datasets are obtained from the on-road test of vehicles within a category listed in Table 4-1 used for model development. These data are also referred to here as "calibration" data, because they were used to calibrate the model. Separately, a "validation" data set was chosen randomly that is incomplete. The validation data contained activity data from a different vehicle within a category, and it required predictions to be made using the model developed from the modeling data set using the activity data of the validation dataset. In making predictions, estimated ranges of variability and/or uncertainty in the predictions are reported. When comparing the model predictions to the true values of emissions for the validation case, the precision of the model should be considered.

Possible causes of error in model predictions include the following:

- The model may be incomplete in that it does not have a sufficient set of explanatory variables;

- the model may not have the most appropriate functional form;

- the model may have been calibrated with data that contained measurement errors, the validation data may contain measurement errors for either the explanatory variables and/or the observed emissions;

- the validation data set may have been obtained under conditions substantially different than those for the data used to calibrate the model; and 
- there may be data entry errors.

\subsection{Model Output Variability and Uncertainty}

Several sources of variability go into any model developed from measured data. Variation, acknowledged or not, exists as part of the model development process and needs to be addressed to assess the validity of the model results. In a vehicle emissions model, some of the main sources of variation analyzed include emission measurement variability, vehicle driving and operation variability, vehicle sampling variability, and model output variability.

\subsubsection{Emissions Measurement Variability}

Every measurement is a combination of the true value of the parameter plus the total measurement error. Hence, there is an inherent uncertainty in the use of the measurements to represent a true value. This makes completely accurate measurements impossible. However, measures can be taken to minimize these errors. The instruments in the MEMS system were calibrated before each vehicle test. An uncertainty analysis performed on the instruments in the MEMS system [54] indicates that the results are within $6 \%$ for $\mathrm{NO}_{\mathrm{x}}$ emissions for operation in the NTE region.

\subsubsection{Vehicle Driving/Operational Variability}

For the HDD vehicles, driving and operational variability were not a significant factor in model uncertainty. This is because:

- Model development was not dependent on pre-specified driving cycles. While the testing protocol included pre-specified driving cycles, they were not essential to the model building process.

- The on-road data collection is subject to external factors such as wind and road grade that significantly affect emissions which are accounted for in terms of engine broadcast torque and thus increase the variability of the data far more than small deviations from the driving cycle.

\subsection{Comparison of Validation Data with Predictions}

The selected model for each category was applied to make predictions for a validation data set that was different from the calibration data set. The validation results of the model 
selected for Category 1 are explained below. A similar approach was used for the models selected for each category. A summary of the type of validation performed on each model category is shown in Table 5-1. In Table 5-1, 'Validation 1' represents the type of validation dataset obtained from a vehicle(s) with similar engine configuration. 'Validation 2' represents the validation dataset obtained from a vehicle tested under different test weight as used for the modeling purposes. 'Validation 3' represents the validation dataset obtained from a vehicle with a different engine configuration (for example, different engine rating) was used. It should be noted that each validation dataset was obtained only from the vehicles with the same category.

Table 5-1 Summary of type of validation performed on each model developed within a category

\begin{tabular}{|c|c|c|c|}
\hline $\begin{array}{c}\text { Category/Model } \\
\text { No. }\end{array}$ & Validation 1 & Validation 2 & Validation 3 \\
\hline 1 & $\bullet$ & & \\
\hline 2 & & $\bullet$ & \\
\hline 3 & $\bullet$ & & \\
\hline 4 & $\bullet$ & & $\bullet$ \\
\hline 5 & & & \\
\hline 6 & $\bullet$ & & \\
\hline 7 & $\bullet$ & & \\
\hline 8 & $\bullet$ & & \\
\hline 9 & $\bullet$ & & \\
\hline 10 & $\bullet$ & & \\
\hline 11 & $\bullet$ & & \\
\hline 12 & & & \\
\hline 13 & $\bullet$ & & \\
\hline 14 & $\bullet$ & & \\
\hline 15 & $\bullet$ & & \\
\hline
\end{tabular}

In this section, parity plots are presented to help visualize how well the models are able to make predictions based upon the validation data. An example of a parity plot is given for model 1 in Figure 5-1. The model predictions agreed very well with the observed values in the case of NOx emissions. As observed in Section 4.8.3 a goodness of fit analysis was performed 
with the validation dataset. The R-squared value of 0.9408 indicates that the model can explain 94 percent of the variability in NOx emissions with 95 percent confidence level. The slope of the trend line for NOx is 0.9438 , which is close to one. The lowest and the highest NOx g/s within a 95 percent confidence interval were 0.145 and 0.521 respectively. Thus the range of variation in observed emissions is of the order of 3.6. The model predicts, on average, a variation from 0.146 $\mathrm{g} / \mathrm{s}$ to $0.522 \mathrm{~g} / \mathrm{s}$, which is approximately a factor of 3.6. Therefore, from perspectives of the Rsquared, slope of the trend line, and variability captured by the model, it appears that this model is performing reasonably well.

In Figure 5-1, the prediction interval is also shown. The prediction interval is a 95 percent range of variability in the observed data that is not explained by the model predictions. The details on estimation of prediction interval can be found in literature [101]. The prediction interval should be used as an indication of the precision of the model when making predictions of emissions from individual vehicles.

The plot of model predicted $\mathrm{NO}_{\mathrm{x}}$ against observed $\mathrm{NO}_{\mathrm{x}}$ values for the validation data set for each of the models are given in Figure 5-1- Figure 5-13. The results indicate that the range of uncertainty in predictions is approximately $\pm 20 \%$ of the actual value.

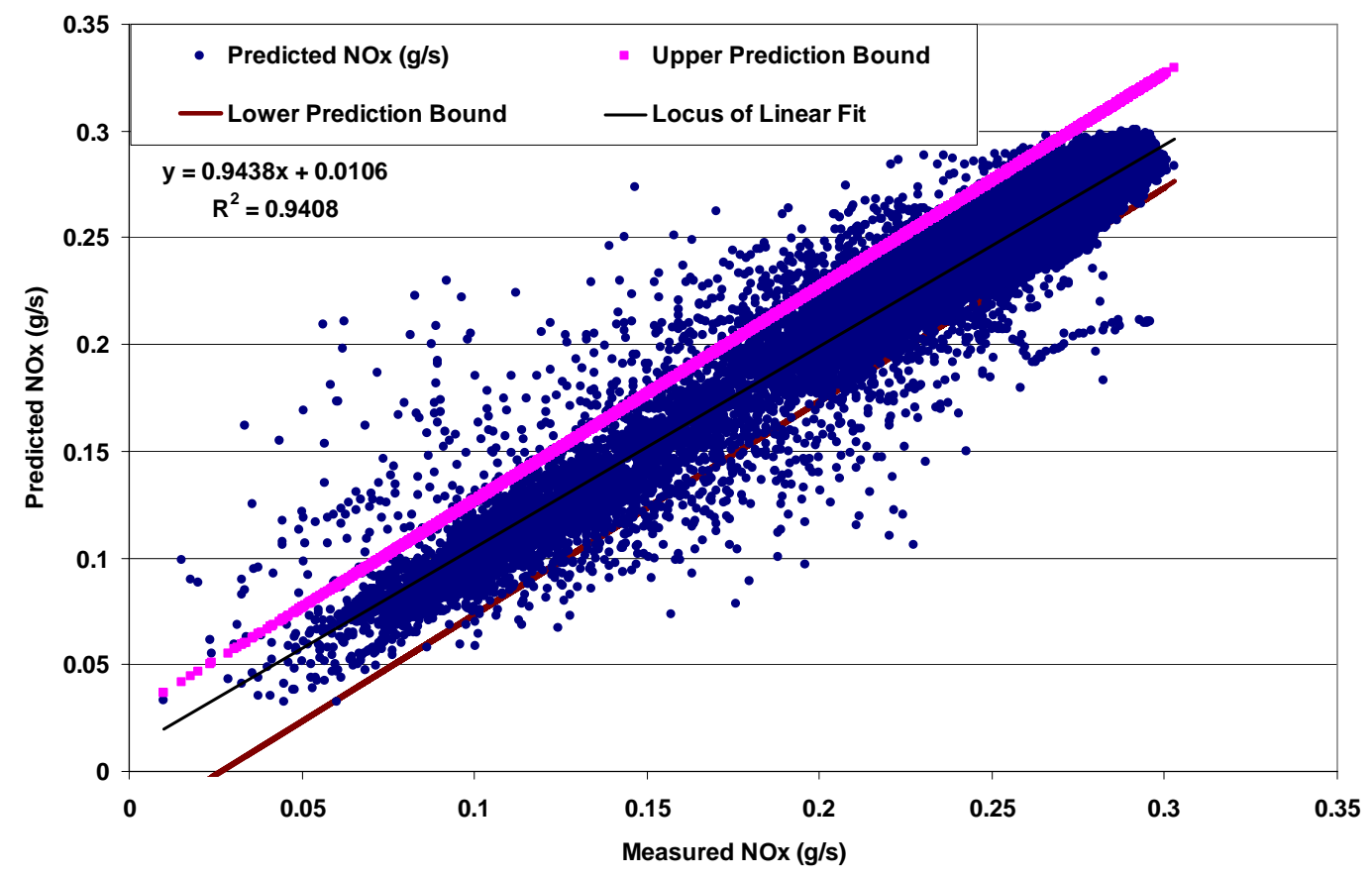

Figure 5-1 Observed vs. Predicted NOx Emissions with 95 \% Confidence Interval on the Individual Predictions Cat 31262001 Validation 1 


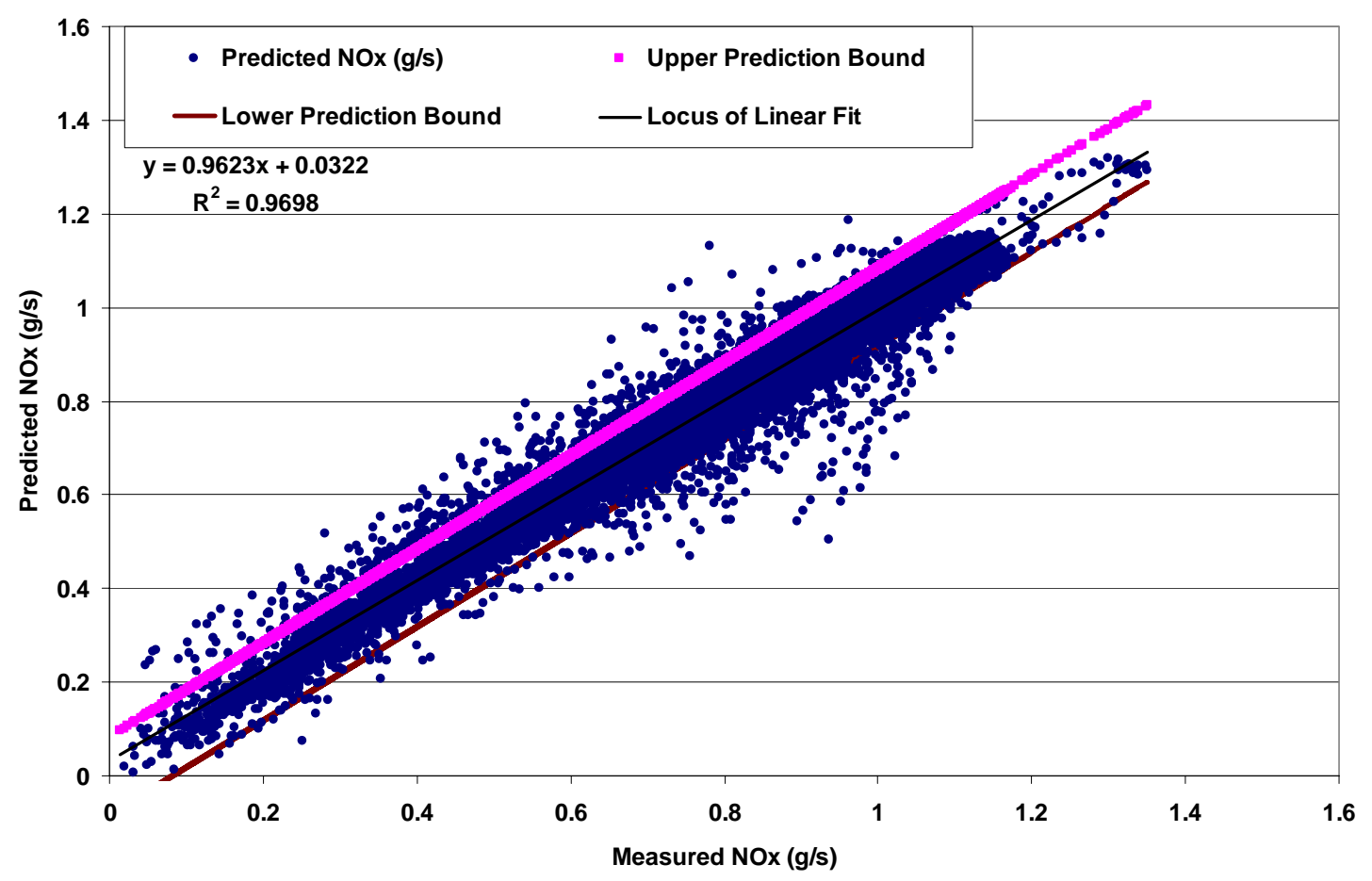

Figure 5-2 Observed vs. Predicted NOx Emissions with $95 \%$ Confidence Interval on the Individual Predictions Cat C16 Validation 1

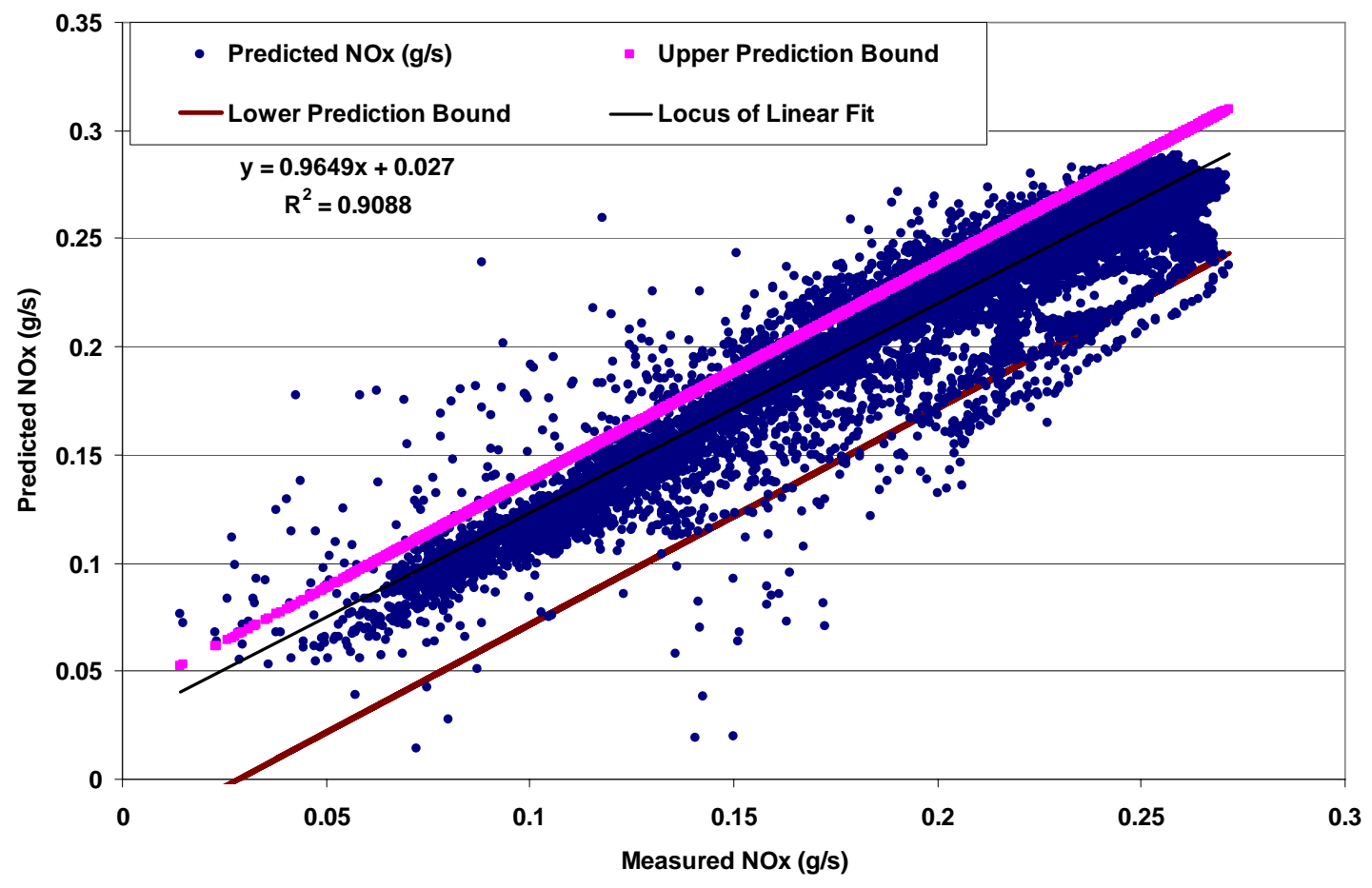

Figure 5-3 Observed vs. Predicted NOx Emissions with 95 \% Confidence Interval on the Individual Predictions Cat 31262002 Validation 1 


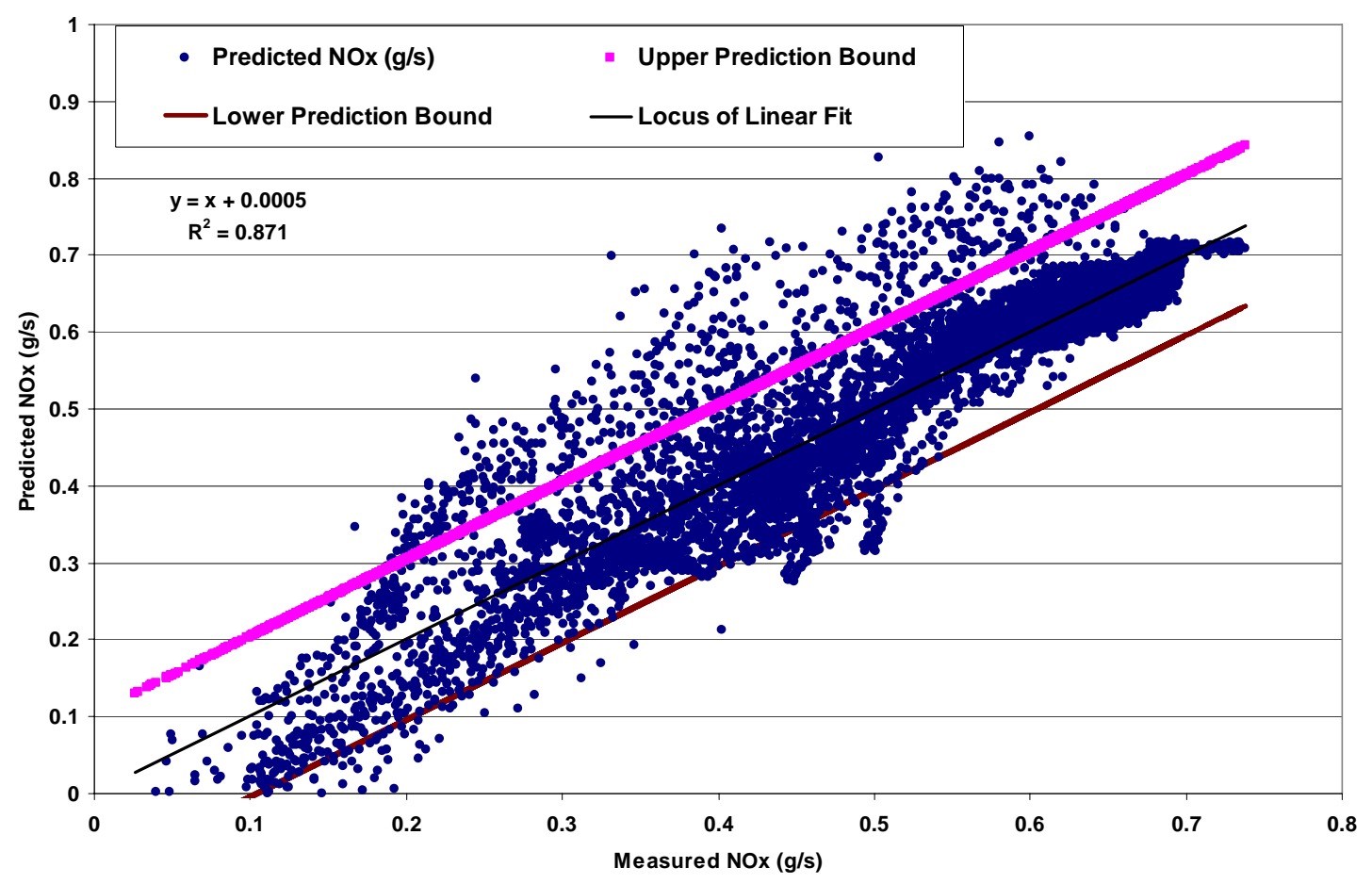

Figure 5-4 Observed vs. Predicted NOx Emissions with 95 \% Confidence Interval on the Individual Predictions Cat C10 2002 Validation 2

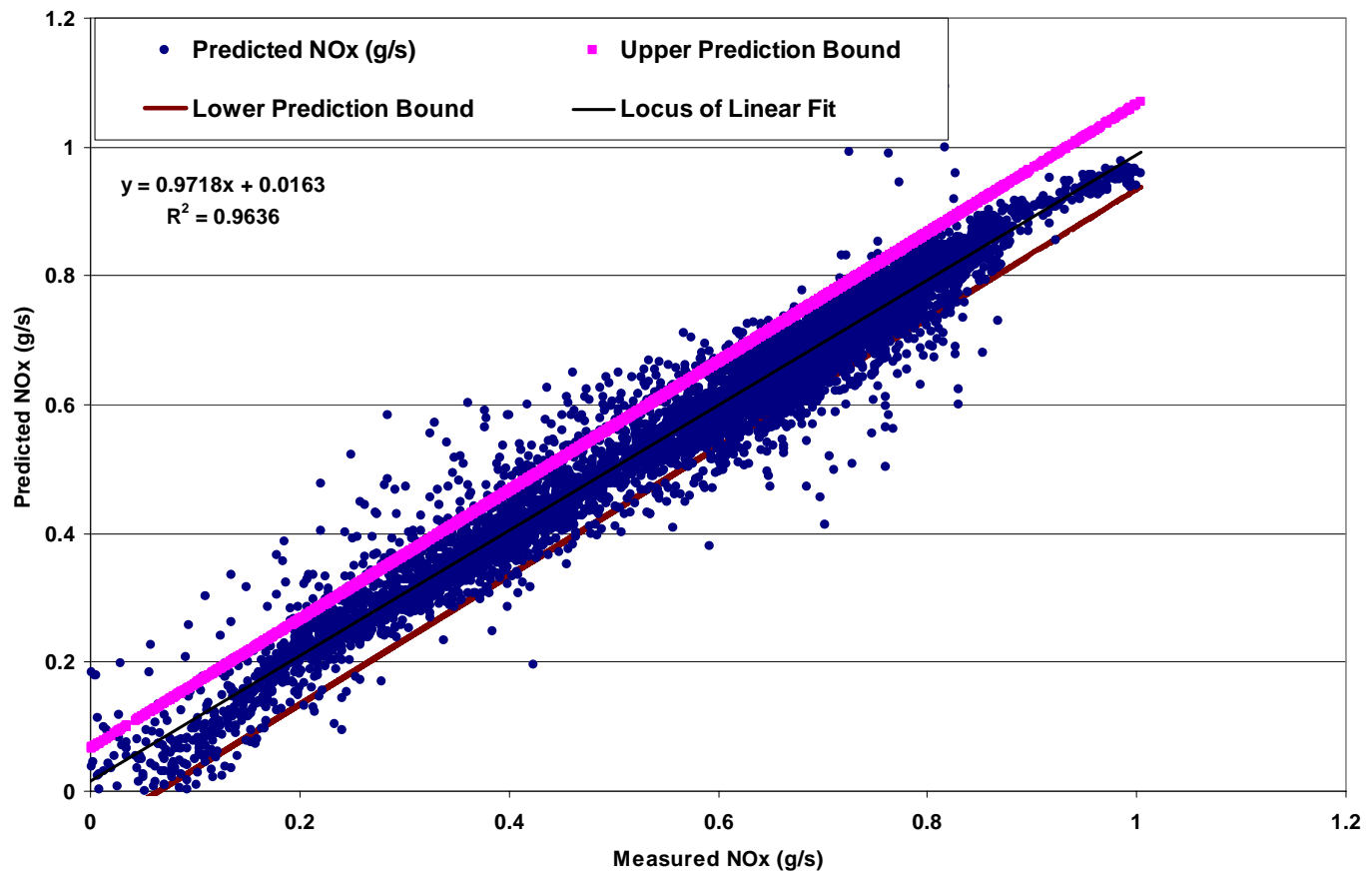

Figure 5-5 Observed vs. Predicted NOx Emissions with 95 \% Confidence Interval on the Individual Predictions Cat C15 2002 Validation 1 


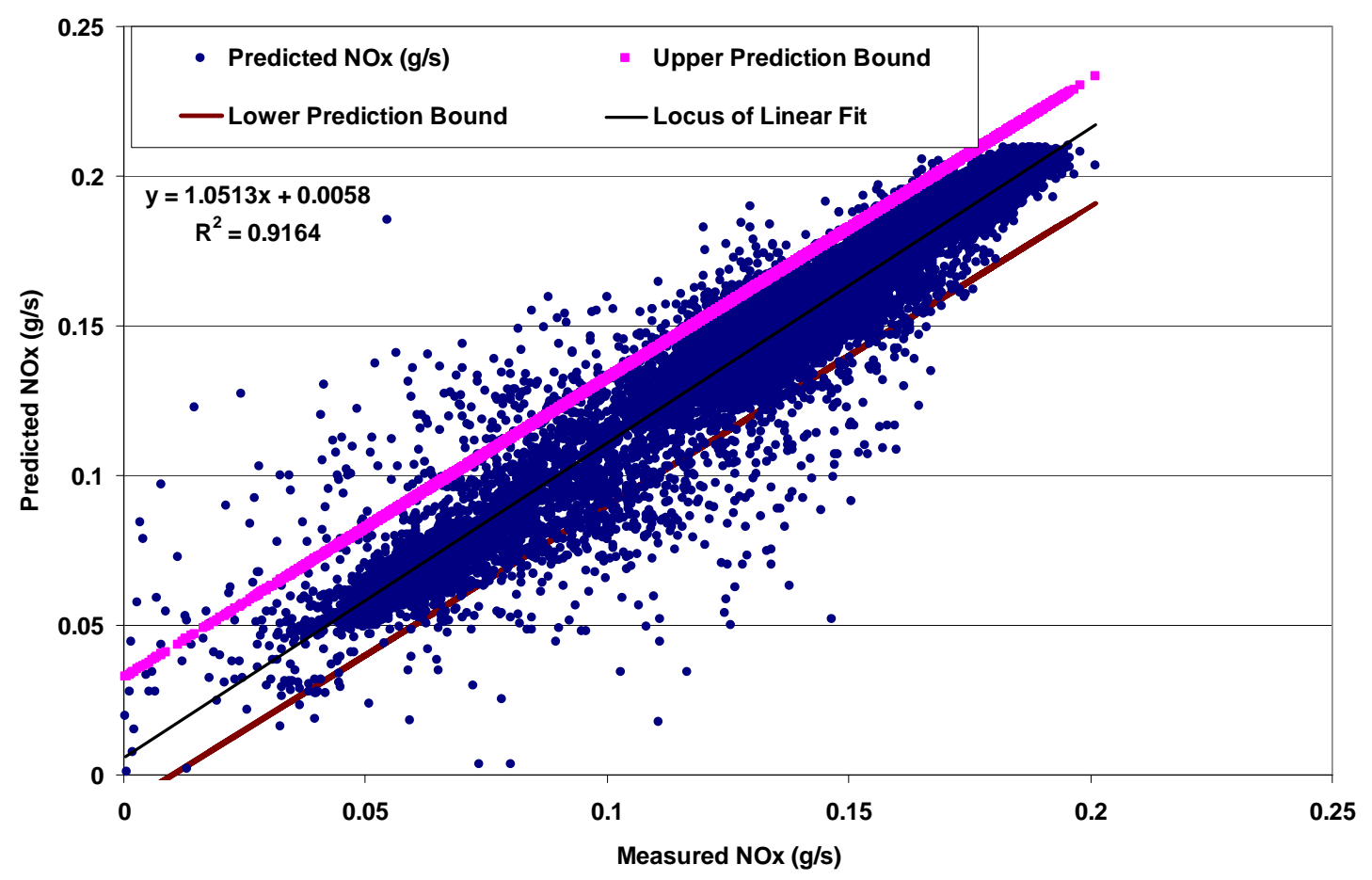

Figure 5-6 Observed vs. Predicted NOx Emissions with 95 \% Confidence

Interval on the Individual Predictions Cat 31262003 Validation 1

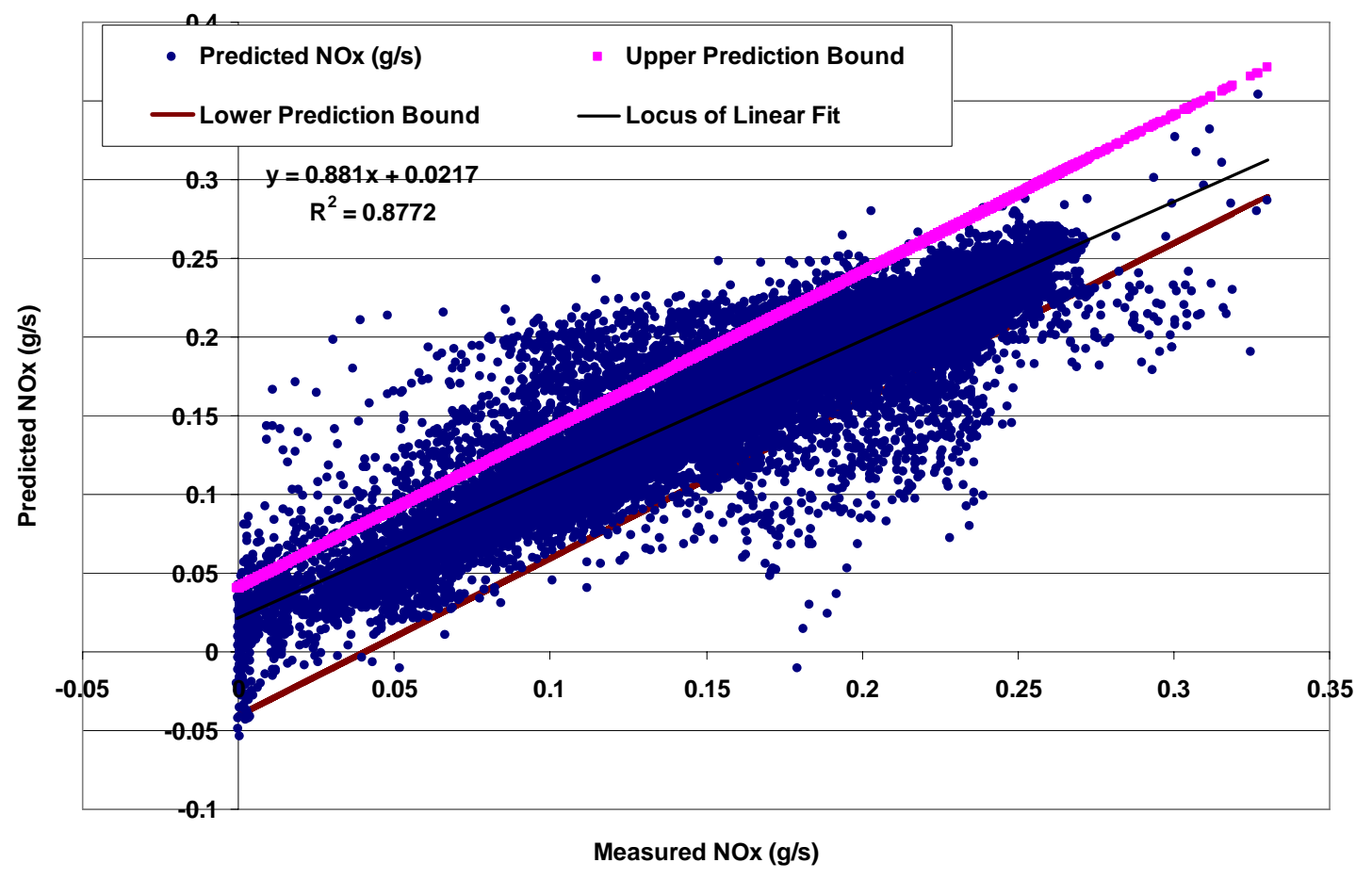

Figure 5-7 Observed vs. Predicted NOx Emissions with 95 \% Confidence Interval on the Individual Predictions Cat 2003 C9 Validation 1 


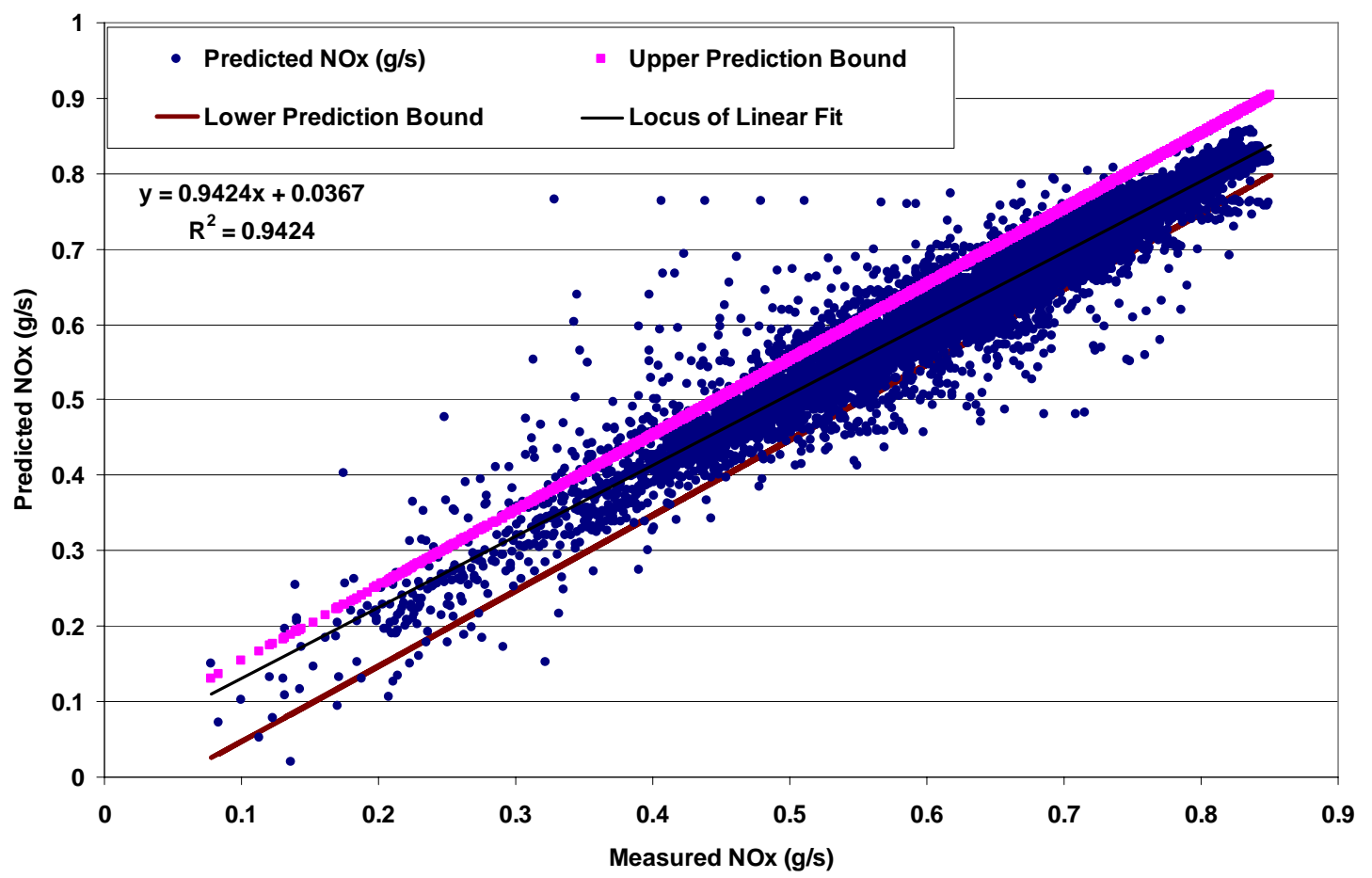

Figure 5-8 Observed vs. Predicted NOx Emissions with 95 \% Confidence Interval on the Individual Predictions Cat C15 2003 Validation 1

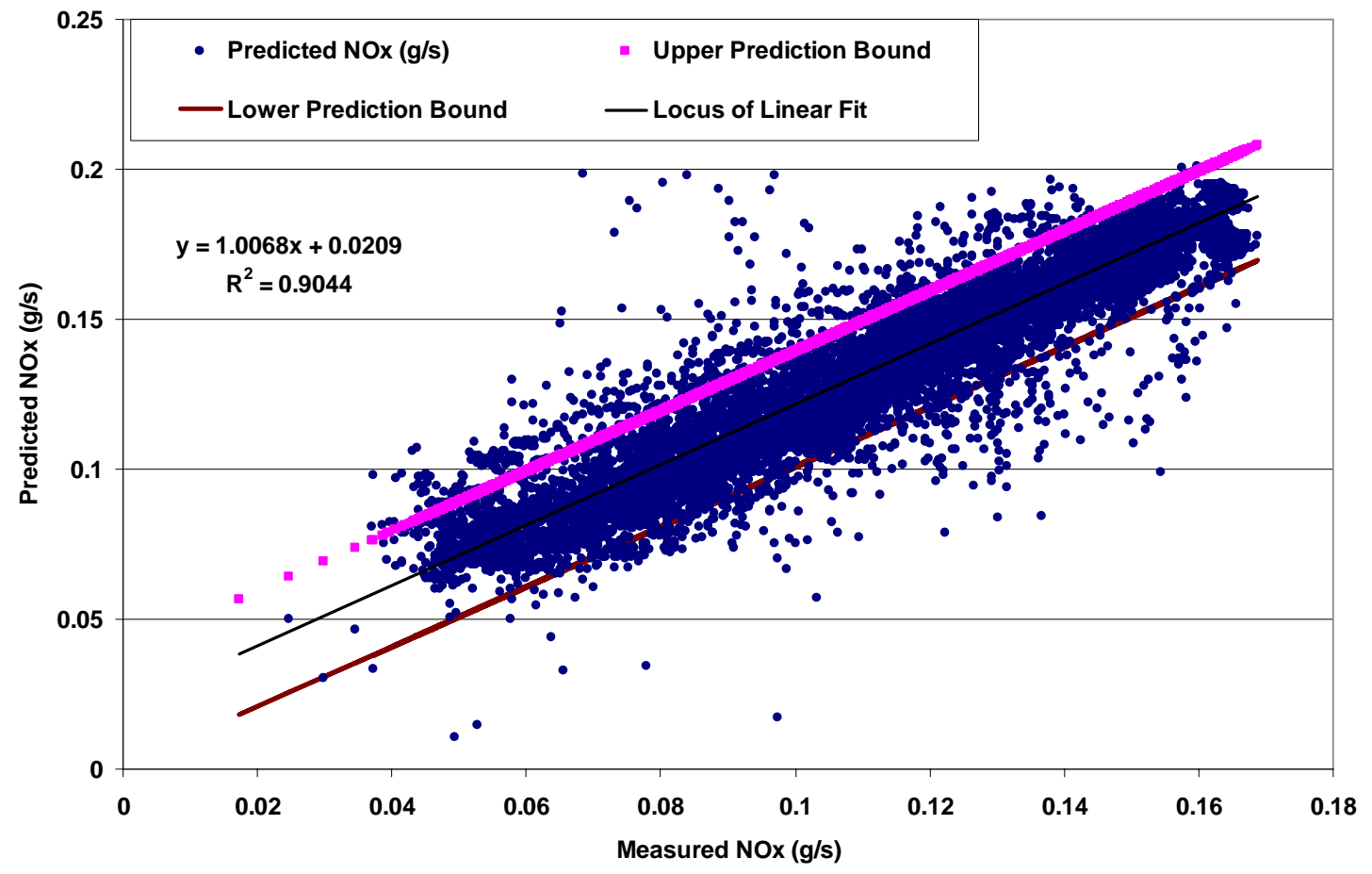

Figure 5-9 Observed vs. Predicted NOx Emissions with $95 \%$ Confidence Interval on the Individual Predictions Cummins ISB Validation 12001 


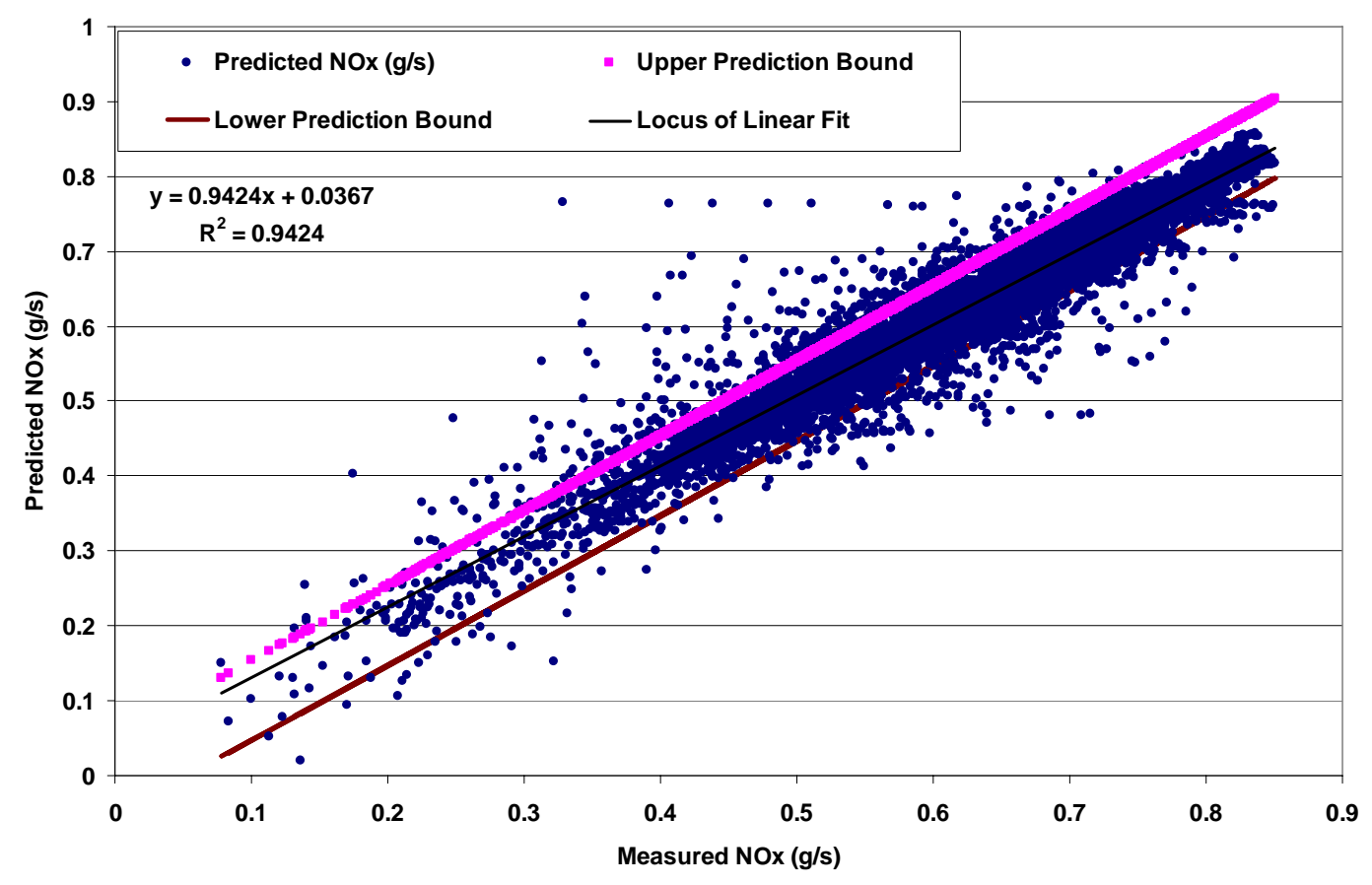

Figure 5-10 Observed vs. Predicted NOx Emissions with 95 \% Confidence Interval on the Individual Predictions Cummins ISC 2001 Validation 1

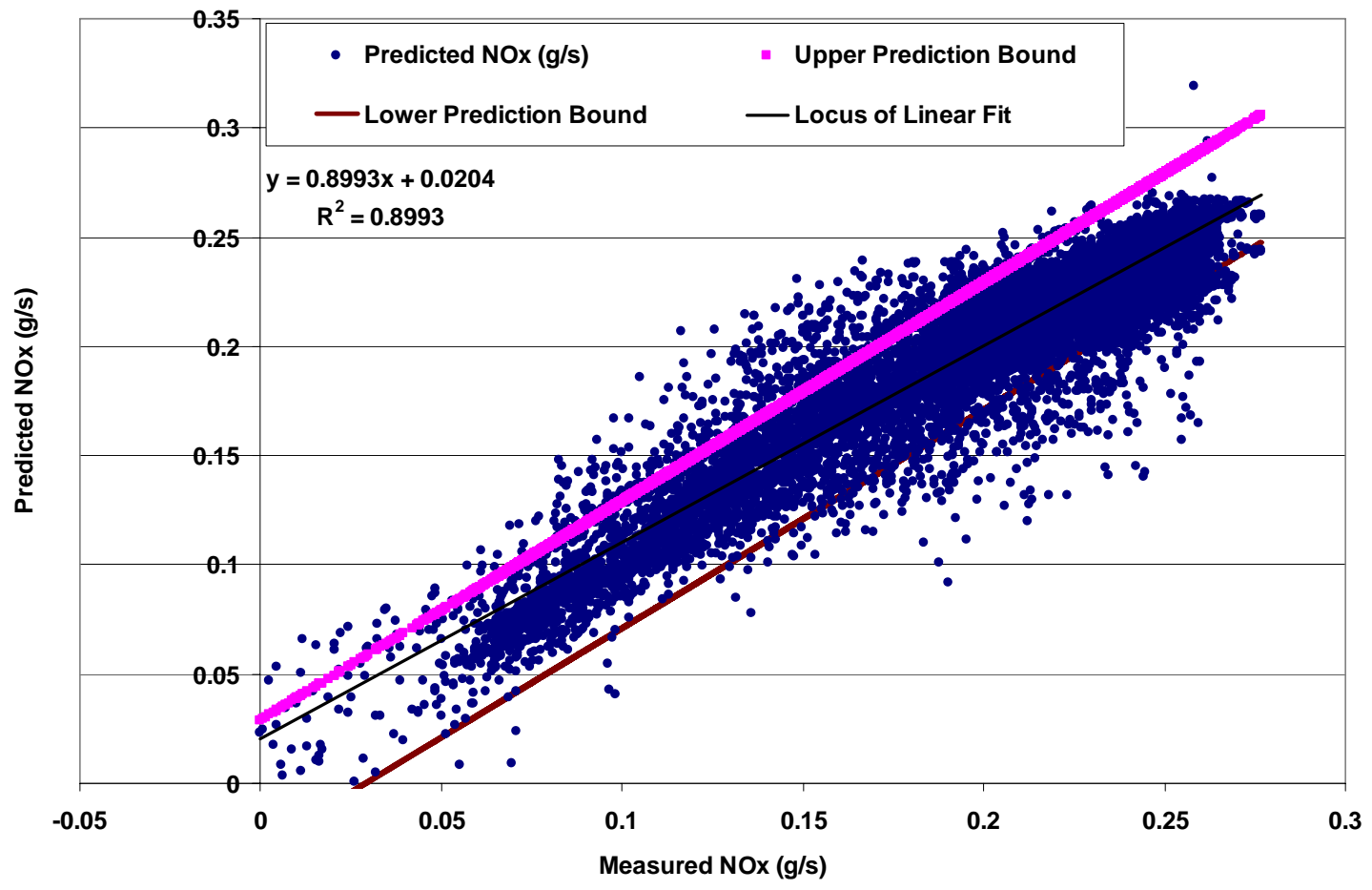

Figure 5-11 Observed vs. Predicted NOx Emissions with 95 \% Confidence Interval on the Individual Predictions Cummins ISB 2002 Validation 1 


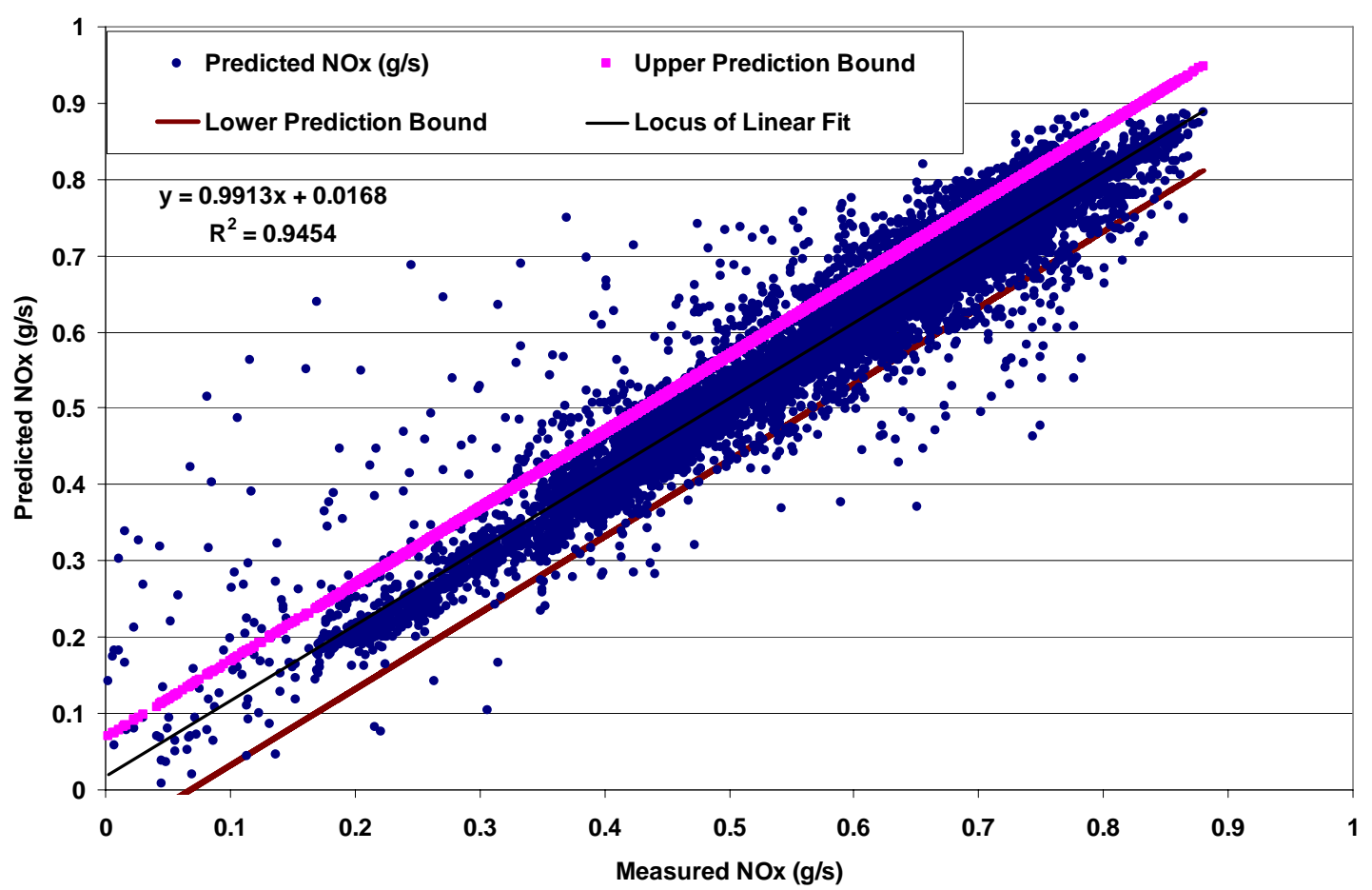

Figure 5-12 Observed vs. Predicted NOx Emissions with $95 \%$ Confidence Interval on the Individual Predictions Cummins ISX 2002 Validation1

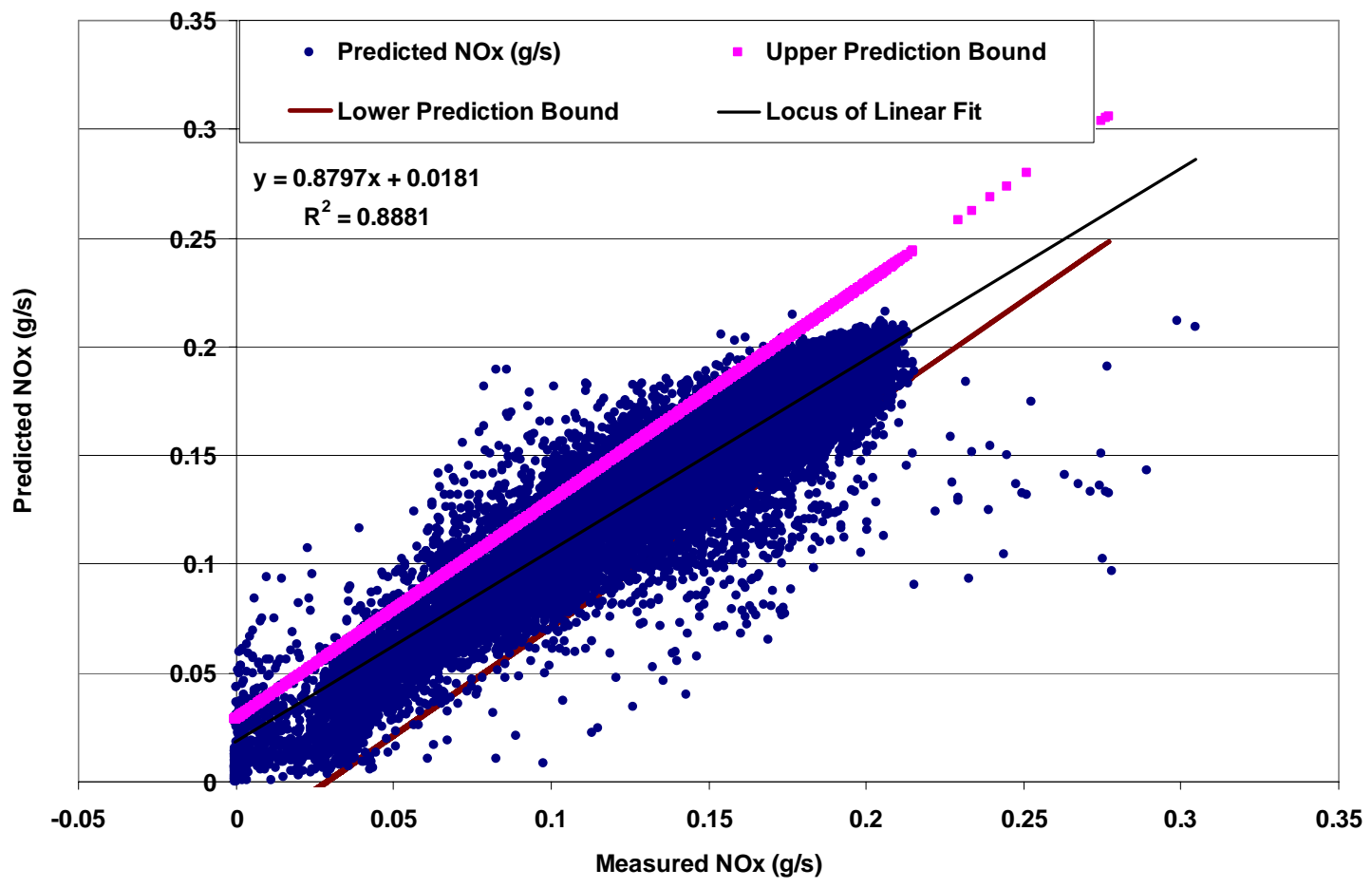

Figure 5-13 Observed vs. Predicted NOx Emissions with $95 \%$ Confidence Interval on the Individual Predictions Cummins ISB 2003 Validation 1 


\subsubsection{Variability in model output due to different engine ratings}

The effect of engine power rating on the emission and, in turn, on the model predictive capability has been studied. In category 4, the vehicles were powered by engines with ratings of $475 \mathrm{hp}$ and $515 \mathrm{hp}$. The calibration data set included data from vehicles powered by $475 \mathrm{hp}$ engine. The validation data set included data from vehicles powered by $515 \mathrm{hp}$ engine. The comparison of actual and predicted NOx for the validation data set (Validation 2) is given in Figure 5-14. These results indicate that the model can explain approximately $80 \%$ of the variability in the data, and that there is some bias in the model predictions. The bias can be corrected using the slope and intercept from the trend line to convert a model prediction more closely to match the observed emissions. The results of comparison between predicted NOx applied and actual NOx, after the correction was applied, is given in Figure 5-15. The author would like to warn the reader that the validation of this kind was done only on a particular engine model type and should not be generalized for other types of engines and engine configurations.

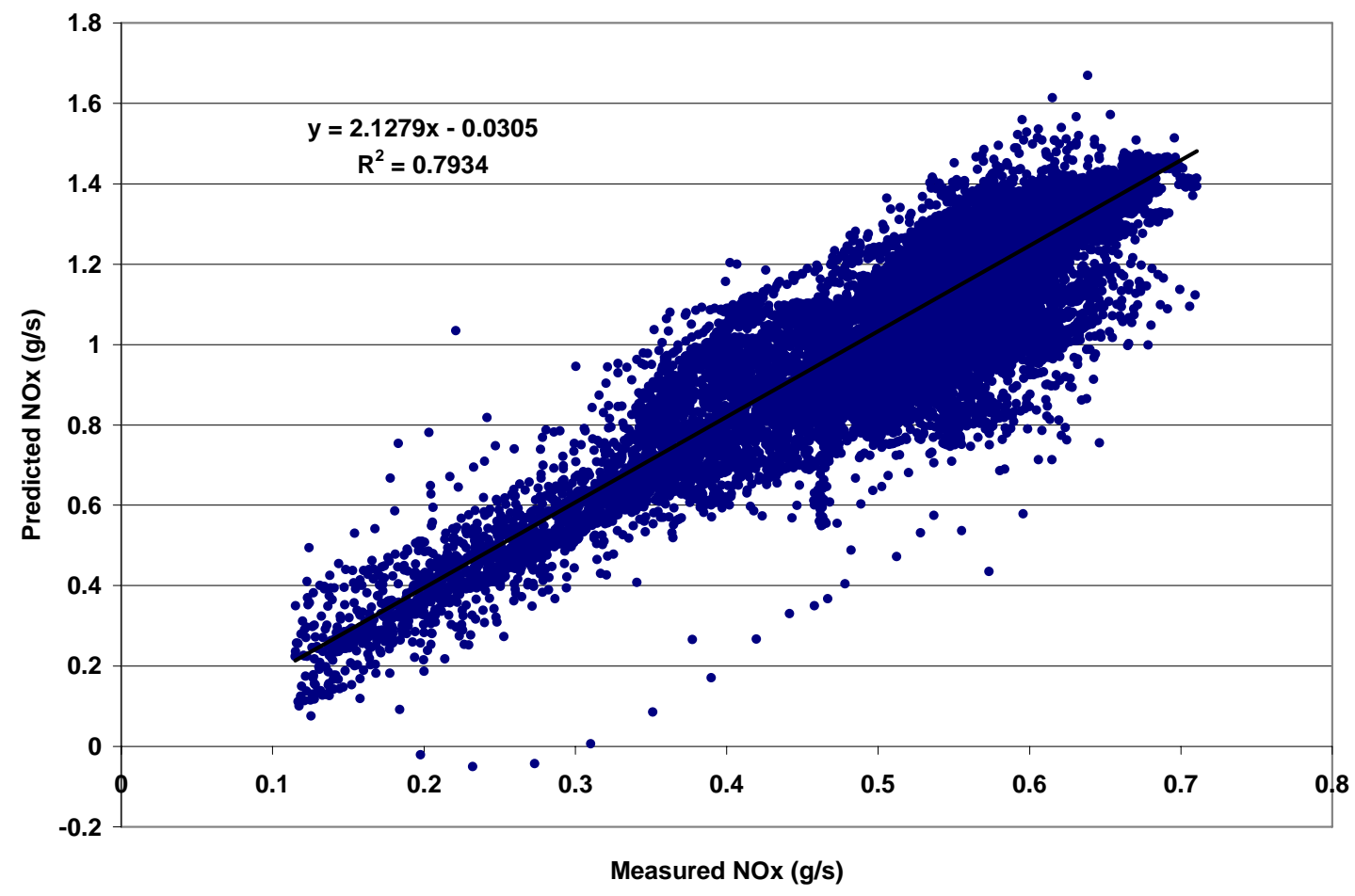

Figure 5-14 Parity plot for Validation type 2 showing bias 


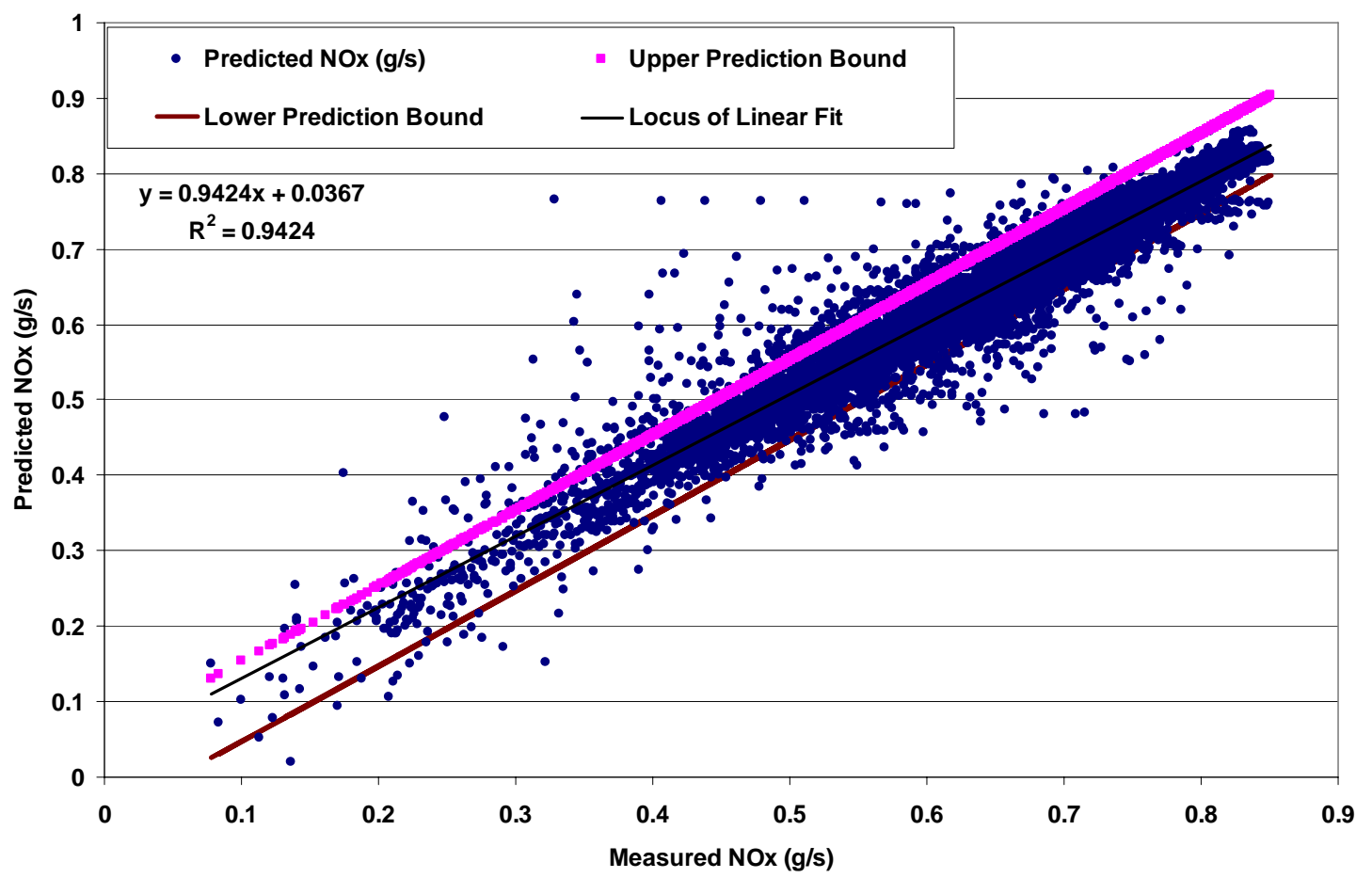

Figure 5-15 Observed vs. Predicted NOx Emissions with 95 \% Confidence

\section{Interval on the Individual Predictions Cummins N14 2001 Validation 2 (different hp)}

\subsubsection{Variability in model output due to test weight}

Test results show that the test weight had an impact on the emissions of $\mathrm{NO}_{\mathrm{x}}(\mathrm{g} / \mathrm{s})$. The calibration data set included data from vehicles with test weight $80 \mathrm{k}$ lb. The validation data set included data from vehicles with test weight of $60 \mathrm{k} \mathrm{lb}$. These results indicate that the model can explain approximately $90 \%$ of the variability in the data [as seen in Figure 5-16], and that there is some bias in the model predictions. The bias was corrected using the slope and intercept from the trend line to convert a model prediction more closely to match the observed emissions thereby reducing MSE and MAD. The results of comparison between predicted and actual NOx after the correction was applied is given in Figure 5-17. 


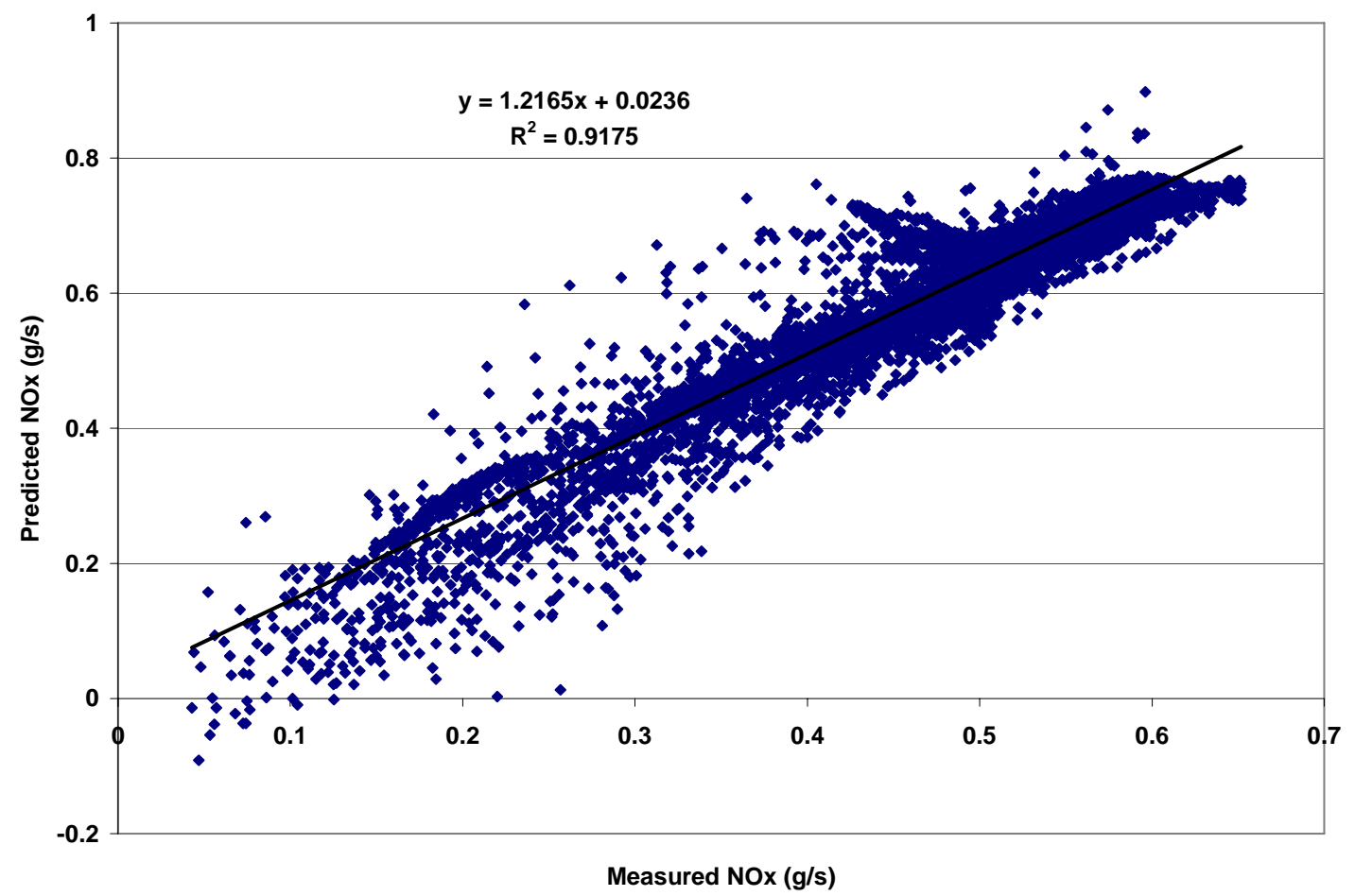

Figure 5-16 Cat C10 2001 Validation 2 different test weight showing bias

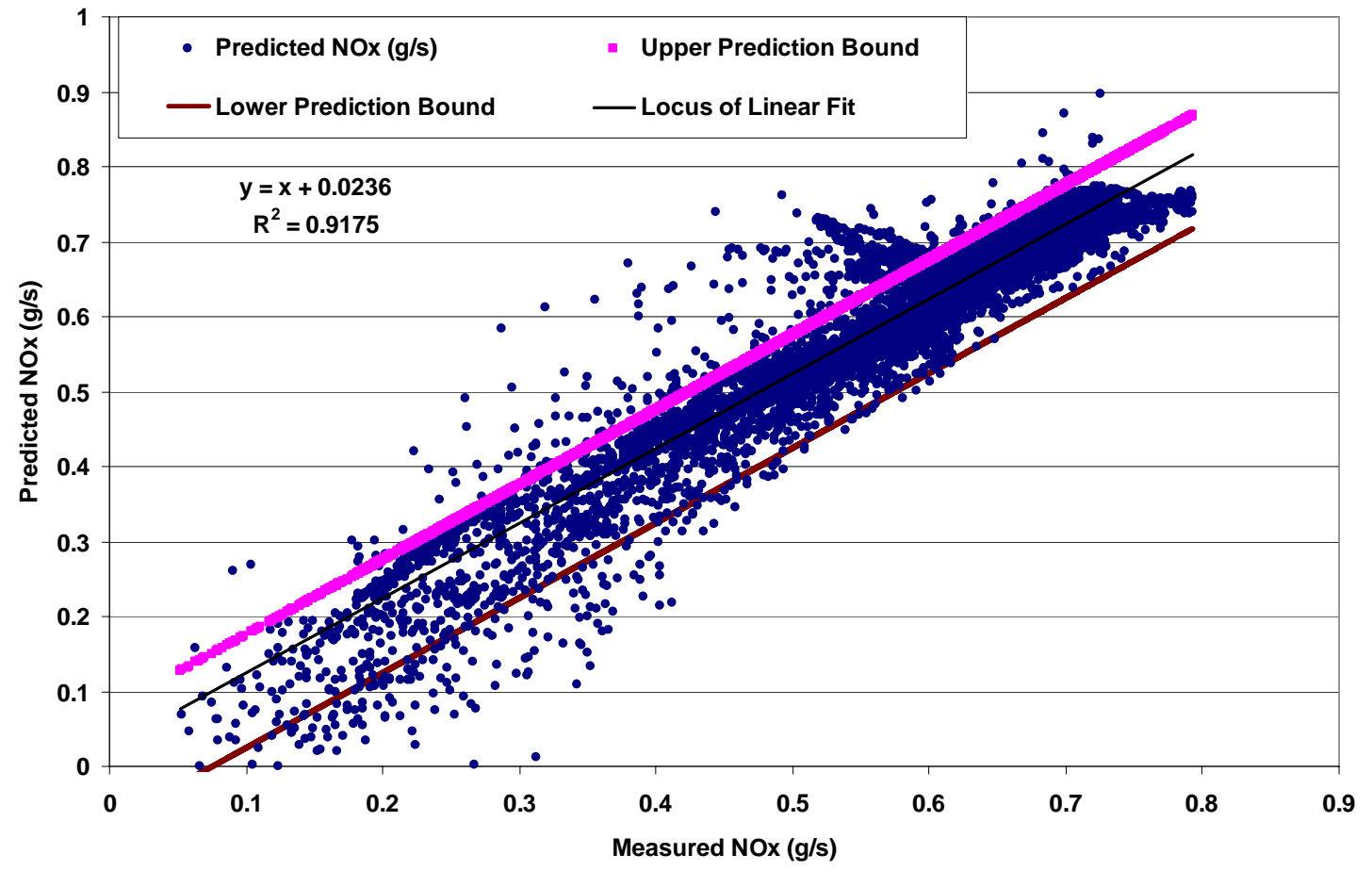

Figure 5-17 Cat C10 Validation 2 different test weight after correction for bias 


\subsection{Summary of Model Validation}

This chapter has illustrated the validation procedures employed on a model of real-world tailpipe NOx emissions for HDDV using data obtained from on-board measurements. The key steps in model development that were part of this study included the formation of a database from data reported by the on-board emissions, data quality assurance, exploratory analysis of the data, and fitting of a model to the data. The QA activities included searching for common types of errors that can occur when using on-board instruments. In some cases, data were excluded from the final database in order to prevent the inclusion of include known or suspected errors in the analysis and model calibration effort. 


\section{CONCLUSIONS AND RECOMMENDATIONS}

Emissions modeling for heavy-duty diesel vehicles requires a broad and substantial effort including coordination of planning, data collection, model development, documentation, and evaluation. This study has illustrated the major steps in the development of a real-world $\mathrm{NO}_{\mathrm{x}}$ emissions model of a heavy-duty diesel engine using data obtained from on-board measurements. The key steps in model development that were part of this study included the formation of a database from data collected using an on-board emissions measurement, exploratory analysis of the data, fitting of a model to the data, and evaluation of the developed models.

$\mathrm{NO}_{\mathrm{x}}$ emissions data along with engine operating parameters were collected using WVU's Mobile Emissions Measurement System while the test vehicle was operated on different routes. The routes selected were representative of operation under urban, suburban, and highway driving conditions. The data collected was processed and only data obtained when the engine was operating within NTE region as continuous 30s windows was used for further analysis. In this study, 60 different vehicles were tested with four vehicles of same engine model and model year. The model was developed using MARS employing the different variables chosen. With the emissions models now in place, it is capable of predicting emissions for a wide range of operating conditions for different vehicles. In the developed $\mathrm{HDD} \mathrm{NO}_{\mathrm{x}}$ emission model, secondby-second tailpipe emissions are modeled as a function of engine speed, engine load, MAP, MAT, coolant temperature, oil temperature, and vehicle speed. Statistical analysis was performed to determine the order of importance of these variables. The developed model was then validated using a validation data set that was different from the calibration data set.

Overall, the techniques applied to develop the illustrative conceptual model were useful

in screening the data, creating a data base, exploring the data base, developing the model, characterizing model performance, and quantifying the variability and uncertainty in model predictions. The model developed is first-of-kind; enabling it to account for the effect of engine operating parameters on NOx emissions. These techniques can be applied to larger datasets than were available in this work for the purpose of developing a nationally representative model of HDDV tailpipe emissions. Based on the research presented in this study, the following conclusions can be drawn: 
a) The current emissions models do not account for the variations in engine operating parameters and their effect on NOx emissions.

b) The emissions from engines of a particular model could vary significantly based on the engine rating. This variance is not accounted for in the current models used by the EPA. However, in this study, individual models were developed to account for these variations.

c) The models developed in this study, have been demonstrated to be valid for engine operation within the NTE region. Specifically, the error emission estimates were found to be approximately $\pm 20 \%$ for values within the $95 \%$ prediction limits of validation data.

\subsection{Applications}

The models developed can be used for different applications listed below:

a) The models developed can be used by regulatory agencies in understanding the effect of engine operation on NOx emissions. NOx emissions can be predicted for a particular zone of operation in the NTE region to identify differences in emission rates within different regions.

b) The model can be included into the engine control module and can be used in control of retrofitted after-treatment devices.

c) The models developed can be utilized in the area of sensor failure detection. The models would serve as a virtual sensor and would indicate an eventual sensor failure.

\subsection{Future Work}

When developing the HDD vehicle models, there was an attempt to capture many of the important aspects of vehicle and engine operation and their effect on tailpipe emissions. However, because the production of vehicle emissions is a complex process and dependent on many variables, it was impossible to model every aspect at a high level-of-detail. In addition, these models need to be updated periodically to properly represent the current vehicles in any given fleet. Future vehicle fleets will surely include new technologies that are not represented in this version of these HDD emission models. The following future work is recommended:

\subsubsection{Incorporation of New Vehicle/Technology Categories}

The advent of new emissions standards in 2007 are likely to force significant changes in total emissions and modal behavior of heavy-duty diesel trucks. In order to better estimate 
emission inventories in future years (e.g., 2007, 2010), additional vehicle/technology categories must be incorporated into the model.

\subsubsection{Additional Testing}

The relatively small number of vehicles tested in this program need to be augmented with additional tests. The additional testing should include different test weight, engine of different ratings and different model year engines. 


\section{REFERENCES}

1. “EPA: Air Emissions Trends-Continued Progress Through 2004," U.S. Environmental Protection Agency, Washington DC, August 18, 2005. See also: $<$ http://www.epa.gov/airtrends/2005/econ-emissions.html>

2. King, G. F., Mitchell, W. C., Squier, W. C., Harris, B. D., and Kinsey, J. S. "On-Road Facility to Measure and Characterize Emissions from Heavy-Duty Diesel Vehicles," Journal of the Air \& Waste Management Association, Volume 52, 388-395, April, 2002.

3. "Modeling Mobile Source Emissions,"National Academy Press, National Research Council, Washington, D.C, 2000.

4. Code of Federal Regulations, Title 40, Part 51, "Requirements For Preparation, Adoption, And Submittal Of Implementation Plans," Washington D.C, 2002.

5. "Expanding Metropolitan Highways: Implications for Air Quality and Energy Use," Special Report 245, Transportation Research Board, National Research Council: Washington, D.C, 1998.

6. Gibble, J. C., "Comparison of Heavy-Duty Diesel Engine Emissions Between an OnRoad Route and Engine Dynamometer Simulated On-Road Cycle," M.S Thesis, Department of Mechanical and Aerospace Engineering, West Virginia University, Morgantown, WV, 2003.

7. Frey, H. C., Unal, A., Rouphall, N. M., and Colyar, J. D. "On-Road Measurement of Vehicle Tailpipe Emissions Using a Portable Instrument," Journal of the Air \& Waste Management Association, Volume 53, 992-1002, August, 2003.

8. Kelly, N. A., and Groblicki, P. J., "Real-world emissions from a modern production vehicle driven in Los Angeles," Journal of the Air and Waste Management Association, Volume 43, 1351-1357, July, 1993.

9. "Control of Air Pollution from New Motor Vehicles: Proposed Heavy-Duty Engine and Vehicle Standards and Highway Diesel Fuel Sulfur Control Requirements," EPA, 40 CFR Parts 69, 80 and 86. June 2, 2000. 
10. Code of Federal Regulations, Title 40, Part 86 Subpart N, "Emission Regulations for New Otto-Cycle and Diesel Heavy-Duty Engines; Gaseous and Particulate Exhaust Test Procedures," Washington D.C, 1998.

11. "EPA: Development of Heavy-Duty NOx OFF-CYCLE Emissions Effects for MOBILE 6," U. S. Environmental Protection Agency, EPA420-R-02-004, Washington D.C, January, 2002.

12. Gautam, M., Clark, N. N., Thompson, G. J., Carder, D. K., and Lyons, D. W., "Evaluation of Mobile Monitoring Technologies for Heavy-Duty Diesel-Powered Vehicle Emissions," Phase I Report, Submitted to the Settling Heavy-Duty Diesel Engine Manufacturers by West Virginia University, Morgantown, WV, March 2000.

13. Gautam, M., Clark, N. N., Thompson, G. J., Carder, D. K., and Lyons, D. W., "Development of In-Use Testing Procedures for Heavy-Duty Diesel-Powered Vehicle Emissions," Phase II Report, Submitted to the Settling Heavy-Duty Diesel Engine Manufacturers by West Virginia University, Morgantown, WV, March 2000.

14. Gautam, M., Clark, N. N., Thompson, G. J., Carder, D. K., and Lyons, D. W., "Evaluation of In-Use Heavy-Duty Vehicle Emissions Using the Mobile Emissions Measurement System (MEMS)," Phase III Report, Submitted to the Settling Heavy-Duty Diesel Engine Manufacturers by West Virginia University, Morgantown, WV, December 2002.

15. Friedman, H., " Multivariate Adaptive Regression Splines," The Annals of Statistics, Vol. 19, No. 1, pp. 1-141, 1991.

16. Steinberg, D., “MARS User Guider," San Diego, CA: Salford Systerms, 2001.

17. Haerdle W., “Applied Nonparametric Regression," Cambridge University Press, Cambridge, MA, 1989.

18. Hastie, T., Tibshirani, R., and Friedman, J., "The Elements of Statistical Learning: Data Mining, Inference and Prediction,” Springer-Verlag, San Diego, CA, 2001.

19. Sephton, P., " Forecasting Recessions: Can We Do Better on $\mathrm{MARS}^{(\mathrm{TM})}$ ?," Federal Reserve Bank of St. Louis, March/April, 2001.

20. Das, D., "Interacting Models of Cooperative Gene Regulation," PNAS, Vol. 101, No. 46, pp. 16234-16239, November 16, 2004. 
21. Xu, Q.S, Massart, S., Liang, Y.Z., and Fang, K.T., "Two-step multivariate adaptive regression splines for modeling a quantitative relationship between gas chromatography retention indices and molecular descriptors," Journal of Chromatography, Vol. 998, No. 1-2, pp. 155-167, May 23, 2003

22. Zareipour, H., Bhattacharya, K., Canizares, C., "Forecasting the Hourly Ontario Energy Price by Multivariate Adaptive Regression Splines,” IEEE PES General Meeting, 18-22 June, 2006, Montreal, Quebec, Canada.

23. Barth, M., An, F., Norbeck, J., and M. Ross, "Modal Emissions Modeling: A Physical Approach,” Transportation Research Record, pp.1520:81-88, 1996

24. Barth, M., and J. Norbeck (1997), "NCHRP Project 25-11: The Development of a Comprehensive Modal Emission Model," Proceedings of the Seventh CRC On-Road Vehicle Emissions Workshop, Coordinating Research Council, Atlanta, GA, pp. 6.536.71 .

25. An, F., Barth, M., Ross, M., and Norbeck, J., "The Development of a Comprehensive Modal Emissions Model: Operating Under Hot-Stabilized Conditions," Transportation Research Record, pp.1587:52-62, 1997.

26. Barth, M., Younglove, T., Malcolm, C., and Scora, G., "Mobile Source Emissions New Generation Model: Using a Hybrid Database Prediction Technique," Prepared for EPA by College of Engineering- Center for Environmental Research and Technology, University of California, Riverside, CA, February, 2002.

27. Environmental Protection Agency, "User's Guide to MOBILE 6.1 and MOBILE 6.2," EPA420-R-03-010, Office of Mobile Sources, August 2003.

28. EPA's New Generation Mobile Source Emissions Model: Initial Proposal and Issues. U.S. Environmental Protection Agency, Ann Arbor MI, EPA420-R-01-007, April 2001.

29. Eyth, A., Hanisak, K., Pai, P., and Sepannen, C.; "New Generation Mobile Source Emissions Model: Model Use Cases, Model Graphical User Interface Design, and Model Object-Oriented Design," Prepared for EPA by MCNC Environmental Modeling Center, Research Triangle Park NC, February 11, 2002.

30. "NGM Object-Oriented Design," Revision 5, Prepared for EPA by Cimulus, Inc., Ann Arbor, MI, November 30, 2001. 
31. Sturm, P.J., Almbauer, R., Sudy, C., and Pucher, K., "Application of computational methods for the determination of traffic emissions," Journal of the Air \& Waste Management Association, Vol. 47, pp. 1204-1210, 1997.

32. Washington, S., Wolf, J., and Guensler, R., "A Binary Recursive Partitioning Method for Modeling Hot-stabilized Emissions from Motor Vehicles," 76th Annual Meeting, Transportation Research Board, Washington, D. C, 1997.

33. Traver, M. L., Atkinson, R. J., and Atkinson, C. M. (1999), "Neural Network-Based Diesel Engine Emissions Prediction using In-Cylinder Combustion Pressure," SAE Technical Paper Series, SAE 1999-01-1532, Warrendale, PA, 1999.

34. Jimenez-Palacios, J., "Understanding and Quantifying Motor Vehicle Emissions with Vehicle Specific Power and TILDAS Remote Sensing," PhD Thesis, Massachusetts Institute of Technology, Cambridge, MA, 1999.

35. Jimenez J. L., "Vehicle Specific Power: A Useful Parameter for Remote Sensing and Emissions Studies," Proceeding of the 9th CRC Conference, San Diego, CA, 1999.

36. Strehlow R. A., "Fundamentals of Combustion," International Textbook Company, 1984

37. Sierens, R. and Rosseel, E., "The Physical and the Chemical Part of the Ignition Delay in Diesel Engines," SAE Technical Paper No. 961123, Warrendale, PA, 1996.

38. Uludogan, A.D, Foster, D.E., and Reitz, R. D "Modeling the Effect of Engine Speed on the Combustion Process and Emissions in a DI Diesel Engine," SAE Technical Paper No. 962056, Warrendale, PA, 1996.

39. Frey, H. C., Unal, A., and Chen, J., "Recommended Strategy for On-Board Emission Data Analysis and Collection for the New Generation Model," Submitted by Department of Civil Engineering, North Carolina State University for Office of Transportation and Air Quality, U.S, EPA, Raleigh, NC, January, 2002.

40. Yu, L. and Qiao, F., "Collection and Evaluation of On-Road Vehicle Emission and Activity Data," Submitted to Texas Commissions for Energy and Quality by Texas Southern University for Houston Advanced Research Center, Houston, TX, April, 2004.

41. Grondin, O., Stobart, R., Chafouk, H., and Maquet, J., "Modeling the Compression Ignition Engine for Control: Review and Future Trends," SAE Technical Paper No. 200401-0423, Warrendale, PA, 2004. 
42. Caraceni, A., Cristofaro, D. F., Ferrara, F., Scala, S., and Philipp, O., "Benefits of Using a Real-Time Engine Model During Engine ECU Development," SAE Technical Paper No. 2003-01-1049, Warrendale, PA, 2003.

43. Nelles, O., "Non-Linear System Identification with Local Linear Neuro-Fuzzy Models," Ph.D Thesis submitted to Darmstadt University of Technology, Darmstadt, Germany, 1999.

44. He, Y. and Rutland, J. C., "Modeling of a Turbocharged DI Diesel Engine Using Artificial Neural Networks," SAE Technical Paper No. 2002-01-2772, Warrendale, PA, 2002.

45. Brahma, I. and Rutland, J. C., "Optimization of Diesel Engine Operating Parameters Using Neural Networks," SAE Technical Paper No. 2003-01-3228, Warrendale, PA, 2003.

46. Schoggl, P., Koegeler, H. M., Gschweitl, K., Kokal, H., Williams, P., Hulak, K., "Automated EMS Calibration using Objective Driveability Assessment and Computer Aided Optimization Methods," SAE Technical Paper No. 2002-01-0849, Warrendale, PA, 2002.

47. “Technology Licensing," Caterpillar Inc., Peoria, IL. See Internet Posting: www.cat.com.

48. Rask, E. and Sellnau, M., "Simulation-Based Engine Calibration: Tools, Techniques, and Applications," SAE Technical Paper No. 2004-01-1264, Warrendale, PA, 2004.

49. Qiang, H., Fuyuan, Y., Ming, Z., and Minggao, O., "Study on Modeling Method for Common-Rail Diesel Engine Calibration and Optimization," SAE Technical Paper No. 2004-01-0426, Warrendale, PA, 2004.

50. Himer, Z., Wertz, V., Kovacs, J., and Kortela, U., "Control of Combustion Base On Neuro-Fuzzy Model," Proceedings of the IASTED International Conference on Modeling Identification and Control, Geindelwald, Switzerland, 2004.

51. Emissions Standards: USA - Heavy Duty Truck and Bus Engines, www.dieselnet.com, EcoPoint Inc., May 2003.

52. "Notice of Filing of Consent Decree under the Clean Air Act," Federal Register, Vol 63, No. 212, Office of the Federal Register, National Archives and Records Administration, Washington D.C, November 3, 1998. 
53. Thompson, G., Gautam, M., Clark, N., and Lyons, D., "Inference of Torque and Power From Heavy-Duty Diesel Engines for On-Road Emissions Monitoring,” SAE Technical Paper No. 2002-01-0614, Warrendale, PA, 2002.

54. Krishnamurthy, M., "Characterization of In-Use Emissions from On-Highway HeavyDuty Diesel Engines," M.S Thesis, Department of Mechanical and Aerospace Engineering, West Virginia University, Morgantown, WV, December, 2003.

55. Chan, L., Carlson, D. H., and Johnson, J. H., "Evaluation and Application of a Portable Tailpipe Emissions Measurement Apparatus for Field Use," SAE Technical Paper No. 921647, Warrendale, PA, 1992.

56. Spears, M. W., “An Emissions-Assisted Maintenance Procedure for Diesel-Powered Equipment," University of Minnesota, Center for Diesel Research, Minneapolis, MN, 1997.

57. Englund, M. S., "Field Compatible $\mathrm{NO}_{\mathrm{x}}$ Emission Measurement Technique," SAE Technical Paper No. 820647, Warrendale, PA, 1982.

58. Human, D. M., and Ullman, T. L., "Development of an I/M Short Emissions Test for Buses," SAE Technical Paper No. 920727, Warrendale, PA, 1992.

59. Bentz, A. and Weaver, E., "Marine Diesel Exhaust Emissions Measured By Portable Instruments," SAE Technical Paper No. 941784, Warrendale, PA, 1994.

60. Bruneel, H., "Heavy Duty Testing Cycles Development: a New Methodology," SAE Technical Paper No. 2000-01-1860, Warrendale, PA, 2000.

61. "Construction Equipment Retrofit Project," Northeast States for Coordinated Air Use Management, Boston, MA, 1998.

62. Butler, J. W. Korinski, T.J., Reading, A. R., and Kotenko, T. L, "Dynamometer Quality Data On-Board Vehicles for Real-World Emissions Measurements," Proceedings of the Ninth CRC On-Road Vehicle Workshop, April 19-21, San Diego, CA, 1999.

63. Vojtisek-Lom, M. and Cobb, J. T., "Measuring On-Road Heavy-Duty Vehicle Emissions using a Portable On-Board System," Proceedings of the Ninth CRC On-Road Vehicle Workshop, April 19-21, San Diego, CA, 1999.

64. Vojtisek-Lom, M. and Cobb, J. T., "On-Road Light-Duty Vehicle Mass Emission Measurements using a Novel Inexpensive On-Board Portable System," Proceedings of the Ninth CRC On-Road Vehicle Workshop, April 20-22, San Diego, CA, 1998. 
65. Scarbro, C. “ An Investigation of Rover's Capabilities to Accurately Measure the In-use Activity and Emissions of Late-Model Diesel and Gasoline Trucks," Proceedings of the $10^{\text {th }}$ CRC On-Road Vehicle Emissions Workshop, San Diego, CA; Coordinating Research Council: Atlanta, GA, 2000.

66. Jetter, J., Maeshiro, S., Hatcho, S., and Klebba, R., "Development of An On-Board Analyzer for Use on Advanced Low-Emission Vehicles," SAE Technical Paper No. 2000-01-1140, Warrendale, PA, 2000.

67. Reading, A., "Technical Advances in Portable Emission Measurement Systems," Proceedings of the Government/Industry Meeting, Washington D.C., May 12-14, 2003.

68. Miyazaki, T., Takada, Y., and Lida, N., "Development of On-Board System to Measure Running Condition and Actual $\mathrm{NO}_{\mathrm{x}}$ Emissions from Freight Vehicle," SAE Technical Paper No. 2002-01-0613, Warrendale, PA, 2002.

69. Nakamura, H., Kihara, H., Adachi, M., and Ishida, K., "Development of a Wet-Based NDIR and Its Application to On-Board Emission Measurement System," SAE Technical Paper No. 2002-01-0612, Warrendale, PA, 2002.

70. Kihara, N., Tsukamoto, T., Matsumoto, K., Ishida, K., Kon, M., and Murase, T., "RealTime, On-Board Measurement of Mass Emission of $\mathrm{NO}_{\mathrm{x}}$, Fuel Consumption, Road Load, and Engine Output for Diesel Vehicles," SAE Technical Paper No. 2000-01-1141, Warrendale, PA, 2000.

71. Pankratz, D., Johnson, K.C, Smith, M.R, Welch, W.A., Norbeck, J.M, “Develop OnRoad System for Emissions Measurement from Heavy-Duty Trucks," Final Report submitted to South Coast Air Quality Management District, Diamond Bar, CA, May 31, 2001.

72. Miller, J. W., Cocker, D., Johnson, K.C., Park, C. S., Welch, W. A., Norbeck, J. M., “Use of a Mobile Laboratory to Measure HDD Real World Emissions from a Number of Standard and Non-Standard Cycles," Proceeding of the 12th CRC On-Road Vehicle Emissions Workshop, San Diego, CA, April 15-17, 2002.

73. Miller, J. W., Cocker, D., Johnson, K.C.,Shah, S., Norbeck, J. M., "Measuring 'Real World' Heavy-Duty Diesel Emissions with a Mobile Lab," Proceedings of the 8th Diesel Engine Emissions Reduction (DEER) Conference. San Diego, CA, August 29, 2002. 
74. Thompson, G., Gautam, M., Clark, N., Carder, D. K., Riddle, W., Shade, B., and Lyons, D., "Measurement of In-Use, On-Board Emissions from Heavy-Duty Diesel Vehicles: Mobile Emissions Measurement System," SAE Technical Paper No. 2001-01-3643, Warrendale, PA, 2001.

75. Czachura, B., Brandon, L., May, Al., "Demonstration of the "Simple, Portable, OnVehicle Testing' (SPOT) System on a Class 8 Vehicle," Proceedings of the $11^{\text {th }}$ On-road Vehicle Emissions Workshop, San Diego, CA, 2001.

76. Jimenez, J. L., Mcrae, G. J., Nelson, D. D., Zahniser, M. S., and Kolb, C. E., “ Final Report: Remote Sensing of $\mathrm{NO}$ and $\mathrm{NO}_{2}$ Emissions from Heavy-Duty Diesel Trucks Using Tunable Diode Lasers," National Center for Environmental Research, EPA Grant No. R824794, Washington D.C., 1998.

77. Weaver, C. S., and Balam-Almanza, M. V., "Development of the "RAVEM" Ride-Along Vehicle Emission Measurement System for Gaseous and Particulate Emissions," SAE Technical Paper No. 2001-01-3644, Warrendale, PA, 2001.

78. Weaver, C. S., Chan, L. and Peety, L. "Measurement of Air Pollutant Emissions From InService Passenger Ferries," Engine, Fuel and Emissions Engineering, Inc., Emissions data report submitted to San Francisco Bay Area Water Transit Authority, San Franscisco, CA, 2002.

79. Vojtisek-Lom, M., Lambert, D. C., Wilson, J., "Real-World Emissions From 40 HeavyDuty Diesel Trucks Recruited At Tulare, CA, Rest Area," SAE Technical Paper No. 2002-01-2901, 2002.

80. Vojtisek-Lom, M. and Allsop, J. E., "Development of Heavy-Duty Diesel Portable, OnBoard Mass Exhaust Emissions Monitoring System With $\mathrm{NO}_{\mathrm{x}}, \mathrm{CO}_{2}$ and Qualitative PM Capabilities," SAE Technical Paper No. 2001-01-3641, 2001.

81. Frey, H.C. and Eichenberger, D. A., "Remote Sensing of Mobile Source Air Pollutant Emissions: Variability and Uncertainty in On-Road Emissions Estimates of Carbon Monoxide and Hydrocarbons for School and Transit Buses," FHWY/NC/97-005, Prepared by North Carolina State University for North Carolina Department of Transportation, Raleigh, 1997.

82. Frey, H.C., Bharvirkar, R., and Zheng, J., "Quantification of Variability and Uncertainty in Emission Factors," Paper No. 99-267, Proceedings of the 92nd Annual Meeting (held 
June 20-24 in St. Louis, MO), Air and Waste Management Association, Pittsburgh, Pennsylvania, 1999.

83. Frey, H.C., Rouphail, N. M., Unal, A., and Colyar, J., "Measurement of On-Road Tailpipe CO, NO, and Hydrocarbon Emissions Using a Portable Instrument," Proceedings, Annual Meeting of the Air \& Waste Management Association, Pittsburgh, PA, 2001.

84. Yu, L. and Qiao, F., "Collection and Evaluation of On-Road Vehicle Emission and Activity Data," Submitted by Texas Southern University for Houston Advanced Research Center, Houston, TX, April, 2004.

85. Hawirko, J. D. and Checkel, D. M., "Real-Time, On-Road Measurement of Driving Behavior, Engine Parameters and Exhaust Emissions," SAE Technical Paper No. 200201-1714, Warrendale, PA, 2002.

86. Miyazaki, T., Takada, Y., and Lida, N., "Development of On-Board System to Measure Running Condition and Actual $\mathrm{NO}_{\mathrm{x}}$ Emissions from Freight Vehicle," SAE Technical Paper No. 2002-01-0613, Warrendale, PA, 2002.

87. Brodrick, C.J., Laca, E., Farshchi, M., and Dwyer H.A., "Effect of On-Road Loads on Gaseous Emissions from a Modern Heavy-Duty Diesel Truck," Transportation Research Record, Washington D.C., 2002.

88. Brodrick, C.J., Laca, E., Farshchi, M., and Dwyer H.A., "Gaseous Emissions from Idling Heavy-Duty Diesel Truck Engines," Journal of the Air \& Waste Management Association, Volume 52, 174-182, September, 2002.

89. "Diamond II+ Annubar Flow Element- Product Data sheet-00813-0100-4760, DS-4009," Dietrich Standard Inc., Boulder, CO, 80301.

90. "Powertrain Control Interface for Electronic Controls Used in Medium and Heavy Duty Diesel On-Highway Vehicle Applications," SAE Standard, SAE J1922, Warrendale, PA,1989.

91. "Joint SAE/TMC Electronic Data Interchange Between Microcomputer Systems in Heavy-Duty Vehicle Applications," SAE Standard, SAE J1587, Warrendale, PA,1996. 92. “Vehicle Application Layer,” SAE Standard, SAE J1939/71, Warrendale, PA,1996. 
93. Krishnamurthy, M. and Gautam, M., "Quality Assurance of Exhaust Emissions Measured Using Mobile Emissions Measurement System," SAE Technical Paper No. 2005-013799, Warrendale, PA, 2005.

94. Frey, H.C., "Variability and Uncertainty in Highway Vehicle Emission Factors," Emission Inventory: Planning for the Future (held October 28-30 in Research Triangle Park, NC), Air and Waste Management Association, Pittsburgh, Pennsylvania, pp. 208219, 1997.

95. Barth, M., Younglove, T., Wenzel, T., Scora, G., An, F., Ross, M., and Norbeck, J., "Analysis of Modal Emissions from a Diverse In-Use Vehicle Fleet," Transportation Research Record, 1587:73-84, 1997.

96. Morgan, M.G. and Henrion, M., (1990), "Uncertainty," Cambridge University Press, New York, 1990.

97. Taylor, N. B. and Kuyatt, E. C. "Guidelines for Evaluating and Expressing the Uncertainty of NIST Measurement Results," National Institute of Standards and Technology, Technical Note 1297, Washington D.C.,1994.

98. "Test Uncertainty," The American Society of Mechanical Engineers, ASME PTC 19.1, 1998.

99. Velosa, J., "Error Analysis of the Vehicle Exhaust Emission Measurement System," SAE Technical Paper No. 930393, Warrendale, PA,1993.

100. De Veaux, R. and Ungar, H., "A Comparison of Two Non-Parametric Estimation Schemes: MARS and Neural Networks." Comp. Chemical. Engineering, Vol 17, pp 819$837,1993$.

101. Neter, J., Kutner, M.H., Nachtsheim, C.J., and Wasserman, W., "Applied Linear Statistical Models,” WCB/McGrawHill, 4th edition, New York,1996. 
APPENDIX A BASIS FUNCTIONS AND MODEL 


\section{MODEL 31262001 CATERPILLAR}

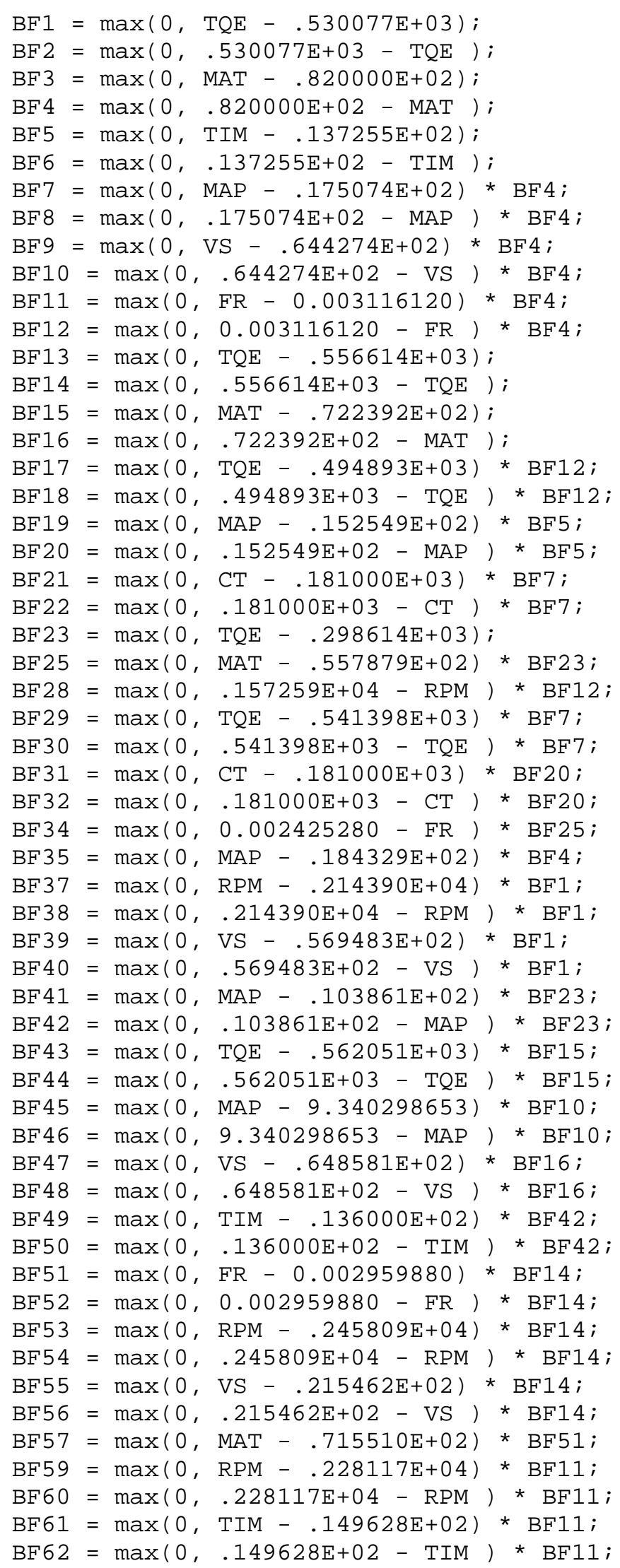




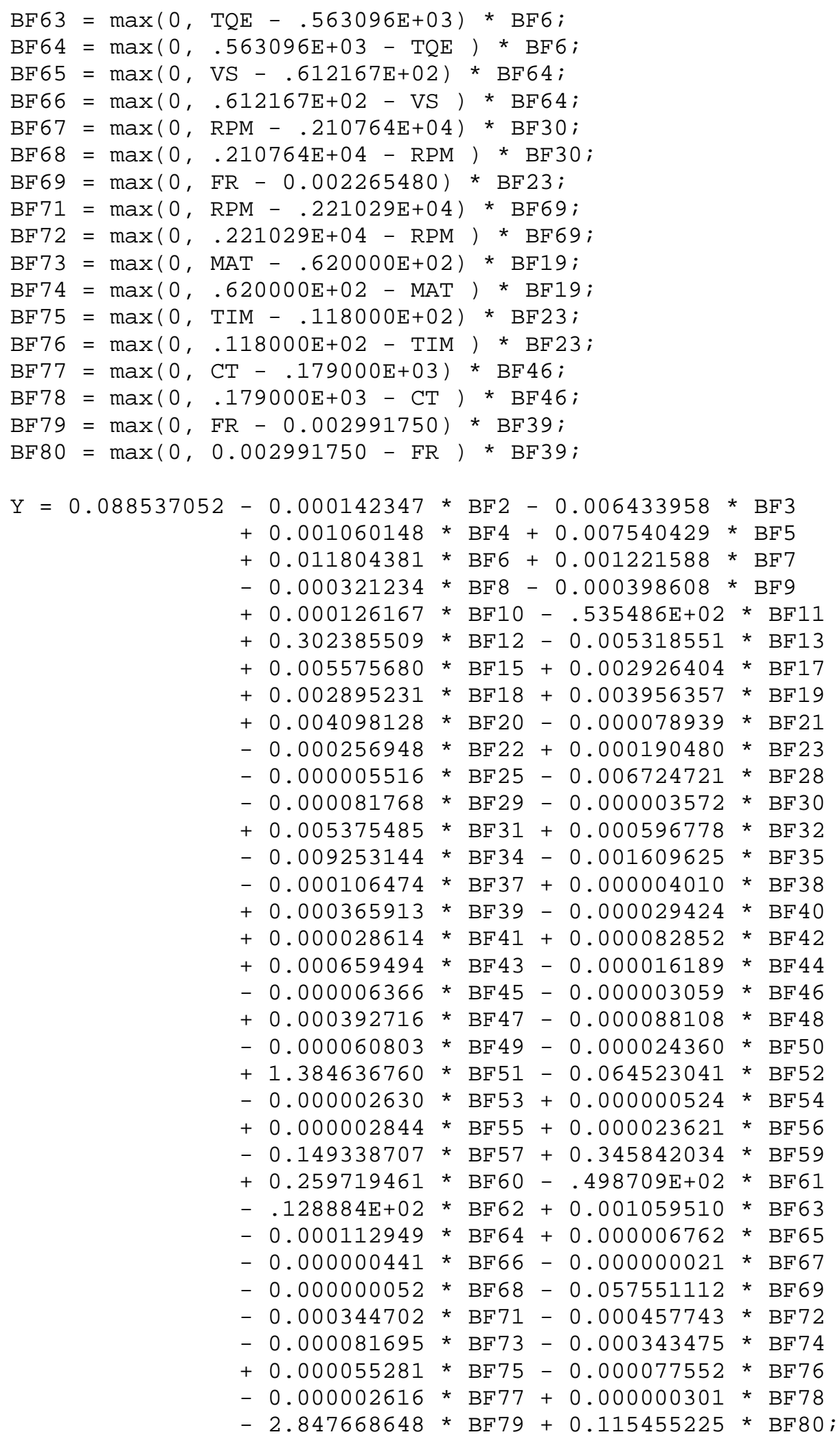




\section{MODEL C10 2001 CATERPILLAR}

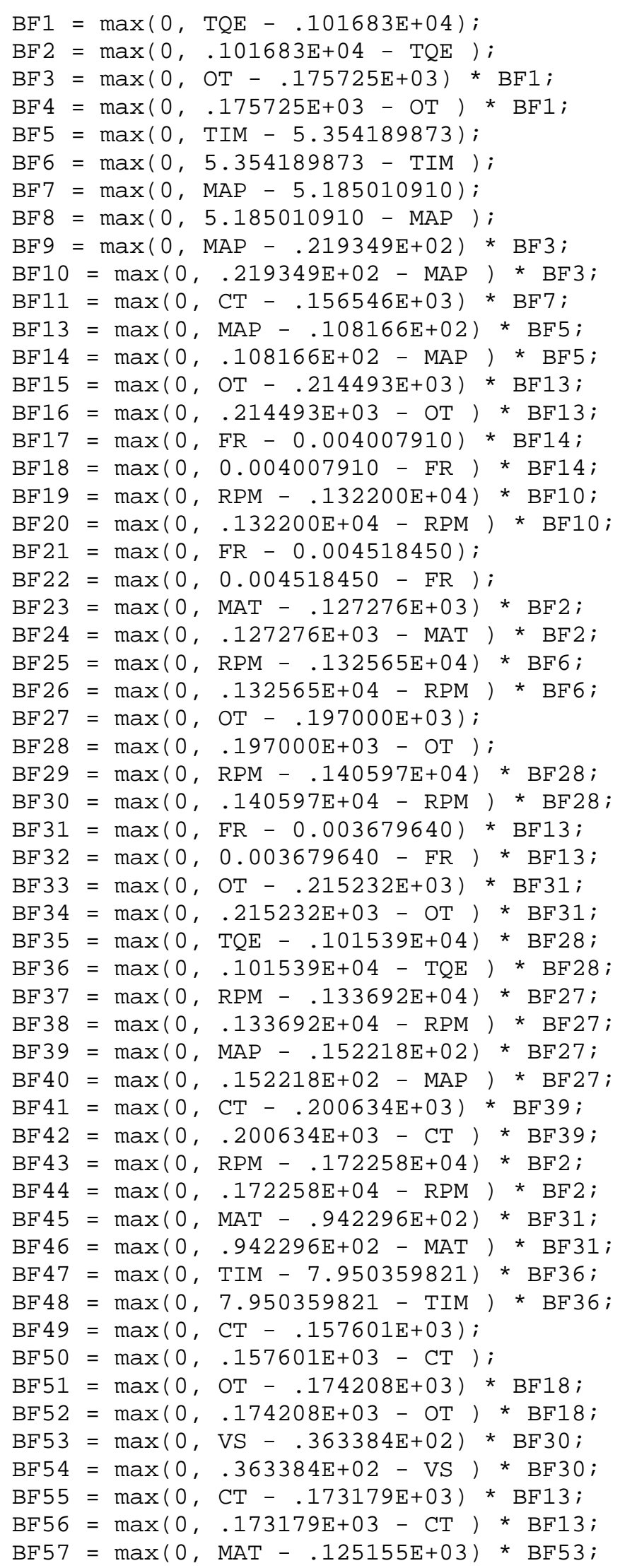




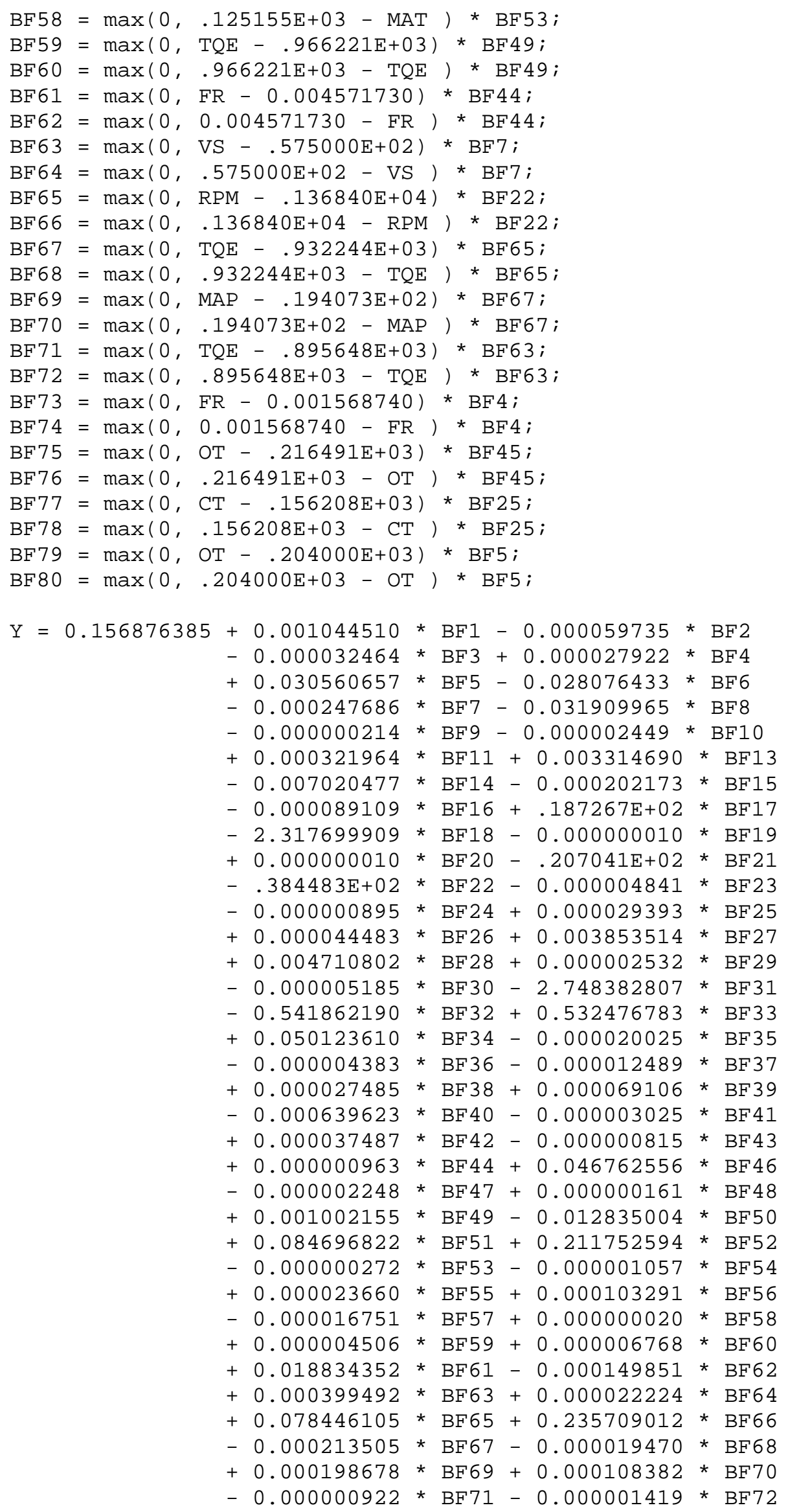


-0.003136400 * BF73 - 0.053629294 * BF74

-0.008481760 * BF75 + 0.000275968 * BF76

-0.000000177 * BF77 + 0.0000022617 * BF78

-0.000799052 * BF79 - 0.000130462 * BF80; 


\section{MODEL C15 2001 CATERPILLAR}

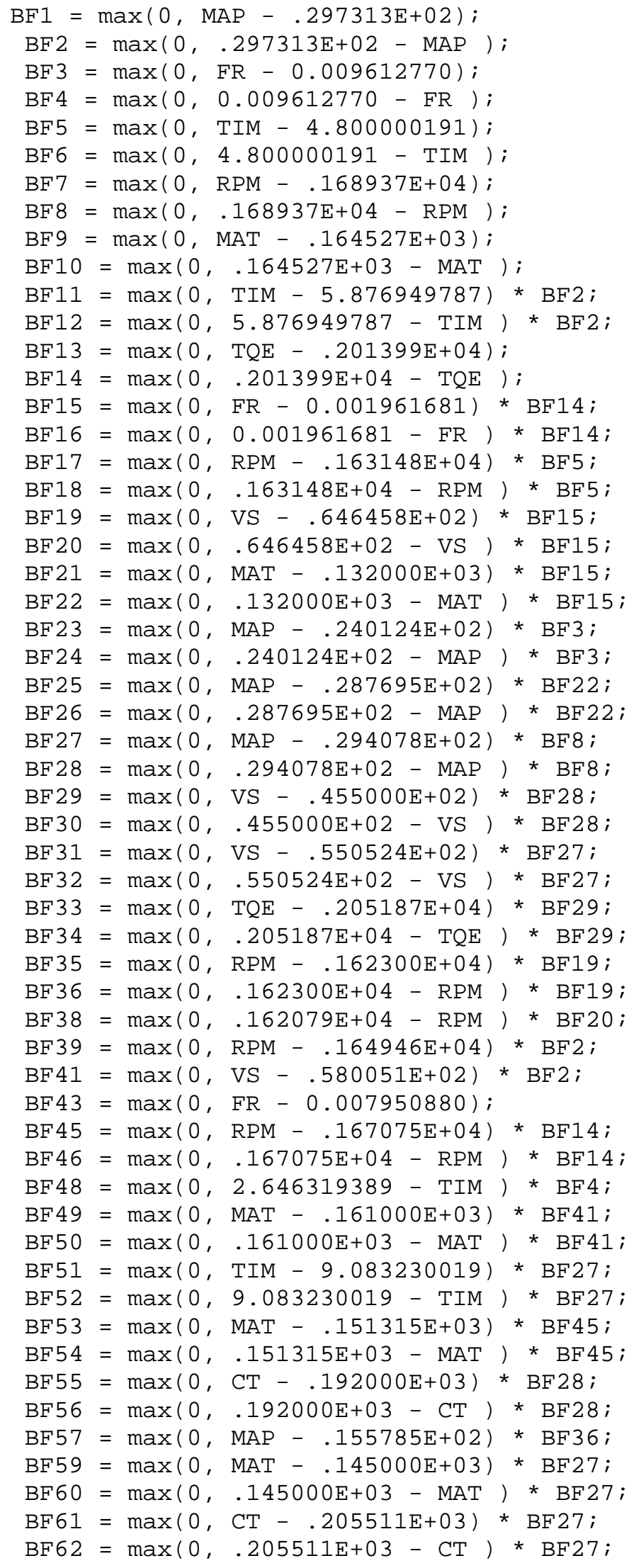




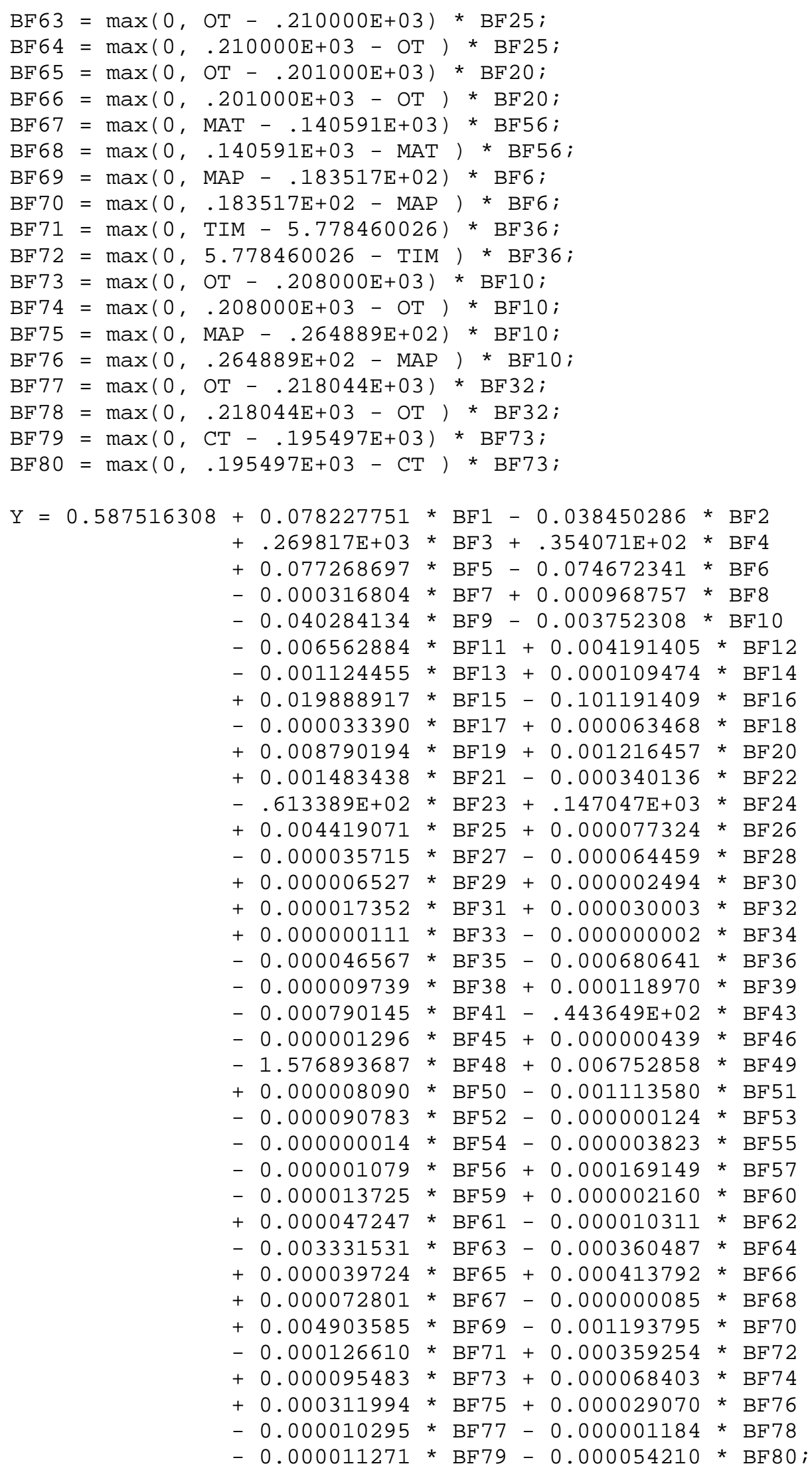




\section{MODEL 31262002 CATERPILLAR}

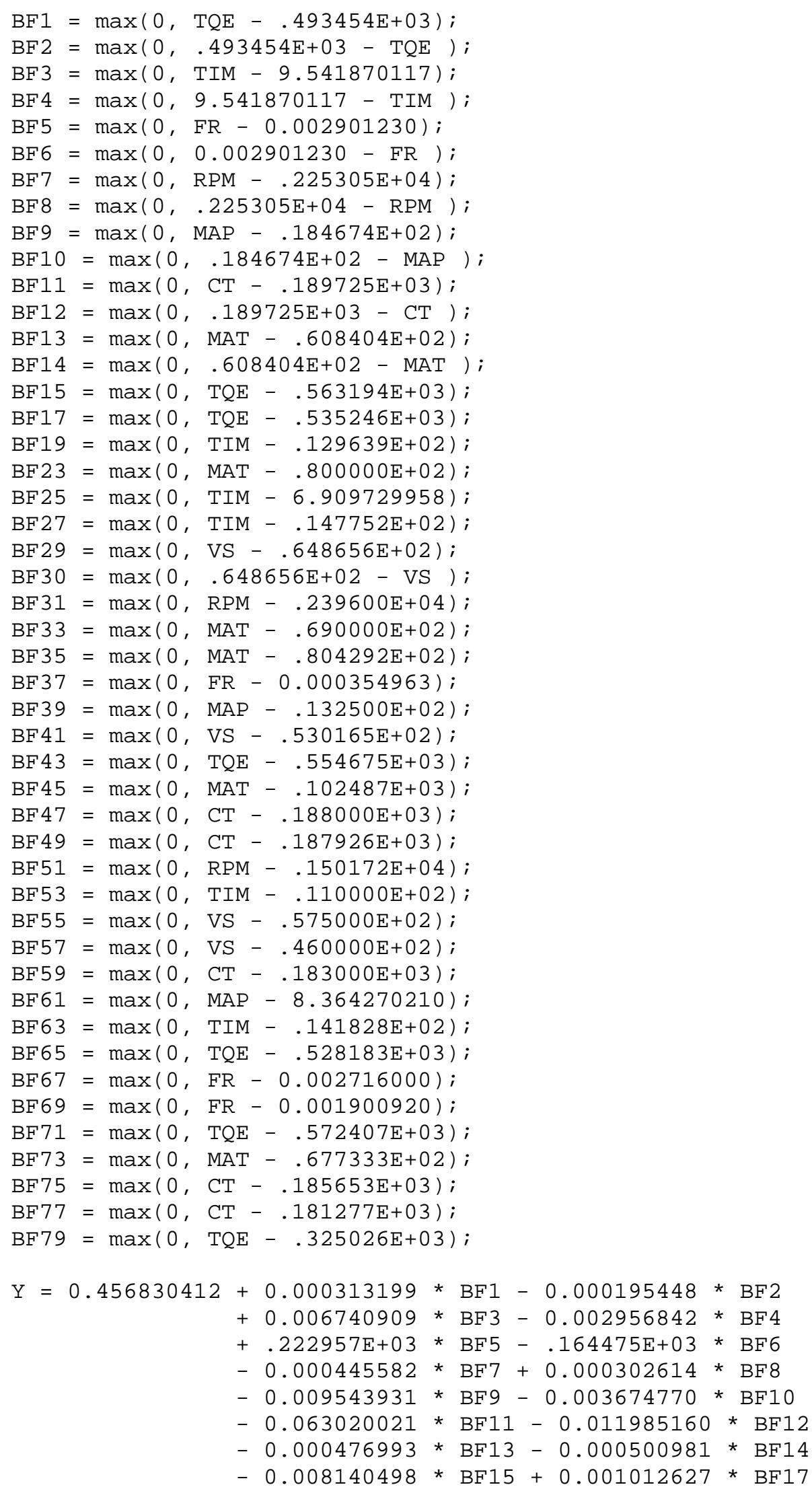




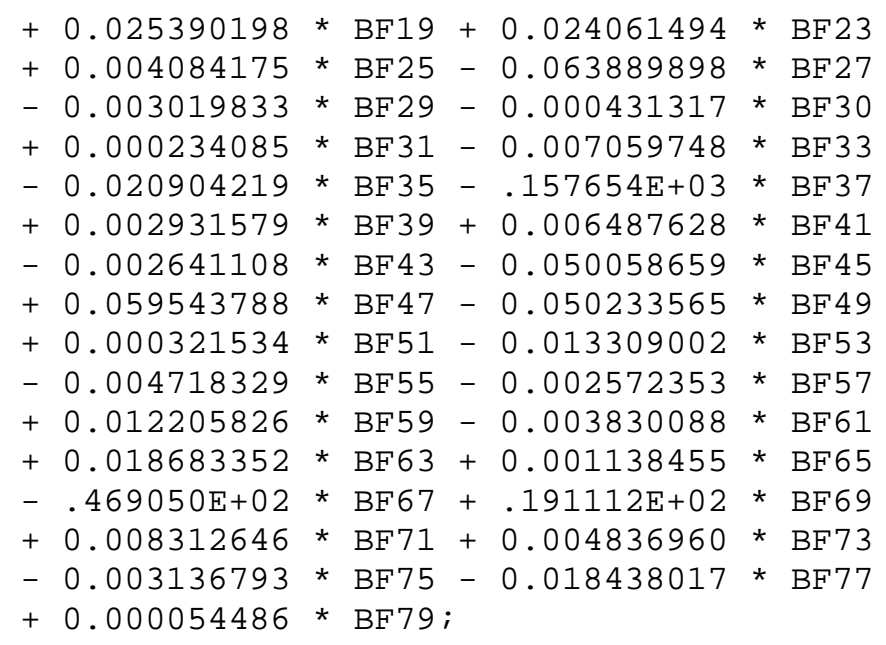




\section{MODEL C10 2002 CATERPILLAR}

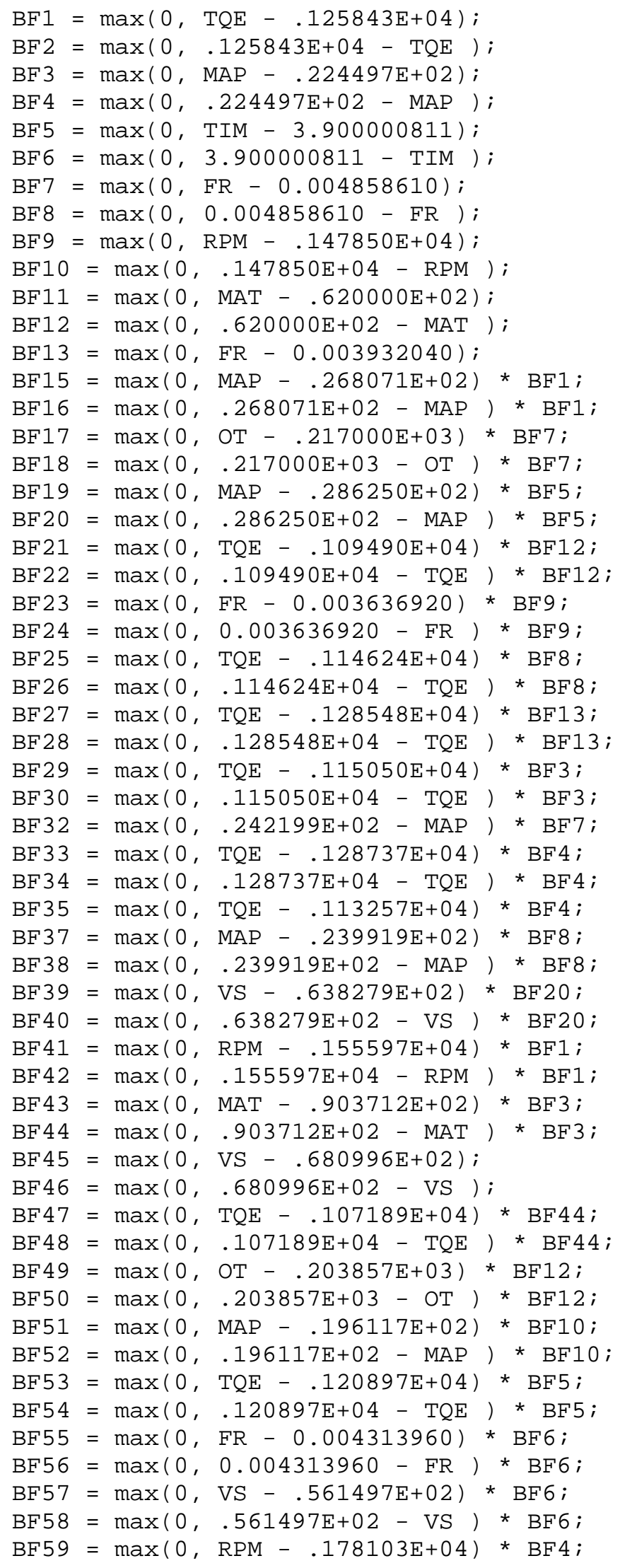




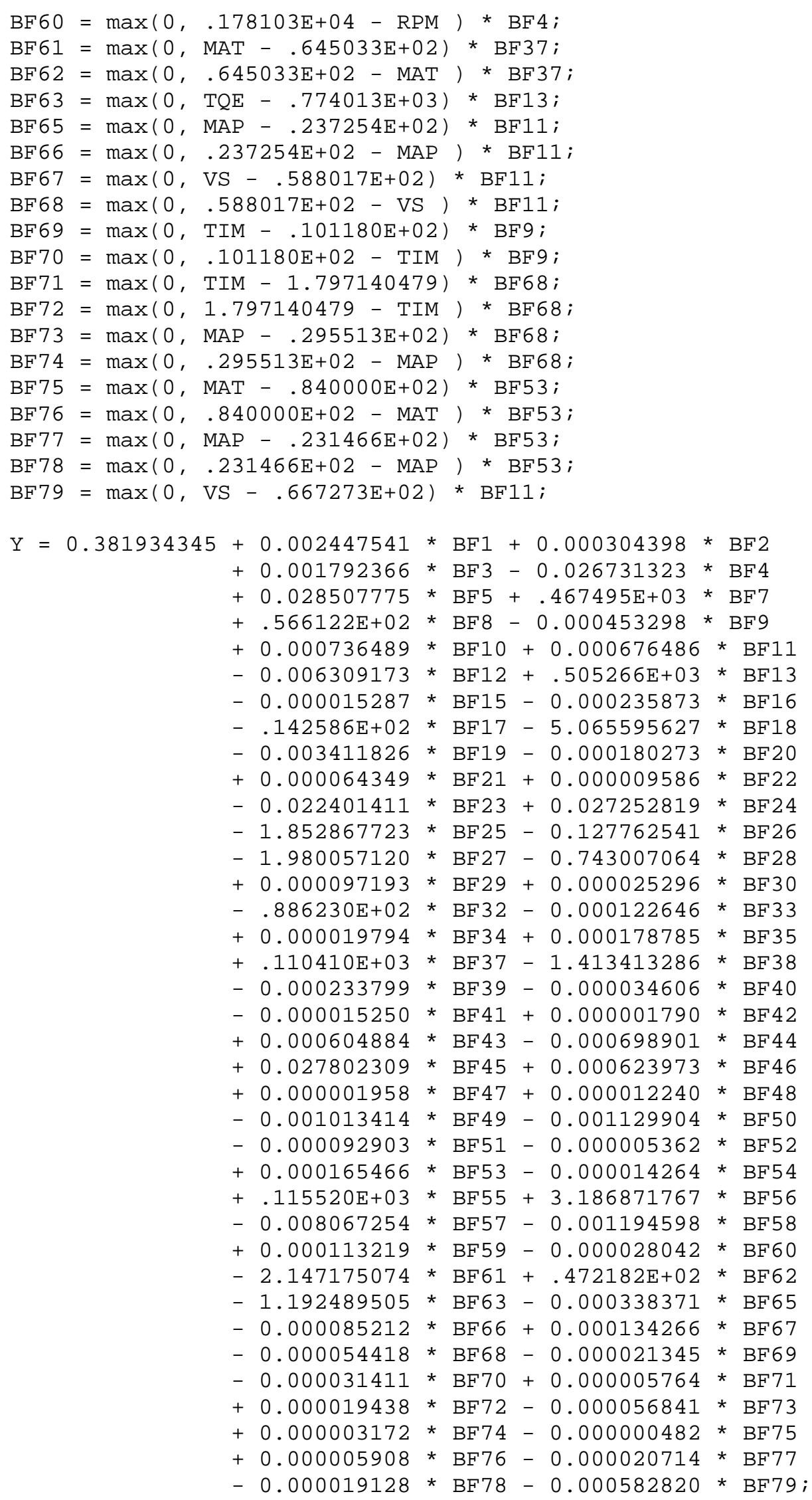




\section{MODEL C15 2002 CATERPILLAR}

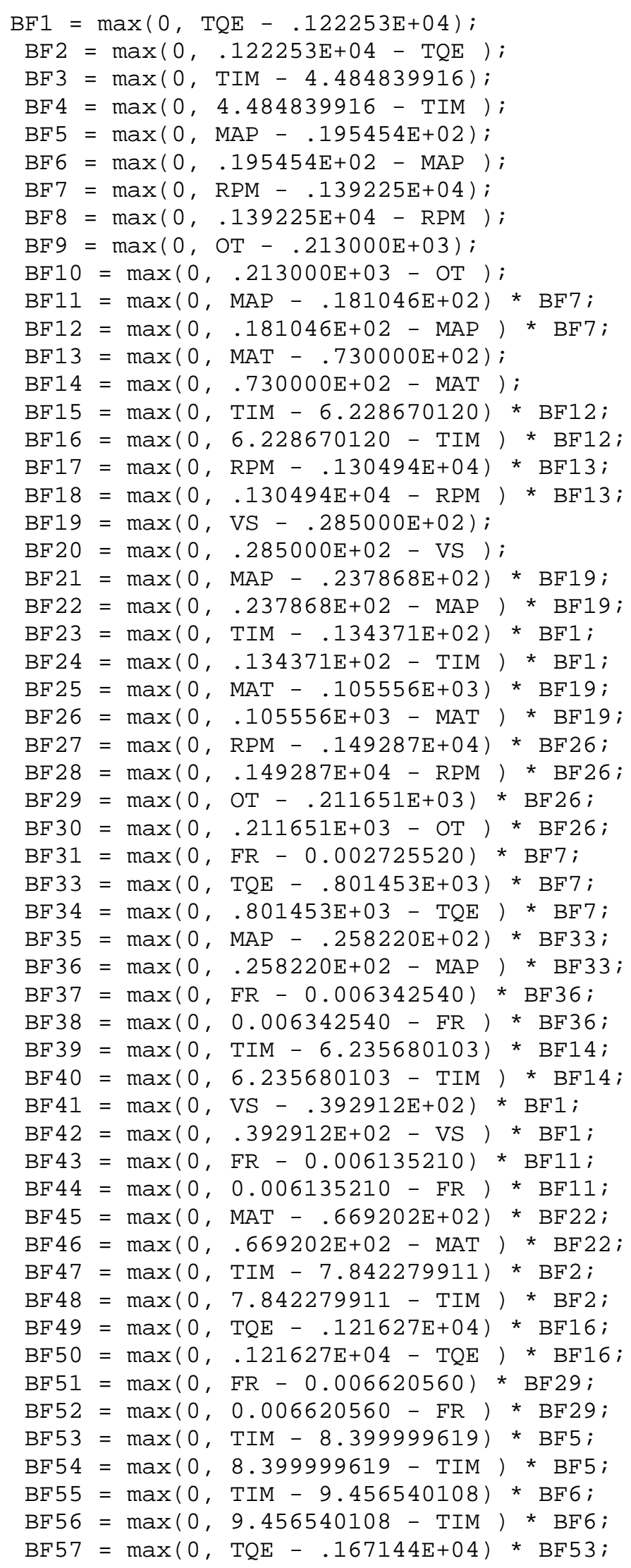




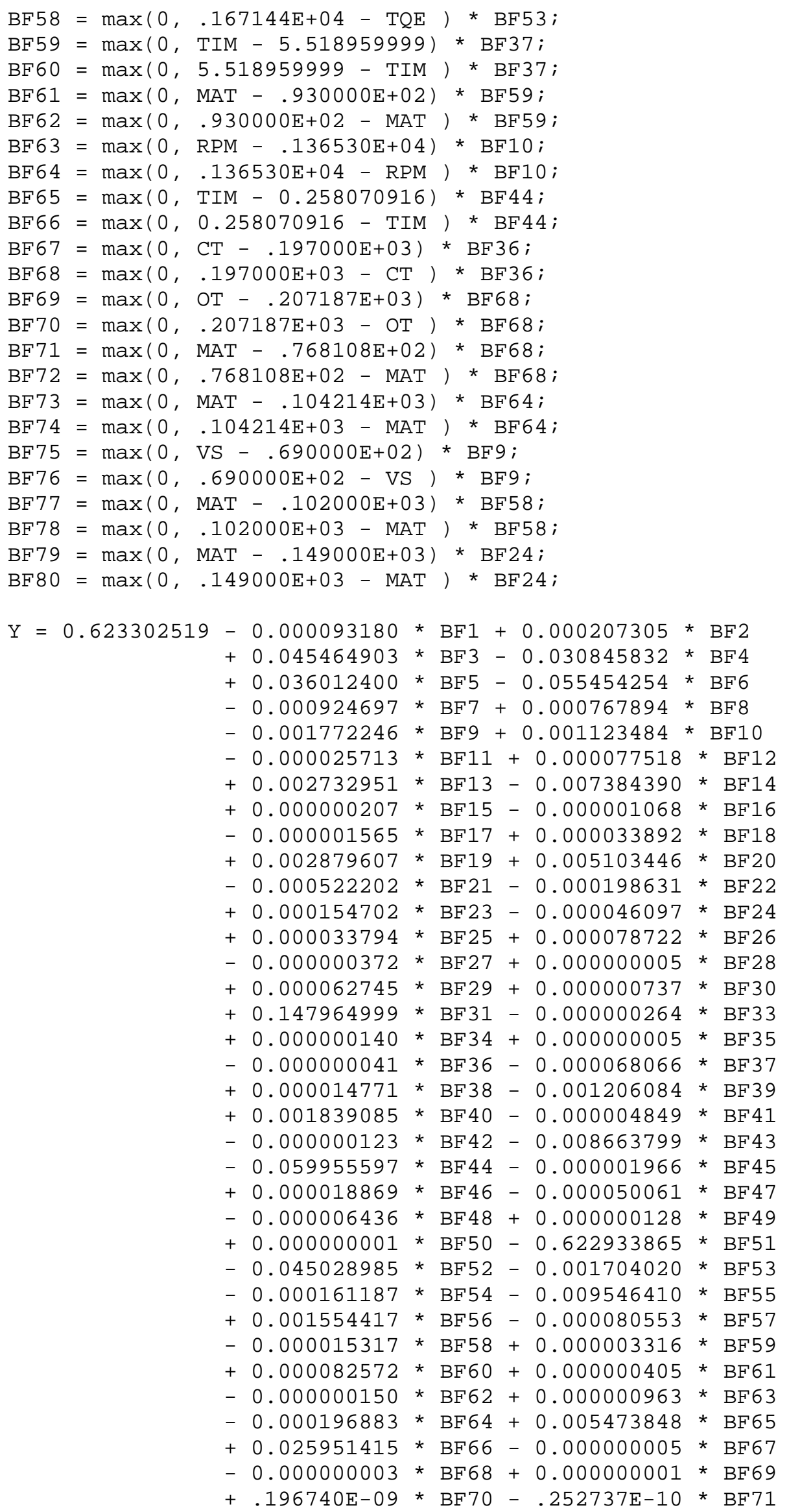




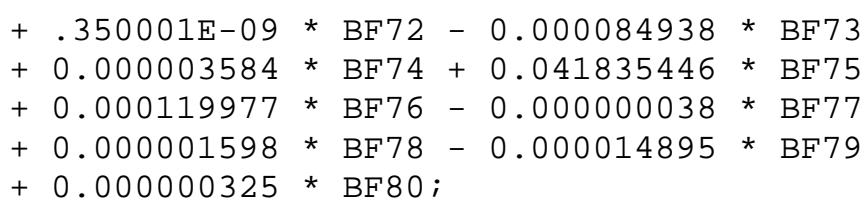




\section{MODEL 31262003 CATERPILLAR}

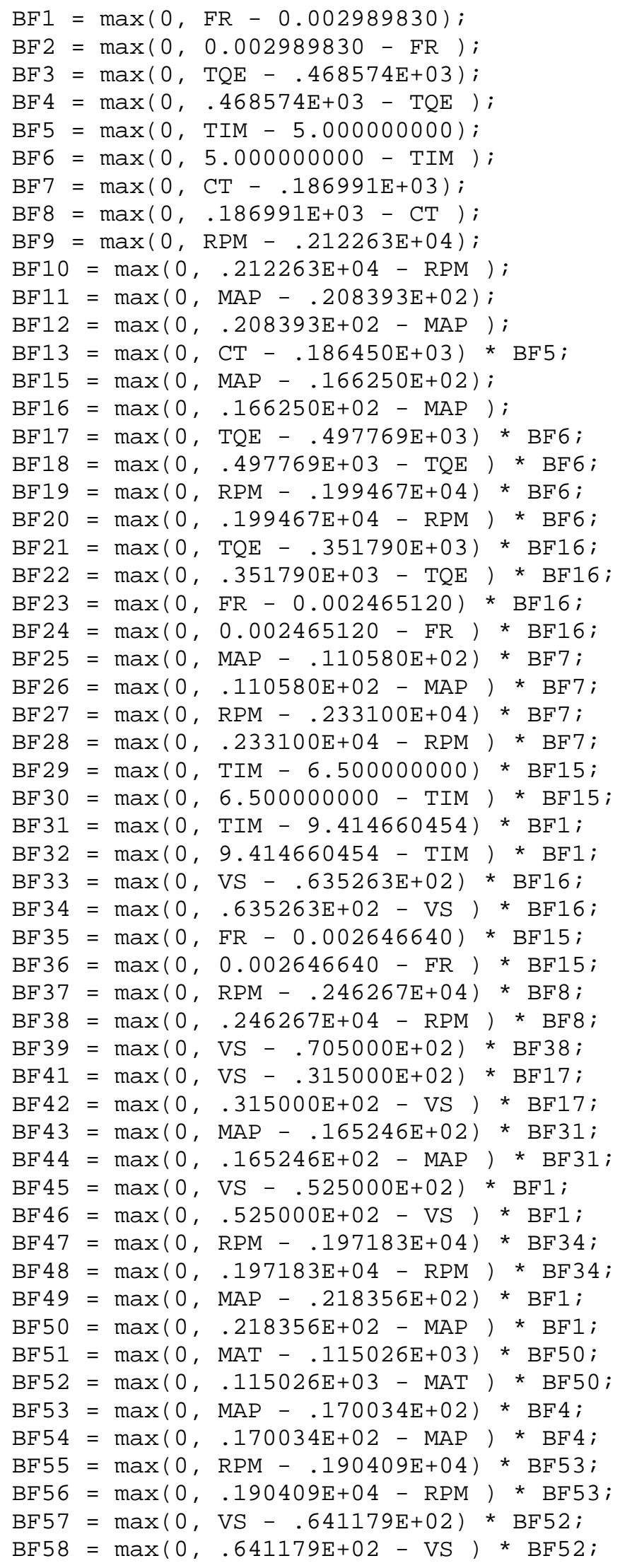




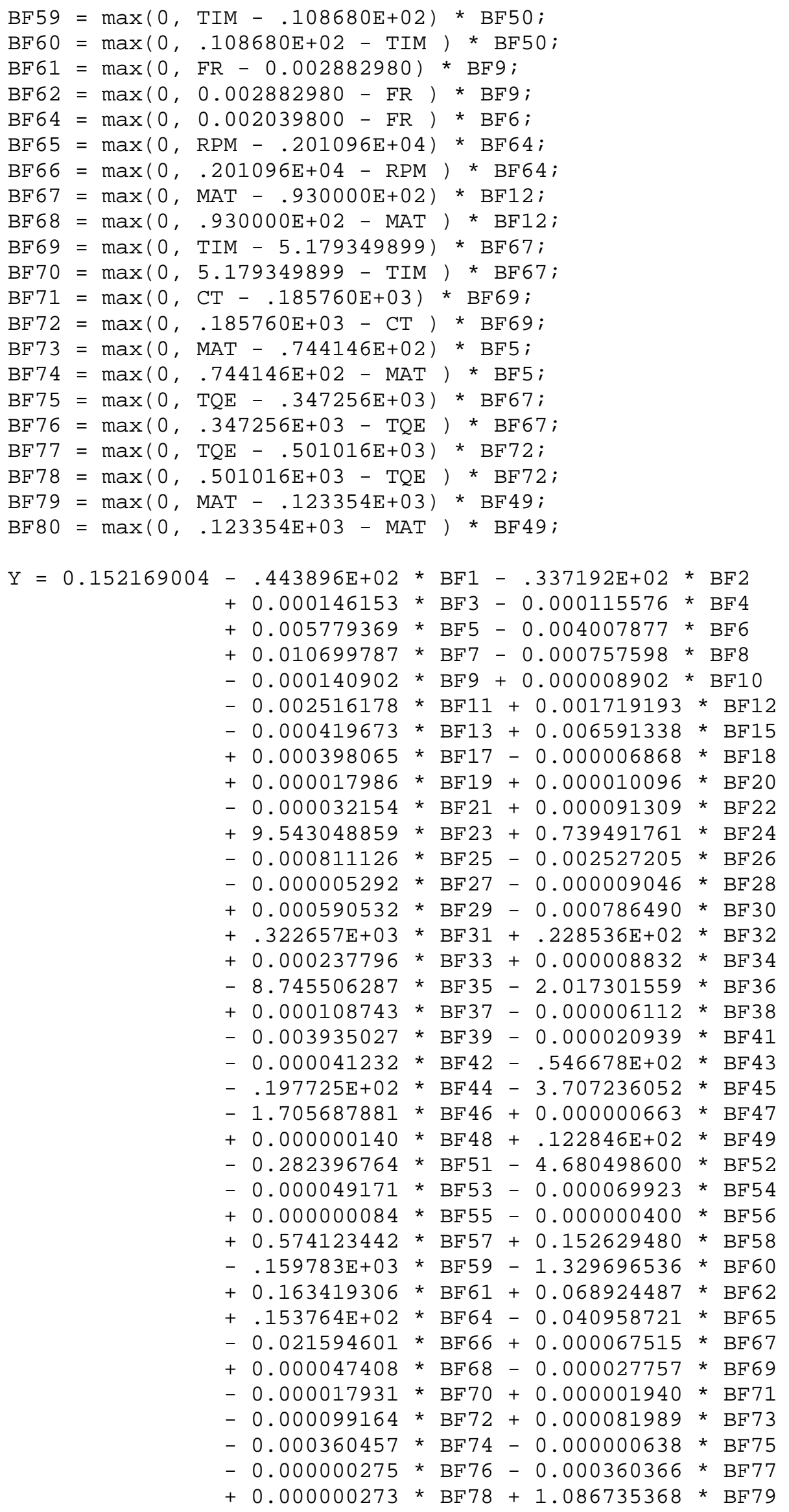


+5.493851662 * BF80; 


\section{MODEL C9 2003 CATERPILLAR}

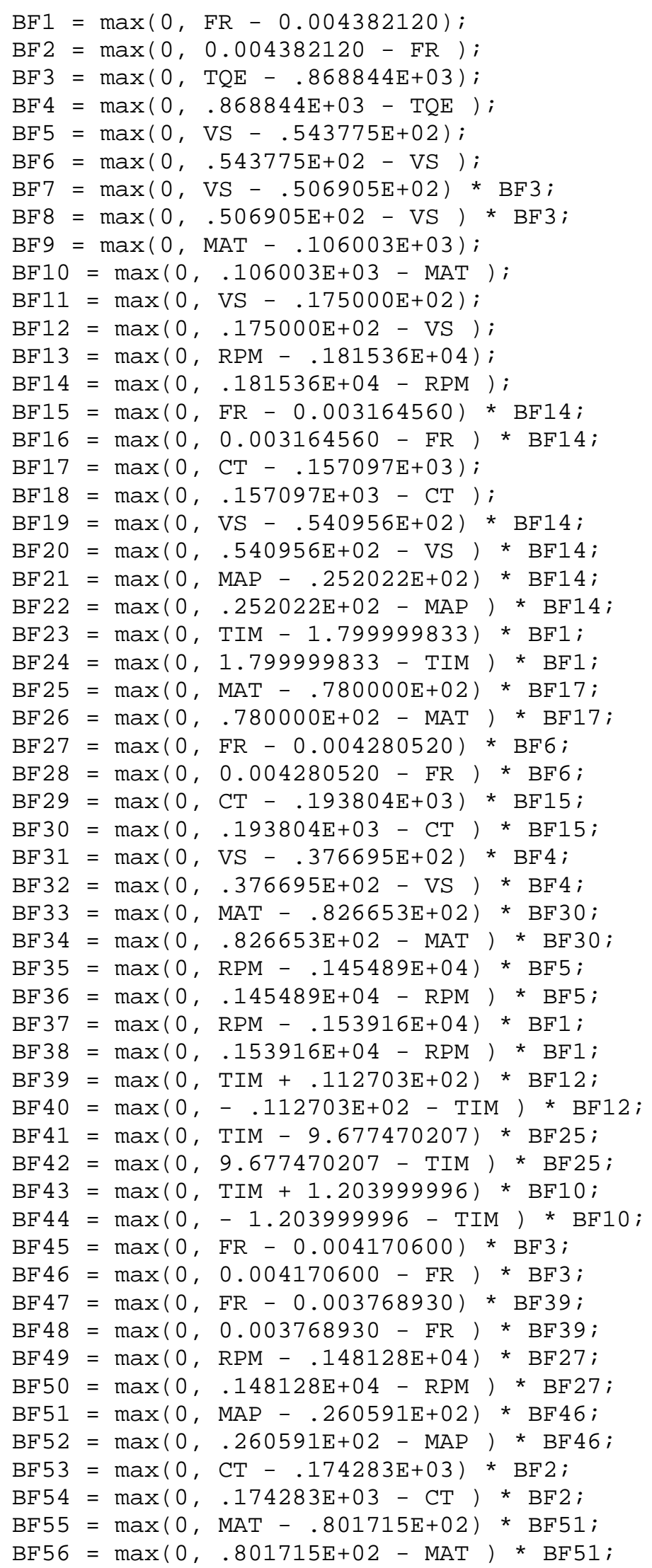




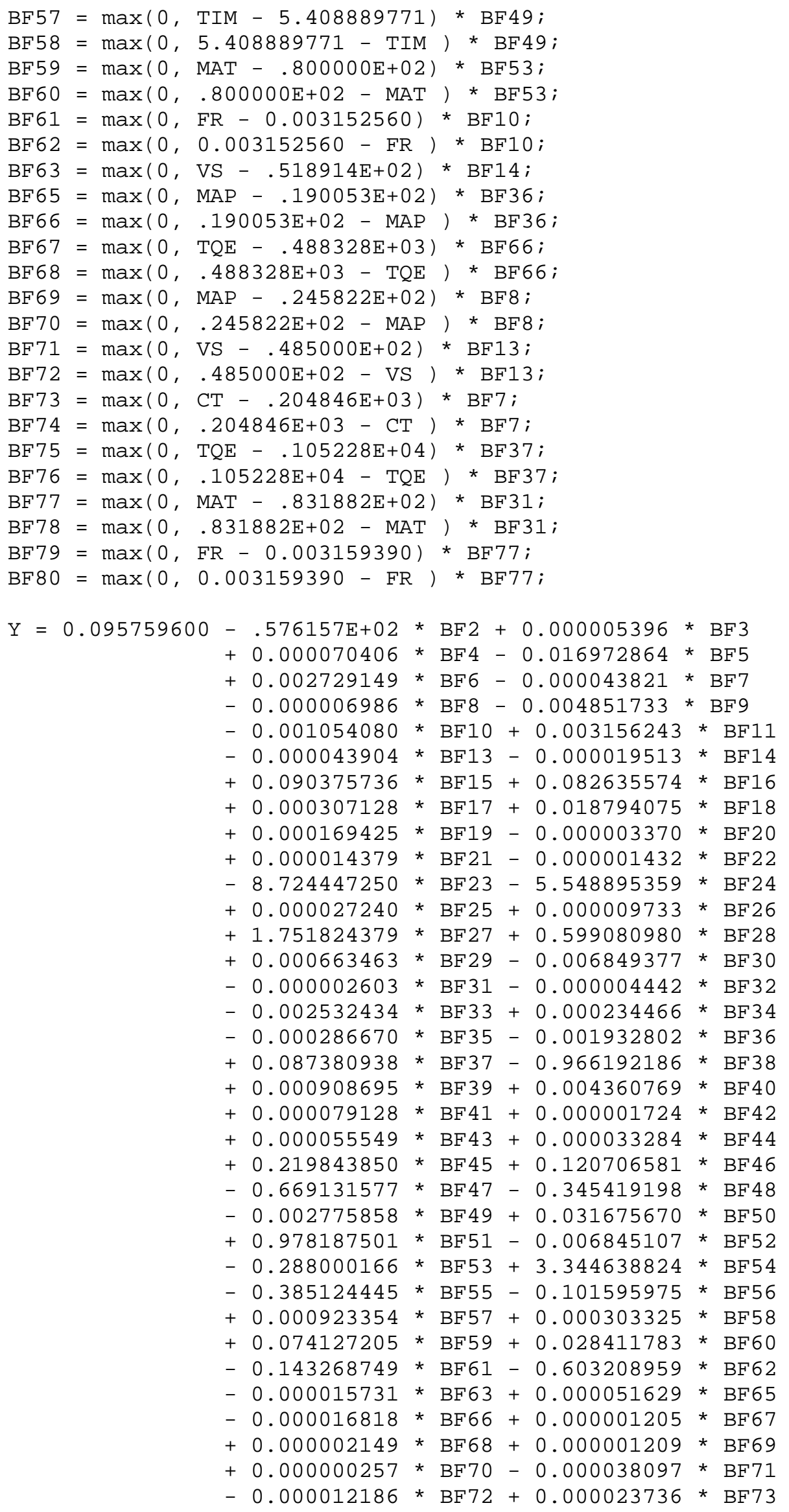




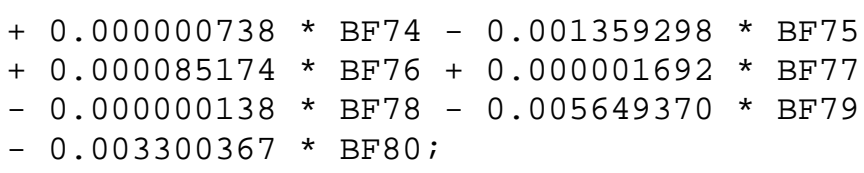




\section{MODEL C15 2003 CATERPILLAR}

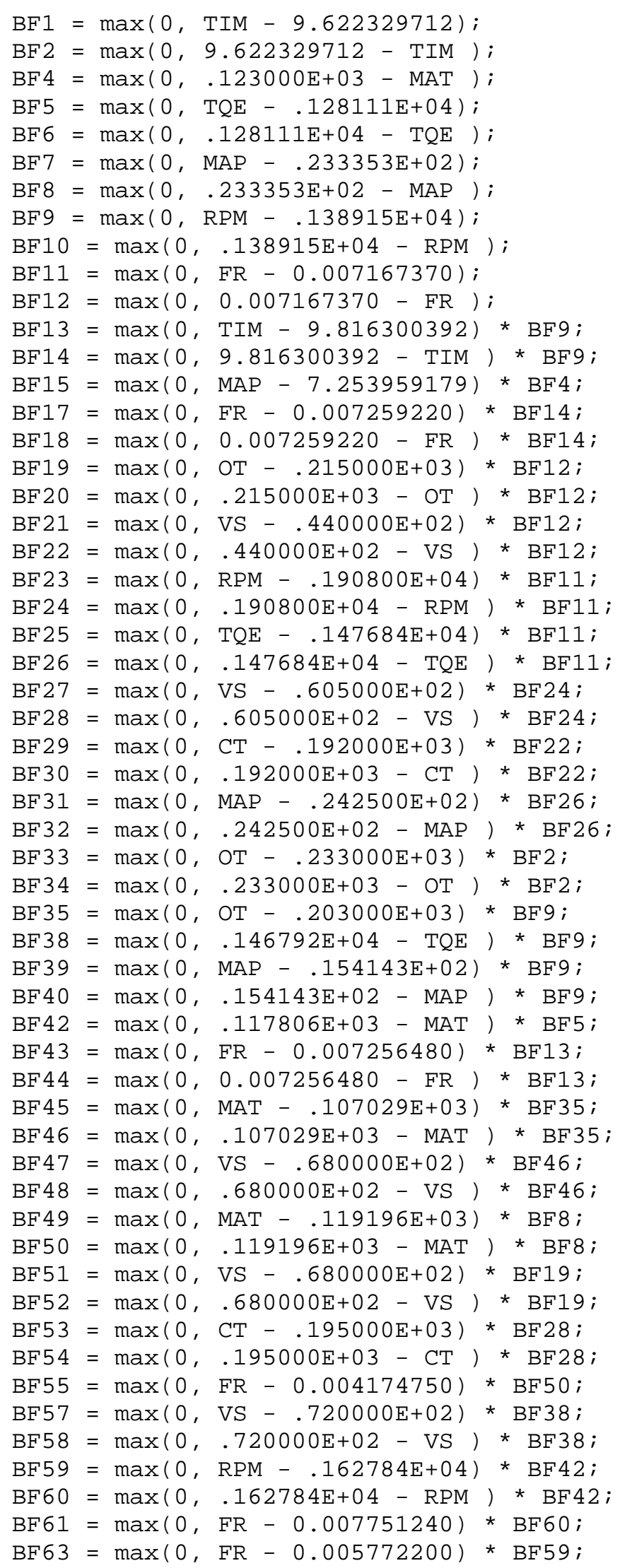




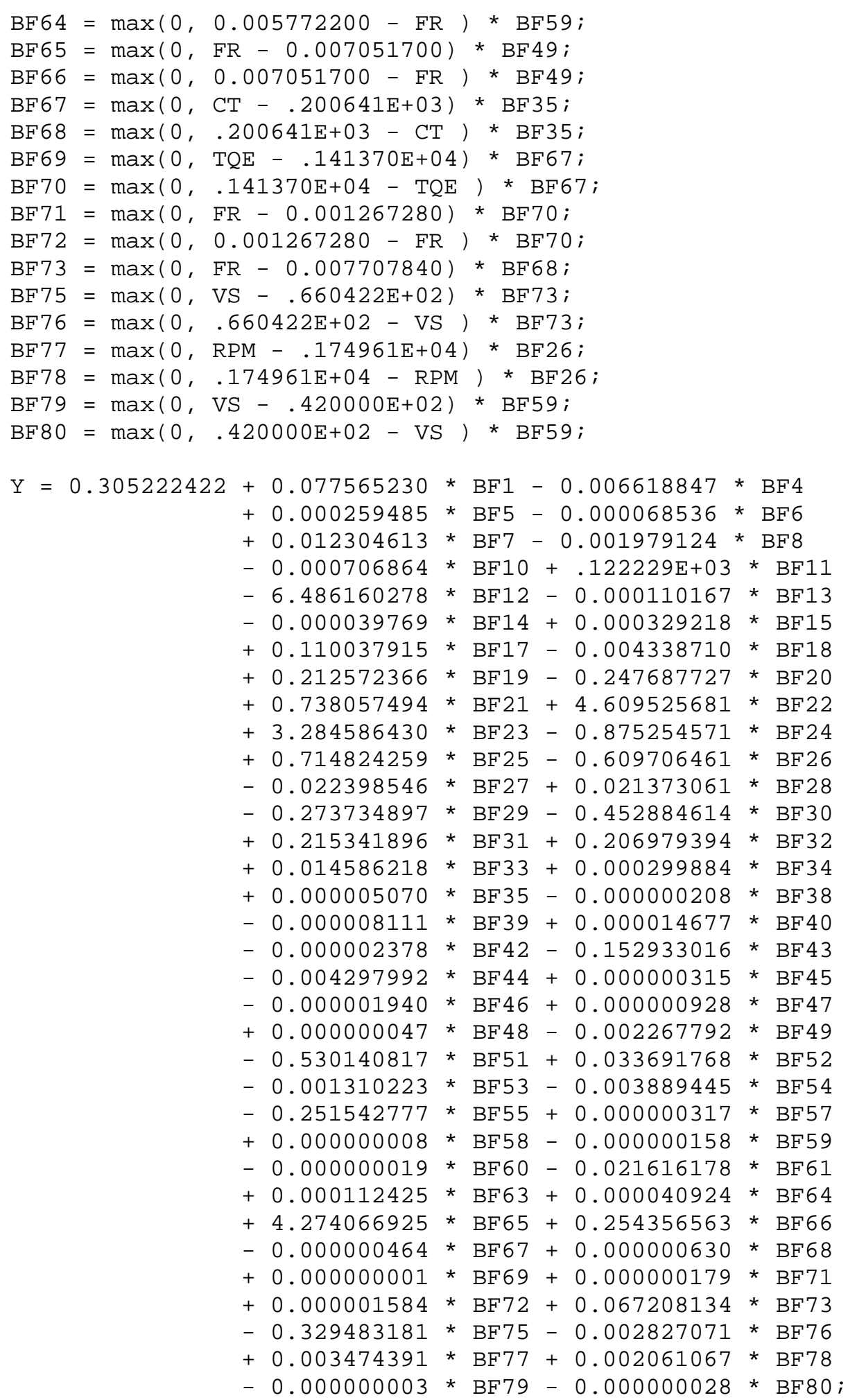




\section{MODEL ISB 2001 CUMMINS}

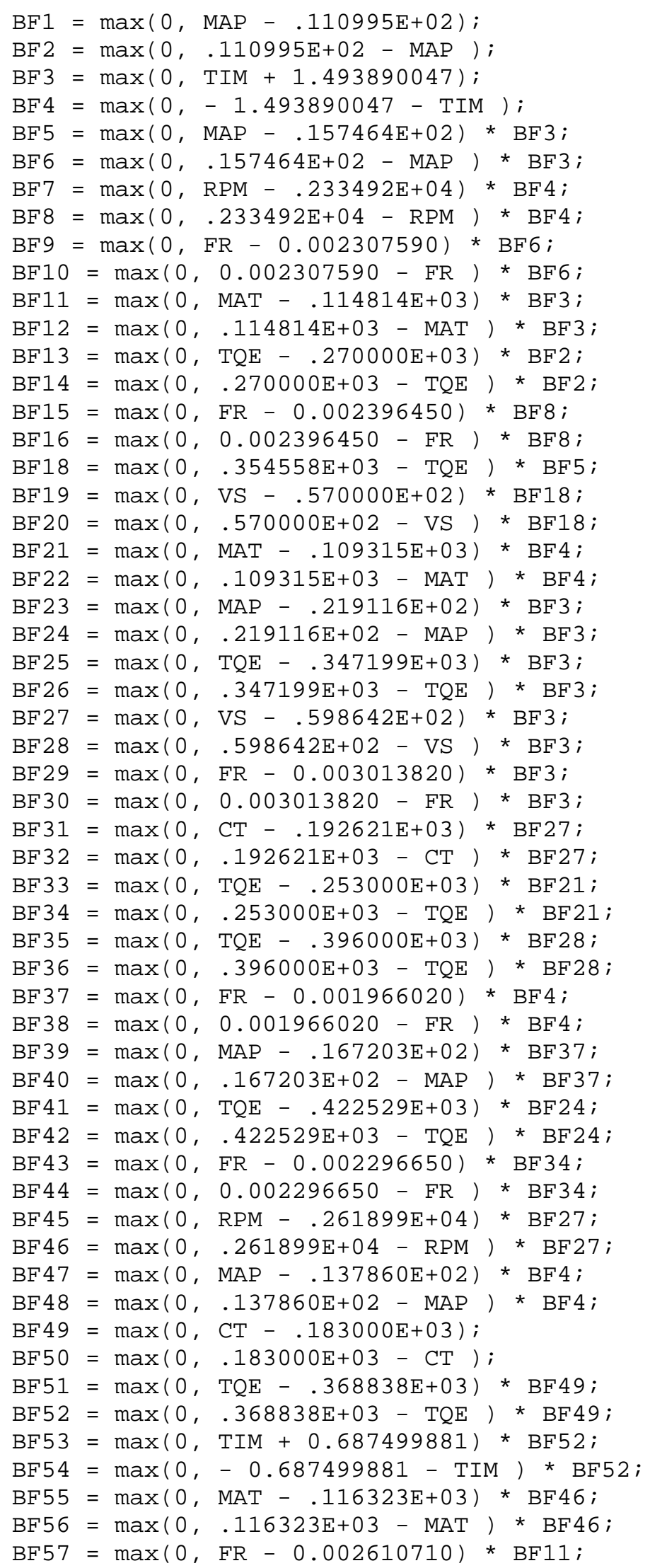




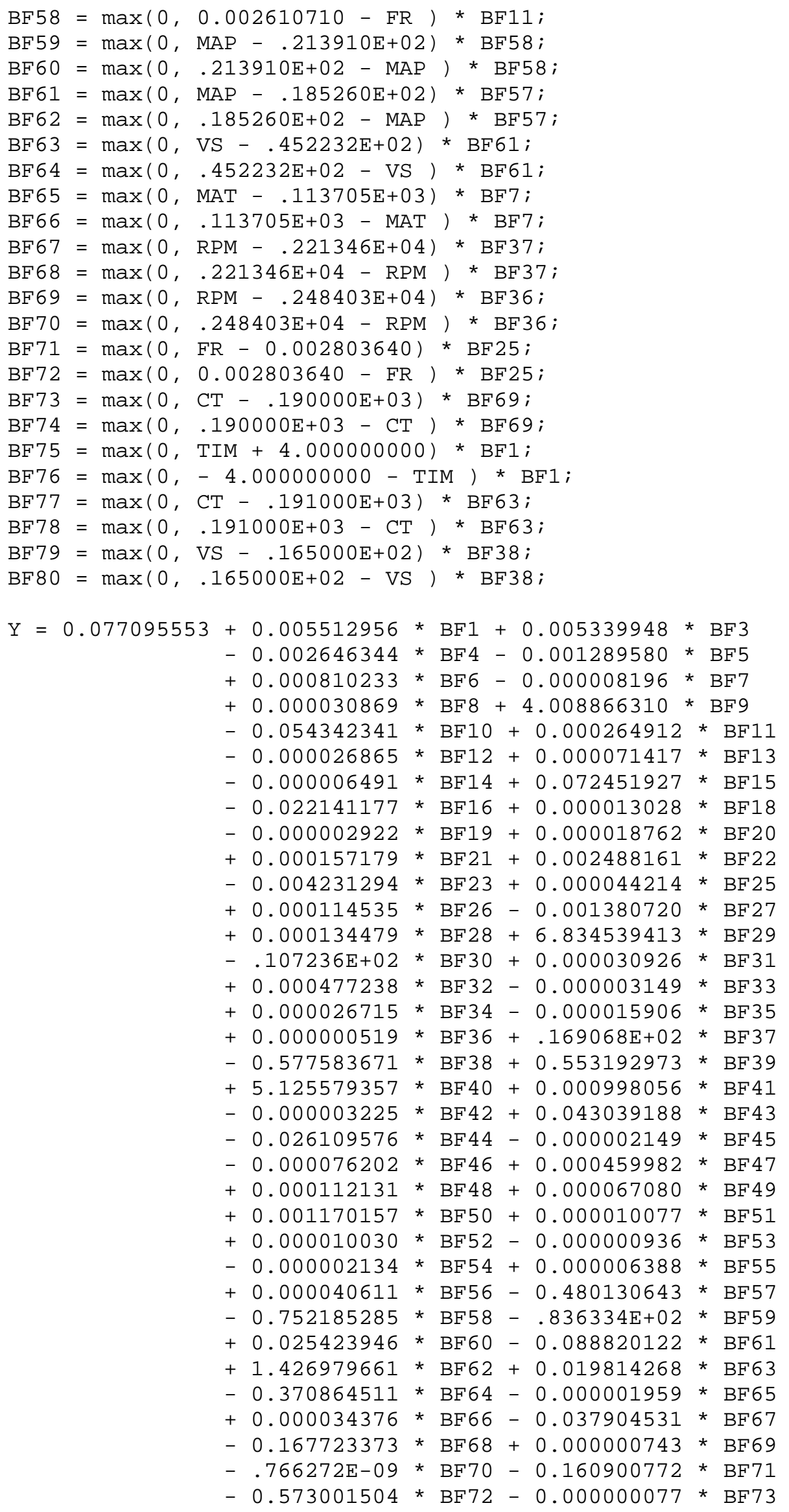


-0.000000042 * BF74 + 0.001401576 * BF75

- 0.000252224 * BF76 - 0.000902067 * BF77

-0.007223721 * BF78 - 0.045488235 * BF79

+3.490283251 * BF80; 


\section{MODEL N-14 2001 CUMMINS}

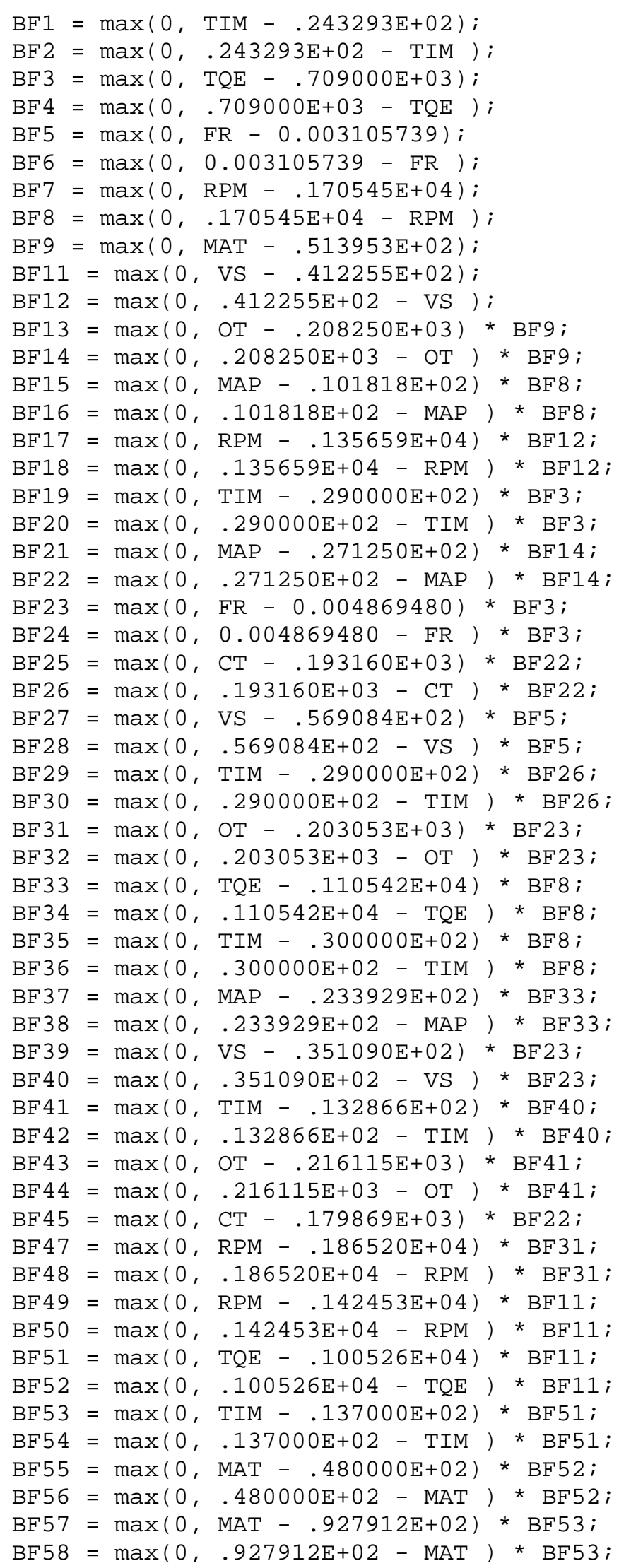




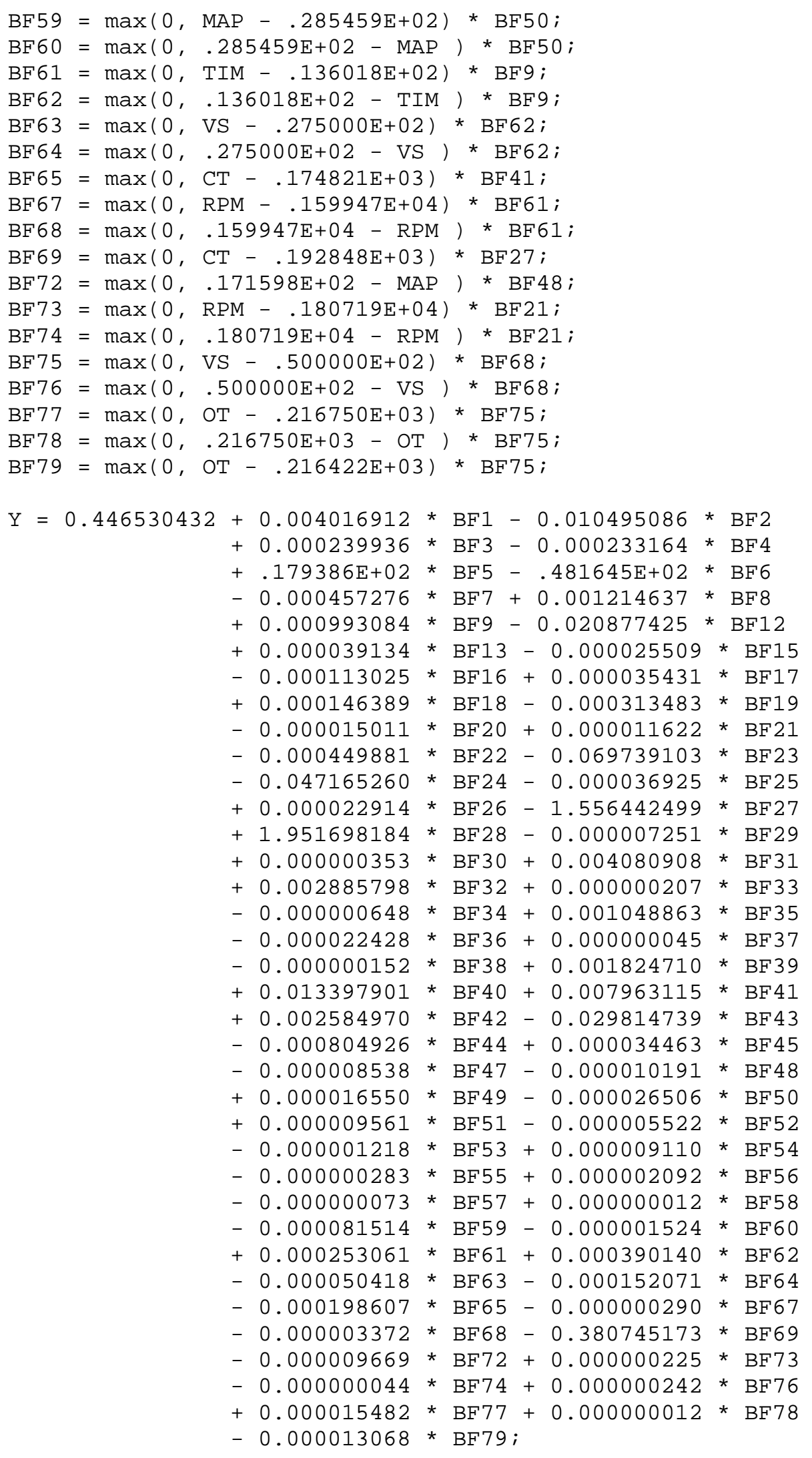




\section{MODEL ISB 2002 CUMMINS}

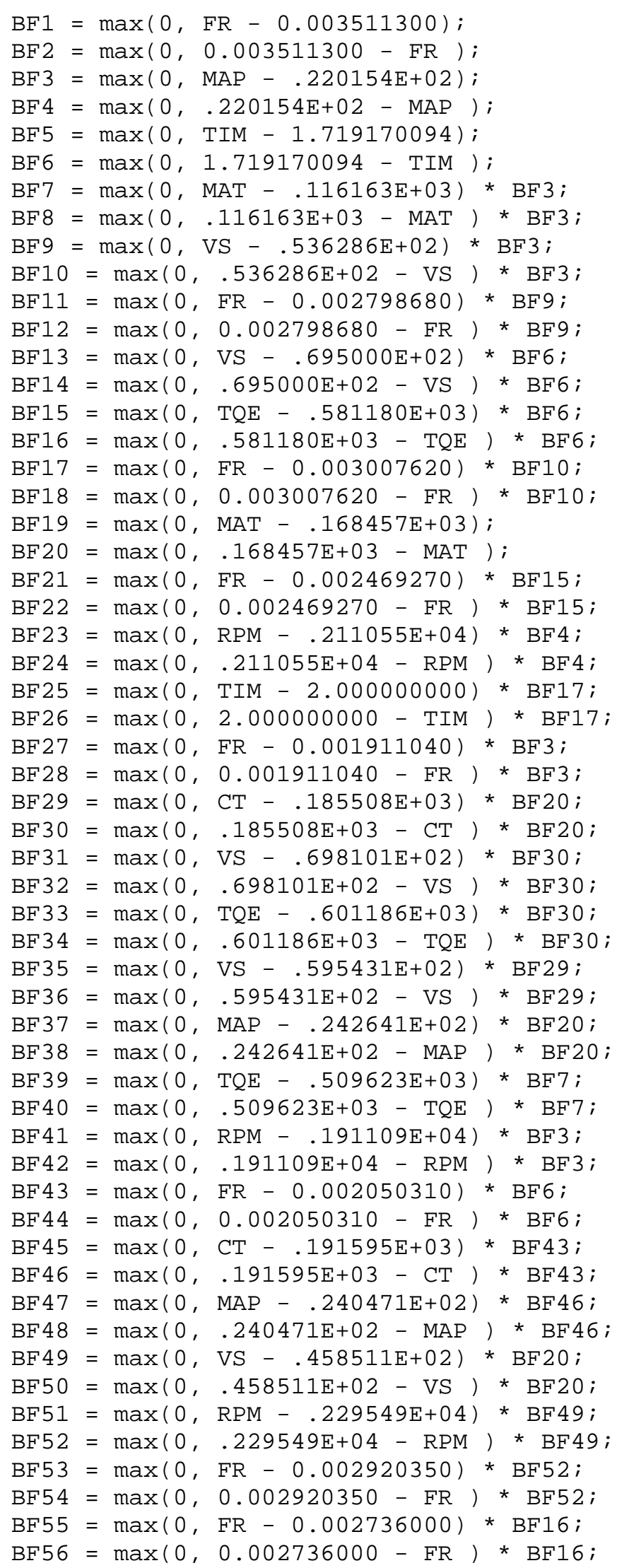




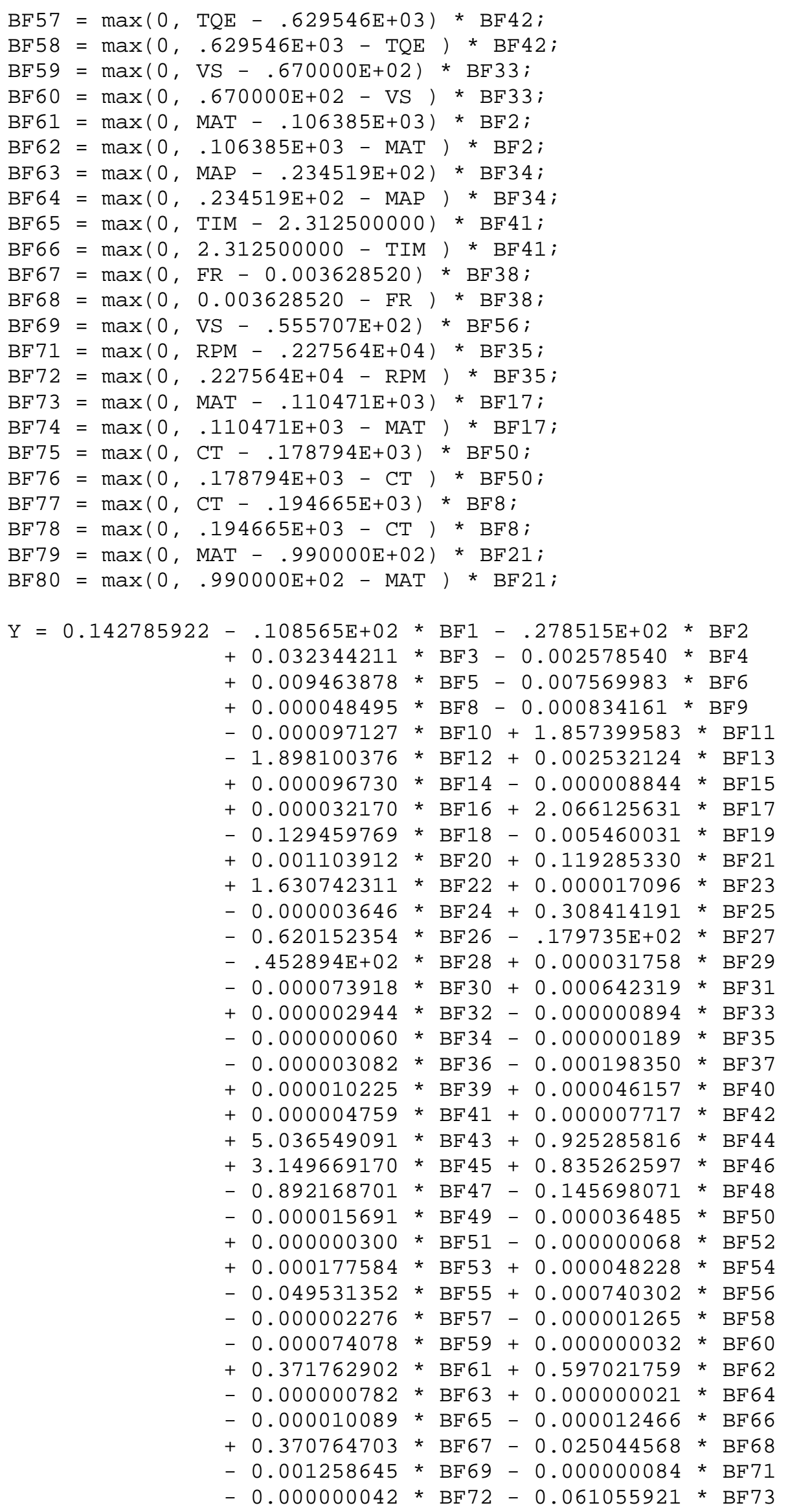


$-0.085405372 * \mathrm{BF} 74+0.000003808$ * BF75

$+0.000018429 * \mathrm{BF} 76-0.001040446$ * BF77

+0.000030604 * BF78 - 0.011165324 * BF79

-0.054362204 * BF80; 


\section{MODEL ISC 2002 CUMMINS}

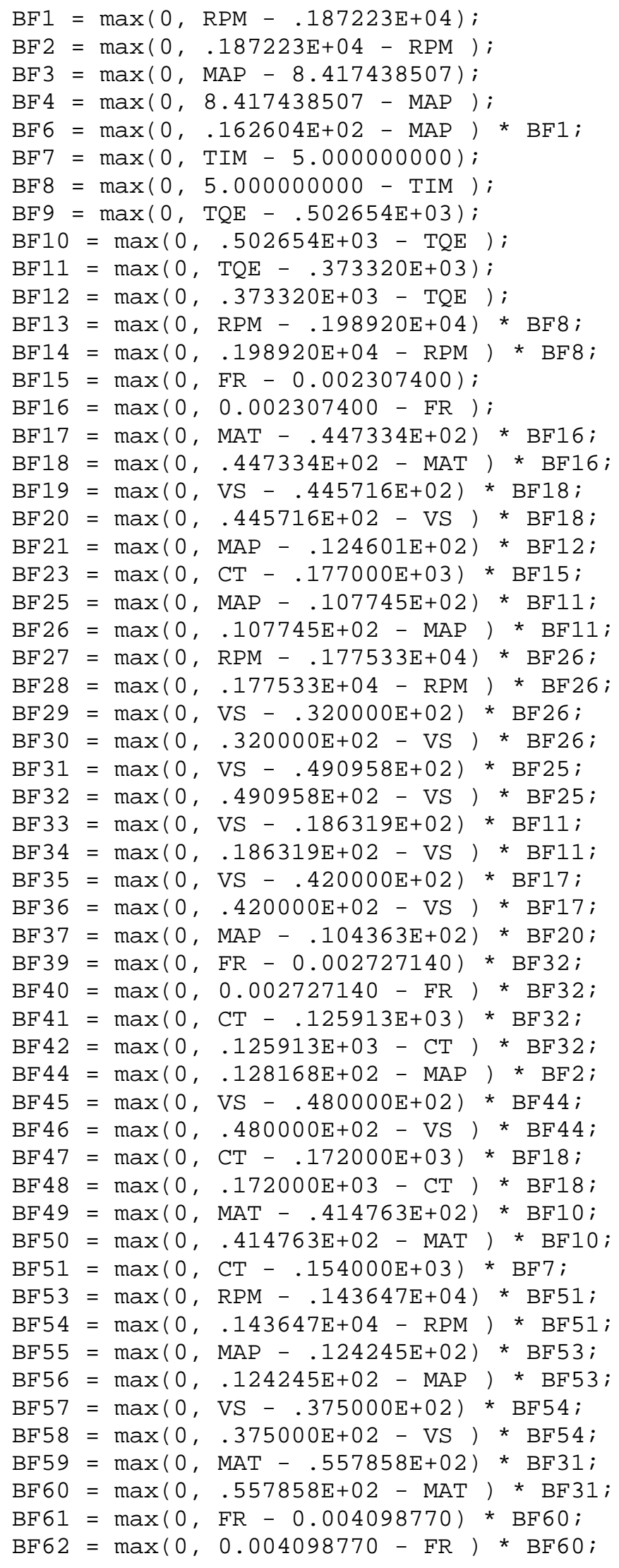




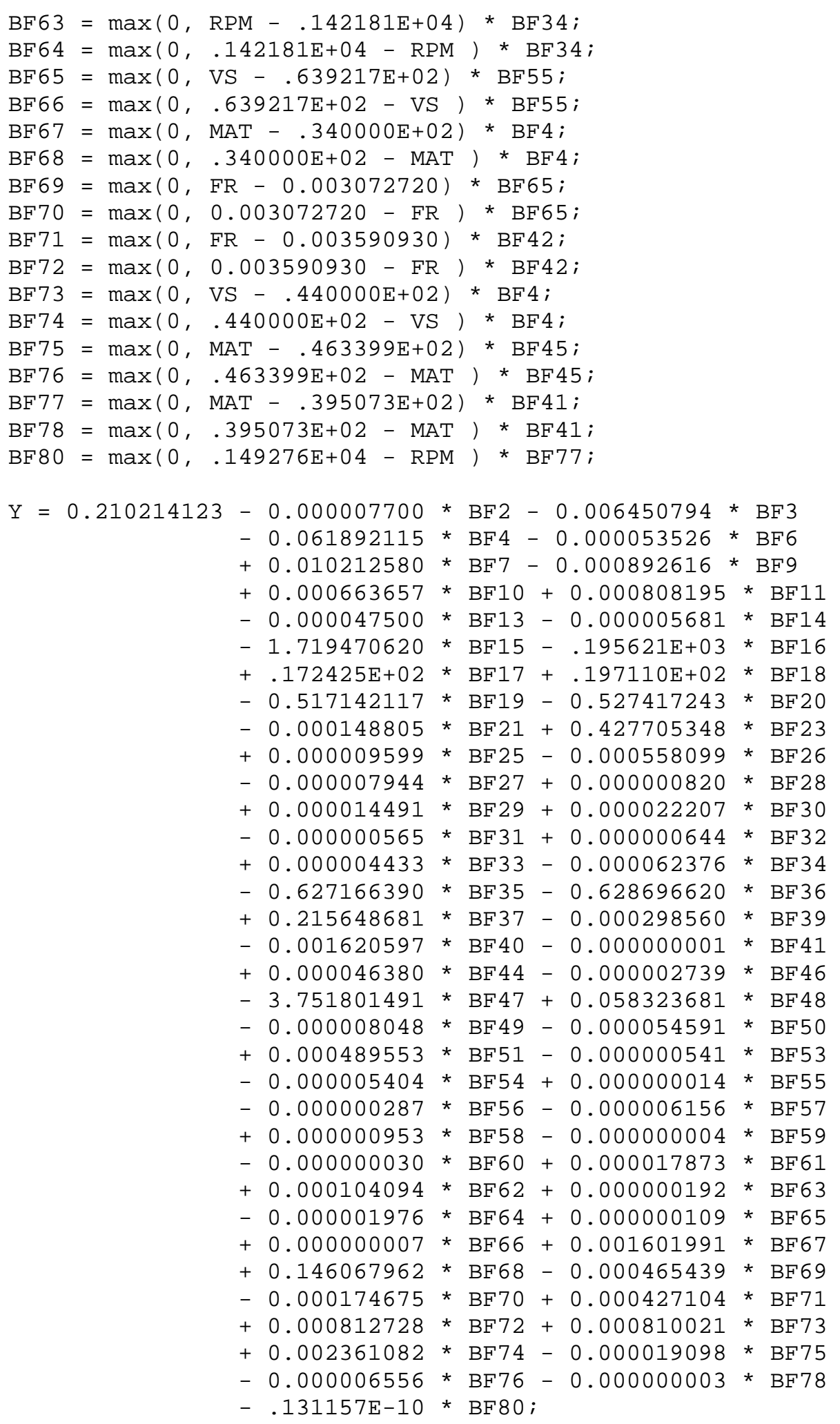




\section{MODEL ISX 2002 CUMMINS}

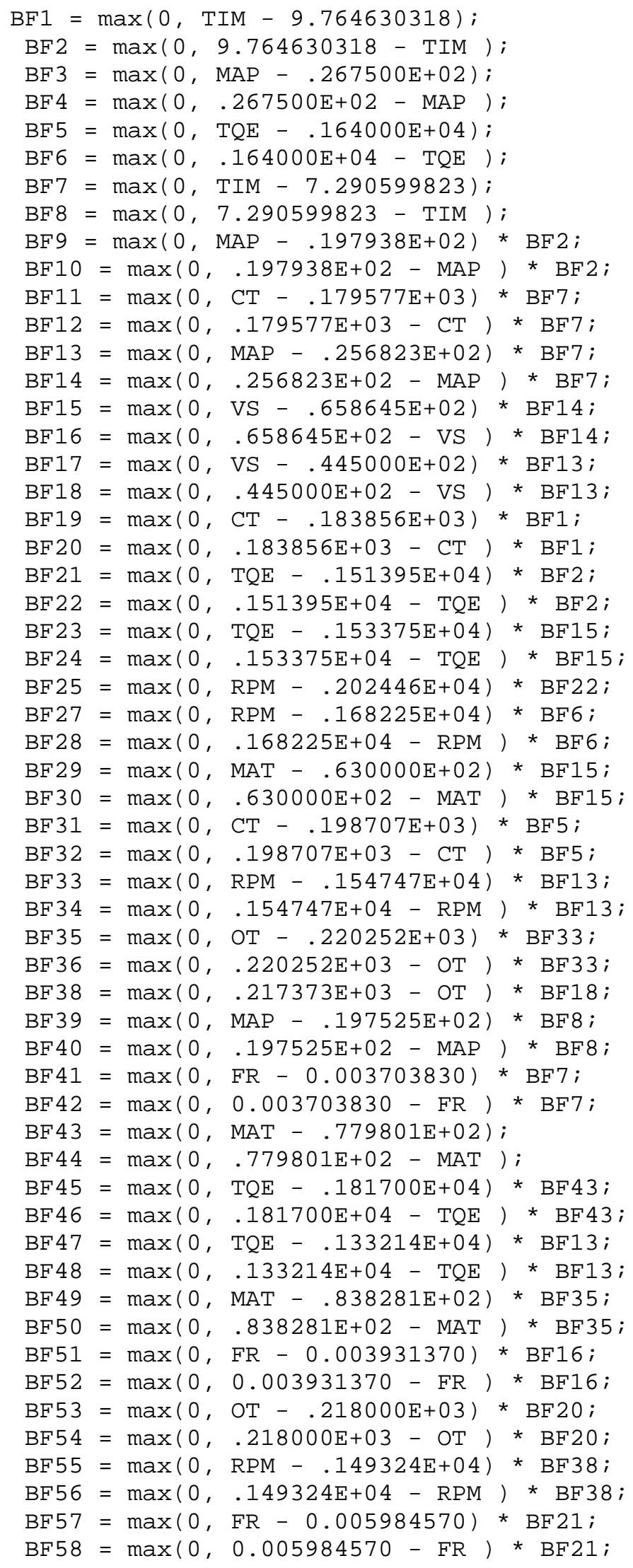




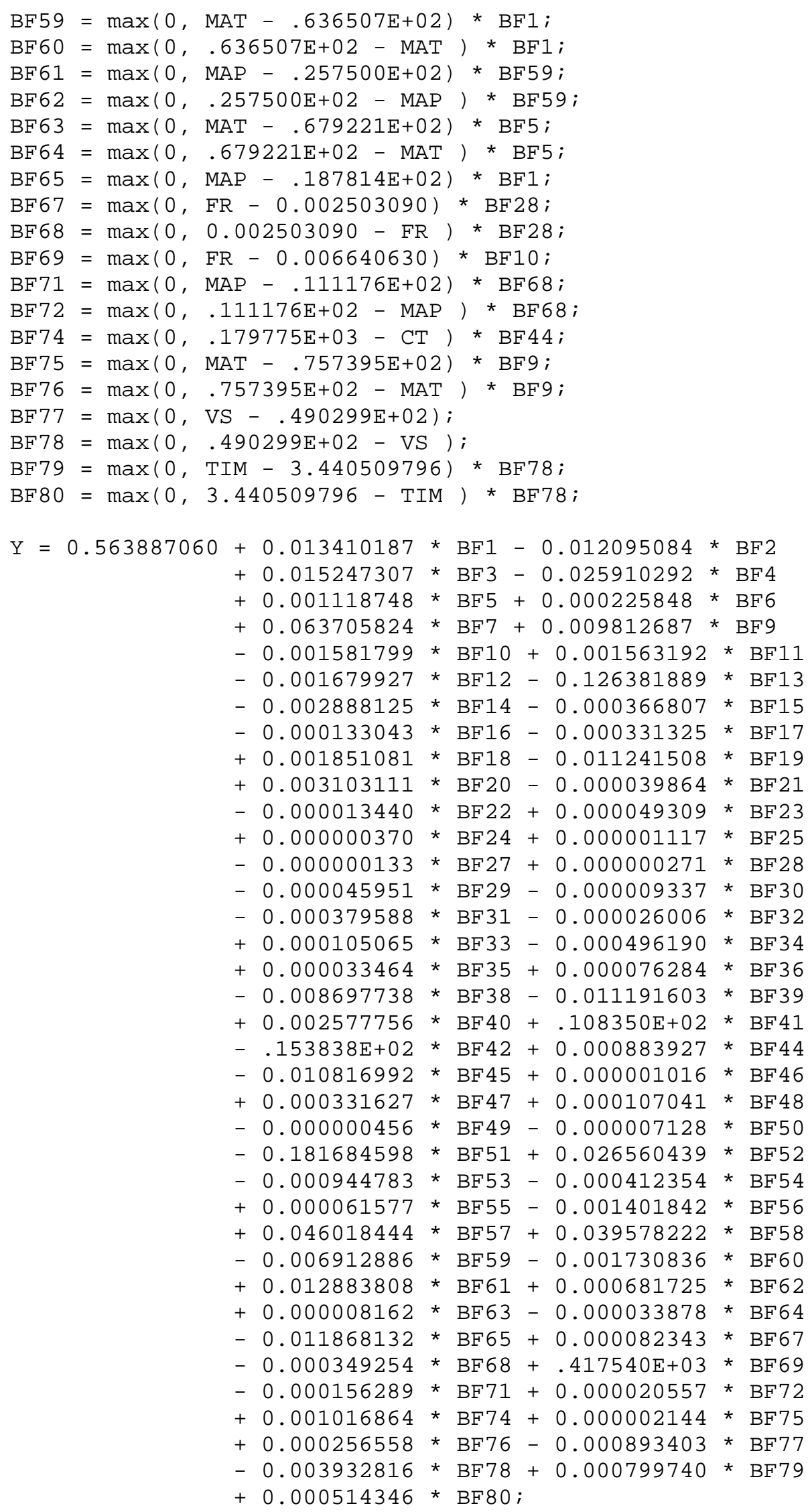




\section{MODEL ISB 2003 CUMMINS}

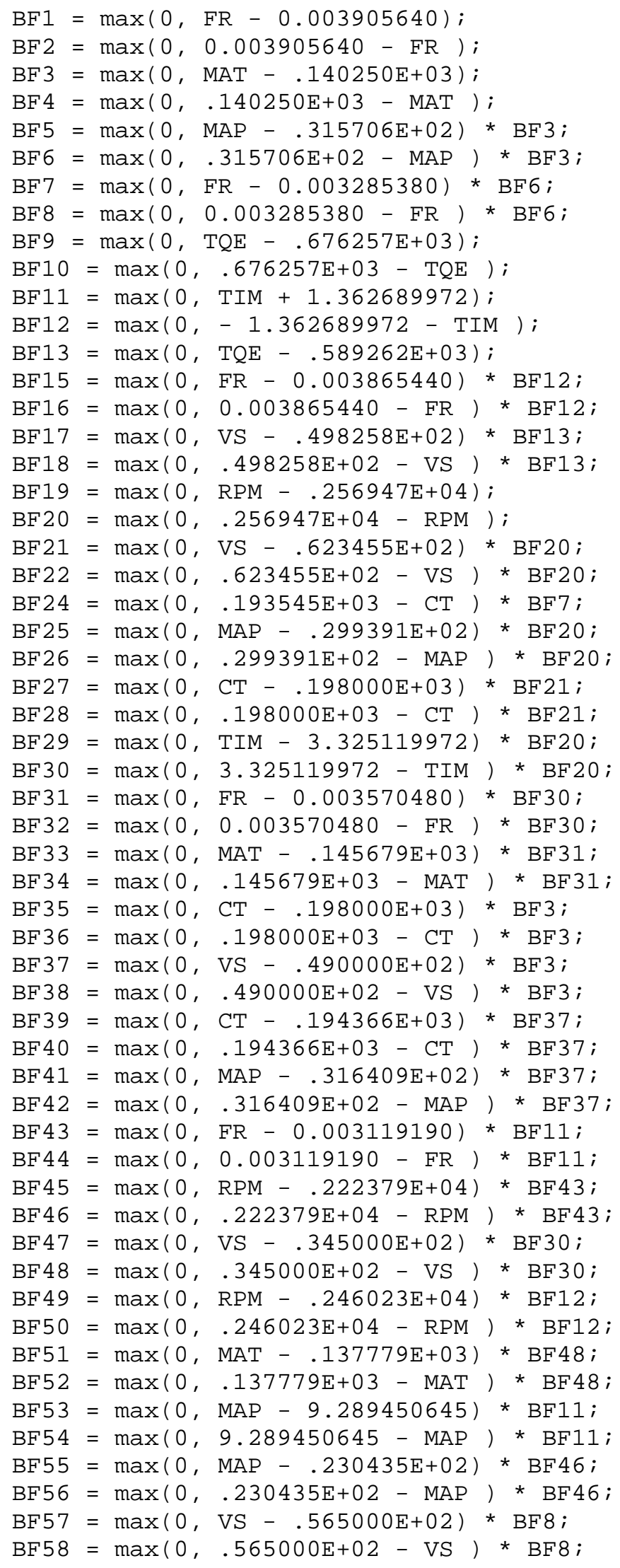




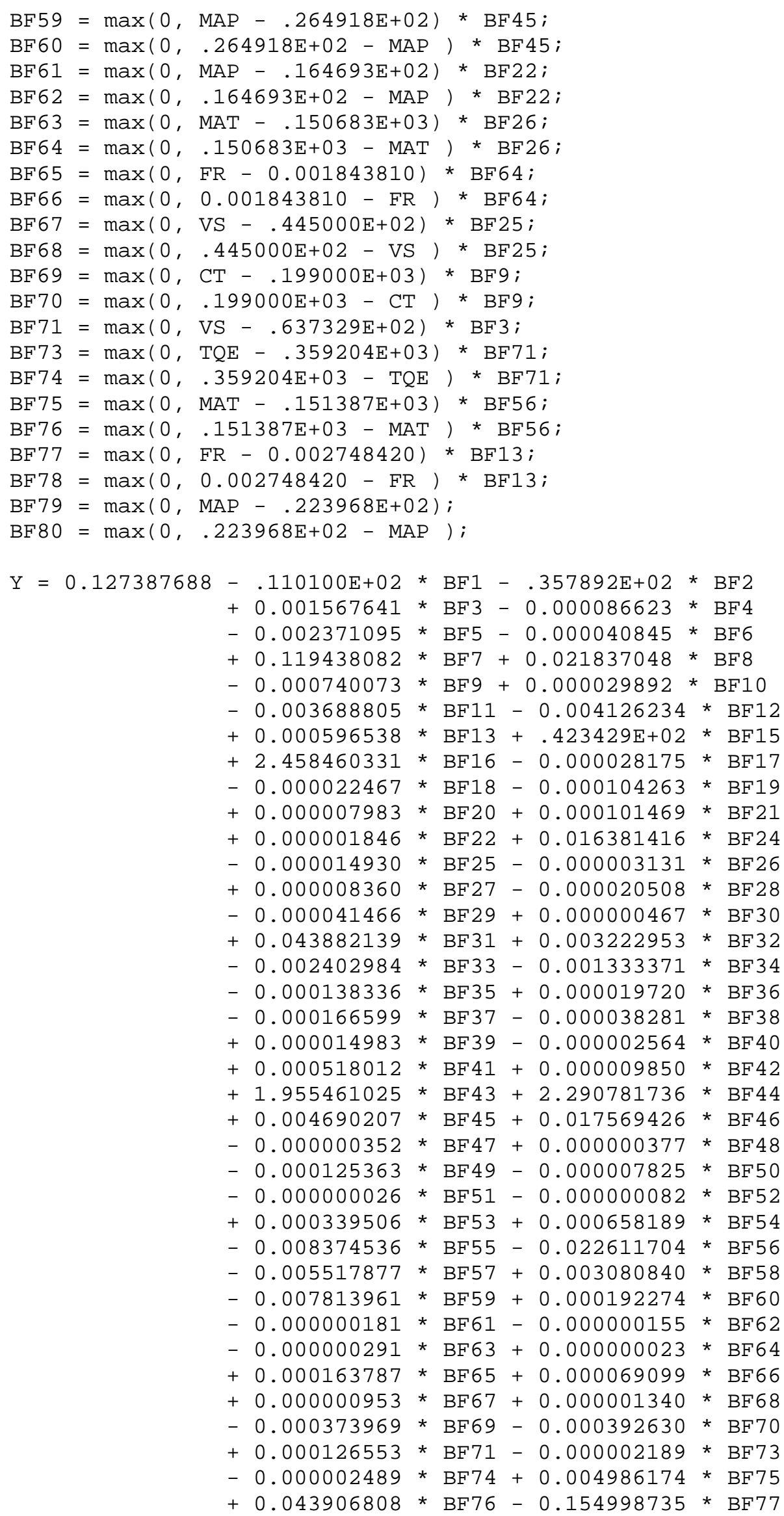


$-0.151998803 * \mathrm{BF} 78+0.002462340 * \mathrm{BF} 79$

-0.000231702 * BF80; 